\title{
THE EFFECTIVENESS OF TILLAGE RADISH® TO IMPROVE THE GROWING MEDIUM
} FOR TREES

\author{
by \\ Shawn Mayhew-Hammond, \\ Bachelor of Arts, North Bay, Ontario, June 10, 2011 \\ A thesis dissertation \\ presented to Ryerson University \\ in partial fulfillment of the \\ requirements for the degree of \\ Master of Applied Science \\ in the Program of \\ Environmental Applied Science and Management
}

Toronto, Ontario, Canada, 2014

CShawn Mayhew-Hammond 2014 


\section{Author's Declaration}

\section{AUTHOR'S DECLARATION FOR ELECTRONIC SUBMISSION OF A THESIS}

I hereby declare that I am the sole author of this thesis. This is a true copy of the thesis, including any required final revisions, as accepted by my examiners.

I authorize Ryerson University to lend this thesis to other institutions or individuals for the purpose of scholarly research.

I further authorize Ryerson University to reproduce this thesis by photocopying or by other means, in total or in part, at the request of other institutions or individuals for the purpose of scholarly research.

I understand that my thesis may be made electronically available to the public. 


\section{Statement of Co-Authorship}

First Author (Shawn H. MAYHEW-HAMMOND)

-Conceptualized and designed the study

-Collected the data

-Analyzed the data

-Wrote up the report

Co-Author (Andrew A. MILLWARD)

-Aided in study conceptualization and design

-Aided in data collection

-Funded the study

-Provided expert advice during analysis

-Provided editorial support 


\title{
The Effectiveness of Tillage Radish ${ }^{\circledR}$ to Improve the Growing Medium for Trees
} Shawn Mayhew-Hammond, Master of Applied Science, 2014

Environmental Applied Science and Management, Ryerson University

\begin{abstract}
Urban trees provide ecosystem services, the value of which is dependent on canopy coverage. However, canopy growth is often restricted by soil compaction. Compaction reduces plant access to important soil resources and mechanically impedes root growth. Bio-drilling plants offer an alternative approach to conventional remediation methods. The study evaluated the effectiveness of growing Tillage Radish ${ }^{\circledR}$ to remediate soil compaction and improve soil quality under established trees. The study plot was located in Guelph, Ontario. Soil data was collected before and after planting radish. Results indicated that 1) radish growth was limited by nutrients but not soil compaction. And, 2) Tillage Radish® reduced surface compaction in moderately to highly compact soils. Other soil characteristics did not change significantly. The results suggested that planting Tillage Radish ${ }^{\circledR}$ has potential to remediate compaction in the rooting zone of trees. However, fertilization may be necessary to maximize radish growth and its associated soil remediation benefits.
\end{abstract}




\section{Acknowledgements}

I would like to thank my advisor, Dr. Andrew Millward, for providing me with the opportunity to work with him and Ryerson University's Urban Forest Research \& Ecological Disturbance

(UFRED) Group. It is needless to say, that without Dr. Millward, this project would not have been possible. From project design to project completion, Dr. Millward has provided insight, supported my ideas, and helped collect data. I would like to give a special thanks to Vadim Sabetski, the group's research assistant. Vadim was involved in most, if not all, of the grunt work, and was always enthusiastic, giving extra attention to detail and providing advice and expertise throughout the project. I would also like to thank the following people Adriano Nicolucci, James Steenberg, and Patricia (Tricka) Bicomong for aiding me in my data collection and processing; and Kellie Fitzgerald, Michelle Blake, Gary Grewal, and Chris Scarpone for providing me with their expert advice, editorial support, and emotional support along the way. 


\section{Dedication}

I would like to dedicate this thesis dissertation to my Mom, Kathy Mayhew, who always pushed me to do well in school, and to my Dad, Steve Hammond, who through various outdoor excursions, sparked my keen interest in the environment. 


\section{Table of Contents}

Authors Declaration ......................................................... ii

Statement of Authorship Co-Authorship ......................................... iii

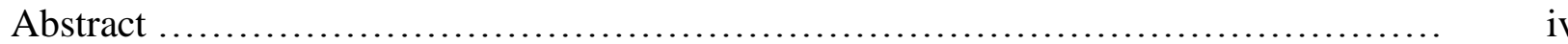

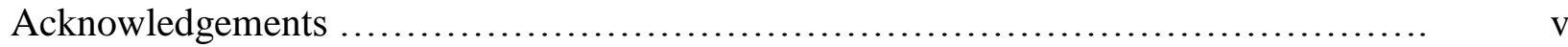

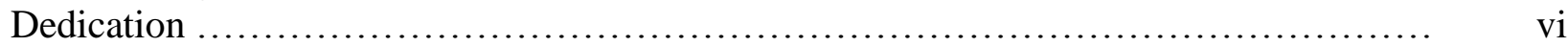

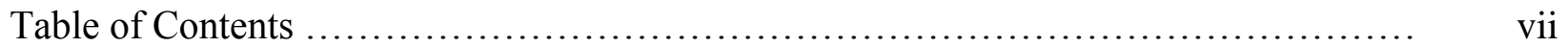

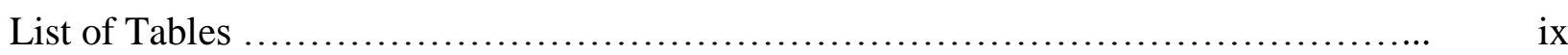

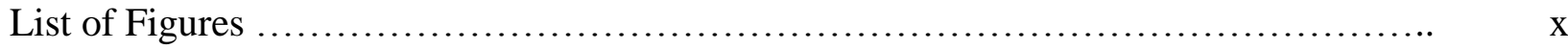

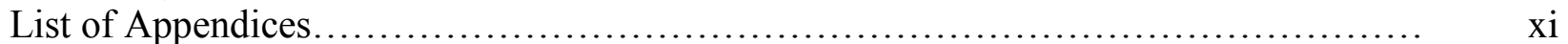

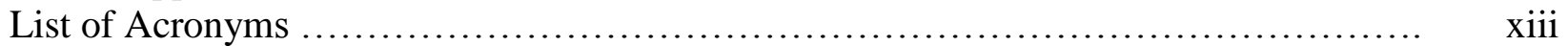

Chapter 1 ....................................................................... 1

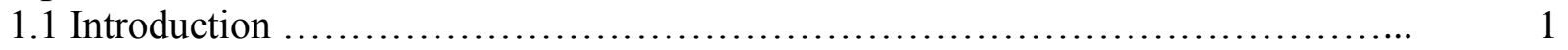

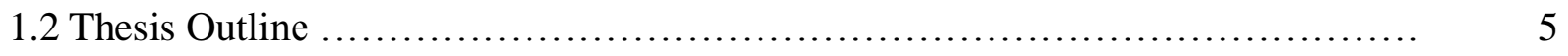

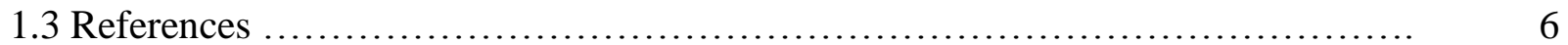

Chapter 2 ............................................................................. 10

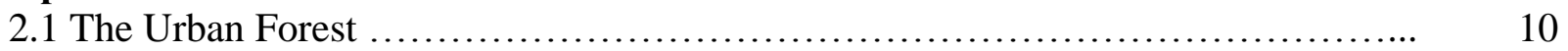

2.11 Ecosystem Services ................................................ 11

2.15 Toronto's Urban Forest ............................................ 15

2.2 Tree Growth .......................................................... 17

2.21 Root Growth and Morphology ....................................... 17

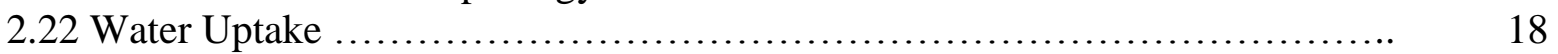

2.23 Mineral Nutrient Uptake ........................................... 19

2.24 Oxygen Uptake ..................................................... 21

2.25 Sustaining Tree Growth in the Urban Forest ............................. 21

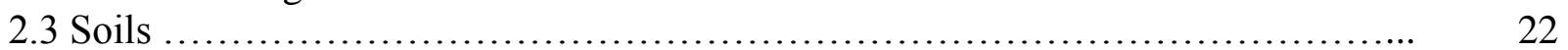

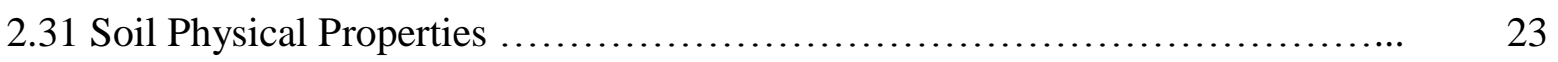

2.32 Soil Chemical and Biological Properties ............................... 27

2.33 Urban Soils ......................................................... 30

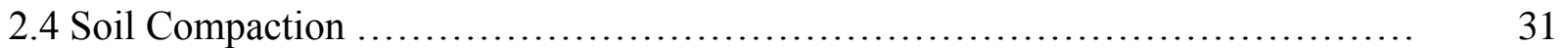

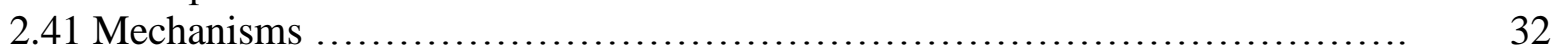

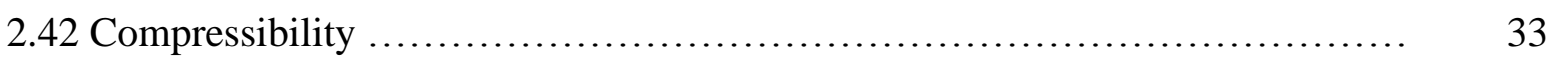

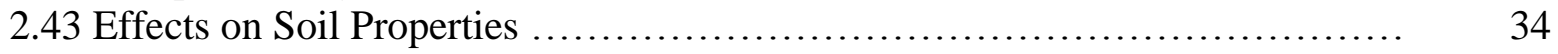

2.44 Effects on Tree Growth .................................................. 36

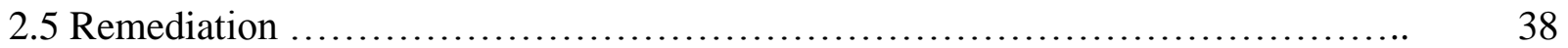

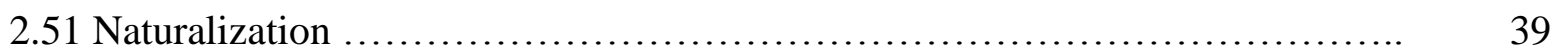

2.52 Mechanized Soil Loosening.......................................... 39

2.53 Aeration and Drainage Systems ..................................... 40

2.54 Soil Amendment And Replacement ....................................... 41

2.6 Soil Remediation Using Plants ......................................... 43

2.61 Effects on Soil Properties ............................................ 43

2.62 Effects on Plant Growth ............................................ 45

2.63 Radish .............................................................. 47

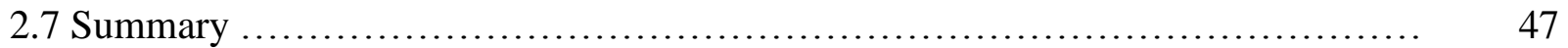

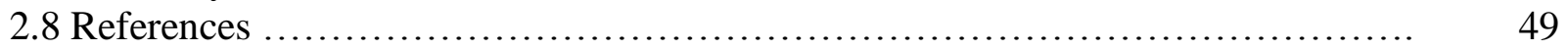




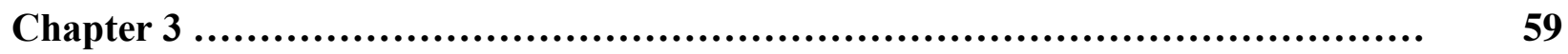

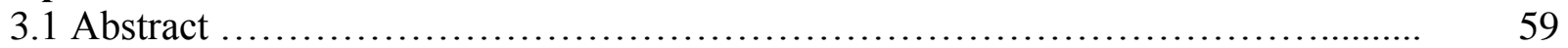

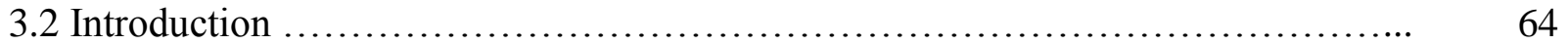

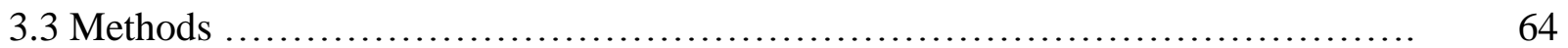

3.31 Study Site and Site Description ........................................ 66

3.32 Soil Data Collection ................................................ 67

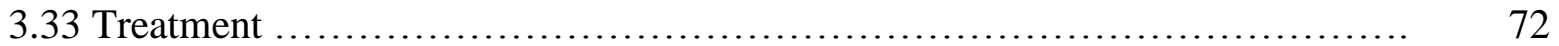

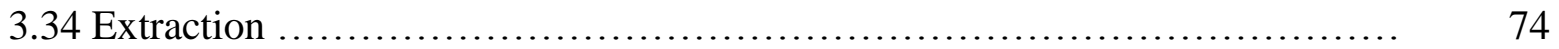

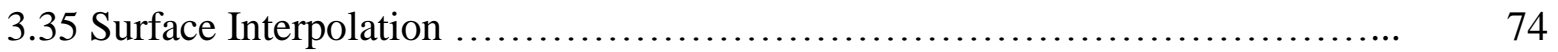

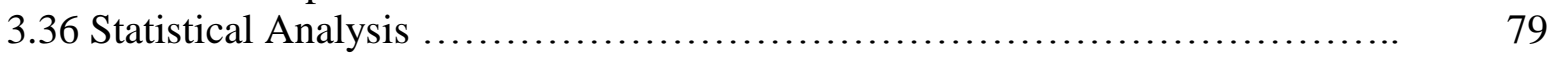

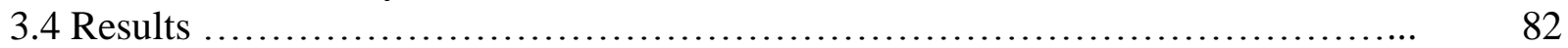

3.41 Soil Descriptive Statistics and Interpolated Surfaces ...................... 82

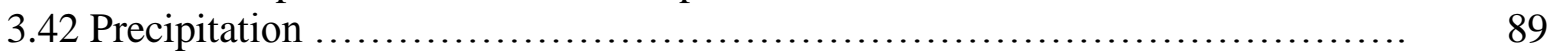

3.43 Radish Growth ...................................................... 90

3.44 Effect of Treatment ................................................... 93

3.5 Discussion ................................................................. 102

3.51 Tillage Radish ${ }^{\circledR}$ Growth ............................................... 103

3.52 Effect of Tillage Radish ${ }^{\circledR}$ Treatment on Measured Soil Properties............... 105

3.6 Conclusion .................................................................. 111

3.7 References ................................................................ 113

Chapter 4 .......................................................................... 125

4.1 Limitations ................................................................. 125

4.2 Future Research........................................................ 126

4.3 Management Applications..................................................... 127

4.4 References .............................................................. 130

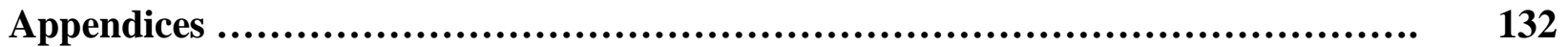

Appendix A: Descriptive Statistics of Block Data............................................... 132

Appendix B: Cross Validation Results of the Interpolated Surfaces.................... 134

Appendix C: Allometric Model Output.......................................... 135

Appendix D: Growth Response Model Output.................................... 138

Appendix E: ANCOVA Model Output......................................... 143

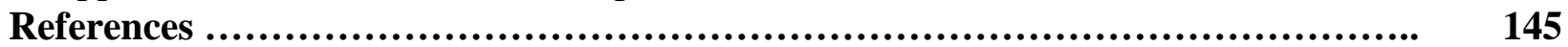




\section{List of Tables}

Table 2.1: Plant macronutrients and micronutrients and their roles, adequate plant tissue concentrations, and forms available for uptake Table 3.1: Change in nutrient availability $\left(\mu \mathrm{g} / \mathrm{cm}^{2} / 42\right.$ days) of two re-measured points on block 4, a treatment block, versus block 5, a control block. 


\section{List of Figures}

Figure 2.1: Soil texture triangle, classified by the USDA. 24

$\begin{array}{lr}\text { Figure 2.2: Soil } \mathrm{pH} \text { and soil nutrient availability in organic soils. } & 29\end{array}$

Figure 3.1: Ignatius Jesuit Centre plot location. $\quad 65$

Figure 3.2: Sampling locations and treatment blocks for the study. 67

Figure 3.3: Prediction surfaces of a) soil $\mathrm{pH}, \mathrm{b}$ ) infiltration capacity, and c) bulk 83

density.

Figure 3.4: Penetration resistance $(\mathrm{kPa})$ prediction surfaces at a) depth $1(2.5-15 \mathrm{~cm}), \mathrm{b}) \quad 86$ depth $2(15-30 \mathrm{~cm})$, and c) depth $3(30-45 \mathrm{~cm})$.

Figure 3.5: Prediction surfaces of bioavailable nutrients ( $\mu \mathrm{g} / 10 \mathrm{~cm}^{2} / 42$ days) for a)

nitrate, b) ammonium, c) phosphorous, d) calcium, e) potassium, f) magnesium, and g)

sulfur.

Figure 3.6: Scatter plot and regression line displaying the change in penetration

resistance at depth $1(2.5-15 \mathrm{~cm})$ versus the initial penetration resistance on the southeastern blocks, categorized by treatment.

Figure 3.7: Scatter plot and regression line displaying the change in penetration

resistance $(\mathrm{kPa})$ at depth $1(2.5-15 \mathrm{~cm})$ versus the initial penetration resistance on the northwestern blocks, categorized by treatment.

Figure 3.8: Scatter plot and regression lines displaying the change in penetration resistance at depth $2(15-30 \mathrm{~cm})$ versus the initial penetration resistance on the southeastern blocks, categorized by radish growth.

Figure 3.9: Scatter plot and regression lines displaying the change in penetration resistance at depth $2(15-30 \mathrm{~cm})$ versus the initial penetration resistance on the northwestern blocks, categorized by radish growth.

Figure 3.10: Scatter plot and regression lines displaying the change in bulk density $\left(\mathrm{Mg} / \mathrm{cm}^{3}\right)$ versus initial bulk density $\left(\mathrm{Mg} / \mathrm{cm}^{3}\right)$, categorized by treatment.

Figure 3.11: Scatter plot displaying the change in infiltration rate $(\mathrm{mm} / \mathrm{hr})$ versus the change in penetration resistance at depth $1(\mathrm{kPa})(2.5-15 \mathrm{~cm})$, categorized by treatment.

Figure 3.12: Scatter plot and regression lines displaying the change in infiltration capacity versus the change in initial penetration resistance, categorized by treatment. 


\section{List of Appendices}

A.1.i: Descriptive statistics of the soil penetration resistance (PR), infiltration rate (IR), 132 bulk density $\left(\mathrm{D}_{\mathrm{b}}\right)$, texture, and $\mathrm{pH}$ for each block in year 1

A.1.ii: Descriptive statistics of the soil penetration resistance (PR), infiltration rate (IR), 132 bulk density $\left(\mathrm{D}_{\mathrm{b}}\right)$, texture, and $\mathrm{pH}$ for each block in year 2

A.2: Descriptive statistics of available macronutrients for each block in year 1

133

B.1: Cross validation results for the interpolated surfaces describing penetration resistance $(\mathrm{kPa})$

B.2: Cross validation results for the interpolated surfaces describing macronutrient availability (ug/10 $\mathrm{cm}^{2} / 42$ days), infiltration rates $(\mathrm{mm} / \mathrm{hr})$, bulk density $\left(\mathrm{Mg} / \mathrm{m}^{3}\right)$, and $\mathrm{pH}$ C.1: Multiple regression analysis summary for the allometric growth models expressed by equations 2 and 3 .

C.2.i: Scatter plot and regression line comparing the $\mathrm{z}$ scores of the residual errors versus the $\mathrm{z}$ scores of the predicted values for equation 2

C.2.ii: Scatter plot and regression line comparing the $\mathrm{z}$ scores of the residual errors versus the $\mathrm{z}$ scores of the predicted values for equation 3

C.3.i: Scatter plot and regression line comparing the observed values versus the predicted values of equation 2

C.3.ii: Scatter plot and regression line comparing the observed values versus the predicted values of equation 3

D.1.i: Multiple regression analysis summary for the Tillage Radish ${ }^{\circledR}$ root growth response model (equation 1)

D.1.ii: Multiple regression analysis summary for the Tillage Radish ${ }^{\circledR}$ shoot growth response models (Equations 4, 5 and 6)

D.2.i: Scatter plot and regression line comparing the $\mathrm{z}$ scores of the residual errors versus the $\mathrm{z}$ scores of the predicted values for equation 1

D.2.ii: Scatter plot and regression line comparing the $\mathrm{z}$ scores of the residual errors versus the $\mathrm{z}$ scores of the predicted values for equation 4

D.2.iii: Scatter plot and regression line comparing the $\mathrm{z}$ scores of the residual errors versus the $\mathrm{z}$ scores of the predicted values for equation 5

D.2.iv: Scatter plot and regression line comparing the $\mathrm{z}$ scores of the residual errors versus the $\mathrm{z}$ scores of the predicted values for equation 6

D.3.i: Scatter plot and regression line comparing the observed values versus the predicted values of equation 1

D.3.ii: Scatter plot and regression line comparing the observed values versus the predicted values of equation 4

D.3.iii: Scatter plot and regression line comparing the observed values versus the predicted values of equation 5

D.3.iv: Scatter plot and regression line comparing the observed values versus the predicted values of equation 6

E.1: Analysis of covariance of $\Delta \mathrm{PR}_{1}(2.5-15 \mathrm{~cm})$ on the southeastern half of the plot, with initial penetration resistance and treatment as factors

E.2: Analysis of covariance of $\Delta \mathrm{PR}_{1}(2.5-15 \mathrm{~cm})$ on the northwestern half of the plot, 143 with initial penetration resistance and treatment as factors

E.3: Analysis of covariance of $\Delta \mathrm{PR}_{2}(17.5-30 \mathrm{~cm})$ on the southeastern half of the plot, 
with initial penetration resistance and treatment as factors

E.4: Analysis of covariance of $\triangle \mathrm{PR}_{2}(17.5-30 \mathrm{~cm})$ on the northwestern half of the plot, 143 with initial penetration resistance and treatment as factors

E.5: Analysis of covariance of $\Delta I R$ (removed outlier), with initial penetration resistance and treatment as factors

E.6: Analysis of covariance of $\Delta \mathrm{Db}$, with initial penetration resistance and treatment as factors 


\section{List of Acronyms}

IDW - Inverse Distance Weighted

OK - Ordinary Kriging

$\mathrm{D}_{\mathrm{b}}-$ Bulk Density

IR - Infiltration Rate

PR - Penetration Resistance

SD - Standard Deviation

$\Delta D_{b}-$ Change in Bulk Density from year 1 to year $2\left(\Delta D_{b}=D_{b}\right.$ year $2-D_{b}$ year 1$)$

$\Delta \mathrm{IR}$ - Change in Infiltration Rate from year 1 to year $2(\Delta \mathrm{IR}=\mathrm{IR}$ year 2 - IR year 1$)$

$\Delta \mathrm{PR}-$ Change in Penetration Resistance from year 1 to year $2(\Delta \mathrm{PR}=\mathrm{PR}$ year 2 . PR year 1$)$

RMSE - Root Mean Square Error

MAE -Mean Absolute Error

RMSSE -Root Mean Square Standardized Error

MSE - Mean Standard Error

ASE - Average Standard Error

PRS - Plant Root Simulator

M - Mean

B - Beta Coefficient

$\beta$-Standardized Beta Coefficient

SE - Standard Error

$\mathrm{Rpm}$ - revolutions per minute 


\section{Chapter 1}

\subsection{Introduction}

Urban forests are an important component of city infrastructure. They provide a multitude of beneficial ecological services to city residents, such as storing carbon dioxide (Nowak \& Dwyer, 2007; Akbari, 2002), mitigating storm water runoff (Dwyer et al., 1992), improving aesthetic value (Bolund \& Hunhammar, 1999), moderating microclimate (Rosenzweiget al, 2006; Akbari, 2002), providing habitat for wildlife (Dwyer et al., 1992), removing air pollutants (Nowak et al., 2006; Hill, 1971), reducing noise pollution (Bolund \& Hunhammar, 1999), and increasing property values (Nowak \& Dwyer, 2007), and they provide these services relatively cheaply (Millward et al., 2011). As city populations grow, and as urban areas become more built up, the ecological services provided by city trees are becoming increasingly important to the health and vibrancy of urban centres (van Bueren, 2011; van Bohemen, 2011; Dwyer et al., 2003; Dwyer et al., 1992). Many studies have indicated that the total benefits received from the ecological services provided by city trees are dependent on the amount, species, age, and growing location of vegetation within the urban environment (Rosenzweiget al, 2006; Dwyer et al., 1992). Therefore, it is important to maintain and enhance the urban forest resource as well as provide proper planning and management (Clark et al., 1997). Numerous cities around the world have recognized this, and have implemented goals and strategies to increase total urban forest coverage (e.g., the City of Toronto's Urban Forest Management Plan). Unfortunately, urban environments contribute to a variety of challenges that can limit tree growth and longevity (van Bueren, 2011; Jim, 1998; Craul, 1992). If cities are to achieve their urban forestry goals, these challenges must be addressed. 
One of the largest challenges of growing trees in an urban environment relates to the growing medium, specifically the availability of adequate soil quantity and quality (Jim, 1998). Soil quality is a major determinant of tree growth and survivorship (Craul, 1985). Unfortunately, in urban environments, soils are constantly being disturbed by human activity. This can lead to several complications; soil compaction being one of the most pervasive (Hamza \& Anderson, 2005; Rosolem et al., 2002; Kozlowski, 1999; Craul, 1992).

Soil compaction refers to the exertion of pressure on the surface of a soil resulting in the breakdown of soil aggregates and the rearrangement of soil particles, increasing the soil's bulk density (Hamza \& Anderson, 2005; Kozlowski, 1999; Soane, 1990). Compaction alters the physical, biological and chemical properties of a soil (Kozlowski, 1999), including reductions to: macropore volume and pore continuity (Gomez et al., 2002), aeration (Gregory et al., 2006), water content (Motavalli et al., 2003), infiltration capacity (Bassett et al., 2005), organic matter (Williamson \& Neilson, 2003), micro-organism activity (Breland \& Hansen, 1996), and nutrient content (Kozlowski, 1999); it can also lead to increases in soil temperature (Kemper \& Derpsch, 1981). Studies indicate that these changes can physically impede plant root growth and result in reduced water, nutrient, and oxygen uptake, inhibiting plant function and growth (Kozlowski, 1999; Craul, 1992). Ultimately, plants growing in compacted soils will have smaller root systems, which can reduce access to new pools of nutrients as well as limit availability of water and oxygen, further limiting the growth of roots and shoots (Gomez et al., 2002; Patterson, 1977). The degree to which plant growth is impeded depends on the type of plant, the degree of compaction, and the initial properties of the soil (Kozlowski, 1999; Craul, 1992). Soil compaction is particularly prominent in urban areas due to the high level of human and vehicle traffic (Jim, 1993; Pan \& Bassuk, 1985). Thus, in order to retain adequate tree growth in cities, it 
is imperative that suitable soil remediation methods exist to combat the effects of compaction (Jim, 2008; Craul, 1992).

Currently, compacted soils in urban areas are remediated through a number of methods, including aerating the soil, adding various soil amendments, replacing the soil, and tilling the soil (Hamza \& Anderson, 2005; Kozlowski, 1999; Craul, 1992). However, these methods each have their limitations (Rosolem et al. 2002; Day and Bassuk, 1994). For example, mechanistic methods, such as tilling the soil and aerating the soil, are highly expensive, may cause further degradation to the structure of the soil, and can damage existing plant roots (Chen and Weil, 2010; Kozlowski, 1999; Kemper \& Derpsch, 1981). And, less intensive remediation methods, such as the surface applications of organic matter and fertilizers, are often limited in their effectiveness (Day and Bassuk, 1994). Alternatively, naturalization, a method of allowing natural soil processes to improve soil quality, has shown promising results, and can be implemented relatively cheaply. Unfortunately, the soil benefits of naturalization are often not evident for years to decades and, naturalization is not always practical as the area must be isolated from human activity (Millward et al., 2011). One possible solution, which has been largely unexplored in urban environments, is the use of cover crop plants to remediate soil compaction.

Cover crops are fast growing annuals that are often planted in no-tillage agricultural crop systems to manage soil quality between crop rotations. In agriculture, this process is referred to as cover cropping (Dabney et al., 2001; Radford et al., 2001). Cover cropping provides several benefits to the soil, such as reducing soil erosion (Weil \& Kremen, 2007; Hartwig \& Ammon, 2002), reducing water runoff, increasing water infiltration (Meisinger et al., 1991; Wilson et al., 1982), increasing organic matter content (Hartwig \& Ammon, 2002), increasing animal and micro-organism activity (Dabney et al., 2001), and increasing nutrient content during subsequent 
spring plantings (Snapp et al., 2005; Hartwig \& Ammon, 2002). More recently, due to the ability of cover crops to break up soils, to create root channels, and to penetrate compacted soil pans, research has focused on the capability of cover crops to ameliorate soil compaction (Chen \& Weil, 2010; Weil \& Kremen, 2007; Williams \& Weil, 2004; Rosolem et al., 2002). In addition to soil quality improvement, cover crops have been shown to enhance subsequent crop yields (Weil \& Kremen, 2007; Williams \& Weil, 2004; Wyland et al., 1996; Frye et al., 1985; Wilson et al., 1982). However, while Broughton (1977) found that a leguminous cover crop species was able to effectively increase rubber tree yields for up to 20 years after cover crop treatments, there have been few other studies that have looked into the effects of cover crops on tree growth. Ultimately, bio-remediating plants are particularly attractive for use in an urban setting as they are cheap, require low energy inputs, target pertinent soil issues, and have been shown to be effective in agricultural systems. However, there has been little to no research on the effect of cover crops on urban soils. Therefore, research that focuses on the ability of plants to remediate soil compaction and to improve tree growth in an urban setting is required. This includes the use of such plants in non-agricultural soils, both where trees have already been established and in preparation for new plantings.

Tap rooted cover crop plant species, as opposed to fibrous species, are thought to better penetrate compacted soil pans and grow deeper into the soil and have thus, been termed "biodrilling" plants (Chen \& Weil, 2010; Rosolem et al., 2002). Radish are a bio-drilling plant species that are known for their large, fast growing tubers that create deep root channels and absorb large quantities of nutrients (Chen \& Weil, 2010; Malik et al., 2008; Weil \& Kremen, 2007; Williams \& Weil, 2004). Radish were chosen for use in this study. 
The purpose of this study is to assess the ability of Tillage Radish®, a genetically selected variant of radish, to remediate soil compaction and improve soil quality, under a zero nutrient input scenario, in non-agricultural soil, containing established trees. Specific study objectives include: 1) determine if Tillage Radish@ can alleviate soil compaction and improve surface water infiltration rates; 2) if soil quality is found to improve, determine the magnitude of improvement; and, 3) evaluate the ability of Tillage Radish ${ }^{\circledR}$ to grow in compacted, unfertilized, non-agricultural soil and assess its ability to grow under tree canopy coverage.

\subsection{Thesis Outline}

This thesis dissertation has been organized into a manuscript format; it contains four chapters. Chapter one introduces the thesis topic, provides context to demonstrate the importance of the research, and outlines the purpose and objectives of the study. Chapter two contains the literature review, which provides necessary background information, discusses current research that lays the groundwork for this study, and identifies the gaps within the current research base. Chapter three contains a completed manuscript that has been formatted for submission to the journal Plant and Soil. This chapter includes the following sections: an abstract, an introduction, a body of methods, the results of the study, a discussion of the results, and the conclusions of the study. Chapter four discusses the limitations of the study, considers management implications of the study, and discusses the potential for future research. 


\subsection{References}

Akbari, H. (2002). Shade trees reduce building energy use and CO2 emissions from power plants. Environmental Pollution, 116: 119-126.

Bassett, I. E., Simcock, R. C., and Mictchell, N. D. (2005). Consequences of soil compaction for seedling establishment: Implications for natural regeneration and restoration. Ecological Society of Australia, 30: 827-833.

Bolund, P., and Hunhammar, S. (1999). Ecosystem services in urban areas. Ecological Economics, 29: 293-301.

Breland, A., Hansen, S. (1996). Nitrogen mineralization and microbial biomass as affected by soil compaction. Soil Biology and Biochemistry, 28: 655-663.

Broughton, W. J. (1977). Effect of various covers on soil fertility under Hevea brasiliensis Muell. Arg.and on the growth of the tree. Agro-Ecosystems, 3: 147-170.

Chen, G., \& Weil, R. R. (2010). Penetration of cover crop roots through compacted soils. Plant and Soil, 331: 31-43.

Clark, J. R., Matheny, N. P., Cross, J., and Wake, V. (1997). A model of urban forest sustainability. Journal of Arboriculture, 23: 17-30.

Craul, P. J. (1992). Urban soil in landscape design. New York, NY :John Wiley and Sons.

Craul, P. J. (1985). A description of urban soils and their desired characteristics. Journal of Arboriculture, 11

Dabney, S., Delgado, J., \& Reeves, D. (2001). Using winter cover crops to improve soil and water quality. Communications in Soil Science and Plant Analysis, 32: 1221-1250.

Day, S. D., \& Bassuk, N. L. (1994). Effects of soil compaction and amelioration treatments on landscape trees. Journal of Arboriculture, 20: 9-17.

Dwyer, J.F., McPherson, E.G., Schroeder, H.W., and Rowntree, R.A. (1992). Assessing the benefits and costs of the urban forest. Journal of Arboriculture, 18: 227-234.

Dwyer, J.F., Nowak, D.J., and Noble, M.H. (2003). Sustaining urban forests. Journal of Arboriculture, 29: 49-55.

Frye, W. W., Smith, W. G., and Williams, R. J. (1985). Economics of winter cover crops as a source of nitrogen for no-till corn. Journal of Soil Water Conservation. 40: 246-249.

Gomez, J., Guzman, M., Giraldez, and J., Fereres, E. (2009). The influence of cover crops and 
tillage on water and sediment yield, and on nutrient, and organic matter losses in an olive orchard on a sandy loam soil. Soil \& Tillage Research, 106: 137-144.

Gregory, J. H., Dukes, M. D., Jone, P. H., and Miller, G. L. (2006). Effect of urban soil compaction on infiltration rate. Journal of Soil and Water Conservation, 61: 117-123.

Hamza, M., \& Anderson, W. (2005). Soil compaction in cropping systems: A review of the nature, causes and possible solutions. Soil and Tillage Research, 82: 121-145.

Hartwig, N. L., and Ammon, H. U. (2002). Cover crops and living mulches. Weed Science, 50: 688-699.

Hill, A.C. (1971). Vegetation: a sink for atmospheric pollutants. Journal of the Air Pollution Control Association, 21: 341-346.

Jim, C. Y. (2008). Opportunities and alternatives for enhancing urban forests in compact cities and developing countries. Carreiro, M. M., Song, Y. C., and Wu, J., Ecology, planning, and management of urban forests: international perspectives (118-467). Springer: New York.

Jim, C. Y. (1998). Urban soil characteristics and limitations for landscape planting in Hong Kong. Landscape and Urban Planting, 40: 235-249.

Jim, C. Y. (1993). Soil compaction as a constraint to tree growth in tropical \& subtropical urban habitats. Environmental Conservation, 20: 35-49.

Kemper, B., and Derpsch, R. (1981). Results of studies made in 1978 and 1979 to control erosion by cover crops and no-tillage techniques in Parana, Brazil. Soil \& Tillage Research, 1: 253-267.

Kozlowski, T. (1999). Soil compaction and growth of woody plants. Scandinavian Journal of Forest Research, 14: 596-619.

Malik, M. S., Norsworthy, J. K., Culpepper, A. S., Riley, M. B., and Bridges, W Jr. (2008). Use of wild radish (Raphanus raphanistrum) and rye cover crops for weed suppression in sweet corn. Weed Science, 56: 588-595.

Meisinger, J. J., Hargrove, W. L., Mikkelsen, R. L., Williams, J. R., and Benson, B. W. (1991). Effects of cover crops on groundwater quality (57-68). In W .L. Hargrove (ed.) Cover Crops for Clean Water. Ankeny, IA: SWCS.

Millward, A., Paudel, K., \& Briggs, S. (2011). Naturalization as a strategy for improving soil physical characteristics in a forested urban park. Urban Ecosystems, 14: 261-278. 
Motavalli, P. P., Stevens, W. E., and Hartwig, G. (2003). Remediation of subsoil and compaction effects on corn $\mathrm{N}$ availability by deep tillage and application of poultry manure in a sandy-textured soil. Soil and Tillage Research, 71: 121-131.

Nowak, D. J., and Dwyer, J. F. (2007). Understanding the benefits and costs of urban forest ecosystems. In J. E. Kuser (Eds.), Urban and Community Forestry in the Northeast ( $2^{\text {nd }}$ Ed) (25-13). New York, NY: Springer.

Nowak, D. J., Crane, D. E., and Stevens, J. C. (2006). Air pollution removal by trees and shrubs in the United States. Urban Forestry \& Urban Greening, 4: 115-123.

Pan, E., and Bassuk, N. (1985). Effect of soil type and compaction on the growth of Ailanthus altissima seedlings. Journal of Environmental Horticulture, 3: 158-162.

Patterson, J. C. (1977). Soil compaction: Effects on urban vegetation. Journal of Arboriculture, 3: 161-167.

Radford, B. J., Yule, D. F., McGarry, D., and Playford, C. (2001). Crop responses to applied soil compaction and to compaction repair treatments. Soil and Tillage Research, 61: 157-166.

Rosenzweig, C., Solecki, W.D., and Slosberg, R. (2006). Mitigating New York City's heat island with urban forestry, living roofs, and light surfaces. A report to the New York State Energy Research and Development Authority, Retrieved September 20, 2012 from - http//www.fs.fed.us/ccrc/topics/urban-forests/docs/NYSERDA_heat_island.pdf

Rosolem, C., Foloni, J., \& Tiritan, C. (2002). Root growth and nutrient accumulation in cover crops as affected by soil compaction. Soil and Tillage Research, 65: 109-115.

Snapp, S. S., Swinton, S. M., Labarta, R., Mutch, D., Black, J. R., Leep, R., Nyiraneza, J., and O’neil, K. (2005). Evaluating cover crops for benefits, costs, and performance within cropping system niches. Agronomy Journal, 97: 322-332.

Soane, B. D. (1990). The role of organic matter in soil compatibility: A review of some practical aspects. Soil and Tillage Research, 16: 179-201.

van Bohemen, H. (2011). Chapter 2: (Eco)system thinking: Ecological principles for building roads, buildings and industrial and urban areas. In E. van Bueren, H. van Bohemen, L. Itard, \& H. Visscher (Eds.), Sustainable urban environments: An ecosystem approach (14-70). Dordrecht, Heidelberg, London, New York: Springer.

van Bueren, E. (2011). Chapter 1: Introduction. In E. van Bueren, H. van Bohemen, L. Itard, and 
H. Visscher (Eds.), Sustainable urban environments: An ecosystem approach (1-13).

Dordrecht, Heidelberg, London, New York: Springer.

Weil, R., and Kremen, A. (2007). Thinking across and beyond disciplines to make cover crops pay. Journal of the Science of Food and Agriculture, 87: 551-557.

Williams, S. M. W., \& Weil, R. R. (2004). Crop cover root channels may alleviate soil compaction effects on soybean crop. Soil Science Society of America Journal, 68: 1403

Williamson, J. R., and Neilsen, W. A. (2003). The effect of soil compaction, profile disturbance and fertilizer application on the growth of eucalypt seedlings in two glasshouse studies. Soil and Tillage Research, 71: 95-107.

Wilson, G. F., Lal, R., and Okigbo, B. N. (1982). Effects of cover crops on soil structure and on yield of subsequent arable crops grown under strip tillage on an eroded alfisol. Soil \& Tillage Research, 2: 233-250. 


\section{Chapter 2}

\subsection{The Urban Forest}

Urban forests are an important component of urban environments. It is well documented within the scientific literature that urban forests produce ecosystem services that are able to improve the social, economic, environmental, and psychological wellbeing of human populations (Millward et al., 2011; van Bohemen, 2011; van Bueren, 2011; Nowak \& Dwyer, 2007; Rosenzweig et al., 2006; Tyrvainen et al., 2003; Akbari, 2002; Bolund \& Hunhammar, 1999; Dwyer et al., 1992; Hill, 1971). However, the definition of what constitutes an urban forest varies (CUFN, 2012).

Some researchers consider the urban forest to be limited to the trees and forests within the urban environment (Bolund \& Hunhammar, 1999; Clark et al., 1997). While others define urban forests more broadly by including green spaces (Millward et al., 2011; Jim, 2008; Dwyer et al., 1992). The variation in the definition may be attributed to the way in which the term urban forestry has changed over time (CUFN, 2012). Jorgensen (1974) defined the term urban forestry as "... a specialized branch of forestry and has as its objectives in the cultivation and management of trees for their present and potential contribution to the physiological, sociological and economic well-being of urban society. These contributions include the over-all ameliorating effect of trees on their environment, as well as their recreational and general amenity value." Within the context of this definition, urban forests only refer to the trees within the urban environment. However, since then Duneke (2003) has expanded on the definition that Jorgensen first presented. He defines urban forestry as "... the sustained planning, planting, protection, maintenance, and care of trees, forests, greenspace and related resources in and 
around cities and communities for economic, environmental, social, and public health benefits for people...” (Duneke, 2003).

Duneke's definition has broadened the concept of the urban forest to include green spaces as well as trees. That being said, as urban trees tend to be the central focus of many studies and city forestry management plans, the term urban forestry is still often used to refer to only the tree component. In order to be consistent with the changing definition of the urban forest and with the current Canadian Urban Forest Strategy, in this thesis, the urban forest will be defined to include both green spaces and treed environments.

\subsection{Ecosystem Services}

Ecosystem services can be defined as "the benefits human populations derive, directly or indirectly, from ecosystem functions" (Costanza et al., 1995). Costanza et al. (1995) has generalized all ecosystem services into 17 categories. While urban forests only provide about 6 of these, the benefits that are provided alleviate many of the complications of living in an urban environment, and are, thus, vital to the health of city communities (Costanza et al., 1995).

\subsection{Hydrology}

Paved roads, sidewalks and densely constructed buildings that are characteristic of urban areas are highly impervious to water. Impervious surfaces impede water infiltration, resulting in a higher proportion of rainfall runoff (van Bueren, 2011). This can lead to (1) degraded water quality as the water will come into contact with city pollutants, pick them up and carry them to nearby water bodies and water courses; and, (2) an increase in the volume of water discharged into city storm water infrastructure. The latter is especially a problem during high rainfall events. If capacity limits are exceeded, flooding will occur (Nowak \& Dwyer, 2007; Bolund \& Hunhammar, 1999). City trees and green spaces are able to improve surface permeability 
allowing for the percolation of water into soil (van Bohemen, 2011; van Bueren, 2011).

Furthermore, vegetation will remove water from the soil and release it into the air as water vapor (Bolund \& Hunhammar, 1999). By reducing rainfall runoff, urban forests are able to reduce the risk of flooding and reduce storm water treatment costs (Dwyer et al., 1992).

\subsection{Mitigation of Air Pollution and $\mathrm{CO}_{2}$ Storage}

Urban areas are responsible for a large proportion of total air pollution and greenhouse gas emissions (van Bohemen, 2011; van Bueren, 2011). Urban vegetation can be an effective means of reducing pollution close to the source, and can also provide a temporary sink for carbon dioxide (Bolund \& Hunhammar, 1999). Trees are able to absorb gaseous pollutants and carbon dioxide through their leaves, while larger particulates are intercepted on the surface of the plant (Dwyer et al., 1992). The rate at which pollutants and carbon dioxide are taken up is largely dependent on the plant species, the individual health of the plant, and in the case of pollutant uptake, the location of vegetation in relation to the source (Dwyer et al., 1992). Improved air quality can increase the overall health of the urban community, as well as reduce the costs associated with repairing pollution-induced damage to buildings (Rosenzweiget et al., 2006; Dwyer et al., 1992).

\subsection{Moderating Microclimate}

The ambient air temperature in urban environments is, on average, $2.5^{\circ} \mathrm{C}$ warmer than surrounding areas (Bretz et al., 1997). This deviation in temperature is commonly known as the urban heat island effect, and can be attributed to differences in the albedo, defined as the relative proportion of light reflected by a surface, of the contrasting areas (van Bohemen, 2011; van Bueren, 2011; Rosenzweiget al, 2006). The materials that make up built environments, such as concrete and asphalt, tend to have lower albedos and, thus, absorb, rather than reflect, a higher 
percentage of solar radiation that is slowly reradiated as latent heat (Rosenzweiget et al., 2006). Urban forests are able to shade these surfaces, resulting in less heat gain from solar radiation. In addition, urban forests can remove latent heat from the ambient air through evaporative cooling. The combined cooling effects can improve air quality, reduce heat related illnesses, and lessen the overall costs of cooling buildings (Rosenzweiget et al., 2006; Akbari, 2002; Bolund \& Hunhammar, 1999; Dwyer et al., 1992).

Coniferous trees are also able to moderate temperatures in the winter. Trees that are placed on the windward side of buildings can intercept cold winds and, thereby reduce heating costs and provide environmental and economic benefits in the form of energy savings (Akbari, 2002).

\subsection{Aesthetic Value and Psychological Well Being}

The mere presence of trees, vegetation, and green space can beautify a city and even improve the psychological well-being of the individuals within urban areas (van Bueren, 2011; Nowak \& Dwyer, 2007). Studies have shown that urban forests can reduce stress, improve recovery times of hospital patients, increase the sense of safety of a community, and reduce criminal activity within an area (Bolund \& Hunhammar, 1999; Dwyer et al., 1992). In addition, people, for a variety of reasons, are willing to pay more to live close to natural vegetation (Bolund \& Hunhammar, 1999). A study completed in Stockholm revealed that urban parks were heavily utilized by citizens, whereby $90 \%$ of residence visited urban parks at least once a year and 45\% visited weekly (Bolund \& Hunhammar, 1999; Stadbyggnadskontoret, 1994). While it's often difficult to gauge the aesthetic and psychological value that urban forests provide, the importance of this benefit should not be overlooked. 


\subsection{Noise Reduction}

Noise pollution can be a problem in urban areas. Fortunately, urban forests are able to act as noise barriers (van Bohemen, 2011). Density, height and width of vegetation as well as the softness of the ground play a role in the total reduction of noise levels (Nowak \& Dwyer, 2007; Bolund \& Hunhammar, 1999; Dwyer et al., 1992). In a study by Cook (1978), belts of tall vegetation greater than 30 meters in width were found to be able to reduce noise levels by 6 to 10 decibels. Another study showed that dense strips of vegetation less than 3 meters wide were able to reduce noise levels by 3 to 5 decibels (Reethof \& McDaniel, 1978). Therefore, proper placement of trees as sound barriers can significantly reduce noise levels and improve citizen health (Bolund \& Hunhammar, 1999).

\subsection{Increase In Real Estate Values}

Many studies have shown that people are willing to pay more for properties that have trees or vegetation on them, within view, or within the neighborhood. However, estimates of the actual increase to property values vary (Nowak \& Dwyer, 2007). Dwyer et al. (1992) estimates, conservatively, that trees and vegetation increase the real estate value of a property by approximately 5\%. Dwyer et al. (1992) also suggests that any increase to the property value will benefit the larger community by increasing municipal tax revenues (Dwyer et al., 1992).

\subsection{Wildlife Habitat}

Urban forests provide habitat for many species within the city (van Bueren, 2011). This may not directly benefit all individuals as some wildlife is considered a nuisance, and not all individuals value the presence of wildlife equally. Certain species, however, through activities such as pollination, seed distribution, and soil enhancement, promote a healthy urban forest and thereby indirectly benefit communities (Dwyer et al., 1992). 


\subsection{Importance of Ecosystem Services}

The ecosystem services described will become increasingly important as population and cities grow in size (Bolund \& Hunhammar, 1999). According to the UNFPA (2011), over the next 20 years, urban populations are estimated to grow from 3.5 to 5 billion people. In order to ensure the availability of social, economic and ecological services, cities will need to safeguard sufficient urban forestry cover (van Bueren, 2011; van Bohemen 2011; Dwyer et al., 2003; Dwyer et al., 1992).

\subsection{Toronto's Urban Forest}

The city of Toronto's population, like many other highly urbanized areas, is expected to grow significantly over the next 20 years. By 2036, Toronto's population is projected to be 3.45 million, up 23.6 percent from the recorded 2012 population of 2.79 million people (OMF, 2013). The city of Toronto has recognized the importance of enhancing its urban forest to continue to support its future population, and in 2005, developed the Parks, Forestry, and Recreation Plan. The goal for this plan is to increase Toronto's tree cover from $20 \%$ to between $30 \%$ and $40 \%$ cover by 2050 (City of Toronto, 2013). In 2008, the city of Toronto contracted the United States Department of Agriculture (USDA) to perform a study that would, “(1) describe current composition, structure, and distribution of Toronto's Forest; (2) quantify the ecological services and benefits provided by the urban forest; (3) identify opportunities for increasing sustainable tree cover; and, (4) define a baseline forest condition for monitoring progress toward forestry objectives" (City of Toronto, 2013).

The study made several key findings, and was published in a document titled Every Tree Counts: A portrait of Toronto's Urban Forest. Some of the findings relevant to the present study have been summarized below (City of Toronto, 2013). 
In 2008, Toronto's urban tree canopy was composed of 10.2 million trees, of which $6 \%$ were street trees, $34 \%$ were located within parks and natural areas, and $60 \%$ were found on private property, of which most were residential. Toronto's trees, as a whole, were found to be small in stature, with 58\% having a diameter at breast height (DBH) of less than $15.2 \mathrm{~cm}$ (City of Toronto, 2013).

Toronto's 10.2 million trees were found to provide 60 million dollars in annual ecological services. This amount was found to greatly surpass the cost of maintenance. The largest trees with the most leaf area provided the most benefits to the community (City of Toronto, 2013).

Toronto's land area was found to be able to support an additional $41 \%$ tree canopy, of which only $23 \%$ was found to be pervious land. In addition, the majority of plantable land was located on private property and only 3\% was located in parks (City of Toronto, 2013).

Lastly, the study made several projections estimating the number of tree plantings required to reach the 2050 tree canopy goal under different mortality scenarios. The projections were as follows. A $2 \%$ mortality rate would require 55,000 trees to be planted per year. A $3 \%$ mortality rate would require 200,000 trees to be planted per year. And a $4 \%$ mortality rate would require 365,000 trees to be planted per year. The study also found that if new plantings ceased, Toronto's urban canopy cover would decline somewhere between 8 to $16 \%$ over the next 100 years (City of Toronto, 2013).

Findings presented in Every Tree Counts: A Portrait of Toronto's Urban Forest highlight several key points: (1) Toronto's urban forest is important to the health and wellbeing of its citizens, justifying the city's goals to increase the total canopy cover; (2) Toronto will have a limited amount of space for new tree plantings and therefore, will have to make efficient use of the space available; (3) Current trees in Toronto are small, possibly a function of age, and 
therefore, improving tree growth will make more efficient use of space and will reduce the need for new plantings; and, (4) Tree mortality will largely determine the number of tree plantings required to reach the cities canopy goals. Overall, increasing the survivorship of existing and newly planted trees will lower the cost of achieving the 2050 canopy cover goal.

\subsection{Tree Growth}

Trees require carbon dioxide, light energy, water, oxygen, and soil nutrients to grow and to maintain important metabolic processes. Carbon dioxide and light energy are absorbed by the leaves, while nutrients, water and oxygen are taken up by the roots (Eaven et al., 2005; Craul, 1992). If plants are growing well, the roots and shoots can communicate through hormonal signalling in order to maintain a balance of root and shoot growth (Overvoorde et al., 2010; Eaven et al., 2005; Hussain et al., 1999; Craul, 1992; Itai \& Vaadia, 1971). For example, cytokinin, a hormone produced by roots, is responsible for initiating further branching and growth of shoots. Therefore, healthy, fast growing roots will result in a larger shoot system (Itai \& Vaadia, 1971). Furthermore, root growth, including the growth of adventitious roots, root hairs, and lateral roots, have been linked to the shoot produced hormone auxin. So in turn, larger healthy shoot systems will initiate further root growth (Craul, 1992; Overvoode et al., 2010). The inverse is also true; shoot and root growth will slow if either experiences poor growth or if resources are in short supply (Eaven et al., 2005).

\subsection{Root Growth and Morphology}

Roots have three major functions: (1) they absorb water, nutrients, and oxygen needed for plant growth; (2) they provide anchorage, keeping the plant upright; and (3) they can store excess sugars to be utilized by the tree during times of stress (Comery, 2007; Craul, 1992). Plants must 
maintain adequate root growth to support shoot development, which will, in turn, support further root development (Overvoorde et al., 2010; Comery, 2007; Craul, 1992; Itai \& Vaadia, 1971).

Roots undergo two main types of growth: elongation and thickening, and branching. Root thickening is important for its function as a storage organ and anchor, while elongation is essential for maintaining the roots absorption capabilities (Craul, 1992).

Roots elongate by extending into pore spaces following the path of least resistance. A minimum pore diameter of $0.01 \mathrm{~mm}$ is required for root elongation to occur. Cell division occurs in the primary meristem, which is located behind the root cap. Root hairs, which are responsible for the majority of water and nutrient absorption within the root, will form on recent root growth and will remain for several weeks to a couple of months (Eaven et al., 2005; Craul, 1992).

Therefore, continued root elongation is essential for maintaining adequate root hair numbers and ultimately, adequate absorption. The majority of roots responsible for absorption are found within the top 15 to $30 \mathrm{~cm}$ of the soil (Watson \& Kelsey, 2006; Craul, 1992; Nambiar \& Sands, 1992).

\subsection{Water Uptake}

Water is essential for plants to maintain photosynthesis and other metabolic processes. In addition, it is important to maintain cell turgor pressure, nutrient transport, and evapotranspiration, the main mechanism for water uptake (Eaven et al., 2005; Craul, 1992). During water shortages plant roots produce abscisic acid, which travels up the xylem into the leaves, triggering stomata closure, reducing water uptake, and ultimately photosynthesis (Eaven et al., 2005; Hussain et al., 1999). If soil moisture levels become low enough, the matric and capillary forces in the soil acting to retain its water will become stronger than the forces in the plant acting to absorb the water. At this point, a soil is said to be at its wilting point. The water 
will cease flowing to the roots, and the remainder of the soil water will not be available for plant uptake (White, 2006; Craul, 1992). Prolonged drought can also lead to nutrient deficiencies and, ultimately, reduced shoot and root growth.

\subsection{Mineral Nutrient Uptake}

There are 14 essential soil mineral nutrients that are important for various metabolic processes within plants. They can be classified as either macronutrients, which are required in larger amounts, or micronutrients, which are required in smaller amounts. Both types are absorbed by the plant in the form of cations, positively charged ions, or anions, negatively charged ions. Macronutrients include nitrogen, potassium, calcium, magnesium, phosphorous, and sulfur, and micronutrients include chlorine, iron, manganese, boron, zinc, copper, nickel, and molybdenum (Comery, 2007; Eaven et al., 2005; Craul, 1992). See table 2.1 for a list of soil nutrients, adequate tissue requirements, and available forms as well as information on the role of macronutrients in plant function.

Nutrients are taken up by the plant root by way of two main mechanisms: active transport and passive transport (Craul, 1992; Epstein, 1956). Active transport is very selective. The plant root absorbs the nutrients by expending energy to exchange ions through the use of transport carriers. This method requires energy and is, therefore, highly dependent on the health of the plant and the environment. Passive transport is non-selective and does not require extra energy. Nutrients can be taken up along with the water by way of mass flow, diffused through the soil along a concentration gradient, or intercepted with the root surface (Roberts et al., 2006; Craul, 1992; Epstein, 1956). If any of the soil nutrients, especially macronutrients, are in short supply, the plant may exhibit deficiency symptoms. Nitrogen and phosphorous tend to be the limiting nutrients for tree growth in most soils (Roberts et al., 2006; Eaven et al., 2005; Craul, 1992). 
Table 2.1: Plant macronutrients and micronutrients and their roles, adequate plant tissue concentrations, and forms available for uptake

\begin{tabular}{|c|c|c|c|c|}
\hline \multirow[b]{2}{*}{ Element } & \multirow{2}{*}{$\begin{array}{l}\text { Form } \\
\text { Available } \\
\text { to Plants }\end{array}$} & \multirow[b]{2}{*}{ Function } & \multicolumn{2}{|c|}{$\begin{array}{c}\text { Adequate } \\
\text { Concentration } \\
\text { in Dry Tissue }\end{array}$} \\
\hline & & & $\mathrm{mg} / \mathrm{kg}$ & $\%$ \\
\hline \multicolumn{5}{|l|}{ Micronutrients } \\
\hline Molybdenum & $\mathrm{MoO}_{4}{ }^{2-}$ & $\begin{array}{l}\text { Required for nitrogen fixation and nitrate } \\
\text { reduction. }\end{array}$ & 0.1 & 0.00001 \\
\hline Nickel & $\mathrm{Ni}^{2+}$ & $\begin{array}{l}\text { Essential part of enzyme functioning in nitrogen } \\
\text { metabolism. }\end{array}$ & $* * 0.1$ & $* * 0.00001$ \\
\hline Copper & $\mathrm{Cu}^{+}, \mathrm{Cu}^{2+}$ & $\begin{array}{l}\text { Activator or component of some enzymes } \\
\text { involved in oxidation reduction. }\end{array}$ & 6 & 0.0006 \\
\hline Zinc & $\mathrm{Zn}^{2+}$ & Activator or component of many enzymes. & 20 & 0.002 \\
\hline Manganese & $\mathrm{Mn}^{2+}$ & $\begin{array}{l}\text { Activator of some enzymes; required for } \\
\text { integrity of chloroplast membrane and for } \\
\text { oxygen release in photosynthesis. }\end{array}$ & 50 & 0.005 \\
\hline Boron & $\mathrm{H}_{3} \mathrm{BO}_{3}$ & $\begin{array}{l}\text { Influences } \mathrm{Ca}^{2+} \text { utilization, nucleic acid } \\
\text { synthesis, and membrane integrity. }\end{array}$ & 20 & 0.002 \\
\hline Iron & $\mathrm{Fe}^{3+}, \mathrm{Fe}^{2+}$ & $\begin{array}{l}\text { Required for chlorophyll synthesis; component } \\
\text { of cytochromes and nitrogenase. }\end{array}$ & 100 & 0.01 \\
\hline Chlorine & $\mathrm{Cl}^{-}$ & $\begin{array}{l}\text { Involved in osmosis and ionic balance; probably } \\
\text { essential in photosynthetic reactions that } \\
\text { produce oxygen. }\end{array}$ & 100 & 0.01 \\
\hline \multicolumn{5}{|l|}{ Macronutrients } \\
\hline Sulfur & $\mathrm{SO}_{4}^{2-}$ & $\begin{array}{l}\text { Needed as a constituent of proteins, amino acids } \\
\text { and vitamins.* }\end{array}$ & 1000 & 0.1 \\
\hline Phosphorous & $\begin{array}{l}\mathrm{H}_{2} \mathrm{PO}_{4}^{-} \\
\mathrm{HPO}_{4}^{2-}\end{array}$ & $\begin{array}{l}\text { Essential to the energy transfer and } \\
\text { photosynthetic systems as phosphorylated } \\
\text { sugars; component of } \\
\text { nucleoproteins, phytin, etc.; important to } \\
\text { flowering and seed production, protein } \\
\text { metabolism, respiration, and enzyme synthesis.* }\end{array}$ & 2000 & 0.2 \\
\hline Magnesium & $\mathrm{Mg}^{2+}$ & $\begin{array}{l}\text { Part of the chlorophyll molecule; needed for } \\
\text { enzyme activity, formation of carbohydrates, } \\
\text { proteins, etc., and cell division.* }\end{array}$ & 2000 & 0.2 \\
\hline Calcium & $\mathrm{Ca}^{2+}$ & $\begin{array}{l}\text { Control physiological processes in the cells, root } \\
\text { growth, and elongation. Calcium is a component } \\
\text { of the middle lamella of the cell wall.* }\end{array}$ & 5000 & 0.5 \\
\hline Potassium & $\mathrm{K}^{+}$ & $\begin{array}{l}\text { Needed for carbohydrate formation, } \\
\text { photosynthesis, protein synthesis, increases } \\
\text { osmotic pressure, aids water absorption and } \\
\text { frost resistance.* }\end{array}$ & 10000 & 1 \\
\hline Nitrogen & $\mathrm{NO}_{3}^{-}, \mathrm{NH}_{4}^{+}$ & $\begin{array}{l}\text { Essential component of proteins, chlorophyll, } \\
\text { nucleic acids, and enzymes. Performs a critical } \\
\text { role in assimilation and metabolic processes of } \\
\text { growth, such } \\
\text { as stem and root elongation.* }\end{array}$ & 15000 & 1.5 \\
\hline
\end{tabular}

Note: Adopted from Eaven et al. (2005), *Craul (1992), and **Brown et al. (1987). 


\subsection{Oxygen Uptake}

Oxygen uptake is important to maintain root respiration. Respiration is the process of converting plant sugars to energy, ATP, for the purpose of cellular metabolism (Geigenberger, 2003; Craul, 1992). At low soil oxygen concentrations, below 2\%, most tree species will not increase in biomass (Lyr \& Hoffman, 1967). Growth of current roots and initiation of new roots requires higher oxygen levels (Geigenberger, 2003; Craul, 1992). At oxygen concentrations below the requirements for respiration, cellular concentrations less than $.013 \%$, plants will start to undergo fermentation, a process much less efficient and which produces substances that are toxic, such as ethylene (Geigenberger, 2003). According to Hussain et al. (1999), ethylene produced in the roots of plants may further act to inhibit growth of both roots and shoots. For short periods of time, fermentation can help deal with low oxygen concentrations; the toxic substances will easily break down once the environment returns to aerobic conditions. However, over the long term, fermentation can irreparably damage plants (Geigenberger, 2003; Craul, 1992).

\subsection{Sustaining Tree Growth in the Urban Forest}

Toronto, like other metropolitan areas around the world, is attempting to increase its total canopy cover. Under the constraints of limited planting space, cities will have to make efficient use of the space available by attempting to maximize tree growth. Unfortunately, the nature of urban areas creates many complicating factors (van Bueren, 2011; Millward \& Sabir, 2010; Dwyer et al., 2003). For example, hydro wires, construction projects and other urban infrastructure can impede or limit growth, damage established trees, limit soil and rooting space, and obstruct light. In addition, human activity can cause damage to trees, whether purposefully or accidently (Millward \& Sabir, 2010; Clark et al., 1997; Craul, 1992; Craul, 1985). However, 
while these issues can cause conflicts, they are visible and well understood, and with proper planning and consideration, could be largely avoided (Jim, 1998; Clark et al., 1997). Soil quality is one of the largest determinants of overall health and tree growth (Day et al., 2010; Comery, 2007; Jim, 1998); however, it is often overlooked. This can be attributed to the fact that soils are very complex and that they are below ground and out of site (Jim, 1998; Craul, 1992; Craul, 1985). If enhancing tree growth is a municipal goal, it is essential that urban foresters begin to evaluate soil quality and have available strategies that will effectively remediate poor quality soils (Jim, 1998; Karlen et al, 1997).

\subsection{Soils}

Craul (1992) defines soils as, "a dynamic, natural system synthesized in profile form at the minerals and decaying organic matter, under the influence of climatic and topographic conditions and living organisms; which supplies, when containing the proper amounts of air and water, mechanical support, and in part, sustenance for plants" (Craul, 1992).

Soils are the result of various physical, chemical, and biological processes that work on the earth's crust and weathered minerals over time and are thus, very complex. Differences in soil type result from variations in geology and climate and can be classified based on regional similarities in formation (White, 2006; Craul, 1992).

Regardless of soil type, all soils are made up of four major components: air, minerals, water, and organic matter. In most soils, the air component usually makes up about 10 to $25 \%$, the water component about 20 to $50 \%$, the mineral component about 40 to $60 \%$, and the organic matter component will make up the rest (White, 2006; Craul, 1992).

As soils form they build up, and as a result of the varying processes acting along the vertical profile, will form horizons. These horizons can be classified into the $\mathrm{O}, \mathrm{A}, \mathrm{B}$, and $\mathrm{C}$ 
horizons. The $\mathrm{O}$ horizon is the upper horizon and contains a significant amount of undecomposed organic material. The A horizon is the upper mineral component of the subsoil and contains some organic matter. The B horizon is the lower mineral component of the subsoil with very little organic matter. And, the $\mathrm{C}$ horizon contains the parent material, material that has been recently weathered from the underlying bedrock. Changes in horizons are not usually abrupt, and are often determined by variations in colour (Craul, 1992).

Soil has particular biological, physical, and chemical properties that affect its ability to function as a plant growing medium (Day et al., 2010; Roberts et al, 2006; Craul, 1992). Overtime, natural processes, disturbances, and remediation efforts can change a soils properties and functionality (White, 2006; Kozlowski, 1999; Craul, 1992).

\subsection{Soil Physical Properties}

The texture, structure, and bulk density of a soil largely determine its total porosity, pore size distribution, and pore continuity, and in turn, influence water and oxygen content. Soil temperature will also impact soil water and oxygen content, and in addition, will impact organism activity and nutrient cycling.

\subsection{Texture}

Soil texture is a classification system used to describe the distribution of the particle sizes of a soil. Soils can consist of clay, soil particles less than $.002 \mathrm{~mm}$ in size; silt, soil particles ranging from $0.002 \mathrm{~mm}$ to $0.05 \mathrm{~mm}$ in size; and sand, soil particles ranging from $0.05 \mathrm{~mm}$ to 2 $\mathrm{mm}$ in size. Soil texture is classed based on the relative proportion of clay, silt, and sand in the soil (Figure 2.1). The texture of a soil has a large effect on other soil properties, such as soil water, soil drainage, aeration, structure, bulk density, and cation exchange capacity (White, 2006; Fitzpatrick et al., 1999; Craul, 1992). 


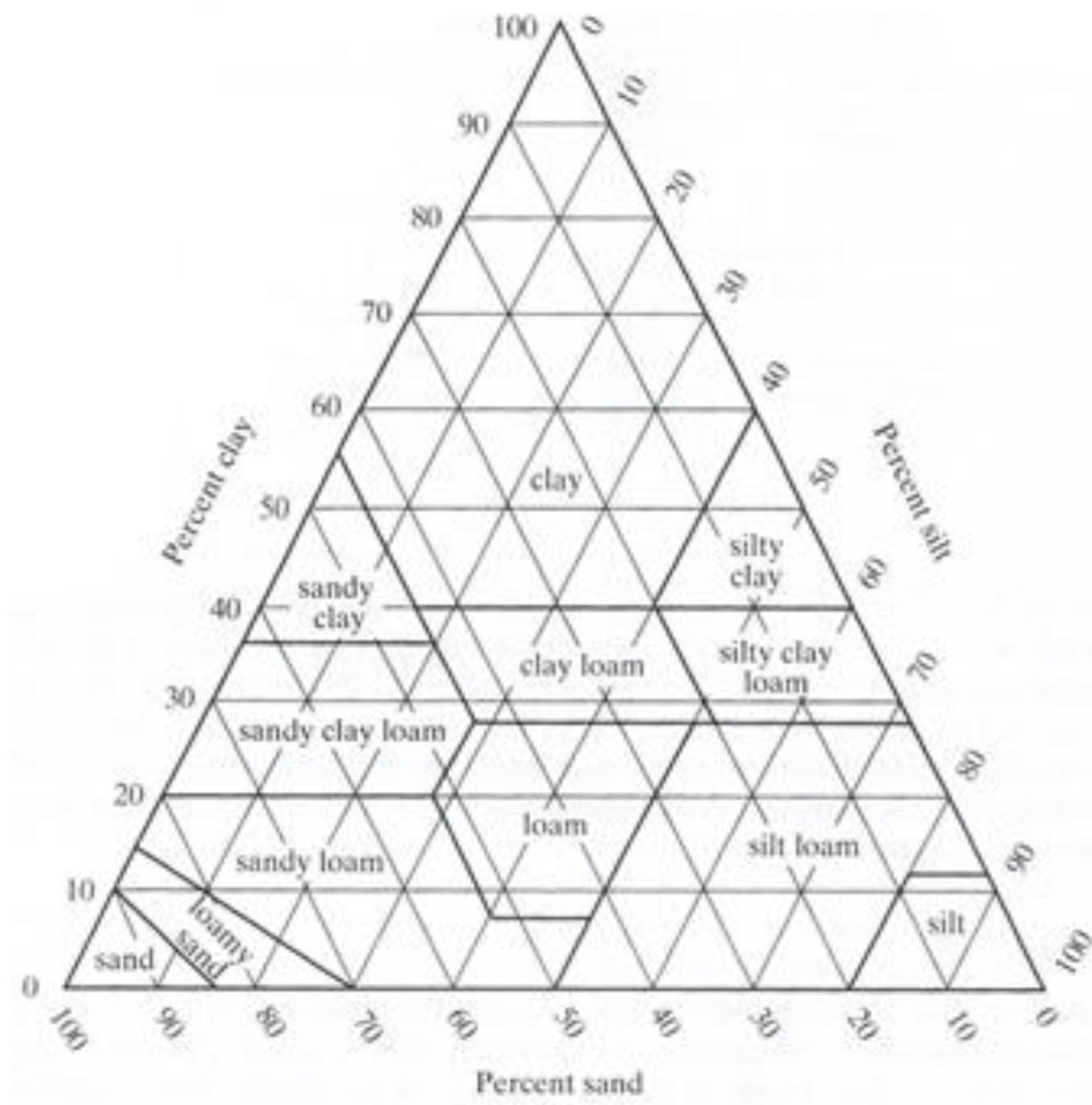

Figure 2.1: Soil texture triangle, classified by the USDA (Craul, 1992).

\subsection{Structure}

Soil structure refers to the way in which the soil particles have aggregated into larger units of geometric patterns called peds (White, 2006; Craul, 1992). Peds are formed through the lateral movement in soils caused by freeze thaw cycles, soil swelling and shrinking, and organism activity (Day et al., 2010). The attractive forces of clays and organic matter act to cement the sand and silt particles together. Silt particles will aggregate more easily than sand. During the formation of peds, macropores, larger pore spaces, will form between peds while micropores, smaller pore spaces, will form within the peds (Day et al., 2010; Craul, 1992). The 
distribution of pore sizes affects the water storage, drainage, and aeration of a soil (Roberts et al., 2006; White, 2006; Craul, 1992). Overtime, soils will naturally move towards structural organization. However, it is important to note that soils with structure are actually more compressible than soils without structure. When stresses are applied, structured soil will compact and become less structured. Organic matter provides some protection against compressive forces and can, therefore, help maintain the structural integrity of the soil (Rivenshield \& Bassuk, 2007; White, 2006; Craul, 1992).

\subsection{Bulk Density}

Bulk density describes how densely packed soil particles are in a given volume. It is calculated as the oven dry weight $(\mathrm{Mg})$ per soil volume $\left(\mathrm{m}^{3}\right)$ (Rivenshield \& Bassuk, 2007; Craul, 1992). The average density of soil particles in a dried soil containing no pore space is 2.65 $\mathrm{Mg} / \mathrm{m}^{3}$, and thus, bulk densities of natural soils, which will contain at least some pore space, will not exceed this value (Craul, 1992). Typically, bulk densities of uncompact soils will range from 1.0 to $1.8 \mathrm{Mg} / \mathrm{m}^{3}$ and is a factor of the pore space between the soil particles, which is largely determined by the texture and the structure of the soil (Craul, 1992; Aubertin \& Kardos, 1965). Soils with a higher proportion of clay, silt, and organic matter will typically have lower bulk densities, 1.0 to $1.6 \mathrm{Mg} / \mathrm{m}^{3}$, as these soils have a greater proportion of pore space (Aubertin \& Kardos, 1965). Due to their small particle sizes, clays and silts pack in ways that create a larger proportion of micropores, which adds significantly to pore space. In addition, they aggregate more easily favouring the formation of macropores (Hawver \& Bassuk, 2007; Roberts et al., 2006; White, 2006; Craul, 1992). Sand tends to have higher bulk densities as sandy soils tend to lack micropores and do not aggregate well (Roberts et al., 2006; Craul 1992). Bulk density is generally greater in sub soils as they tend to have less structure (Craul, 1992). 


\subsection{Aeration}

Aeration refers to the air component of the soil found in the pore spaces and is very important to plant growth. Oxygen and the other soil gases enter the soil through diffusion. As the tortuosity and length of the diffusion pathway increases, the rate of diffusion decreases. This results in lower oxygen contents at greater soil depths. In soils with plant activity, oxygen will be taken and carbon dioxide will be released. In these soils, carbon dioxide concentrations will be greater deeper in the soil and will diffuse out (Craul, 1992). Soil aeration is a factor of the total

porosity, pore continuity, pore space distribution, and temperature of a soil. Soils will have poor aeration if they lack pore space, lack pore continuity, and lack macropores (Hawver \& Bassuk, 2007; Watson \& Kelsey, 2006; Craul, 1992).

\subsection{Soil Water and Drainage}

Soil water and drainage are important to plant growth. Soils that drain too quickly and do not have the capacity to store water may not be able to meet the water requirements of plants. However, soils with poor drainage may become inundated with water and will have inadequate aeration (Hawver \& Bassuk, 2007; Craul, 1992). Soil water and drainage is largely determined by the total porosity, pore continuity and pore size distribution of a soil. The total porosity determines the amount of water that can be held within a saturated soil. Saturation occurs when all pore spaces are filled. However, it is the distribution and continuity of micropores and macropores that determine soil water availability and drainage (White, 2006; Craul, 1992).

Macropores, the largest classification of pore space, drain rather quickly and are only filled during saturation. The total amount of macropore space and the continuity of the macropore spaces will largely determine soil water drainage, where soils with a greater amount of macropore space and macropore continuity will drain better. Typically, sands will have high 
drainage, well-structured finer textured soils and compacted sands will have medium drainage, and compact finer textured soils will have slow drainage (Hawver \& Bassuk, 2007; Roberts et al., 2006; Craul, 1992).

Once the macropores have drained, the water remaining is largely retained in the micropores of the soil by way of matric and capillary forces. At this point, where the forces acting to retain soil water are equal to the gravitation forces acting to drain them, the soil is said to be at field capacity. This water is largely available for plant uptake. The total available water for plant uptake can be calculated by finding the difference between the moisture content at a soils field capacity and wilting point, and is largely a factor of having a structural balance of macropores and micropores (Hawver \& Bassuk, 2007; White, 2006; Craul, 1992).

\subsection{Soil Temperature}

Soil temperature impacts the rate of organism activity, moisture content, nutrient availability, gaseous diffusion, and the development of soil structure. Soils with an abnormally high temperature may experience moisture stress, a reduction in organism activity and nutrient availability, and may also impede the diffusion of carbon dioxide out of the soil. On the other hand, organism activity and nutrient activity will decline if soil temperatures are too cold (Craul, 1992). Ideally, soil temperatures will stay within a range that will support root growth and organism activity during the growing season (Craul, 1992). According to Lyr and Hoffman (1967) the optimum range for most temperate tree species is from $2^{\circ} \mathrm{C}$ to $25^{\circ} \mathrm{C}$.

\subsection{Soil Chemical and Biological Properties}

The chemical and biological properties of a soil have a large impact on the nutrient availability for plant uptake. 


\subsection{Nutrient Content}

Within the soil, nutrients can be found dissolved in the soil water solution, attached to clay or organic matter particles, or in an unavailable form. All available soil nutrients are present within the soil as either cations, positively charged ions, or anions, negatively charged ions (Roberts et al., 2006; Craul, 1992). Nutrient ions that are dissolved in the soil water, if not taken up by plants, can be leached from the soil rather quickly. Soils with clays and organic matter can retain cations more readily (Craul, 1992) (See section 2.322, Cation Exchange Capacity). The total plant available nutrient content of a soil is dependent on a number of factors, including soil $\mathrm{pH}$, organic matter content, rate of organic matter decomposition and mineralization, and the parent material (Craul, 1992).

\subsection{Cation Exchange Capacity}

Clay and organic matter have negative surface charges that attract and lightly bind cations within the soil. These cations will be protected from leaching and will be available for plant uptake at a later time. The exchange of nutrient ions attached to the negative charges with hydrogen is called cation exchange. Hydrogen is released from plants to facilitate cation uptake. The total exchange capacity of a soil depends on the number of negative charges and is, therefore, greatly affected by the proportion of clay and, to a greater extent, the amount of organic matter in a given soil (Roberts et al., 2006; Saebo \& Ferrini, 2006; Craul, 1992).

\subsection{Soil $\mathrm{pH}$}

Soil $\mathrm{pH}$, potential hydrogen, is a measure of the concentration of hydrogen ions in a soil solution. Pure water will have equal parts hydrogen $\left(\mathrm{H}^{+}\right)$to hydroxyl $\left(\mathrm{OH}^{-}\right)$. Soils with a greater amount of hydrogen are acidic while soils with a greater amount of hydroxyl are considered basic. A soils $\mathrm{pH}$ is classified using the $\mathrm{pH}$ scale, the log of the reciprocal molar concentration of 
hydrogen ions in the soil solution. The $\mathrm{pH}$ scale ranges from 1, very acidic, to 14, very basic, where a pH of 7 is neutral (Eaven et al., 2005, Craul, 1992).

Soil $\mathrm{pH}$ is well correlated with nutrient availability as it determines both soil nutrient form (Figure 2.2) and the level of organism activity, the later which governs the decomposition of organic matter and the mineralization of nutrient ions (Day et al., 2010; Roberts et al., 2006). It is generally agreed upon that a $\mathrm{pH}$ of 6.5 to 7 is ideal for both soil nutrient solubility and organism activity (Craul, 1992).

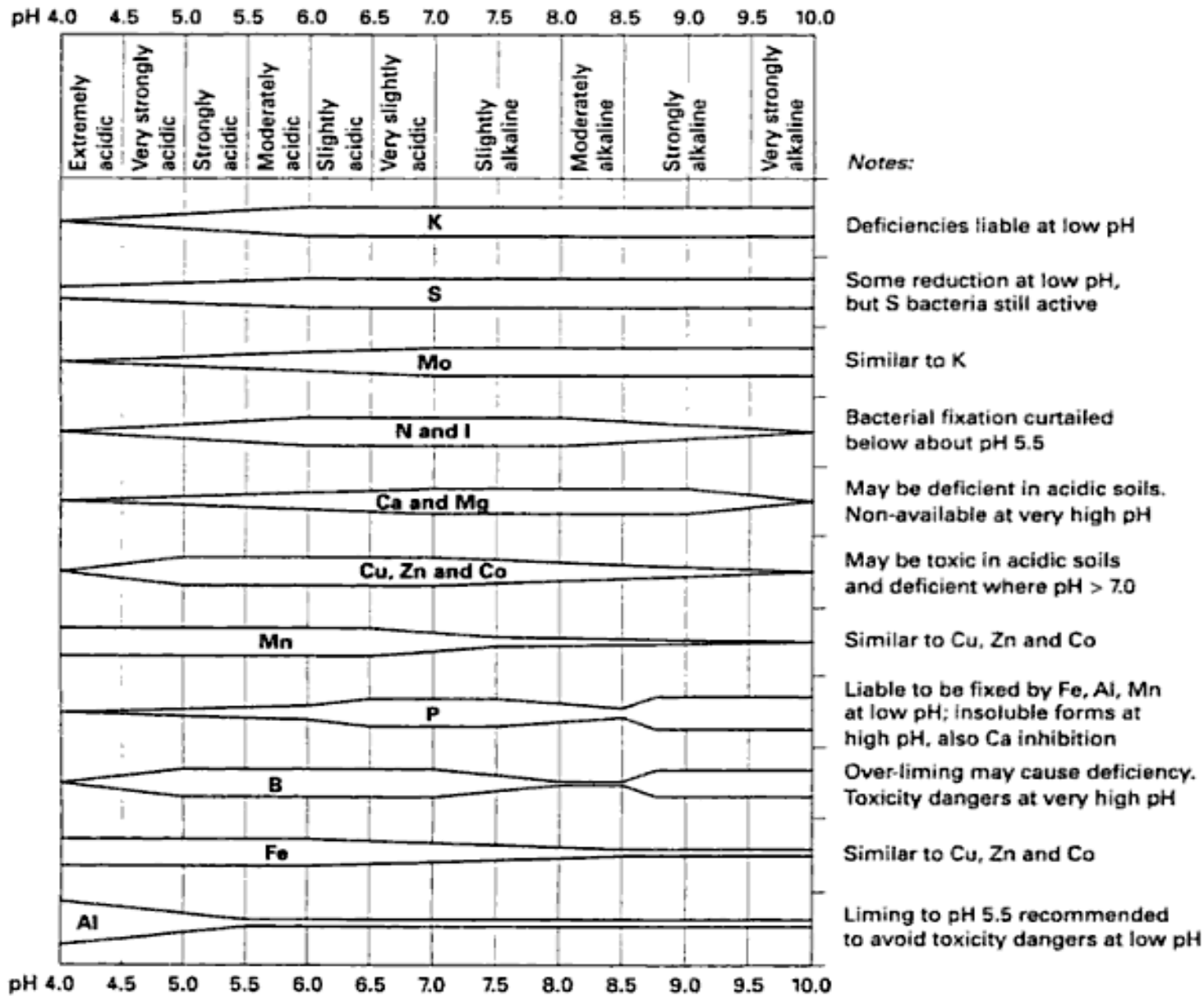

Figure 2.2: Soil pH and nutrient availability in organic soils (Roberts et al., 2006). 


\subsection{Organism Activity, Organic Matter, and Nutrient Cycling}

Many organisms exist within the soil medium, including species of macroorganisms, mesoorganisms, and microorganisms; all of which play a role in organic matter and nutrient cycling (Craul, 1992). In addition, organism activity, especially that of larger soil organisms, can enhance the formation of soil structure (Roberts et al., 2006). Greater organic matter and organism activity will speed up the rate at which nutrients are cycled (Craul, 1992). Soil organisms tend to favour similar conditions to plants and thus, are the most active in soils that have a neutral $\mathrm{pH}$, that are well aerated, that are between $26^{\circ} \mathrm{C}$ to $32^{\circ} \mathrm{C}$ and that have sufficient moisture and organic matter content (Craul, 1992).

\subsection{Rhizosphere}

The rhizosphere is a 1 to $10 \mathrm{~mm}$ area around the root that has different soil conditions as a result of the interaction between the root and the soil. During root growth, the root exudates carbohydrates, amino acids, and vitamins into the soil. This promotes bacteria activity and nutrient absorption, especially in the case of phosphorous, which is often fixed by soil particles (Craul, 1992). A productive rhizosphere can be important for plant growth (Day et al., 2010; Craul, 1992).

\subsection{Urban Soils}

Urban soils differ from natural soils in that they usually have had some degree of disturbance or modification by human activity (Day et al., 2010; Jim, 1998; Craul, 1985). This creates a unique and challenging environment for root and tree growth. Some of these challenges include a lack of a vertical profile, the absence of an organic layer, reduced nutrient cycling and organism activity, a diminished capacity for water drainage and aeration, the presence of foreign materials, an altered $\mathrm{pH}$, soil compaction, and a modified soil temperature regime (Day et al., 
2010; Roberts et al., 2006; Jim, 2008; Craul, 1985). Soil compaction is one of the most widespread and difficult to manage of the listed soil quality issues. Soil compaction can greatly alter soil physical, chemical, and biological properties, which, in turn, can greatly affect its function as a plant growing medium; it is difficult to reverse; it is difficult to prevent; and, it will exacerbate many of the other soil quality issues that are common in urban environments (Hamza \& Anderson, 2005; Kozlowski, 1999; Jim, 1998; Craul, 1985).

\subsection{Soil Compaction}

Soil compaction can be defined as, "the process by which the soil grains are rearranged to decrease void space and bring them into closer contact with one another, thereby increasing the bulk density" (Soil Science Society of America, 1996). The changes described alter the physical, chemical, and biological properties of a soil, affecting both soil function and plant growth, the degree of change depending greatly on the process of compaction and on the individual properties of the soil themselves (Logsdon \& Karlen, 2004; Kozlowski, 1999; Dexter, 1991). Soil compaction can occur as a result of either natural soil processes or as a result of compressive forces acting on the surface of the soil (Basset et al., 2005; Kozlowski, 1999; Rolf, 1994; Craul, 1992; Soane, 1990). In urban environments, it is the compressive forces of human and vehicle traffic that are of the largest concern (Hamza \& Anderson, 2005; Kozlowski, 1999; Patterson, 1976).

\subsection{Mechanisms}

Natural compaction tends to occur in loose soils as a result of settling and slumping. Particles settle as a consequence of freeze/thaw and wetting and drying cycles. The swelling and shrinking weaken the bonds that hold the soil particles together, causing them to rearrange. 
Slumping occurs in wet soils; water weakens the soil particle bonds and weighs down the particles, compacting them (Kozlowski, 1999).

More commonly, soils are compacted due to compressive forces that act on soil surfaces, such as animal trampling and vehicle traffic. The compressive forces must be strong enough to break down the soil aggregates in order to cause rearrangement. Animal and vehicle traffic compact soil by way of three compacting forces: vertical stress, which is the downward force caused by the load of the compactor, shear stress, which is the downward, horizontal force that occurs due to the slippage of the compactor, and ground vibrations, which occur due to engine vibrations in heavy vehicles (Kozlowski, 1999; Rolf, 1994; Craul, 1992). Generally, the severity and depth of compaction will be greater with heavier loads (Hamza \& Anderson, 2005; Rolf, 1994). For example, animal trampling has been shown to compact soils to a depth of $20 \mathrm{~cm}$, with the greatest compaction occurring at $5 \mathrm{~cm}$ depths, while heavier traffic can compact soil to a depth of 1 meter, with the greatest compaction occurring within the top $30 \mathrm{~cm}$ (Hamza \& Anderson, 2005; Vzzotto et al., 2000; Tarashima et al., 1999; Kozlowski, 1999). According to Bakker and Davis (1995), the largest proportion of surface compaction occurs after the first few passes of a vehicle, and additional passes have little effect. However, continued passes can increase soil compaction at greater depths (Kozlowski, 1999).

\subsection{Compressibility}

The mechanism and source of soil compaction can have a great effect on the severity of compaction. However, not all soils react in the same way. The properties of a soil determine its compressibility, which can be defined as soil susceptibility or risk of being compacted (Craul, 1992). Four main soil properties govern compressibility: (1) texture, (2) moisture levels, (3) pH, and (4) organic matter content (Kozlowski, 1999; Craul, 1992). 
The risk of compaction usually increases with decreasing particle size, clay dominant soils being the most at risk. Sandy soils are the least susceptible to compaction as the larger surface areas of the particles mean they are usually in contact with each other, leaving little room for translocation. In addition to having smaller surface areas, medium and fine textured soils tend to develop greater structure and, thus, have a higher volume of macropore space that can be filled in between the soil aggregates (Kozlowski, 1999; Craul, 1992).

Usually, the risk of compaction increases with soil moisture. Water weakens the soil bonds and acts as a lubricant, reducing the friction between soil particles. However, as soils reach saturation, they become less susceptible to compaction due to the fact that the water has nowhere to be displaced (Hamza \& Anderson, 2005; Kozlowski, 1999; Craul, 1992).

pH affects soil aggregate stability; stability decreasing with an increase in acidity. Therefore, soils with lower $\mathrm{pH}$ are more at risk for compaction (Kozlowski, 1999).

Soils with higher organic matter content are less at risk of compaction (Soane, 1990). According to Soane (1990), this can be mostly attributed to the ability of organic matter to bind soil aggregates and also serve to promote soil elasticity.

\subsection{Effects on Soil Properties}

Compaction directly affects soil porosity, bulk density, soil strength, infiltration capacity, soil water content, aeration of soils, and indirectly effects soil temperature, organic matter content, micro-organism activity, and nutrient content (Craul, 1992).

Soil compaction increases bulk density, reducing the amount of pore space and pore continuity (Gregory et al., 2006; Gomez et al., 2002; Nambiar \& Sands, 1992). The loss of pore space can be mostly attributed to a loss of macropore volume (Kozlowski, 1999). In a study by Breland and Hansen (1996), soil compaction reduced the number of pores with a diameter of 30 
$\mu \mathrm{m}$ or greater from $30.4 \%$ to $14.6 \%$ of the total soil volume, and actually found that the number of micropores, those less than $3 \mu \mathrm{m}$ in diameter, increased by $2.9 \%$. Similar results were reported by Jusoff (1989) and Monti and Mackintosh (1979), who found that an increase in soil compaction reduced the volume of macropores within a soil body. Patterson (1976) looked at the effect of human traffic on bulk densities in urban areas of Washington D.C. and found that soil bulk densities were increased from a range of $1.20-1.60 \mathrm{Mg} \mathrm{m}^{-3}$ to a range of $1.70-2.20 \mathrm{Mg}$ $\mathrm{m}^{-3}$, bulk densities that have been well documented to inhibit tree growth (Basset et al., 2005; Kozlowski, 1999; Day \& Bassuk, 1994; Pan \& Bassuk, 1985).

Compaction reduces a soils capacity for water infiltration (Gregory et al., 2006; Bassett et al., 2005), water storage (Motavalli et al., 2003), and aeration (Day \& Bassuk, 1994). The resulting loss of capacity can be attributed to the reduction in macropore volume and the decrease in pore space continuity (Kozlowski, 1999). The loss in volume of macropores and pore continuity slows the rate at which water can infiltrate into the soil and in which gases can diffuse in and out (Gregory et al., 2006; Basset et al., 2005). In a study by Gregory et al. (2006), infiltration rates were slower in compacted soils compared to un-compacted soils: respectively, infiltration rates were $8-175 \mathrm{~mm} \mathrm{hr}^{-1}$ compared to $377-634 \mathrm{~mm} \mathrm{hr}^{-1}$ for forests, $225 \mathrm{~mm} \mathrm{hr}^{-1}$ compared to $23 \mathrm{~mm} \mathrm{hr}^{-1}$ for pastureland, and $160-188 \mathrm{~mm} \mathrm{hr}^{-1}$ compared to $637-652 \mathrm{~mm} \mathrm{hr}^{-1}$ for plantations. Studies by Bharati et al. (2002) and Meek et al. (1992) also found that infiltration rates were lower on compacted sites. Reduced infiltration can lead to increased surface runoff and as a result, increased soil erosion (Gregory et al., 2006; Bassett et al., 2005).

With regard to soil aeration, a study by Currie (1984) found that increasing the bulk density of a soil from $1.04 \mathrm{~g} \mathrm{~cm}^{-3}$ to $1.54 \mathrm{~g} \mathrm{~cm}^{-3}$ decreased gas diffusion by $38 \%$ in dry soils and $82 \%$ in wet soils. The loss of total porosity also decreases the total capacity of soils to hold water 
and gases. A study by Motavalli et al. (2003) found that in more compacted soils the volumetric water content was reduced to a depth of 20 to $30 \mathrm{~cm}$. The reduction in the rate of water and oxygen recharge in compacted soils in addition to the decrease in the capacity to store water and oxygen can result in water and oxygen deficits. Severe surface compaction can exacerbate water and oxygen shortages (Basset et al., 2005).

Soil compaction increases soil strength (Kozlowski, 1999; Nambiar \& Sands, 1992). The closer packing of soil particles and reduction in soil porosity results in an increase in friction and less possibility for particle rearrangement (Craul, 1992). Soil penetration resistance, which attempts to imitate root penetration into the soil, is a common way of measuring soil strength (Hamza \& Anderson, 2005). Taylor et al. (1965) found that soil penetration resistance increased with bulk density, a good indicator of soil compaction, but would vary depending on soil type and soil properties. It is important to note that there is also a relationship between soil strength and soil moisture, whereby an increase in soil moisture will decrease soil strength. However, if moisture conditions are consistent, soil strength is highly dependent on the bulk density (Hamza \& Anderson, 2005; Day \& Bassuk, 1994).

Soil compaction can indirectly increase soil temperature in two ways. The first can occur due to the resulting decrease in soil moisture, which reduces the ability of the soil to regulate daytime high temperatures. The second can occur as a result of less plant cover or as a result of increased soil erosion, both of which increase the soils exposure to the sun (Craul, 1992; Kemper \& Derpsch, 1981).

Soil compaction can indirectly interrupt nutrient cycling as a result of a lower rate of plant growth (Williamson \& Neilson, 2003; Kozlowski, 1999; Breland \& Hansen, 1996). Overtime, less plant growth will result in reduced plant matter input and less organic matter 
(Williamson \& Neilson, 2003). However, if soil strengths become high enough to impede microorganism activity, organic matter will build up in the soil (Kozlowski, 1999; Breland \& Hansen, 1996; Brady \& Buckman, 1990). A reduction in either organic matter or micro-organism activity will result in lower soil nutrient contents (Kozlowski, 1999; Breland \& Hansen, 1996; Craul, 1992). This is supported by Breland and Hansen (1996), who found that when potted Italianryegrass were grown in compacted soil, the mineralization of cattle manure was reduced by $18 \%$.

\subsection{Effects on Tree Growth}

Soil compaction inhibits plant function and plant growth (Logsdon \& Karlen, 2004; Grant, 1993; Nambiar \& Sands, 1992). Studies have found that plants growing in compacted soils may experience a reduction in root growth (Bulmer \& Simpson, 2010; Gomez et al., 2002;

Kozlowski, 1999), shoot growth (Day \& Bassuk, 1994), reproductive health (Kozlowski, 1999), total yield (Radford et al., 2001), and seedling establishment (Bulmer \& Simpson, 2010; Bassett et al., 2005; Williamson \& Neilson, 2003; Radford et al., 2001), as well as an increase in tree mortality (Bulmer \& Simpson, 2010; Kozlowski, 1999). Compacted soils limit plant growth by either mechanically impeding root growth or by limiting oxygen, water, and nutrient uptake (Kozlowski, 1999; Craul, 1992).

Roots must grow through the soil by elongating into pore spaces. If the pore spaces are too small for the roots to enter or if the soil strength is too high for the roots to widen the pore space, such as in compacted soils, root growth will be mechanically impeded (Basset et al., 2005; Gomez et al., 2002; Pan \& Bassuk, 1985). Plants respond to mechanical impedance by producing higher levels of ethylene, which reduces root elongation and root hair development and triggers an increase in radial root growth and branching (Kozlowski, 1999). Mechanical impedance 
seems to be the dominant mechanism restricting root growth in severely compacted soils (Tackett \& Pearson, 1964).

Compacted soils can also cause plants to experience water, oxygen and nutrient deficits, which may result in decreases to plant function and growth. This is attributed to the reduced capacity of compacted soils to store these resources (Kozlowski, 1999; Day \& Bassuk, 1994). Compacted soils have less available water for plant uptake. Therefore, plant roots can quickly deplete this resource. Stomata closure has been linked to low water contents in compacted soils (Kozlowski, 1999; Mulholland et al., 1995; Tardieu, 1994). Prolonged stomata closure can result in decreased rates of photosynthesis (Gomez et al., 2002). Plants require oxygen for respiration. Compacted soils can decrease the rate of oxygen replenishment and are more easily waterlogged, both of which can lead to anaerobic conditions (Kozlowski, 1999; Grant, 1993). Lower rates of respiration will lead to decreased growth (see section 2.24.) and a reduced capacity for mineral uptake (Day \& Bassuk, 1994). In addition, as compaction can result in losses to soil nutrients, plants growing in compacted soils have access to fewer available nutrients. Reduced mineral uptake can cause further losses to plant function (see table 2.1), including a reduction in the rate of photosynthesis due to the loss of leaf area (Kozlowski, 1999). Water, oxygen, and nutrient deficiencies seem to primarily limit plant growth at moderate levels of compaction, while the physical impedance of roots primarily limit plant growth at high levels of compaction (Day \& Bassuk, 1994).

Ultimately, a smaller root system, regardless of the cause, will result in less access to untapped nutrient pools and a lowered capacity for resource uptake, which will further limit shoot and root growth (Bassett et al., 2005; Gomez et al., 2002; Kozlowski, 1999; Craul, 1992). 
In general, soil compaction can be considered growth limiting at bulk densities between 1.4 and $1.6 \mathrm{Mg} / \mathrm{m}^{3}$ for fine textured soils and between 1.7 and $1.8 \mathrm{Mg} / \mathrm{m}^{3}$ for courser textured soils (Kozlowski, 1999). However, this can vary depending on the soil moisture and other soil properties, therefore, soil strength, measured in Megapascals (MPa), is often preferred when describing the effect of soil compaction on tree growth (Day et al., 2000). A soil strength of 2 $\mathrm{MPa}$ is frequently considered as the threshold in which compaction will start to limit tree growth (Hamza \& Anderson, 2005; Kozlowski, 1999; Day \& Bassuk 1994; Materechera et al., 1992). This is supported by (Taylor \& Burnett, 1964) who found that a soil strength of $2.5 \mathrm{MPa}$ significantly reduced the root growth of upland cotton (Gossypium hirsutum), while a soil strength of 3 Mpa stopped growth completely. A study by Sands et al. (1979) found similar results; the root growth of Monterey pine (Pinus radiate) ceased at soil strengths greater than 3 MPa. However, plant and trees species vary in their tolerance to soil compaction (Bassett et al., 2005; Day et al., 2000). Species that are tolerant of wet conditions, such as silver maple, may also be more tolerant of compacted soils. These species are able to undergo root growth in wet condition and therefore, take advantage of lower soil strengths, while trees that require drier soils to grow must overcome greater soil strengths (Williamson \& Neilson, 2003; Day et al., 2000). Therefore, while a soil strength of $2 \mathrm{MPa}$ is a good indicator of growth limiting soil compaction, it should only be used as a guideline and not an exact threshold.

\subsection{Remediation}

There are several methods currently used to remediate compacted soils, including tilling the soil, aerating the soil, installing drainage systems, amending or replacing the soil, and naturalization (Hamza \& Anderson, 2005; Kozlowksi, 1999; Craul, 1992). 


\subsection{Naturalization}

Naturalization is a soil management method in which areas are enclosed and activities are restricted. Natural processes, such as freeze thaw, root activity, micro-organism activity, will overtime, expand the soil and create structure. In agriculture, this method is referred to as 'letting an area go fallow'. It has the potential to improve soil aeration, infiltration, organic matter, organism activity, nutrient content, and penetration resistance (Kozlowski, 1999; Rolf, 1994). According to a study by Millward et al. (2011), naturalization has the potential to be an effective soil remediation method. And, in deep subsoil, naturalization may be the only way in which compaction can be alleviated (Radford et al., 2001). In a study of Kew Gardens, Toronto, Canada, low compaction, bulk density and high infiltration rates were correlated with areas that had been enclosed for naturalization purposes for a period of six years, while high use areas were correlated with higher often debilitating levels of compaction, bulk density and infiltration capacity (Millward et al. 2011). However, some soil types can take decades to become uncompacted (Millward et al., 2011; Kozlowski, 1999). Therefore, in urban areas, this method is only useful where activity can be restricted for several years, limiting its usefulness to naturalized areas and urban parkland.

\subsection{Mechanized Soil Loosening}

Mechanized soil loosening such as subsoiling, which breaks up compact soil without inverting the soil, and ploughing, which turns the soil to break it up, are commonly used methods to break-up surface and subsurface compaction and to remove soil pans in agriculture (Hamza \& Anderson, 2005; Craul, 1992; Dexter, 1991). Many studies indicate that mechanized loosening can improve soil bulk density and crop yields (Osunbitan et al., 2005; Motavalli et al., 2003; Varsa et al., 1997; Bennie \& Botha, 1986). However, the benefits only last a few years, and over 
the long term, compaction may actually become worse than under initial conditions (Day \& Bassuk, 1994). According to Ramos et al. (2010) and Dexter (1991), this can be attributed to the fact that subsoiling and ploughing methods destroy soil structure; after which, as the soil is no longer in equilibrium and as soils that lack structure are more easily compressible, the particles will re-compact closer together. Negative effects of mechanized loosening were reported in a study by (Johnson et al., 1987), in which the heavy equipment required for mechanized loosening increased penetration resistance by 240 to $300 \%$, while initial improvements were only 20 to $50 \%$. A study by Bishop \& Grimes (1978) found similar results. In this study, improvements to soil strength and yield were no longer significant within two years of mechanized loosening. Other long-term studies have found that soil quality and crop yields under a no tillage system were no worse than under a mechanized loosening system (Logsdon \& Karlen, 2004). And, in some cases, crops performed better (Radford et al., 2001; Unger \& Jones, 1998). According to Craul (1992), in order to maintain soil and yield benefits under a tillage system, soils should be tilled every few years. Unfortunately, this is not possible in urban forests as mechanized loosening post-planting will damage tree roots (Day \& Bassuk, 1994; Craul, 1992). Another limiting factor of implementing mechanized loosening in urban areas is the cost of the equipment (Rosolem et al., 2002).

\subsection{Aeration and Drainage Systems}

Aeration techniques and drainage systems are soil remediation methods that aim to improve oxygen levels and water infiltration rates (Kozlowski, 1999; Day \& Bassuk, 1994; Craul, 1992). Generally, aeration techniques are less intrusive, improving air flow and drainage through cracks and fissures made at the surface of the soil, while drainage systems require soil installations that bypass areas of compaction (Craul, 1992). Both techniques have been shown to 
be successful at improving aeration and drainage and at increasing plant growth (Craul, 1992;

Nambiar \& Sands, 1992; Smiley et al., 1990). However, poor aeration and drainage are only symptoms of compaction; aeration techniques and drainage systems mostly fail to improve bulk density or any other indicators of soil compaction (Day et al., 1995; Smiley et al., 1990). On a large scale, aeration techniques would be easier to implement (Craul, 1992); however, benefits are only short term, from a few days to a week (Day \& Bassuk, 1994). On the other hand, drainage systems will benefit soil quality and plant growth for at least as long as they are installed (Nambiar \& Sands, 1992), but they are more expensive and as they do not actually reduce compaction, they are not likely worth the expense (Day et al., 1995).

\subsection{Soil Amendment and Replacement}

Amending a soil involves the addition of inorganic or organic material to a soil in order to improve soil conditions, while soil replacement involves replacing all or part of a contaminated or low quality soil with a soil that has desired characteristics. Amendments can be added to the surface of a soil, incorporated into the subsoil, or mixed with extracted soil and replacing it as backfill. Materials can include organic matter, inorganic fertilizers, or larger inorganic or organic materials, such as granite, gravel, fly ash, bark, and slate (Day \& Bassuk, 1994; Craul, 1992; Soane, 1990; Patterson, 1977).

The incorporation or surface application of fertilizers and organic matter offers several benefits to urban soil. Fertilizers and organic matter can improve soil nutrient contents, which can enhance the growth of plants on compacted soils (Williamson \& Neilson, 2003; Kozlowski, 1999; Soane, 1990). Organic matter offers additional benefits. It has been linked to lower soil bulk densities, improved soil moisture, and enhanced soil structure (Soane, 1990). However, studies on the ability of organic matter additions to remediate compaction have been mixed. 
Long-term studies by Morachan et al. (1972) and Sommerfeldt and Chang (1985), 13 year and 5year studies respectively, found that the addition of organic matter improved soil bulk densities. While, a two-year study by Motavalli et al. (2003) reported that surface applications of poultry manure provided no additional improvements to bulk densities. It is important to note that, in order to incorporate organic matter or fertilizers into the subsoil, tilling or subsoiling is required (Motavalli et al., 2003). And, as mentioned in section 2.52, while tilling can break up soil compaction and improve plant yields, it will also increase costs, may cause further damage to soil structure, and may damage existing tree roots. Considering the risk of tilling to tree roots, surface applications are more applicable to urban environments. An additional benefit of surface applications of organic matter or fertilizers is that they could be used in tandem with other remediation methods.

Another option is to amend or replace the soil. Compacted soils can be amended with larger, rigid, less dense material or replaced with loose uncompact soil (Day \& Bassuk, 1994; Craul, 1992). Amended or replaced soil will be less compact, allowing for more airflow, better drainage, and easier root growth. Another benefit is that soils can be amended or replaced for new planting sites and around established trees. For established trees, trenches are excavated out radially from the trunk between the roots. For new plantings, the holes dug for the roots are backfilled with the amended or replaced soils (Day \& Bassuk, 1994; Craul, 1992). While, amending and replacing soil has shown to be able to improve root growth (Day et al., 1995; Patterson, 1977); it is limited by the costs of labour, equipment, and materials (Hummel \& Johnson, 1985). 


\subsection{Soil Remediation using Plants}

Bio-remediating plants, or cover crops as they are called in agriculture, are an attractive option for remediating compaction (Williams \& Weil, 2004; Rosolem et al., 2002). They are able to naturally enhance soil properties and ultimately increase the growth of subsequent plants (Rosolem et al., 2002; Dabney et al., 2001; Radford et al., 2001). In addition, cover crops grow fast, reaching maturity within a single season; they can provide significant benefits to both soil quality and plant yields after a single treatment; they have low energy requirements; and they are relatively cheap compared to other remediation methods (Hartwig \& Ammon, 2002; Wyland et al., 1996). Cover crops are currently used in agriculture as an alternative to deep tillage and no tillage farming (Rosolem et al., 2002). However, they have yet to be adopted for use in urban environments.

\subsection{Effects on Soil Properties}

Cover crops are fast growing plants that usually grow well in compacted soils. They typically have a dense, fibrous root system or a large, deep penetrating tap-root (Rosolem et al., 2002; Dabney et al., 2001). They are usually planted in the fall in-between crop rotations, and grow to maturity in 6 to 12 weeks (Hartwig \& Ammon, 2002). The cover crops die or are killed over winter and start to biodegrade, adding organic matter into the soil (Constantin et al., 2010; Dabney et al., 2001; Wilson et al., 1982). In the spring, the root channels, a result of root activity, remain in the soil and are often visible (Chen \& Weil, 2010; Weil \& Kremen, 2007; Snapp et al., 2005). While initially adopted to reduce nitrogen leaching, more recently, studies on cover crops have focused on their ability to improve compaction related ailments (Sarrantonio \& Gallandt, 2014). 
The increase in rooting activity and organic matter content favours soil aggregation and ped formation, enhancing soil structure and increasing porosity (Chen \& Weil, 2010; Folorunso et al., 1992; Wilson et al., 1982). The increase in porosity is largely a result of the increase in macropore volume due to the remaining root channels but can also be a result of an increase in macro and microrganism activity (Sanchez et al., 2007; Hartwig \& Ammon, 2002; Wilson et al, 1982). By regulating soil temperatures and providing food, cover crops create ideal conditions for soil organisms. The soil activity of organisms, especially those of macrorganisms, such as earth worms, further enhance soil structure (Dabney et al., 2001; Wilson et al., 1982; Kemper \& Derpsch, 1981). The resulting enhancement to soil structure and porosity can result in a decrease in bulk density and penetration resistance (Folorunso et al., 1992; Wilson et al., 1982). However, in many studies there were no significant changes to bulk density or penetration resistance (Chen \& Weil, 2010; Weil \& Kremen, 2007; Williams \& Weil, 2004). In these studies, it was suggested that bulk density and penetration resistance measurements may not be able to fully gauge the benefit that the root channels provide to the soil (Williams \& Kremen, 2007). This can be attributed to the fact that roots of subsequent plants can grow into the root channels rather than penetrating the soil. Estimating the benefits of root channels to the plant is best done by determining yield increases (Williams \& Weil, 2004).

Cover crops are able to improve soil aeration, increase soil infiltration rates, and increase soil water holding capacity through their ability to enhance soil structure and to provide root channels that bypass compaction zones (Hartwig \& Ammon, 2002; Folorunso et al., 1992; Wilson et al., 1982). Increased infiltration will result in reduced erosion and improvements to soil drainage and water recharge (Gomez et al., 2009; Hartwig \& Ammon, 2002). The increase in 
organic matter content associated with cover crops can also improve water retention (Rosolem et al., 2002).

Cover crops can also enhance soil fertility (Constantin et al., 2010; Ramos et al., 2010). During growth, the roots absorb nutrients, thereby, preventing them from leaching out of the soil (Askegaard et al., 2011; Justes et al., 1999). The nutrients are added back to the soil the following spring in the form of organic matter. The organic matter is mineralized into usable form, resulting in an increase in nutrient availability during the growing season (Constantin et al., 2010; Dabney et al., 2001; Justes et al., 1999).

Other additional benefits of cover crops include their ability to supress weeds and to reduce pests (Malik et al., 2008; Dabney et al., 2001; Altieri \& Schmidt, 1986).

There are several species of cover crops available to choose from, some of which are more appropriate to certain purposes than others (Sarrantonio \& Gallandt, 2014; Chen \& Weil, 2010; Rosolem et al., 2002). Therefore, species selection is an important management decision. Generally, cover crop species are from the Brassicacea, Poaceae, and Fabaceae families (USDA, 2014). Recent research indicates that species with large tap roots, such as radish or rapeseed from the Brassicacea family, are more suitable for alleviating subsurface compaction (Chen \& Weil, 2010; Weil \& Kremen, 2007; Williams \& Weil, 2004; Materechera et al., 1992). However, in areas with only surface compaction, it may be more appropriate to plant species that have dense growing fibrous roots, such as rye from the Poaceae family, or to plant a combination of tap-rooted and fibrous rooted species (Rosolem et al., 2002).

\subsection{Effects on Plant Growth}

The effects of cover crops on crop growth are generally positive and have been well documented (Weil \& Kremen, 2007; Radford et al., 2001; Dabney et al., 2001; Kemper \& 
Derpsch, 1981). Cover crops are able to improve crop yields on sites where yields have been impeded by severe compaction (Wilson et al., 1982; Kemper \& Derpsch, 1981). In a study by Wilson et al. (1982), cover crops were able to significantly increase maize and cowpea yields. They are more cost effective than other no tillage management systems (Hartwig \& Ammon, 2002). In addition, cover crops often increase the yield of subsequent crops better than conventional tillage methods (Williams \& Weil, 2004; Radford et al., 2001). However, in dry regions or in drought years, when soil moisture is low, cover crops may have a negative effect on the yields of subsequent crops. The water needs of the cover crop species may diminish soil water reserves, limiting the available water for the following plant species. Sufficient irrigation when needed may be able to mitigate water shortages (Dabney et al., 2001; Meisinger et al., 1991).

Less researched is the ability of cover crops to improve tree growth. While only a few studies have been conducted, results seem promising. In one study, cover crops were grown in the rows between apple trees. Trees treated with cover crops experienced greater trunk growth and higher apple yields than trees on control sites (Sanchez et al., 2007). Studies by Broughton (1977) and Mainstone (1969) found similar results. However, where resources are lacking (i.e., water and nutrients), cover crops may compete with the established trees (Broughton, 1977). This is what likely happened in a study by Foshee et al. (1995), in which tree growth was significantly supressed by the growth of cover crops. Therefore, when growing cover crops together with trees, it is important to ensure that plant resources are sufficient (Broughton, 1977). Continued research on the effects of cover crops on tree growth will be necessary. 


\subsection{Radish}

Radish species, from the genus Raphanus and the family Brassicacea, are known for their thick, long tap-root that grows deep into the soil (Chen \& Weil, 2010). In scientific research, radishes tend to outperform other species in their ability to grow through compacted soils and to increase subsequent crop yields (Chen \& Weil, 2010; Weil \& Kremen, 2007; Williams \& Weil, 2004). In a study by Chen and Weil (2010), radish not only showed better growth than rye and rapeseed in compacted soils, it was also found that higher levels of compaction, usually debilitating to other plant species, may even improve radish growth. However, the effects of severely debilitating levels of compaction were never tested. In addition, radishes have also been found to be good nitrogen scavengers and weed suppressors (Malik et al., 2008; Snapp et al., 2005; Dabney et al., 2001; Justes et al., 1999).

Tillage Radish®, a genetically selected species of radish, has been chosen for use in this study. According to CCS (2012), Tillage Radish® grows a larger tap-root, develops more quickly than conventional radish, and is a good scavenger of nitrogen, phosphorous, potassium, calcium, and sulfur. In addition, it has been backed by scientific research in its ability to improve soil conditions better than natural varieties and as a result, is an officially recognized variety under U.S. Plant Variety Protection (variety CCS-779).

\subsection{Summary}

Soil compaction is of great concern in urban areas. A high degree of pedestrian and vehicle traffic have been shown to increase soil bulk densities to ranges that inhibit plant growth. Of major concern is that an increase in world population could lead to progressively greater levels of urban soil compaction, which would significantly alter soil function, severely inhibit tree growth, and increase tree mortality in cities. While soil quality issues are often ignored in 
urban environments, in order to ensure adequate tree growth and maintain the important benefits that trees provide, cost-effective soil remediation methods are needed. Current soil remediation methods are often damaging to existing root systems, too expensive, or ineffective.

A largely unexplored urban soil remediation method is the use of bio-remediating plants. Typically used in agriculture to improve soil quality between crop rotations, bio-remediating plants have roots with higher resistances to soil compaction and thus, can grow in soils that are debilitating to most other plants. When planted in higher densities, they may accelerate the naturalization process through increased root activity, which has been shown to benefit the soil by improving soil structure, aeration, infiltration rates, moisture content, organic matter content, nutrient availability, soil temperature, and erosion control. In agricultural studies, the improvements to soil properties have been able to increase the yields of successive crops. In addition, bio-remediating plants are relatively cheap and have low energy requirements. However, several gaps in the knowledge base still exist. Can cover crops remediate soil compaction and improve tree growth in an urban setting? Can cover crops be used to remediate areas with established trees as well as to prepare soil for new tree plantings? At what point does soil compaction limit the growth of cover crops in urban areas? And, can cover crops remediate soil without nutrient inputs?

This thesis, as it is part of a larger study, seeks to answer these questions in part. Specifically, the present study will analyse the ability of Tillage Radish® to remediate soil compaction and improve soil quality in urban soils where trees have been established. And, to assess a low cost management approach to the improvement of soil quality, Tillage Radish® will be analyzed to determine how well it will grow in soil without nutrient input. 


\subsection{References}

Akbari, H. (2002). Shade trees reduce building energy use and CO2 emissions from power plants. Environmental Pollution, 116: 119-126.

Altieri, M. A., and Schmidt, L. L. (1986). Cover crops affect insect and spider populations in apple orchards. California Agriculture, 40:15-17.

Askegaard, M., Olesen, J. E., Rasmussen, I. A., and Kristensen, K. (2011). Nitrate leaching from organic arable crop rotations is mostly determined by autumn field management. Agriculture, Ecosystems and Environment, 142: 149-160.

Aubertin, G. M., and Kardos, L. T. (1965). Root growth through porous media under controlled conditions: I. Effect of pore size rigidity. Soil Science Society of America, 29: 290-293

Bakker, D. M., Davis, R. J. (1995). Soil deformation observations in Vertisol under field traffic. Australian Journal of Soil Research, 33: 817-832

Bassett, I. E., Simcock, R. C., and Mictchell, N. D. (2005). Consequences of soil compaction for seedling establishment: Implications for natural regeneration and restoration. Austral Ecology, 30: 827-833.

Bennie, A. T. P., and Botha, F. J. P. (1986). Effects of deep tillage and controlled traffic on root growth, water-use efficiency and yield of irrigated maize and wheat. Soil and Tillage Research, 7: 85-95.

Bharati, L., Lee, K., Isenhart, T. M., and Schultz, R. C. (2002). Soil-water infiltration under crops, pasture, and established riparian buffer in midwestern USA. Agroforestry Systems, 56: $249-257$.

Bishop, J. C., and Grimes, D. W. (1978). Precision tillage effects on potato root and tuber production. American Potato Journal, 55: 65-71.

Bolund, P., and Hunhammar, S. (1999). Ecosystem services in urban areas. Ecological Economics, 29: 293-301.

Brady. N. C., and Buckman, H. O. (1990). The nature and properties of soils $\left(10^{\text {th }} \mathrm{ed}.\right)$. Macmillan, New York: Prentice Hall.

Breland, A., Hansen, S. (1996). Nitrogen mineralization and microbial biomass as affected by soil compaction. Soil Biology and Biochemistry, 28: 655-663.

Bretz, S., Akbari, H., \& Rosenfeld, A. (1997). Practical issues for using solar-reflective materials to mitigate urban heat islands. Atmospheric Environment, 32: 95-101. 
Broughton, W. J. (1977). Effect of various covers on soil fertility under Hevea brasiliensis Muell. Arg. and on the growth of the tree. Agro-Ecosystems, 3: 147-170.

Brown, P. H., Welch, R. M., and Cary, E.E. (1987). Nickel: A micronutrient essential for higher plants. Plant Physiology, 85: 801-803.

Bulmer, G. E., and Simpson, D. G. (2010). Soil compaction reduced the growth of Lodgepole Pine and Douglas-fir seedlings in raised beds after two growing seasons. Soil Science Society of America Journal, 74: 2162-2174.

Canadian Urban Forest Network (2012). Canadian urban forest strategy 2013-2018. Retrieved from www.treecanada.ca/publications/pdf/cufs.pdf.

Chen, G., and Weil, R. R. (2010). Penetration of cover crop roots through compacted soils. Plant and Soil, 331: 31-43.

City of Toronto (2013). Every Tree Counts. Retrieved from http://www.toronto.ca/trees/ every_tree_counts.htm

Clark, J. R., Matheny, N. P., Cross, J., and Wake, V. (1997). A model of urban forest sustainability. Journal of Arboriculture, 23: 17-30.

Comery, W. R. (2007). Tree roots versus sidewalks and sewers. In J. E. Kuser (Ed.), Urban and Community Forestry in the Northeast (261 - 266). (2 $2^{\text {nd }}$ ed.). New York, NY: Springer.

Constantin, J., Mary, B., Laurent, F., Aubrion, G., Fontaine, A., Kerveillant, P., and Beaudoin, N. (2010). Effects of catch crops, no till and reduced nitrogen fertilization on nitrogen leaching and balance in three long-term experiments. Agriculture, Ecosystems and Environment, 135: 268-278.

Cook, D. I. (1978). Trees, solid barriers, and combinations: Alternatives for noise control. Proceedings of the National Urban Forestry. Conference (G. Hopkins, ed.), SUNY College of Environmental Science and Forestry, Syracuse, NY, pp. 330-339.

Costanza, R., and Patten, B. (1995). Defining and predicting sustainability. Ecological Economics, 15:193-196.

Craul, P. J. (1992). Urban soil in landscape design. New York, NY :John Wiley and Sons.

Craul, P. J. (1985). A description of urban soils and their desired characteristics. Journal of Arboriculture, 11.

Currie, J. A. (1984). Gas diffusion through soil crumbs: The effects of compaction and wetting. Journal of Soil Science, 35: 1-10. 
Dabney, S., Delgado, J. and D. Reeves. (2001). Using winter cover crops to improve soil and water quality. Communications in Soil Science and Plant Analysis, 32: 1221-1250.

Day, S. D. and Bassuk, N. (1994). A Review of the effects of soil compaction and amelioration treatments on landscape trees. Journal of Arboriculture, 20: 9-17.

Day, S. D., Bassuk, N. L., and van Es, H. (1995). Effects of four compaction remediation methods for landscape trees on soil aeration, mechanical impedance, ands tree establishment. Journal of Environmental Horticulture, 13: 641-671.

Day, S. D., Seiler, J. R., and Persaud, N. (2000). A comparison of root growth dynamics of silver maple and flowering dogwood in compacted soil at differing soil water contents. Tree Physiology, 20: 257-263.

Day, S. D., Wiseman, P. E., Dickinson, S. B., and Harris, R. J. (2010). Tree root ecology in the urban environment and implications for a sustainable rhizosphere. Arboriculture and Urban Forestry, 35: 193-205.

Deneke, F. (1993). Urban Forestry in North America: Towards a Global Ecosystem Perspective. Proceedings of the First Canadian Urban Forests Conference. Winnipeg, MB: Canada.

Dexter, A. R. (1991). Amelioration of soil by natural processes. Soil and Tillage Research, 20: 87-100.

Dwyer, J.F., McPherson, E.G., Schroeder, H.W., and Rowntree, R.A. (1992). Assessing the benefits and costs of the urban forest. Journal of Arboriculture, 18: 227-234.

Dwyer, J.F., Nowak, D.J., and Noble, M.H. (2003). Sustaining urban forests. Journal of Arboriculture, 29: 49-55.

Eaven, P. H., Evert, R. F., and Eichhorn, S. E. (2005). Biology of Plants (7 ${ }^{\text {th }}$ ed.). New York, NY : W. H. Freeman and Company Publishers.

Epstein, E. (1956). Mineral nutrition of plants: Mechanisms of uptake and transport. Plant Physiology, 7: 1-24.

Fitzpatrick, R. W., McKenzie, N., and Maschmedt, D. J. (1999). Soil morphological indicators and their importance to soil fertility. In K. I. Pervill, L. A. Sparrow, \& D. L. Reuter. (Eds.), Soil Analysis: An Interpretation Manual (55-68). Collingwood, VIC: CSIRO Publishing.

Folorunso, O. A., Rolston, D. E., Prichard, P. T., and Louie, D. T. (1992). Cover crops lower soil surface strength, may improve soil permeability. California Agriculture, 46: 26-27. 
Foshee, W. G., Goff, W. D., Patterson, M. G., and Ball, D. M. (1995). Orchard floor crops reduce growth of young pecan trees. Horticultural Science, 30: 979-980.

Geigenberger, P. (2003). Response of plant metabolism to too little oxygen. Current Opinion in Plant Biology, 6: 247-256.

Gomez, A., Powers, R. F., Singer, M. J., and Horwath, W. R. (2002). Soil compaction on growth of young Ponderosa Pine following litter removal in California's Sierra Nevada. Soil Science Society of America Journal, 66: 1334-1343.

Gomez, J., Guzman, M., Giraldez, and J., Fereres, E. (2009). The influence of cover crops and tillage on water and sediment yield, and on nutrient, and organic matter losses in an olive orchard on a sandy loam soil. Soil \& Tillage Research, 106: 137-144.

Grant, R. F. (1993). Simulation model of soil compaction and root growth. Plant and Soil, 150: $1-14$.

Gregory, J. H., Dukes, M. D., Jone, P. H., and Miller, G. L. (2006). Effect of urban soil compaction on infiltration rate. Journal of Soil and Water Conservation, 61: 117-123.

Hamza, M. and Anderson, W. (2005). Soil compaction in cropping systems: A review of the nature, causes and possible solutions. Soil and Tillage Research, 82: 121-145.

Hartwig, N. L., and Ammon, H. U. (2002). Cover crops and living mulches. Weed Science, 50: $688-699$.

Hawver, G. A., and Bassuk, N. L. (2007). Soils: The key to successful establishment of urban vegetation. In J. E. Kuser (Ed.), Urban and Community Forestry in the Northeast (165182). ( $2^{\text {nd }}$ ed.). New York, NY: Springer.

Hill, A.C. (1971). Vegetation: a sink for atmospheric pollutants. Journal of the Air Pollution Control Association, 21: 341-346.

Hummel, R. L., and Johnson, C. R. (1985). Amended back-fills: Their cost and effect on transplant growth and survival. Journal of Environmental Horticulture, 3: 76-79.

Hussain, A., Black, C. R., Taylor, I. B., and Roberts, J. A. (1999). Soil compaction. A role for ethylene in regulating leaf expansion and shoot growth in tomato? Plant Physiology, 121: $1227-1237$.

Itai, C., and Vaadia, Y. (1971). Cytokinin activity in water-stressed shoots. Plant Physiology, 47: 87-90.

Jim, C. Y. (2008). Opportunities and alternatives for enhancing urban forests in compact cities 
and developing countries. Carreiro, M. M., Song, Y. C., and Wu, J., Ecology, planning, and management of urban forests: international perspectives (118-467). Springer: New York.

Jim, C. Y. (1998). Urban soil characteristics and limitations for landscape planting in Hong Kong. Landscape and Urban Planting, 40: 235-249.

Johnson, J. F., Voorhees, W. B., Randall, G. W. (1987). Effect of recompaction on penetrometer resistance on a soil loosened by subsoil tillage. Agronomy Journal, 79: 24.

Jorgensen, E. (1974). Towards an urban forestry concept. Proceedings of the 10th Commonwealth Forestry Conference. Ottawa, Ontario: Canada.

Jusoff, K. (1989). Physical soil properties associated with recreational use of a forested reserve area in Malaysia. Environmental Conservation, 16: 339-342.

Justes, E., Mary, B., and Nicolardot, B. (1999). Comparing the effectiveness of radish cover crop, oilseed rape volunteers, and oilseed rape residues incorporation for reducing nitrate leaching. Nutrient Cycling in Agroecosytems, 55: 207-220.

Karlen, D. L., Mausbach, M. J., Doran, J. W., Cline, R. G., Harris, R. F., and Schuman, G. E. (1997). Soil quality: A concept, definition, and framework for evaluation (a guest editorial). Soil Science Society of America Journal, 61: 4-10.

Kemper, B., and Derpsch, R. (1981). Results of studies made in 1978 and 1979 to control erosion by cover crops and no-tillage techniques in Parana, Brazil. Soil \& Tillage Research, 1: $253-267$.

Kozlowski, T. (1999). Soil compaction and growth of woody plants. Scandinavian Journal of Forest Research, 14: 596-619.

Logsdon, S. D., and Karlen, D. L. (2004). Bulk density as a soil quality indicator during conversion to no-tillage. Soil and Tillage Research, 78: 143-149.

Lyr, H., and Hoffman, G. (1967). Growth rates and growth periodicity of tree roots. International Review of Forestry Research, 2: 181-236.

Mainstone, B. J. (1969). Residual effects of ground cover and nitrogen fertilisation of Hevea prior to tapping. Journal of the Rubber Research Institute of Malaysia, 21: 113-125.

Malik, M. S., Norsworthy, J. K., Culpepper, A. S., Riley, M. B., and Bridges, W Jr. (2008). Use of wild radish (Raphanus raphanistrum) and rye cover crops for weed suppression in sweet corn. Weed Science, 56: 588-595. 
Materechera, S. A., Alston, A. M., Kirby, J. M., and Dexter, A. R. (1992). Influence of root diameter on the penetration of seminal roots into a compacted subsoil. Plant and Soil, 144: 297-303.

Meek, B. D., Rechel, E. R., Carter, L. M., DeTar, W. R., and Urie, A. L. (1992). Infiltration rate of a sandy loam soil: Effects of traffic, tillage, and plant roots. Soil Science Society of America Journal, 56: 908-913.

Meisinger, J. J., Hargrove, W. L., Mikkelsen, R. L., Williams, J. R., and Benson, B. W. (1991). Effects of cover crops on groundwater quality (57-68). In W .L. Hargrove (ed.) Cover Crops for Clean Water. Ankeny, IA: SWCS.

Millward, A., Paudel, K., and Briggs, S. (2011). Naturalization as a strategy for improving soil physical characteristics in a forested urban park. Urban Ecosystems, 14: 261-278.

Millward, A.A., and Sabir, S. (2010). Structure of a forested urban park: Implications for strategic management. Journal of Environmental Management, 91: 2215-2224.

Monti, P. W., and Mackintosh, E. E. (1979). Effects of camping on surface soil properties in the boreal forest region of northwestern Ontario, Canada. Soil Science Society of America Journal, 43: 1024-1029.

Morachan, Y.B., Moldenhauer, W.C. and Larson, W.E. (1972). Effects of increasing amounts of organic residues on continuous corn. I. Yields and soil physical properties. Agronomy Journal, 64: 199-203.

Motavalli, P. P., Stevens, W. E., and Hartwig, G. (2003). Remediation of subsoil and compaction effects on corn $\mathrm{N}$ availability by deep tillage and application of poultry manure in a sandy-textured soil. Soil and Tillage Research, 71: 121-131.

Mulholland, B. J., and Fullen, M. A. (1991). Cattle trampling and soil compaction on loamy sands. Soil Use and Management, 7: 189-193.

Nambiar, E. K. S., and Sands, R. (1992). Effects of compaction and simulated root channels in the subsoil on root development, water uptake and growth of radiate pine. Tree Physiology, 10: 297-306.

Nowak, D. J., and Dwyer, J. F. (2007). Understanding the benefits and costs of urban forest ecosystems. In J. E. Kuser (Eds.), Urban and Community Forestry in the Northeast $\left(2^{\text {nd }}\right.$ Ed) (25-13). New York, NY: Springer.

Ontario Ministry of Finance (OMF). (2013). Ontario population projections update (ISBN 
978-1-4606-2022-9). Ontario: CA. Queen's printer for Ontario.

Osunbitan, J. A., Oyedele, D. J., and Adekalu, K. O. (2005). Tillage effects on bulk density, hydraulic conductivity and strength of a loamy sand soil in southwestern Nigeria. Soil and Tillage Research, 82: 57-64.

Overvoorde, P., Fukaki, H., and Beeckman, T. (2010). Auxin control of root development. Cold Spring Harbor Perspectives in Biology, 2: 1-16.

Pan, E., and Bassuk, N. (1985). Effect of soil type and compaction on the growth of Ailanthus altissima seedlings. Journal of Environmental Horticulture, 3: 158-162.

Patterson, J. C. (1977). Soil compaction: Effects on urban vegetation. Journal of Arboriculture, 3: $161-167$.

Radford, B. J., Yule, D. F., McGarry, D., and Playford, C. (2001). Crop responses to applied soil compaction and to compaction repair treatments. Soil and Tillage Research, 61: 157-166.

Ramos, M. E., Benitez, E., Garcia, P. A., Robles, A. B. (2010). Cover crop under different managements vs. frequent tillage in almond orchards in semiarid conditions: Effects on soil quality. Applied Soil Ecology, 44: 6-14.

Reethof, G., and McDaniel, O. H. (1978). Acoustics and the urban forest. Proceedings of the National Urban Forestry Conference (G. Hopkins, ed.), SUNY College of Environmental Science and Forestry, Syracuse, NY, pp. 321-329.

Rivenshield, A., and Bassuk, N. L. (2007). Using organic amendments to decrease bulk density and increase macroporosity in compacted soils. Arboriculture and Urban Foresty, 33: 140-146.

Roberts, J., Jackson, N., and Smith, M. (2006). Tree roots in the built environment. Norwich, NOR: The Stationary Office.

Rolf, K. (1994). A review of preventative and loosening measures to alleviate soil compaction in tree planting areas. Arboricultural Journal, 18: 431-448.

Rosenzweig, C., Solecki, W.D., and Slosberg, R. (2006). Mitigating New York City's heat island with urban forestry, living roofs, and light surfaces. A report to the New York State Energy Research and Development Authority, Retrieved September 20, 2012 from - http//www.fs.fed.us/ccrc/topics/urban-forests/docs/NYSERDA_heat_island.pdf

Rosolem, C., Foloni, J., and Tiritan, C. (2002). Root growth and nutrient accumulation in cover crops as affected by soil compaction. Soil and Tillage Research, 65: 109-115. 
Saebo, A., and Ferrini, F. (2006). The use of compost in urban green areas - A review for practical application. Urban Forestry and Greening, 4: 159-169.

Sanchez, E. E., Giayetto, A., Cichon, L., Fernandez, D., Aruani, M. C., and Curetti, M. (2007). Cover crops influence soil properties and tree performance in an apple (Malus domestica Borkh) orchard in northern Patagonia. Plant and Soil, 292: 193-203.

Sands, R., Greacen, E. L and Gerard, C. J. (1979). Compaction of sandy soils in radiata pine forests. I A penetrometer study. Australia Journal of soil Research, 17: 101-113.

Sarrantonio, M., and Gallandt, E. (2014). The role of cover crops in North American cropping systems. Journal of Crop Production, 8: 53-74.

Smiley, E.T., Watson, G. W., Fraedrich, B. R., and Booth, D. C. (1990). Evaluation of soil aeration equipment. Journal of Arboriculture, 16: 118-123.

Snapp, S. S., Swinton, S. M., Labarta, R., Mutch, D., Black, J. R., Leep, R., Nyiraneza, J., and O'neil, K. (2005). Evaluating cover crops for benefits, costs, and performance within cropping system niches. Agronomy Journal, 97: 322-332.

Soane, B. D. (1990). The role of organic matter in soil compatibility: A review of some practical aspects. Soil and Tillage Research, 16: 179-201.

Soil Science Society of America, (1996). Glossary of Soil Science Terms. Madison, WI: Soil Science Society of America Inc.

Sommerfeldt, T.G. and Chang, C. (1985). Changes in soil properties under annual applications of feedlot manure and different tillage practices. Soil Science Society of America Journal, 49: 983-987.

Stadbyggnadskontoret, 1994. Miniskrift om Stockholms parker och naturomra ${ }^{\circ}$ den (Brochure on parks and nature areas in Stockholm). SBK, 94: 6-16 (in Swedish).

Tarashima, E., Fujii, E., Mishima, K., 1999. Experimental studies on the effect of trampling on the root system of seedlings of Zelkova serrate Makino. Technical Bulletin of Faculty Horticulture Chiba University, 53: 85-92.

Tackett, J. L., and Pearson, R. W. (1964). Oxygen requirements of cotton seedling roots for penetration of compacted soil cores. Soil Science Society of America Journal, 28: 600605.

Tardieu, F. (1994). Growth and functioning of roots and of root systems subjected to soil 
compaction: Towards a system with multiple signalling. Soil and Tillage Research, 30: $217-243$.

Taylor, H. M., and Burnett, E. (1964). Influence of soil strength on the root-growth habits of plants. Soil Science, 98: 174-180.

Taylor, H. M., Roberson, G. M., and Parker, J. J Jr. (1966). Soil strength-root penetration relations for medium- to course-textured soil materials. Soil Science, 102: 18-22.

Tyrvainen, L., Silvennoinen, H., and Kolehmainene, O. (2003). Ecological and aesthetic values in urban forest management. Urban Forestry and Urban Greening, 1: 135-149.

UNFPA (United Nations Population Fund). (2011). State of world population 2011 - People and possibilities in a World of 7 Billion. New York - UNFPA.

Unger, P. W., and Jones, O. R. (1998). Long-term tillage and cropping systems affect bulk density and penetration resistance of soil cropped to dryland wheat and grain sorghum. Soil and Tillage Research, 45: 39-57.

United States Department of Agriculture (USDA). (2014). Cover crop plants. Retrieved from http://plants.usda.gov/java/coverCrops.

van Bohemen, H. (2011). Chapter 2: (Eco)system thinking: Ecological principles for building roads, buildings and industrial and urban areas. In E. van Bueren, H. van Bohemen, L. Itard, \& H. Visscher (Eds.), Sustainable urban environments: An ecosystem approach (14-70). Dordrecht, Heidelberg, London, New York: Springer.

van Bueren, E. (2011). Chapter 1: Introduction. In E. van Bueren, H. van Bohemen, L. Itard, and H. Visscher (Eds.), Sustainable urban environments: An ecosystem approach (1-13). Dordrecht, Heidelberg, London, New York: Springer.

Varsa, E. C., Chong, S. K., Abolaji, J. O., Farquhar, D. A., and Olsen, F. J. (1997). Effect of deep tillage on soil physical characteristics and corn (Zea mays L.) root growth and production. Soil and Tillage Research, 43: 219-228.

Vzzotto, V. R., Marchezan, E., Segabinazzi, T. (2000). Effect of cattle trampling on lowland soil physical properties. Ciencia Rural, 30: 965-969.

Watson, G. W., and Kelsey, P. (2006). The impact of soil compaction on soil aeration and fine root density of Quercus palustris. Urban Forestry and Greening. 4: 69-74.

Weil, R., and Kremen, A. (2007). Thinking across and beyond disciplines to make cover crops pay. Journal of the Science of Food and Agriculture, 87: 551-557. 
White, R. E. (2006). Principles and practice of soil science. Malden, MA :Blackwell Publishing.

Williams, S. M. W., and Weil, R. R. (2004). Crop cover root channels may alleviate soil compaction effects on soybean crop. Soil Science Society of America Journal, 68: 1403.

Williamson, J. R., and Neilsen, W. A. (2003). The effect of soil compaction, profile disturbance and fertilizer application on the growth of eucalypt seedlings in two glasshouse studies. Soil and Tillage Research, 71: 95-107.

Wilson, G. F., Lal, R., and Okigbo, B. N. (1982). Effects of cover crops on soil structure and on yield of subsequent arable crops grown under strip tillage on an eroded alfisol. Soil \& Tillage Research, 2: 233-250.

Wyland, L. J., Jackson, L. E., Chaney, W. E., Klonsky, K., Koike, S. T., and Kimple, B. (1996). Winter cover crops in a vegetable cropping system: Impacts on nitrate leaching, soil water, crop yield, pests and management costs. Agriculture, Ecosystems and Environment, 59: 1-17. 


\section{Chapter 3}

\subsection{Abstract}

Urban trees provide ecosystem services, the value of which is dependent on canopy coverage. However, canopy growth is often restricted by soil compaction. Compaction reduces plant access to important soil resources and mechanically impedes root growth. Bio-drilling plants offer an alternative approach to conventional remediation methods. The study evaluated the effectiveness of growing Tillage Radish ${ }^{\circledR}$ to remediate soil compaction and improve soil quality under established trees. The study plot was located in Guelph, Ontario. Soil data was collected before and after planting radish. Results indicated that 1) radish growth was limited by nutrients but not soil compaction. And, 2) Tillage Radish® reduced surface compaction in moderately to highly compact soils. Other soil characteristics did not change significantly. The results suggested that planting Tillage Radish $®$ has potential to remediate compaction in the rooting zone of trees. However, fertilization may be necessary to maximize radish growth and its associated soil remediation benefits. 


\subsection{Introduction}

Urban forests are an important component of healthy urban environments (Dwyer et al., 2003; Dwyer et al., 1992). They provide many benefits to city residents that include storing carbon dioxide (Nowak \& Dwyer, 2007; Akbari, 2002), reducing storm water runoff (Dwyer et al., 1992), improving aesthetics (Bolund \& Hunhammar, 1999), moderating urban temperatures (Rosenzweiget al, 2006; Akbari, 2002), providing habitat for wildlife (Dwyer et al., 1992), removing air pollutants (Nowak et al, 2006; Hill, 1971), reducing noise pollution (Bolund \& Hunhammar, 1999), and increasing property values (Nowak \& Dwyer, 2007). Many cities, such as Toronto, Baltimore, and New York, have recognized these benefits and have implemented strategies in order to increase total urban forest coverage (City of Toronto, 2013).

As urban populations grow, it will become increasingly important to enhance tree canopy coverage if future populations are to receive similar ecosystem services that city populations receive today (van Bueren, 2011; van Bohemen 2011; Dwyer et al., 2003; Bolund \& Hunhammar, 1999). However, by most accounts, cities are challenging environments for trees to grow in (van Bueren, 2011; Millward \& Sabir, 2010; Dwyer et al., 2003). Trees must compete for space and light with other city infrastructure and, despite the nature of urban soils, establish roots and maintain root and shoot growth (Millward \& Sabir, 2010; Jim, 1998; Clark et al., 1997; Craul, 1985). Urban soils can differ from naturally occurring soils in several fundamental ways: frequently they lack a vertical profile, contain less organic matter, contain foreign material, have a modified soil $\mathrm{pH}$, have a reduced capacity for aeration and water drainage, have a disrupted nutrient cycle, have an altered soil temperature regime, and are more compacted when compared with non-urban soils (Day et al., 2010; Jim, 1998; Craul, 1985). Soil compaction is one of the most problematic soil quality issues in urban environments as it can severely alter the physical, 
chemical and biological properties of a soil, which in an urban environment, often exacerbates many of the soil quality issues already prevalent. In addition, it is well known to restrict plant growth; it is difficult to remediate; and, it is common in high traffic areas (Hamza \& Anderson, 2005; Kozlowski, 1999; Craul, 1992; Patterson, 1977).

Soil compaction is defined by the Soil Science Society of America (1996) as, "the process by which the soil grains are rearranged to decrease void space and bring them into closer contact with one another, thereby increasing the bulk density." It occurs as a result of the vertical, shear, and vibrational stresses originating from human, animal and vehicle traffic but can also occur naturally by way of settling and slumping (Basset et al., 2005; Kozlowski, 1999; Rolf, 1994; Craul, 1992; Soane, 1990). Soil compaction restricts tree growth in two ways. First, it physically impedes root growth by restricting root elongation into soil pores (Basset et al., 2005; Gomez et al., 2002; Pan \& Bassuk, 1985). Second, it reduces the total capacity for a soil to store and replenish oxygen and water as well as interrupts the nutrient cycle, diminishing the ability for plants to obtain the required oxygen, water, and nutrients from the soil (Kozlowski, 1999; Mulholland et al., 1995; Day \& Bassuk, 1994). Generally, root growth of most plants will be restricted at soil strengths greater than $2 \mathrm{MPa}$; and, growth will cease completely at soil strengths in excess of $3 \mathrm{MPa}$ (Hamza \& Anderson, 2005; Materechera et al. 1992; Sands et al., 1979; Taylor \& Burnett, 1964). Ultimately, a smaller root network will result in a reduced capacity for resource uptake and curtail access to new resource pools, further limiting the total potential for tree growth (Bassett et al., 2005; Gomez et al., 2002; Kozlowski, 1999; Craul, 1992).

Soil remediation methods such as deep tillage, which are often used in agricultural settings, are not feasible in urban environments as they are expensive and may damage existing 
tree roots (Rosolem et al., 2002; Day \& Bassuk, 1994; Craul, 1992). In addition, there is evidence that, over the long term, conventional tillage practices can result in further loss to soil structure (Ramos et al., 2010; Dexter, 1991; Bishop \& Grimes, 1978; Johnson et al., 1987). Moreover, alternative soil remediation methods, such as soil aeration techniques, the addition of soil amendments and the installation of drainage systems, are often not cost effective for general use (Motavalli et al., 2003; Day et al., 1995; Smiley et al., 1990; Hummel \& Johnson, 1985). An alternative solution is to allow soils to recover naturally by preventing access to the area. Overtime, freeze thaw cycles, swelling and shrinking, as well as microorganisms and animal and plant root activity will return soils to a less compacted state (Radford et al., 2001; Kozlowski, 1999; Rolf, 1994). Studies have shown that this could be an effective method for remediating soil in urban areas (Millward et al., 2011). However, soil recovery rates associated with naturalization vary with climatic region and soil characteristics (Kozlowski, 1999). Thus, naturalization is rarely feasible for high use areas where human access cannot be limited for prolonged periods of time. An alternate soil remediation approach is to use bio-drilling plants, a type of cover crop, to accelerate the desirable soil processes associated with naturalization. While common in agricultural systems, this method has been largely unexplored in urban environments. Bio-remediating plants are attractive in an urban setting due to their cost effectiveness and low energy requirements.

Cover crops are fast growing, perennial plants that grow well in compacted soils and are used in no-till management systems (Hartwig \& Ammon, 2002; Dabney et al., 2001; Wyland et al., 1996). While originally adapted to improve nutrient management, recent focus has been on the ability of cover crops to ameliorate soil compaction and improve crop yields (Sarrantonio \& Gallandt, 2014; Wilson et al., 1982; Kemper \& Derpsch, 1981). Research has shown that cover 
crops often outperform conventional tillage in their ability to improve yields of crops grown in compacted soils (Williams \& Weil, 2004; Radford et al., 2001). Several species of cover crops have also been shown to have the ability to improve the growth of trees in orchards and plantations (Sanchez et al., 2007; Broughton, 1977; Mainstone, 1969).

Bio-drilling plants are a type of cover crop that have a thick, deep penetrating taproot. Most bio-drilling plants are from the Brassicacea plant family (Chen \& Weil, 2010). In agriculture, bio-drilling plants are of particular importance for their ability to penetrate and break up compacted soils, creating root channels and preventing the leaching of soil nutrients, as well as for their ability to absorb nutrients from deeper in the soil profile (Askegaard et al., 2011; Rosolem et al, 2002; Justes et al., 1999). The root channels and organic matter that remain in the soil during the following season ameliorate the effects of compaction on subsequently planted crops. Root channels can improve drainage and aeration, and provide a pathway of least resistance for other plant roots (Chen \& Weil, 2010; Gomez et al., 2009; Hartwig \& Ammon, 2002; Wilson et al., 1982), while residual organic matter increases soil organism activity and increases nutrient availability during the growing season (Constantin et al., 2010; Sanchez et al., 2007; Snapp et al., 2005; Dabney et al., 2001). In addition, there is some evidence to indicate that bio-drilling plants can decrease penetration resistance in soils (Williams \& Weil, 2004; Folorunso et al., 1992; Wilson et al., 1982).

At present, there is a lack of research on the effectiveness of bio-drilling plants to remediate soil compaction in urban areas, and a lack of research regarding the ability of biodrilling plants to improve tree growth. Specifically, research is required that will evaluate biodrilling plants in their ability to remediate soil quality and improve tree growth, to asses biodrilling plants in their ability to grow in compacted urban soils, and to investigate the effect of 
varying levels of nutrient input on bio-drilling plant growth. The latter is important as fertilization will increase the cost of the management strategy. A no-nutrient input scenario would be ideal. Investigations should also determine the ability of bio-drilling plants to improve soil conditions where city trees are already established and to prepare soil for future tree plantings.

The purpose of this study is to assess the ability of Tillage Radish®, a genetically selected variant of radish, to remediate soil compaction and improve soil quality, under a zero nutrient input scenario, in non-agricultural soil, containing established trees. Specific study objectives include: 1 ) determine if Tillage Radish ${ }^{\circledR}$ can alleviate soil compaction and improve surface water infiltration rates; 2) if soil quality is found to improve, determine the magnitude of improvement; and, 3) evaluate the ability of Tillage Radish ${ }^{\circledR}$ to grow in compacted, unfertilized, non-agricultural soil and assess its ability to grow under tree canopy coverage.

\subsection{Methods}

\subsection{Study Site and Site Description}

Research was conducted at Ignatius Jesuit Centre, 5420 Highway 6 North, Guelph, Ontario Canada, on a $23.25 \mathrm{~m}$ by $11.25 \mathrm{~m}$ plot of land that was selected to emulate growing conditions in an urban park (Figure 3.1). The southern corner of the research plot was located at approximately $43.57^{\circ} 22^{\prime} 27^{\prime \prime} \mathrm{N}, 80.28^{\circ} 40^{\prime} 49^{\prime \prime} \mathrm{W}$, where the length of the plot runs from southwest to northeast. Selecting a research site that emulated an urban park, rather than conducting the study in an urban park, was done for the purpose of controlling human access as any disturbance to the site would negatively alter the outcome of the study. The research plot was established between a road and an apple orchard. The land had never been cultivated and, prior to establishing the research site, was overgrown with grass and other herbaceous plants. 


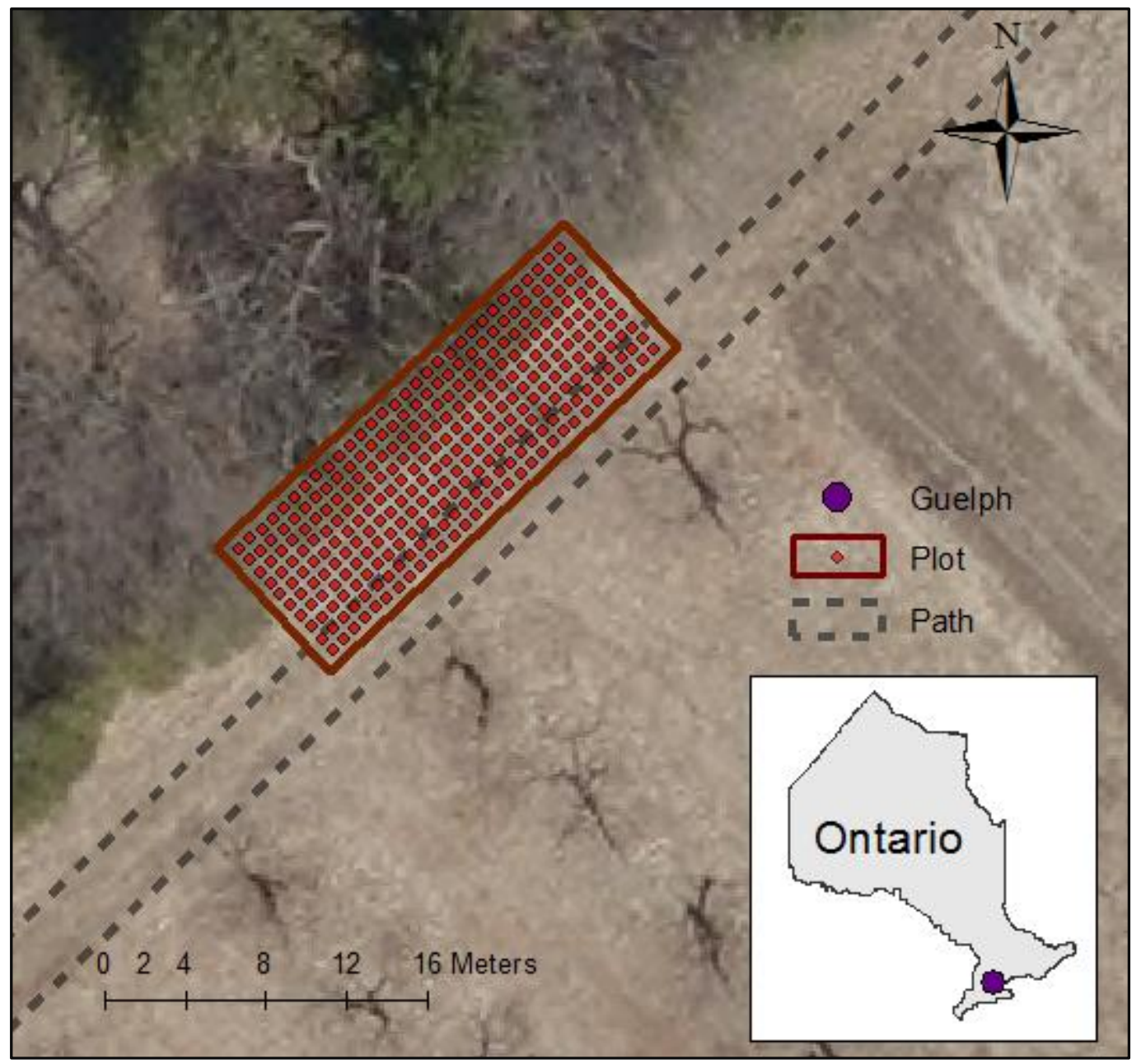

Figure 3.1: Ignatius Jesuit Centre plot location, Guelph, Ontario Canada. The image depicts the locations of the plot, pathway, and tree canopy as well as the location of the plot in reference to Ontario.

The plot location was chosen as it contained two important elements indicative of an urban park: partial canopy cover and highly variable soil conditions (Millward et al. 2011). A row of eastern white cedars (Thuja occidentalis), located along the northwest perimeter of the plot, provided canopy cover, while a pathway of highly compacted soil, running along the southeast side of the plot, created a gradient of soil compaction from the southeast to the northwest. At the outset of the research, trees were pruned to increase light penetration and the grass and herbaceous plants were trimmed. 
The landscape in the vicinity of Guelph, Ontario can be characterized as having gentle and steep rolling hills, a product of the drumlins formed during glaciation (Canada Department of Agriculture, 1963). The Canada Department of Agriculture (1963) describes the surface soils of Guelph as dark, greyish brown, and becoming lighter brown with depth. Where soils with higher clay content they are found as dark brown to dark yellow. The soil parent material is made up of till derived from grey and brown limestone. Naturally occurring soil in this region are classified as having a loam or sandy loam texture, and usually contain a moderate amount of organic matter (Canada Department of Agriculture, 1963).

Total annual precipitation in Guelph is $923.4 \mathrm{~mm}$, of which $771.4 \mathrm{~mm}$ falls as rain. Monthly average temperatures range from $-7.6^{\circ} \mathrm{C}$ in January to $19.7^{\circ} \mathrm{C}$ in July (Environment Canada, 2014).

\subsection{Soil Data Collection}

Soil data were collected over the course of two seasons, 2012 and 2013. In order to control for seasonality effects, sampling for both years occurred during the month of May. In addition, May is an important month for plant growth in southern Ontario as this is when the growing season begins (Gomez et al., 2002). Soil variables collected in the study included penetration resistance, surface water infiltration rate, bulk density, texture, nutrient availability, and $\mathrm{pH}$.

Soil data points were decided using a rectangular 10 by 30 point grid with 0.75 meter spacing (Figure 3.2). Sample point locations were identified in the field using coloured flags. Two sampling designs were used. A systematic design was used to sample soil penetration resistance, where measurements were taken at every point along the grid $(n=300)$. This approach to data collection is highly representative of field conditions, and yields the most accurate 


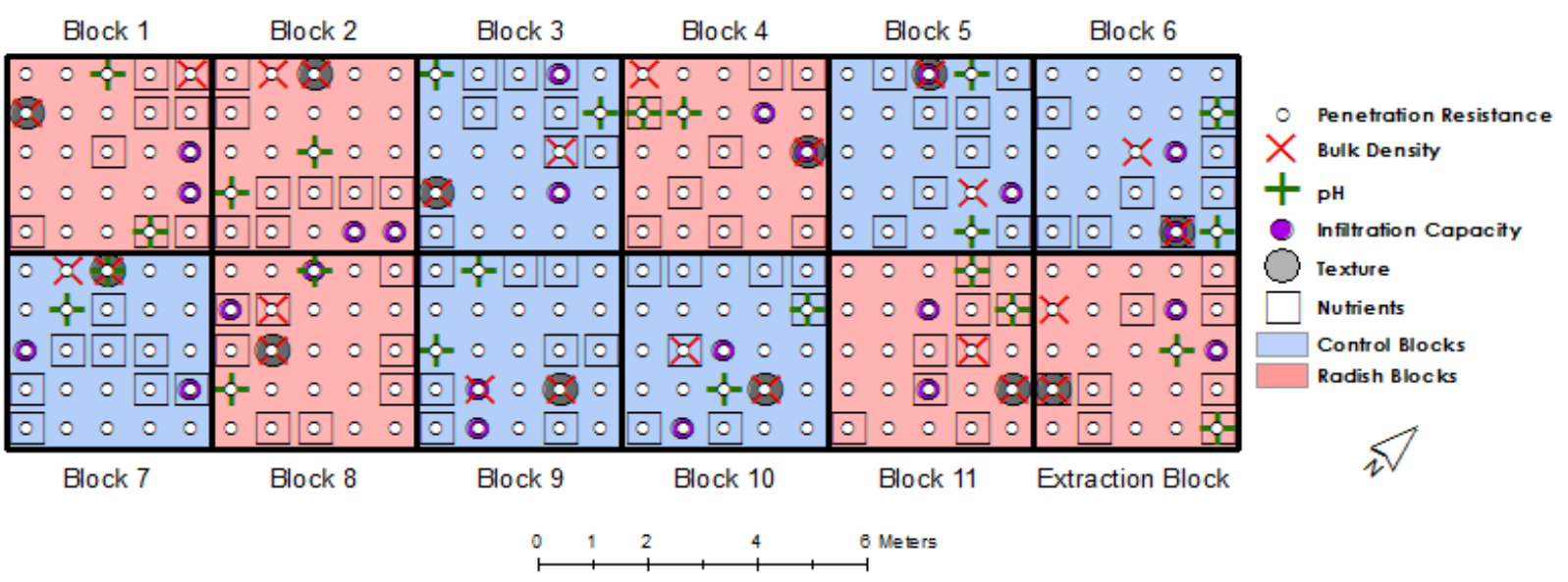

Figure 3.2: Sampling locations and treatment blocks for the study. The study was conducted from May 2012 to May 2013 at Ignatius Jesuit Centre, Guelph, Ontario.

surface interpolation results (Zimmerman et al., 1999; Cochran, 1946). A stratified random approach was used to sample texture, bulk density, surface water infiltration rate, nutrient availability, and $\mathrm{pH}$. This second approach is useful for collecting time consuming and costly spatial data as it maintains the spread of the data while requiring fewer data points, increasing sampling efficiency (Franzen et al., 2011; Cochran et al, 1946). Depending upon site conditions, this sampling approach, when used in conjunction with spatial interpolation, can yield results with similar accuracy as are possible with a systematic approach (Cochran et al, 1946). The sample plot was stratified into 12, 25-point, square blocks; 6 blocks were located along the northwest side and 6 were located along the southeast side (Figure 3.2). Surface water infiltration, bulk density, soil nutrient availability and $\mathrm{pH}$ were collected at two random points per block $(n=24)$, while soil texture was collected at 1 point per block $(n=12)$.

Soil penetration resistance is usually assessed with a soil penetrometer and is a measure of the force required to penetrate a soil medium (Bengough et al., 2000). According to Millward et al. (2011) a cone penetrometer, "provides an empirical measurement of the force required to pass the cone through the ground at known depths". Soil penetration resistance is an important compaction measurement as it correlates well with plant growth (Bassett et al., 2005; Day \& 
Bassuk, 1994). Penetration resistance was measured in the present study using a Field Scout SC900 Penetrometer with a $1.27 \mathrm{~cm}$ diameter cone tip. Resistance measurements were taken every $2.5 \mathrm{~cm}$ to a depth of $45 \mathrm{~cm}$ (Gregory et al., 2006). As suggested by Bassett et al. (2005), soil moisture content was kept constant and close to field capacity, which for sandy loams, soils characteristic of the area, was between 20 and $30 \%$ (Gomez et al., 2002; Craul, 1992). Soil penetration resistance measurements were averaged across three depths, 2.5 to $15 \mathrm{~cm}, 17.5$ to 30 $\mathrm{cm}$, and 32.5 to $45 \mathrm{~cm}$. Average depths were chosen based on previous knowledge of their importance for plant root growth (Gomez et al., 2002; Craul, 1992).

Surface water infiltration rate is a measurement of the amount of water that percolates through the soil in a given time (mm/hr) (Gregory et al., 2005; Craul, 1992). Compacted soils are known to inhibit surface water infiltration rates (Gregory et al., 2006; Bassett et al., 2005). Therefore, successful remediation of soil compaction is also aimed at increasing surface water infiltration rates. The surface water infiltration rate was measured with a double-ring infiltrometer using a falling head approach (Gregory et al., 2005). The infiltrometer was inserted to a depth of $5 \mathrm{~cm}$ into an area of soil that had been cleared of plant material and debris. The outer and inner rings of the infiltrometer were filled to the brim with water. The water was left to drain for 10 minutes, roughly the time required to achieve near saturation (Gregory et al., 2005). Subsequently, the rings were refilled and left to drain for 20 minutes, after which the difference in water level drop (mm) was recorded. Infiltration rate per hour was calculated by multiplying the 20-minute infiltration rate by three.

Soil texture, bulk density and $\mathrm{pH}$ analyses were conducted on soil cores that were collected using a soil auger $(1.9 \mathrm{~cm}$ internal diameter) and taken from a depth of 5 to $15 \mathrm{~cm}$, where the majority of fine roots responsible for nutrient and moisture absorption are found 
(Watson \& Kelsey, 2006; Craul, 1992; Nambiar \& Sands, 1992). Soil texture and pH were only collected in the second year. While these soil properties are unlikely to change over the course of a year, despite the growth of Tillage Radish ${ }^{\circledR}$, a conventional ANOVA was run to confirm that treatment and control plots did not exhibit differences.

Bulk density is a measurement of the mass of dry soil at a given soil volume $\left(\mathrm{Mg} / \mathrm{m}^{3}\right)$. It is a common measurement of soil compaction and can also be used to calculate pore volume, important for understanding soil water drainage and storage (Rivenshield \& Bassuk, 2007; Craul, 1992). Bulk density was calculated using a method outlined by the USDA (2004) and used in a recent study by Millward et al. (2011). Samples of known soil volume were oven dried at a temperature of $100{ }^{\circ} \mathrm{C}$ to a constant weight and then weighed and recorded. Bulk density was calculated by dividing the dry weight of the soil sample $(\mathrm{g})$ by the soil volume $\left(\mathrm{cm}^{3}\right)$ and converting to $\mathrm{Mg} / \mathrm{m}^{3}$ (USDA, 2004).

Soil texture is a measurement of the percent, by weight, of sand silt and clay within a soil sample. It is an important soil property when seeking to understand and evaluate bulk density, penetration resistance, and surface water infiltration rate (White, 2006; Fitzpatrick et al., 1999; Craul, 1992). Soil texture was measured using a process of integrated sieving and sedimentation (Millward et al., 2011; Kettler et al., 2001). Oven dried soil samples were weighed and then, in order to break up the soil particles, ground using a mortar and pestle. The soil was then sieved with screens having openings measuring $2 \mathrm{~mm}$ (for gravel) and $0.05 \mathrm{~mm}$ (for sand). The sieves were then shaken in a sieve shaker for $20 \mathrm{~min}$ at $120 \mathrm{rpm}$. The filtered gravel and sand sized particles were removed and weighed. The remaining silt and clay soil mixture was weighed and placed into a test tube containing $5 \mathrm{ml}$ of distilled water (to moisten the soil). An additional 30 $\mathrm{ml}$ of water was added, followed by $5 \mathrm{ml}$ of sodium hexametaphosphate $\left(\mathrm{NaPO}_{3}\right)$. The test tube 
was agitated for two minutes at $2800 \mathrm{rpm}$, and then left to rest for four minutes while the silt settled to the bottom. The clay water solution was decanted into a waste bucket. The remaining silt solution was oven dried at $100{ }^{\circ} \mathrm{C}$ to a constant weight that was subsequently recorded. By subtracting the dry mass of the silt from the silt and clay mixture, the clay weight was calculated. The percent sand silt and clay was then determined by dividing their dry masses with the dry mass of the original soil sample (Kettler et al., 2001).

Soil $\mathrm{pH}$, also called soil reaction, is a measure of the alkalinity or acidity of a soil (White, 2006; Craul, 1992) and is one of the most important soil quality measurements when considering plant growth. A pH of 4 to 8.5 must be maintained in order to sustain plant growth and organism activity (Craul, 1999). Soil pH largely governs nutrient availability (Day et al., 2010; Craul, 1992). In the present study, soil $\mathrm{pH}$ was measured and recorded by placing an IQ $150 \mathrm{pH}$ meter into a 1:1 solution of soil and distilled water (Craul, 1999). The 1:1 solution was prepared by agitating a test tube filled with $20 \mathrm{ml}$ of a soil and $20 \mathrm{ml}$ of distilled water for one minute at 2800 rpm.

Soil nutrients were measured using Plant Root Simulator (PRS TM) Probes, developed by Western Ag Innovations Inc. PRS probes measure soil nutrients by exchanging ions with the surrounding soil until the probes are either removed or are saturated. They come in pairs; one probe for absorbing anions and one probe for absorbing cations. Each probe is composed of an exchange resin that contains permanently fixed, nonspecific ionic groups, $\mathrm{R}_{-} \mathrm{NH}_{4}{ }^{+}$or $\mathrm{R}-\mathrm{SO}_{3}{ }^{-}$. These ionic groups are saturated with $\mathrm{HCO}_{3}{ }^{-}$and $\mathrm{NA}^{+}$respectively, which, once buried, exchange with the soil nutrient ions (Western Ag Innovations Inc., 2014). Unlike conventional nutrient measurements, which measure total soil nutrients, PRS probes measure bioavailable nutrients. That is, they measure nutrients that are available for plant uptake (Qian \& Schoenau, 
2002). PRS TM probe measurements have been found to be highly correlated with plant tissue nutrient concentrations (Szmigielska et al., 1998; Qian et al., 1996; Liang \& Schoenau, 1995; Qian \& Schoenau, 1995; Greer \& Schoenau, 1994; Tejowulan et al., 1994). Furthermore, the measurements produced by PRS probes are temporally dynamic (i.e., measured over a set period of time, usually days to weeks) (Greer et al., 2003). This characteristic is beneficial to the present study as radish mineralization can continue throughout the spring and into the summer (CCS, 2012). Therefore, PRS probes buried during the duration of radish mineralization will be able to more accurately capture nutrient conditions than a single instant static measurement (Greer et al., 2003). In the present study, PRS probes were buried so that the exchange resins were located at a soil depth between 5 to $15 \mathrm{~cm}$, a location important for nutrient absorption by fine roots (Watson \& Kelsey, 2006; Nambiar \& Sands, 1992). PRS probe pairs were buried at 8 random points per block for a period of 42 days, after which they were removed, thoroughly cleaned of all traces of soil, and shipped to Western Ag Innovations Inc. for analysis. PRS probes were analyzed using a variety of colourimetry methods (Western Ag Innovations Inc., 2014; Hangs et al., 2002). During analysis, groups of four probe pairs, originating from the same block, were analyzed together. Therefore, only two unique values are produced per block (site total $n=24$ ). In order to spatially represent the averaged results, a centroid was produced in the middle of each group of four pairs. Results are expressed as $\mu \mathrm{g} / 10 \mathrm{~cm}^{2} /$ burial time.

Several other ancillary variables were monitored over the course of the growing season, including soil moisture, ambient temperature, precipitation and light intensity. However, an equipment failure rendered much of these ancillary data unusable. Instead, monthly accumulated precipitation (mm) was compared to historical averages. 


\subsection{Treatment}

In this study, Tillage Radish® was selected as the experimental soil remediating, biodrilling plant. Radish are tap-rooted species that have been shown to out-performed other biodrilling species, such as rapeseed, in their ability to grow in compacted soils (Chen \& Weil, 2010), increase infiltration rates (Weil \& Kremen, 2007), decrease weed cover (Malik et al., 2008), absorb and release nitrogen (Weil \& Kremen, 2007), and increase subsequent crop yields (Weil \& Kremen. 2007; Williams \& Weil, 2004). While radish species tend to grow best in full light, they can do well in partial shade (Schmitt et al., 1986). Tillage Radish®, officially known as variety CCS-779 under U.S. Plant Variety Protection, is a genetically selected variant of radish that germinates quickly, grows a particularly large tap-root, and was developed specifically for use as a cover crop (CCS, 2012). Tillage Radish® is grown successfully throughout Ontario and Canada.

Half of the blocks on the plot were established as treatment blocks and half as control blocks. In order to have an equal representation of treated and control blocks on sites that have more surface compaction and sites that have less surface compaction, a stratified random approach was used. Randomness is important when comparing populations using ANCOVA for robust statistical results (Van Brekelen, 2006; Owen \& Froman, 1998). Three blocks were randomly selected as treatment blocks on the northwest side of the plot and three blocks were chosen along the compacted path along the southeast side of the plot. The treatment blocks selected were Blocks 1, 2, 4, 8, 11, and 12.

Treatment blocks receiving Tillage Radish® were planted by hand on August 2, 2012. Considering research by Broughton (1977) and Foshee et al. (1995), nutrient competition between Tillage Radish ${ }^{\circledR}$ and the established trees may be an issue. By planting radish late in the 
summer, when tree growth is less vigorous, there may be less competition for nutrients (Seeley, 1990). Another benefit of planting radish in the fall is that it will absorb available nutrients from deep within the soil, helping to prevent leaching (Dabney et al., 2001; Justes et al., 1999). In spring, the radishes will bio-degrade and release the nutrients that were absorbed. Peak nutrient availability occurs between March and June, a period of time that coincides with rapid tree growth (CCS, 2012). In addition, the rooting activity that occurs during radish growth can help to alleviate soil compaction (Williams \& Weil, 2004). Radish was planted to a depth of 6 to $12 \mathrm{~mm}$ in rows spaced $25 \mathrm{~cm}$ apart with an in row spacing of $15 \mathrm{~cm}$; this represented a slight alteration of the between-row and in-row spacing suggested by CCS (2012), of $38 \mathrm{~cm}$ and $10 \mathrm{~cm}$ respectively, to provide uniform coverage around the grid spacing of the plot. Immediately following planting, radish seeds were watered for several hours using a standard pivoting sprinkler system. Because 2012 was a particularly hot and dry summer (Environment Canada, 2012), and to ensure that water was not a limiting factor for radish growth, a thorough watering of plots was conducted weekly. In order to determine if a no-nutrient input scenario, the most economical approach, could be an effective strategy for soil remediation, Tillage Radish ${ }^{\circledR}$ were not fertilized. However, initial plant growth was found to be modest. In order to ensure adequate light penetration, grass was removed bi-weekly on treatment plots. Control plots were left fallow. Radish shoot length was measured bi-weekly, measured from the base of the hypocotyl to the end of the longest leaf (Bassett et al., 2005), on 12 randomly selected plants per block. A final measurement was taken on October 26, 2012, sufficient time for the radish to achieve maximum growth. Following this, radish plants were killed by clipping their shoots (CCS, 2012). 


\subsection{Extraction}

Many of the benefits associated with Tillage Radish ${ }^{\circledR}$ have been attributed to a large tap root. Understanding the ability of its roots to grow through the soil is important to determining its usefulness as a soil remediation method. Extracting a subset of the plant population is a method for determining root biomass (Mokany et al., 2006). In order to collect data on root biomass, a radish extraction plot was established. Block 12 was chosen as it produced radish with the highest variation in shoot growth.

The procedure for extracting plants and analyzing plant growth is outlined in Ravindranath and Ostwald (2007). A systematic offset sampling approach was used, in which every other radish was extracted. Radishes were unearthed with a shovel, carefully cutting around the radish and removing any attached soil. Root and shoot length were measured and radish were labeled and bagged for subsequent analysis (Ravindranath \& Ostwald, 2007).

Calculating dry weight is a standard approach to measuring biomass. Roots and shoots were separated and dried in a convection oven at a temperature of $100{ }^{\circ} \mathrm{C}$ until there was no subsequent change in weight (approximately 4 hours), after which point dry weight was recorded (Ravindranath \& Ostwald, 2007).

\subsection{Surface Interpolation}

Soil data were uploaded to a GIS and were spatially interpolated. Spatial interpolation estimates unknown points using the values of known points to create continuous surfaces; it assumes the presence of spatial autocorrelation (i.e., closer points are more similar in value than points further away) (Franzen, 2011). These surfaces can then be used to visually and statistically analyse the data. There are several methods of spatial interpolation (Johnston et al., 2001; Zimmerman et al., 1999; Gotway et al., 1996). In the present study, inverse distance weighted 
(IDW) and ordinary kriging interpolation methods were used. These are local methods that rely on a search neighbourhood to average values of neighbouring points (Johnston et al., 2001).

Ordinary Kriging and IDW are used often to estimate soil surfaces. Ordinary Kriging has been used in the literature to estimate soil compaction (Millward et al., 2011; Toleti, 2008), lead contamination (Hooker \& Nathanail, 2006), and soil moisture (Toleti, 2008). IDW has been used recently to estimate soil quality (Cheng et al., 2007), metal concentrations (Aelion et al., 2008), and organic matter, cation exchange, and soil nutrients (Kravchenko \& Bullock, 2000).

\subsection{Inverse Distance Weighted}

Soil bulk density, surface water infiltration rates, $\mathrm{pH}$ and nutrient surfaces were calculated using IDW in ArcMap 10.2 (ESRI, 2013). IDW is a local deterministic interpolation method that calculates points with unknown values by averaging the values of neighbouring points, where closer points are given more weight in the interpolation (Chaplot et al., 2006; Johnston, 2001). Weight is determined using the power function. Higher powers weigh closer points more heavily. Normality is not an assumption of IDW; however, skewed data may affect which power provides the most accurate results (Johnston et al., 2001; Kravchenko \& Bullock 1999; Weber \& Englund 1994). While IDW is usually not as accurate as ordinary kriging, it can still provide good results (Robinson \& Metternicht, 2006). IDW is commonly selected as an interpolation approach when the more stringent minimum sample size requirements of ordinary kriging are not fulfilled (Voltz \& Webster, 1990).

Anisotropy was assessed for each soil variable using the 3-dimensional trend analysis tool and the semi-variogram cloud tool in in ESRI's Geostatistical Analyst (Waller and Gotway, 2004). Where anisotropy is present, it is usually dealt with by changing the shape of the search neighbourhood from a circle to an ellipsoid. When calculating the average of the unknown point, 
the ellipsoid shape includes more points in the direction of anisotropy (Johnston et al., 2001). Unlike in ordinary kriging, there is no optimize function to calculate the anisotropic factor. When employing IDW, the anisotropic factor was calculated by dividing the range of the semivariogram in the direction where anisotropy is highest by the range of the semi-variogram in a perpendicular direction (Khakestar et al., 2013).

The use of IDW requires that several additional parameters be specified, including neighbourhood search size and shape, the power function, and the minimum and maximum points to be included. The selection of neighborhood size and the maximum and minimum points to be included were standardized. The major axis of the search neighbourhood was calculated by determining half of the distance between the two points with greatest separation. The minor axis was determined by dividing the major axis by the anisotropic factor (Khakestar et al., 2013; Johnston et al., 2001). The maximum number of points to be included was set at 10 while the minimum number was set at 4. Mitas \& Mitasova (1999) suggest a minimum of between 10 and 30 points; however, in all cases, a minimum of 4 yielded better results. To find the best accuracy, powers of 1,2, 4, and 6 were tested. Model results were cross-validated and the model which minimized error, the model with a low Root-Mean-Square Error (RMSE) and with the Mean Absolute Error (MAE) close to zero, was chosen.

\subsection{Ordinary Kriging}

Soil penetration resistance surfaces were calculated using ordinary kriging. Ordinary kriging is a local geostatistical approach used to interpolate a surface from points (Johnston et al., 2001). Ordinary kriging involves the computation of a semivariogram, a model of spatial dependency, to which an empirical model is fit (Kivoruchiko, 2005; Johnston et al., 2001). In ordinary kriging, closer points are still weighted more heavily; however, the weighting is 
determined using the relationship between all pairs of points, rather than using a deterministic model (such as with IDW). To minimize computational intensity, ordinary kriging groups pairs of points into bins called lags, which are based on directions and distances between each point. While normality is not an assumption of ordinary kriging, Robinson \& Metternicht (2006) suggest that normal distributions produce the most accurate semivariogram models. The assumption of normality was assessed for soil penetration resistance data in SPSS using the Kolmogorov-Smirnov test (Sheskin, 2004). Data were found to be positively skewed, so a log transformation was applied (Leech et al., 2008). Following this transformation, data that were still not normally distrubuted were visually assessed using box-plots and q-q plots and were deemed to be sufficiently normal to proceed with ordinary kriging (Leech et al., 2008). Penetration resistance data were uploaded to the ArcMap 10.2 software package (ESRI, 2013). Each data set contained 300 points, which exceeded the minimum number of points (100) recommended for kriging by Voltz \& Webster (1990).

The data were evaluated for anisotropy using the trend analysis tool and the semiovariagram cloud tool in Geostatistical Analyst (Waller and Gotway, 2004). Anisotropy is considered to be present when sample points have distinct directionality as reflected by greater auto-correlation of values when compared with other directions. Anisotropy was found in all soil penetration resistance data sets. It was accounted for in the semivariogram modeling process by using an anisotropic model. This approach produced a different model fit for each direction. In the direction of anisotropy, points located at a greater distance from the unknown point were considered for analysis, while in the directions perpendicular to anisotropy, only close points were considered (Ouyang et al. 2003). The presence of anisotropy also suggested a global trend. 
While global trends can be removed prior to the semivariogram modelling process, they can also be dealt with the anisotropic model alone (Johnston et al., 2001).

Surfaces were interpolated using the ordinary kriging function in the geostatistical wizard tool within Geostatistical Analyst (Johnston et al., 2001). During semi-variogram modelling, there are several model parameters that can be altered. These parameters include trend removal, anisotropic direction, search neighborhood size and shape, lag size and direction, and model type. Selection of the neighborhoods major axis and the lag size and shape were made using standard practices based on the distance between the farthest two points (Millward et al., 2011; Johnston et al., 2001). The major axis was set to $11.38 \mathrm{~m}$, half the distance between the two furthest points. However, where the range of the semivariogram was less than that of the major axis, the optimized axis size was chosen. The lag size was set to $0.75 \mathrm{~m}$, which reflected the distance between sampling points (Johnston et al., 2001). Where anisotropy was present, the angle of anisotropy was set accordingly. The minor axis was determined using the optimization function (Millward et al., 2011). Model type and trend removal type were not standardized; instead, an iterative approach was utilized (Millward et al., 2011; Hooker and Nathanail 2006; Ouyang et al., 2003).

Nine surfaces for each data set were produced: one for each combination of trend removal method and model type. Three trend removal methods were tested, including removal using a $1^{\text {st }}$ order polynomial, removal using a $2^{\text {nd }}$ order polynomial, and no trend removal (anisotropic model only). Three model types were fitted, including spherical, exponential, and Gaussian (Millward et al., 2011; Ouyang, 2003). The errors of each iterated model were crossvalidated, and the model that performed best, considering its ability to minimize error, was chosen. The final model selected for ordinary kriging had a low Root-Mean-Square Error 
(RMSE), an Average Standard Error (ASE) close to the RMSE, a Root-Mean-Square

Standardized Error (RMSSE) close to 1, and a Mean Standardized Error (MSE) close to zero (Johnston et al., 2001).

Another advantage of ordinary kriging is that a standard error surface can be produced, to demonstrate the uncertainty present in the prediction surface (Franzen, 2011; Johnston et al., 2001; Gardner et al. 2003; Waller and Gotway, 2004; James and Barber, 1996).

\subsection{Statistical Data Analysis}

Statistical analysis was conducted in IBM $®$ SPSS $®$ Statistics 21.0 for windows statistical package (SPSS-IBM Corp, 2012). Preliminary descriptive statistics were calculated in order to detect possible trends in soil change across treatments and growth among blocks. Subsequent analyses included Analysis of Covariance (ANCOVA) and Multiple Linear Regression.

\subsection{Analysis of Covariance}

Analysis of covariance (ANCOVA) was conducted in order to determine the effect of treatment on soil penetration resistance, bulk density, and surface water infiltration rate. ANCOVA is similar to Analysis of Variance (ANOVA) in that it compares variances between groups to determine if they are significantly different. However, unlike ANOVA, it considers a covariate, which can reduce the error of variance, improving the statistical power of the analysis (Van Brekelen, 2006; Owen \& Froman, 1998). ANCOVA calculates linear regressions for the covariate and the dependant variable for each group and then determines if (1) the covariate has an effect on the dependant variable, and (2) if the upper and lower bounds of the intercepts of the groups are significantly different (Leech et al., 2008; Schefler, 1979). ANCOVA was selected for this study as the magnitude of change in soil conditions was believed to be affected by initial 
soil conditions. ANCOVA assumptions include homogeneity of variance, normality of the residuals, homogeneity of the regression slopes, and a lack of correlation between the covariate and the grouping variable (Schefler, 1979; Owen \& Froman, 1998).

ANCOVA was conducted on each of the dependent variables, including the change in surface water infiltration rate $(\Delta \mathrm{IR})$, bulk density $\left(\Delta \mathrm{D}_{\mathrm{b}}\right)$, and penetration resistances at depth $1\left(\Delta \mathrm{PR}_{1}\right), 2\left(\Delta \mathrm{PR}_{2}\right)$, and $3\left(\Delta \mathrm{PR}_{3}\right)$. The covariates for each dependant variable were $\Delta \mathrm{PR}_{1}$, initial bulk density, and initial penetration resistance, at depth 1,2, and 3, respectively. Changes in soil conditions were calculated by subtracting year two measurements from year one measurements for each variable. Correlations and scatter plots were produced for each dependant variable and its covariate to examine relationships. A log transformation was applied to $\Delta \mathrm{IR}$ and a power transformation to $\triangle \mathrm{PR}$ at depth 1 in order to attain a linear relationship. During analysis, two different grouping variables were used: block growth (control, moderate growth, high growth) and treatment (control blocks and radish blocks). In cases where equal variance could not be satisfied, only treatment was used as a grouping variable as ANCOVA is not as vulnerable to violations of the homogeneity of variance assumption if sample sizes are similar (Owen \& Froman, 1998). In order to maintain statistical power, the analysis was run twice for each dependent variable analysed: the first to test the significance of the covariate, the treatment, and the covariate*treatment (homogeneity of slopes) factors and the second to test the significance of only the covariate and treatment factors (Leech et al., 2008).

\subsection{Multiple Regression Analysis}

Linear regression analysis was performed to (1) analyze Tillage Radish® root biomass in the extraction plot, under varying soil conditions; (2) develop an allometric model that predicts radish root biomass from shoot length; and, (3) use the allometric model, if it is determined to 
have good predictive ability, to investigate radish shoot growth over the entire plot. Assumptions of multiple linear regression include the following: variables should be normally distributed, the relationship between the independent and dependent variable should be linear, and the error should be independent and homoscedastic (Leech et al., 2008).

Soil $\mathrm{pH}$, nutrients, bulk density, and surface water infiltration rate were not available at each point. Instead, the interpolated data generated using inverse-distance weighted were used in the analysis. Each variable was tested for normality using the Shapiro-wilk test. A log transformation was applied to the variables that were not normal. The first model run was the radish root biomass response model, using average root biomass (averaged to the grid points) as the dependent variable. Soil variables that were significantly correlated with the dependent variable were entered into the model using a stepwise approach.

Allometric models use the knowledge of morphological scaling to predict sizes of various anatomical features. Models that predict the root biomass from shoot biomass of herbaceous plants are often in the form of linear equations (Piper, 1989; Nevill \& Holder, 1995). The assumption of these allometric models is that the growth rates of shoots and roots are in constant ratio to one another. It is also assumed that the relationship does not change under varying soil conditions or with time (Piper, 1989). Two allometric models were developed using a linear regression approach. In the first allometric model, root biomass was selected as the dependent variable and shoot length as the independent variable. A second allometric model was produced, predicting average radish root biomass from average shoot length. This alternative model was run to justify averaging shoot length to the grid points in order to analyze growth against soil compaction data. As the allometric growth models produced good results, a radish shoot growth response model was run, with average shoot length as the dependent variable. Independent 
variables that were significantly correlated with shoot length were entered into the model using a stepwise approach. Two alternative models were run using the same approach. These models were produced to predict growth on the northwestern (NW) and southeastern (SE) sections of the research plot, two a priori stratifications that were made in order to control for expected variance in the soil variables.

The residuals of each of the models were tested for normality using both the ShapiroWilk test and the Kolmogorov-Smirnov test. Homoscedasticity was analysed visually by plotting the standardized residuals against the standardized predicted values.

\subsection{Results}

\subsection{Soil Descriptive Statistics and Interpolated Surfaces}

Most of the blocks, with an exception of blocks four and six, had a sandy loam soil texture, bordering around sandy clay loam and loam textures. Blocks four and six had a sandy clay loam texture. The distribution of sand, silt and clay over the whole plot $(n=12)$ was $55 \%$ $(\mathrm{SD}=2.4), 28 \%(\mathrm{SD}=3.0)$, and $17 \%(\mathrm{SD}=4.3)$ respectively. Soil texture found in the present study is in agreement with the textures reported for Guelph, Ontario in Canada Department of Agriculture (1963).

Soil $\mathrm{pH}$ of the site $(\mathrm{n}=24)$ were neutral to slightly basic, with a mean of $7.31(\mathrm{SD}=0.19)$, values which are considered optimal for plant growth and microorganism activity (Craul, 1992). The IDW interpolated pH surface is shown in Figure 3.3a. The surface had a root mean square error (RMSE) of 0.17 and a mean absolute error (MAE) of -0.03. The RMSE is relatively high; however, because RMSE can be sensitive to outliers, and is a function of three characteristics (distribution of error, MAE, sum of squared error) it should be interpreted with caution. Therefore, the MAE is a preferred measurement when evaluating model performance (Willmott 
a)

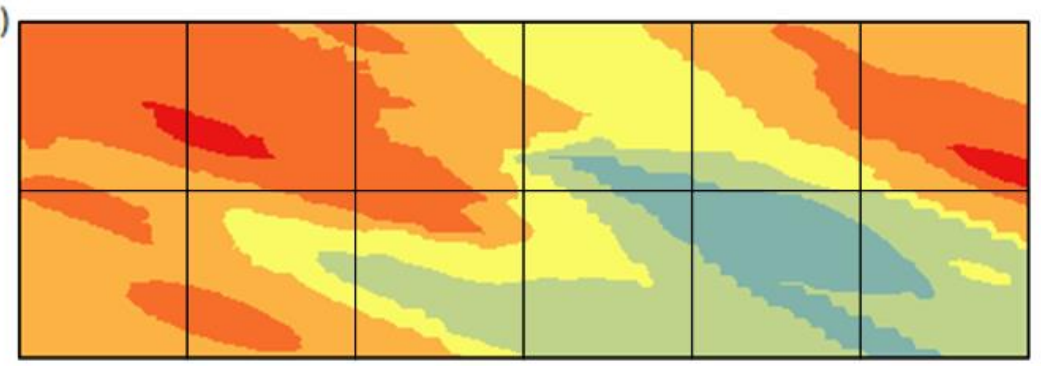

b)
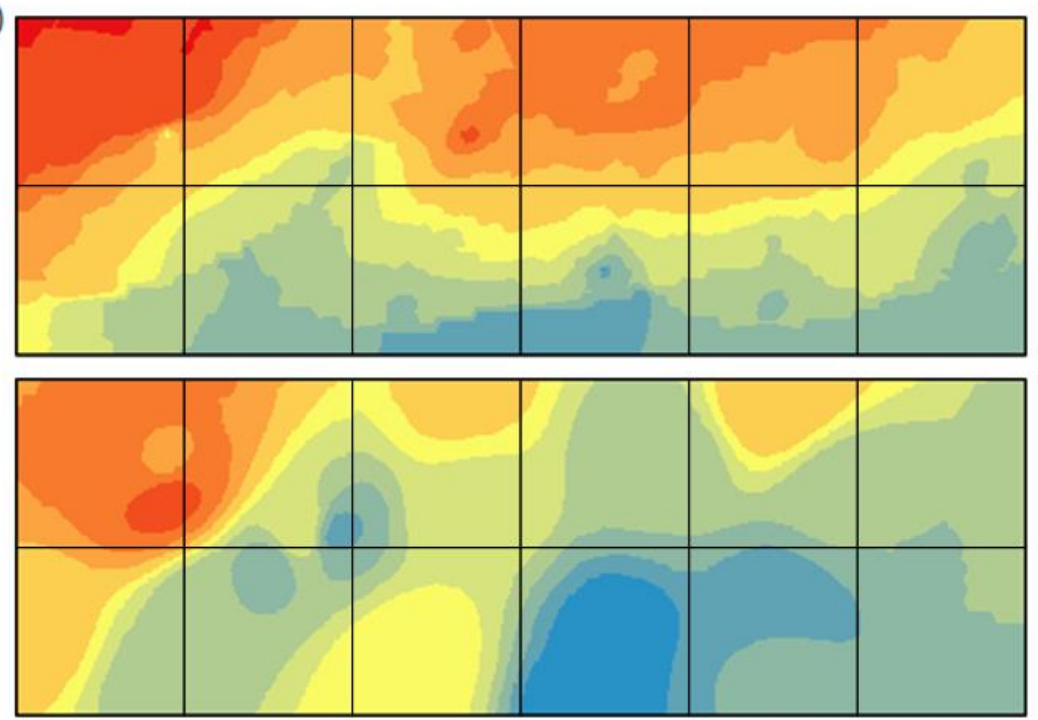

c)
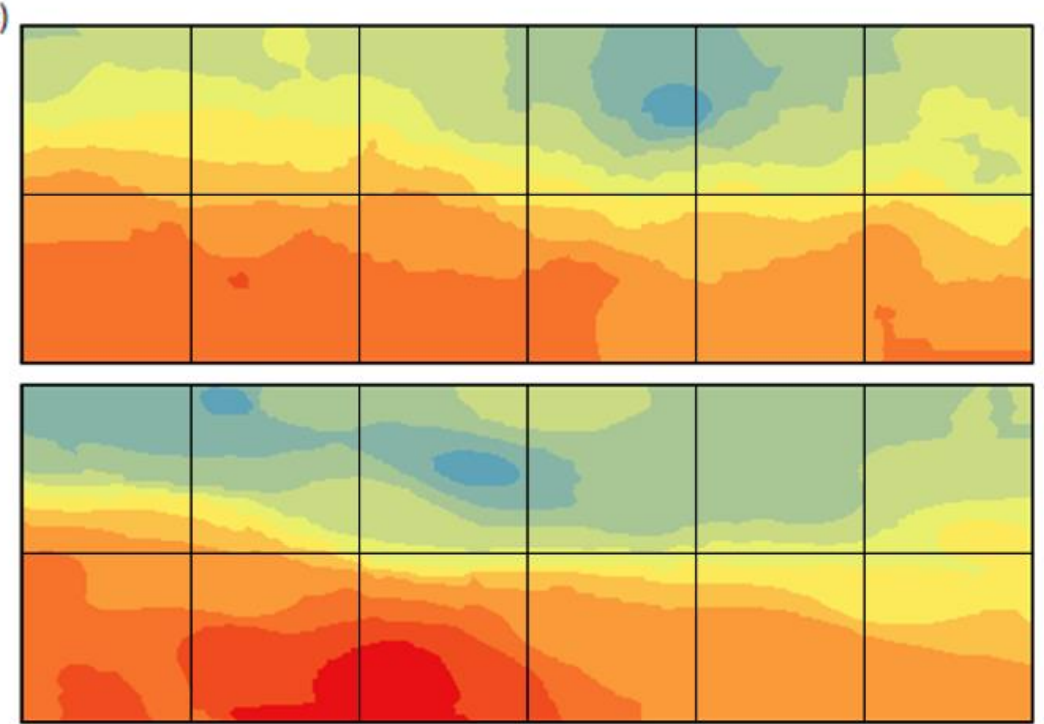

Soil pH

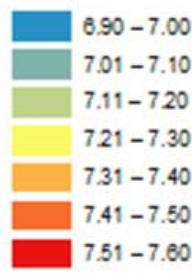

Infiltration Rate ( $\mathrm{mm} / \mathrm{hr})$

$0-15$

$16-30$

$31-60$

$61-100$

$101-150$

$151-200$

$201-300$

$301-400$

$401-500$

$501-800$

$801-1.400$
Bulk Density $\left(\mathrm{Mg} / \mathrm{m}^{2}\right)$

$0-1.00$

$1.01-1.05$

$1.08-1.10$

$1.11-1.15$

$1.16-1.20$

$121-1.25$

$1.26-1.30$

$1.31-1.35$

$1.38-1.40$

$1.41-1.45$

$1.46-1.50$

$1.51-1.60$
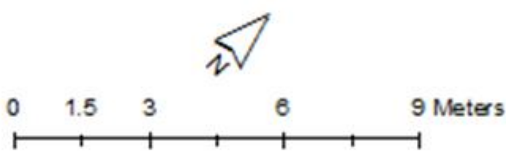

Figure 3.3: Prediction surfaces of a) soil pH; b) IR, year 1 (top) and year 2 (bottom); and c) $D_{b}$, year 1 (top) and year 2 (bottom). Surfaces were calculated using IDW from data collected in May 2012 and May 2013 at Ignatius Jesuit Centre, Guelph, Ontario. 
\& Matsuura, 2005). The MAE is close to zero; thus, on average the surface had an error close to zero. Therefore, overall, $\mathrm{pH}$ is not being underestimated or overestimated (Johnston et al., 2001). The initial surface water infiltration rate (IR) $(n=24)$ was highly variable over the site, ranging from 12 to $1400 \mathrm{~mm} / \mathrm{hr}$, with a mean of $224 \mathrm{~mm} / \mathrm{hr}$ (SD=316) and was positively skewed.

Overall, surface water infiltration rate in the second year $(n=20)$ was not statistically different, ranging from 6 to $540 \mathrm{~mm} / \mathrm{hr}$, with a mean of $140 \mathrm{~mm} / \mathrm{hr}(\mathrm{SD}=139)$. IDW generated prediction surfaces are presented in Figure 3.3b. The surface for year one had a moderate MAE of -24.07 and a high RMSE of 314.48, while the surface for year two had an MAE of 83.17 and a RMSE of -7.89. The interpolations were high as a result of the large range in data values for both years. Surface water infiltration rate showed a trend of decreasing infiltration rates from west to east.

Initial bulk density ( $\mathrm{n}=24$ ) ranged from $0.98 \mathrm{Mg} / \mathrm{m}^{3}$ (uncompact for sandy loams) to 1.48 $\mathrm{Mg} / \mathrm{m}^{3}$ (moderately compact for a sandy loam) with a mean of $1.28 \mathrm{Mg} / \mathrm{m}^{3}(\mathrm{SD}=0.15)$ (Craul, 1999). Second year bulk densities were not statistically different, ranging from 1.00 to 1.56 $\mathrm{Mg} / \mathrm{m}^{3}$, with a mean of $1.26 \mathrm{Mg} / \mathrm{m}^{3}$ ( $\mathrm{SD}=0.17$ ). IDW generated bulk density prediction surfaces are presented in Figure 3.3c. The surface for year one had a low MAE of 0.006 and a moderate RMSE of 0.090, while the surface for year two had an MAE of -0.001 and a RMSE of 0.083. Prediction surfaces indicate a trend of decreasing bulk density from south-southeast to northnorthwest.

\subsection{Soil Penetration Resistance}

Initial penetration resistance (PR) at all depths varied widely and increased in intraannual severity with depth. At all depths, soil compaction was most severe near the path. PR, when averaged from a soil depth of 0 to $15 \mathrm{~cm}$ (depth 1), ranged from 240 to $4275 \mathrm{kPa}$ and had a 
mean of $1205 \mathrm{kPa}$ ( $\mathrm{SD}=731)$. PR, when averaged from a soil depth of 15 to $30 \mathrm{~cm}$ (depth 2), ranged from 725 to $5585 \mathrm{kPa}$ and had a mean of $2105 \mathrm{kPa}(\mathrm{SD}=974)$. And, $\mathrm{PR}$, when averaged

from a soil depth of 30 to $45 \mathrm{~cm}$ (depth 3), ranged from 638 to $4720 \mathrm{kPa}$ and had a mean of 2404 $\mathrm{kPa}(\mathrm{SD}=316)$. In year two, there was a significant decrease in PR at all depths. PR at soil depth 1 ranged from 269 to $1872 \mathrm{kPa}$ and had a mean of $936 \mathrm{kPa}(\mathrm{SD}=298)$. $\mathrm{PR}$ at soil depth 2 ranged from 567 to $2720 \mathrm{kPa}$ and had a mean of $1527 \mathrm{kPa}(\mathrm{SD}=374)$. And, $\mathrm{PR}$ at soil depth 3 ranged from 562 to $3930 \mathrm{kPa}$ and had a mean of $1580 \mathrm{kPa}(\mathrm{SD}=372)$.

Prediction surfaces for soil penetration resistance, calculated using ordinary kriging, are presented in Figure 3.4 These surfaces were generated using data that had received a $\log 1.2$ transformation. Error analysis was conducted and included MAE, mean standardized error (MSE), root-mean-square standardized error (RMSSE), RMSE, and average standardized error (ASE) (Johnston et al., 2001). The prediction surfaces were relatively accurate considering MAE and MSE values were close to 0, i.e. not under or overestimated, and the RMSSE values were close to 1 , suggesting there is not an over or under estimate in the variances of the prediction surfaces (Johnston et al., 2001). RMSE values are difficult to evaluate because the surfaces were calculated using log-transformed data. The RMSE of log transformed data cannot be back transformed as back transformations skew errors. Surfaces for depths 1 and 2 display a trend of decreasing soil compaction from the southeast to the northwest (Figure 3.4a and 3.4b). The surface for Depth 3 displays a u-shaped trend from the southeast to the northwest (Figure 3.4c).

\subsection{Macronutrients}

Soil macronutrients and micronutrients were collected for year 1. However, only soil macronutrient availability $(\mathrm{n}=24)$ is reported. Macronutrients, especially nitrogen, phosphorous, and potassium, are typically the nutrients in limiting supply for most plant species (Aerts \& 
a)
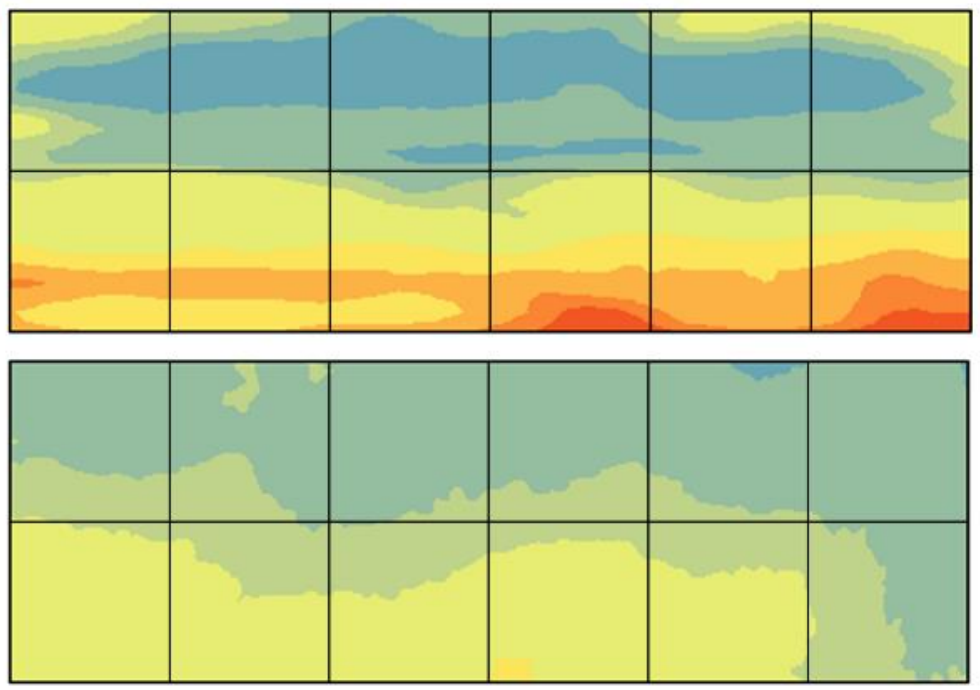

b)
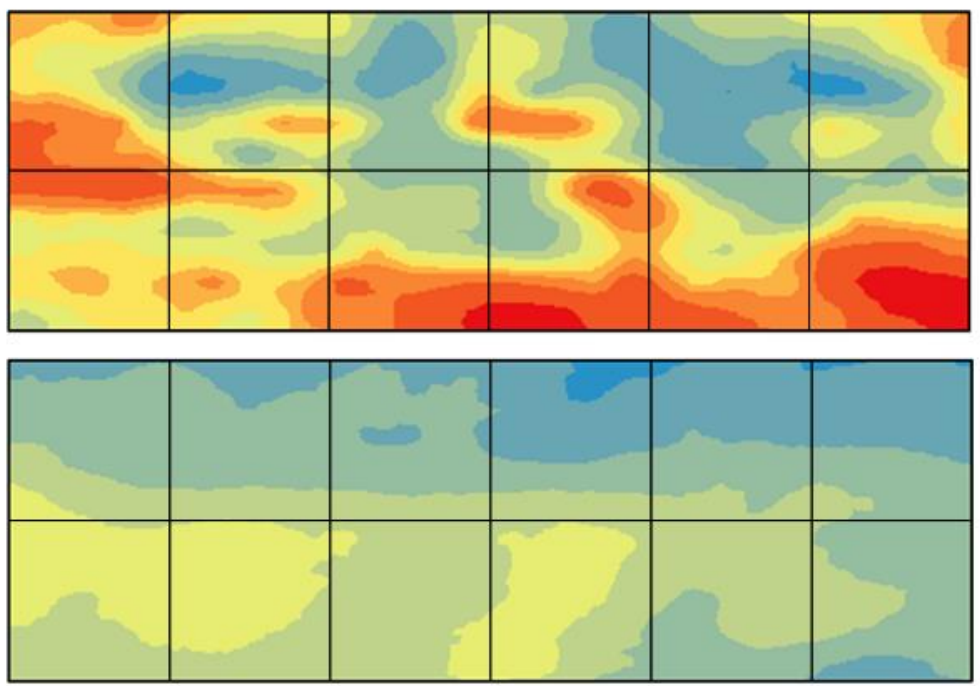

c)
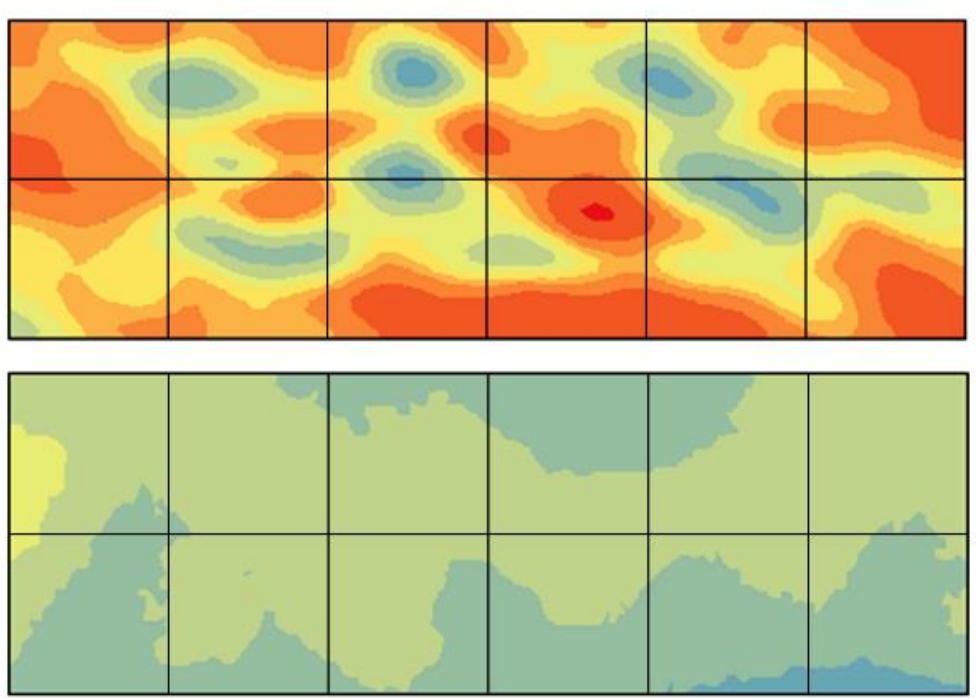

Penetration Resistance (kPa)

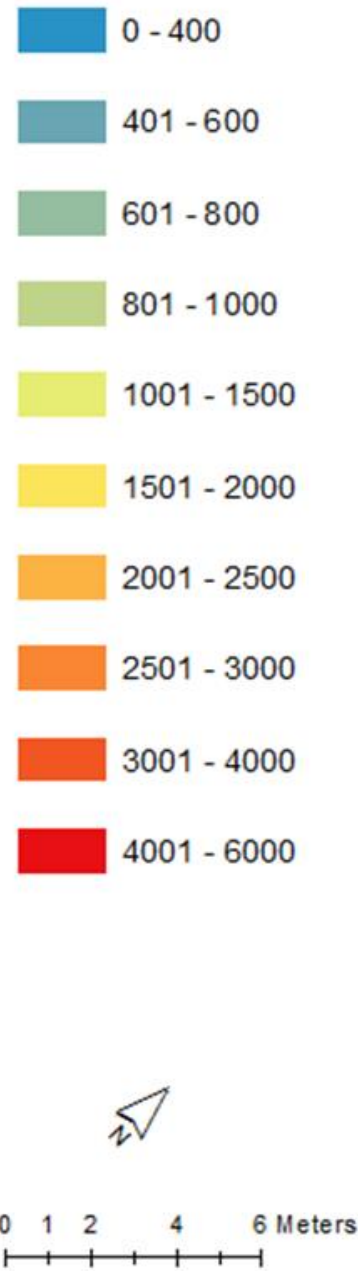

Figure 3.4: Penetration resistance (kPa) prediction surfaces at a) depth $1(2.5-15 \mathrm{~cm}), \mathrm{b})$ depth $2(15-30 \mathrm{~cm})$, and c) depth $3(30-45 \mathrm{~cm})$ for year one (upper) and year two (lower). Surfaces were calculated using ordinary kriging from data collected in May 2012 and May 2013 at Ignatius Jesuit Centre, Guelph, Ontario. 
Chapin, 1999; Verhoeven, 1996). Nitrogen, phosphorous, and potassium are also reported as being important for Tillage Radish ${ }^{\circledR}$ growth, along with other macronutrients, including sulfur and calcium (CCS, 2012). The IDW prediction surfaces for available macronutrients in year 1 are presented in Figure 3.5.

Nitrate $\left(\mathrm{NO}_{3}\right)$ levels varied greatly over the plot but were considered normal for a forested soil, ranging from 7.14 to $243.50 \mu \mathrm{g} / \mathrm{cm}^{2} / 42$ days, with a mean of $45.71 \mu \mathrm{g} / \mathrm{cm}^{2} / 42$ days $(\mathrm{SD}=59.07)$ (Western Ag Innovations Inc., 2014). The interpolated surface had an MAE of -4.32, a small underestimate considering the range, and a RMSE of 41.21. The prediction surface indicates a trend of decreasing nitrates from the northwest to the southeast.

Ammonium $\left(\mathrm{NH}_{4}\right)$ levels varied from low to normal, ranging from 0.36 to 14.42 $\mu \mathrm{g} / \mathrm{cm}^{2} / 42$ days, with a mean of $4.17 \mu \mathrm{g} / \mathrm{cm}^{2} / 42$ days ( $\mathrm{SD}=3.42$ ). Generally, ammonium levels fall between 1 and $10 \mu \mathrm{g} / \mathrm{cm}^{2} / 28$ days in forested and agricultural soils (Western Ag Innovations Inc., 2014). The interpolated surface, presented in Figure 3.5b, had an MAE of -0.006 , virtually no over or underestimate, and a RMSE of 3.56. The prediction surface reveals a trend of decreasing ammonium from north to south.

Phosphorous (P) levels were on the lower end of normal for a forested soil, ranging from 0.64 to $12.98 \mu \mathrm{g} / \mathrm{cm}^{2} / 42$ days, with a mean of $1.87 \mu \mathrm{g} / \mathrm{cm}^{2} / 42$ days ( $\mathrm{SD}=2.40$ ) (Western $\mathrm{Ag}$ Innovations Inc., 2014). The interpolated surface, presented in Figure 3.5c, had an MAE of 0.09 and a RMSE of 2.59. The surface indicates a u-shaped trend from southwest to northeast. A large proportion of the error in this surface likely comes from the outlier of $12.98 \mu \mathrm{g} / \mathrm{cm}^{2} / 42$ days, evident in the prediction surface by the high value in the southern most portion of the plot.

Calcium (Ca) levels were normal across the plot, ranging from 2486 to $3158 \mu \mathrm{g} / \mathrm{cm}^{2} / 42$ days, with a mean of $2789 \mu \mathrm{g} / \mathrm{cm}^{2} / 42$ days ( $\mathrm{SD}=184.77$ ) (Western Ag Innovations Inc., 2014). 

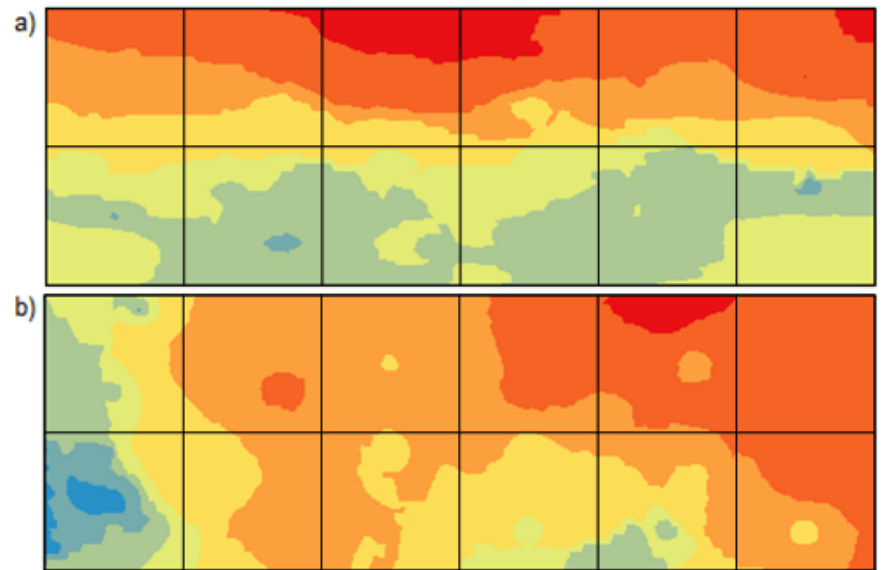

c)

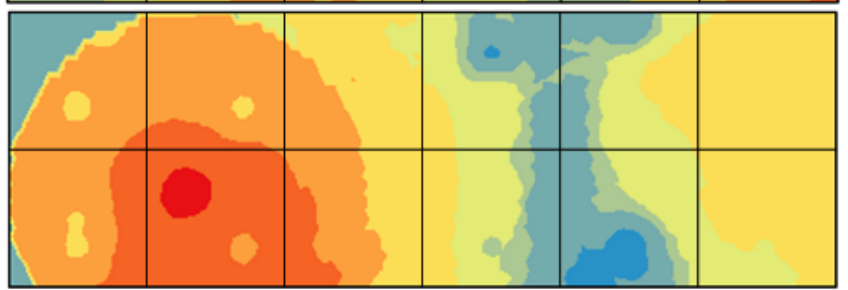

d)

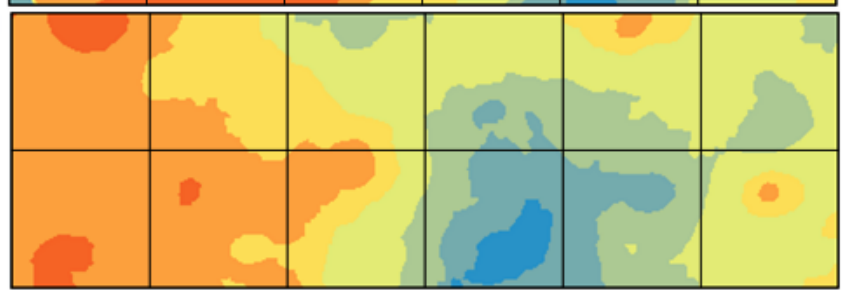

e)
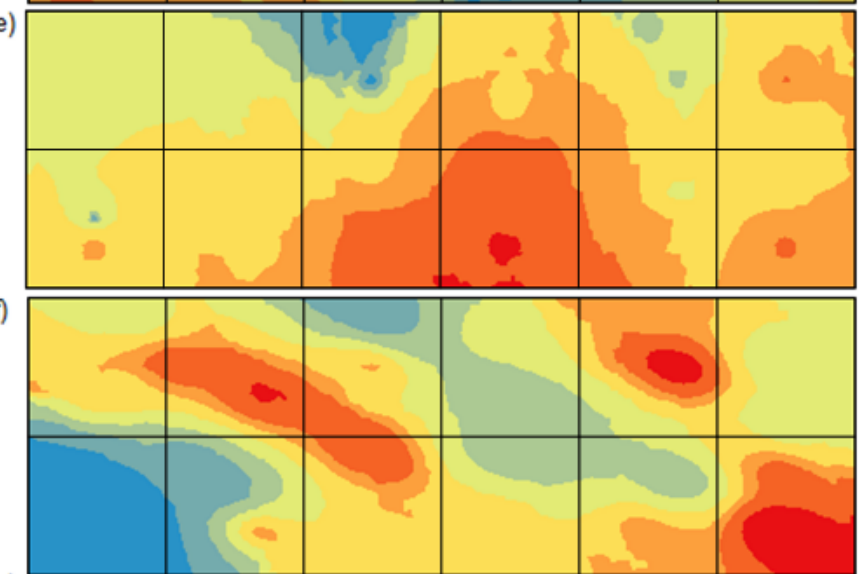

g)

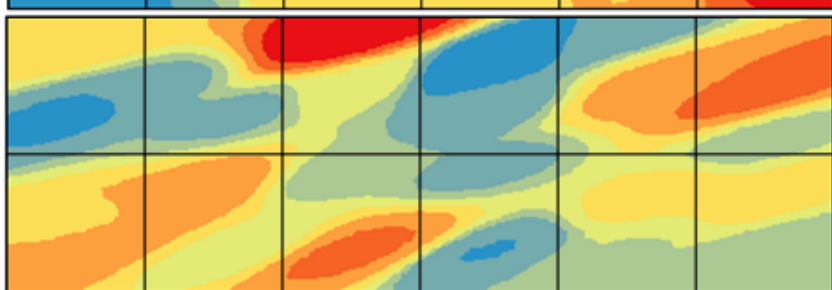

0
25
5

10 Meters

10 Meters

$\mathrm{NO}_{3}$ (ug/ $10 \mathrm{~cm}^{2} / 42$ days)

$7.14-7.93$ $7.93-9.55$

$9.55-12.88$

$12.88-19.72$

$19.72-33.77$

$33.77-62.62$

$\mathrm{NH}_{4}$ (ug/ $10 \mathrm{~cm}^{2} / 42$ days)

$0.38-1.25$

$1.25-1.73$

$1.73-1.97$

$1.97-2.44$

$2.44-3.34$

$3.34-5.04$

$P$ (ug/10 $\mathrm{cm}^{2} / 42$ days)

$\begin{array}{ll}0.64-1.08 & 2.94-5.74 \\ 1.06-1.22 & 5.74-12.98 \\ 1.22-1.28 & \end{array}$

$1.28-1.44$

$1.44-1.88$

$1.88-2.94$

$\mathrm{Ca}$ (ug/ $10 \mathrm{~cm}^{2} / 42$ days)

$2,488-2,568$
$2,959-3,055$

$2,588-2,844$

$2,644-2,714$

$2,714-2,789$

$2,789-2,871$

$2,871-2,959$

$\mathrm{K}$ (ug/10 $\mathrm{cm}^{2} / 42$ days)

$27.08-31.9$

$52.38-64.51$

$31.9-34.93$

$64.51-83.82$

$34.93-36.85$

$36.85-39.88$

$39.88-44.70$

$44.7-52.36$

Mg (ug/ $10 \mathrm{~cm}^{2} / 42$ days)

$$
\begin{array}{l|l}
291-410 & 581-598 \\
410-482 & 598-625
\end{array}
$$

$482-527$

$527-554$

$554-571$

$571-581$

\section{$\mathrm{S}$ (ug/10 $\mathrm{cm}^{2} / 42$ days)}

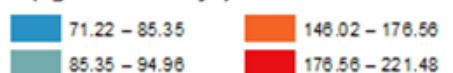

$176.56-221.48$

$94.96-101.50$

101.5 - 111.11

$111.11-125.24$

$125.24-146.02$

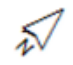

Figure 3.5: Prediction surfaces of bioavailable nutrients $\left(\mu \mathrm{g} / 10 \mathrm{~cm}^{2} / 42\right.$ days) for a) nitrate, b) ammonium, c) phosphorous, d) calcium, e) potassium, f) magnesium, and g) sulfur. Surfaces were calculated using inverse distance weighting from data collected in May 2012 and May 2013 at Ignatius Jesuit Centre, Guelph, Ontario 
The interpolated surface, presented in Figure 3.5d, had an MAE of 0.91 and a RMSE of 172.17. The prediction surface shows a trend of decreasing calcium from southwest to northeast.

Potassium (K) levels were on the low end of what is considered normal for a forested soil, ranging from 27.08 to $83.82 \mu \mathrm{g} / \mathrm{cm}^{2} / 42$ days, with a mean of 44.22 ( $\left.\mathrm{SD}=13.96\right)$. Generally, in a typical forested soil, potassium ranges from 12 to $900 \mu \mathrm{g} / \mathrm{cm}^{2} / 28$ days (Western $\mathrm{Ag}$ Innovations Inc., 2014). The interpolated surface, presented in Figure 3.5e, had an MAE of -0.65 and a RMSE of 13.11. The prediction surface reveals a trend of decreasing calcium from east to west.

Magnesium (Mg) levels ranged from 291 to $625 \mu \mathrm{g} / \mathrm{cm}^{2} / 42$ days and had a mean of 533 $\mu \mathrm{g} / \mathrm{cm}^{2} / 42$ days $(\mathrm{SD}=82.56)$. Typically, soil magnesium values are $20 \%$ of calcium values (Western Ag Innovations Inc., 2014). In this case, the mean was $19 \%$ of the calcium mean, indicating normal magnesium levels. The interpolated surface, presented in Figure 3.5f, had an MAE of -2.21, a small under estimate, and a RMSE of 55.45. The prediction surface suggests that there is no trend of increasing or decreasing magnesium levels across the plot.

Sulfur (S) levels ranged from 71.22 to $221.48 \mu \mathrm{g} / \mathrm{cm}^{2} / 42$ days and had a mean of 113.51 $\mu \mathrm{g} / \mathrm{cm}^{2} / 42$ days $(\mathrm{SD}=32.45$ ), levels that are considered normal for a forested soil (Western Ag Innovations Inc., 2014). The interpolated surface, presented in Figure 3.5g, had an MAE of -3.77, a small underestimate, and a RMSE of 33.33. The prediction surface reveals that there is no trend of increasing or decreasing sulfur levels across the plot.

\subsection{Precipitation}

Precipitation accumulation during 2012 was much lower than average for the months

prior to soil testing (January to April), the months prior to planting (May to July), and during the month of planting (August). During these periods, precipitation totalled $115 \mathrm{~mm}, 162 \mathrm{~mm}$, and $63 \mathrm{~mm}$, respectively. Historical averages during these periods were $257 \mathrm{~mm}, 253 \mathrm{~mm}$, and 85 
mm (The Weather Network, 2014). According to a report by Environment Canada (2012), rainfall periods were fewer and more intense, and temperatures were higher than average.

During the months prior to soil testing in 2013, precipitation accumulation was $236 \mathrm{~mm}$, much closer to the historical average (The weather network, 2014).

\subsection{Radish Growth}

\subsection{Root Biomass Response Model}

Linear regression was used to evaluate root growth (biomass) in the extraction plot. The biomass and root lengths of the extracted roots $(n=138)$ were highly variable. Root biomass ranged from 10 to $3500 \mathrm{mg}$, and had a mean biomass of $256.52 \mathrm{mg}$ (SD =310.8), while root lengths ranged from $8 \mathrm{~cm}$ to $26 \mathrm{~cm}$, and had a mean length of $15 \mathrm{~cm}$. When averaged to the nearest grid point to compare against compaction data, root biomass $(n=25)$ ranged from 35 to $1400 \mathrm{mg}$ and had a mean of $256.16 \mathrm{mg}(\mathrm{SD}=462.20)$. Soil penetration resistance was not found to be correlated with averaged root biomass when averaged over depth 1, depth 2, or depth 3 . However, a few depths were positively correlated, including PR at $22.5 \mathrm{~cm}$ and PR at $42.5 \mathrm{~cm}$, $\mathrm{r}=0.464, \mathrm{p}<.05$ and $\mathrm{r}=0.579, \mathrm{p}<0.01$, respectively. $\mathrm{PR}$ at $42.5 \mathrm{~cm}$ was not entered into the model as root growth did not reach this depth and as it was significantly correlated with PR at $22.5 \mathrm{~cm}$. Phosphorous levels were also correlated with average root biomass, $\mathrm{r}=0.407, \mathrm{p}<0.05$. When entered into the multiple linear regression analysis, PR 22.5 significantly predicted average root biomass, $\mathrm{F}(1,23)=6.33, \mathrm{p}<0.019$, Adjusted $\mathrm{R}^{2=0.182}$. Both the PR 22.5 variable and the constant were considered significant in predicting averaged root biomass, $\mathrm{p}=0.001$ and $\mathrm{p}=0.019$, respectively.

When phosphorous was entered, it improved the adjusted $R^{2}$ by $0.09, F(2,22)=5.44$, $\mathrm{p}=0.012$, Adjusted $\mathrm{R}^{2=0.270}$. However, phosphorous was not considered a significant predictor 
variable $(\mathrm{p}=0.064)$ and, therefore, was not included in the final model. Equation 1 (linear regression model 1) is the equation for the root biomass response model.

Log10(AverageRootBiomass $)=1.3875 \times 0.001[\mathrm{PR}$ at 22.5]

The residuals were normal and homoscedastic. Therefore, the assumptions regarding the distribution of the residuals were satisfied.

\subsection{Allometric Growth Models}

Simple linear regression was used to create allometric growth models to predict radish root biomass from shoot length. Two allometric models were produced: the first to predict radish root biomass $(\mathrm{mg})$ from shoot length $(\mathrm{mm})(\mathrm{n}=138)$ of individual plants, and the second to predict mean root biomass $(\mathrm{mg})$ from mean shoot length $(\mathrm{mm})$ of plants averaged to the closest grid points $(n=25)$. Average shoot length was found to be better correlated with average root length, $\mathrm{r}=0.959, \mathrm{p}<0.01$, than individual shoot length was with individual root length, $\mathrm{r}=0.886$, $\mathrm{p}<0.01$. When entered into a simple linear regression analysis, individual shoot length significantly predicted root biomass, $\mathrm{F}(1,136)=494.152, \mathrm{p}<0.001$, Adjusted $\mathrm{R}^{2}=0.783$. However, the predictive capability of Model 2 was higher, $\mathrm{F}(1,23)=261.34$, $\mathrm{p}<0.001$, Adjusted $\mathrm{R}^{2}=0.916$. Therefore, averaging shoot length to the closest grid point will be an accurate method of analyzing root growth over the plot. In each of the models, the constant and the predictor variables were considered to be significant. The allometric growth models are displayed below, see equations 2 (linear regression model 2) and 3 (linear regression model 3).

Log $10($ RootBiomass $)=0.560+0.015($ ShootLength $)$

Log10(AverageRootBiomass $)=0.41+0.019($ AverageShootLength $)$

Equation 2 explains the variance in root biomass with shoot length; while equation 3 explains the variance in average root biomass with average shoot length. Both models suggest 
that root biomass can be accurately predicted from shoot length. The residuals in each model were normally distributed and homoscedastic, satisfying assumptions regarding the distribution of residuals.

\subsection{Shoot Growth Response Models}

Multiple linear regression was used to determine the effects of soil properties on the growth of shoots over the whole plot, on the northwestern half of the plot, and on the southeastern half of the plot.

Radish shoot lengths were averaged to the closest grid points $(n=59)$ in order to compare them with the soil penetration resistance data collected. Bulk density, infiltration rates, and nutrients were obtained from the interpolated surfaces. Shoot lengths ranged from 45 to $250 \mathrm{~mm}$, with a mean of $103.12(\mathrm{SD}=37.15)$. Shoot length was significantly correlated with $\mathrm{NO}_{3}(\mathrm{r}=0.273$, $\mathrm{p}<0.05) . \mathrm{K}(\mathrm{r}=0.241, \mathrm{p}>0.05)$ and $\mathrm{NH}_{4}(\mathrm{r}=0.236, \mathrm{p}>.05)$ were not significantly correlated with shoot length; however, as there were no other significantly correlated variables and as they are often cited as important nutrients for shoot growth (Verhoeven et al, 1996), they were also chosen to be entered into the regression model. Soil compaction averaged at depth $1(\mathrm{r}=-0.079)$, depth $2(\mathrm{r}=0.078)$, and depth $3(\mathrm{r}=-0.035)$ were not significant and had very low correlations, and thus, were not entered into the model. When entered into the multiple linear regression analysis, $\mathrm{K}$ and $\mathrm{NO}_{3}$ were able to significantly predict shoot length, $\mathrm{F}(2,56)=9.145$, $\mathrm{p}<0.001$, Adjusted $\mathrm{R}^{2}=0.219 . \mathrm{K}$ and $\mathrm{NO}_{3}$ were both significant variables in the prediction of shoot length, $\mathrm{p}<0.001$; however, the constant was not significant, $\mathrm{p}=0.293$. Radish shoot growth response model 1 is presented as equation 4 (linear regression model 4)

$\log 10($ ShootLength $)=-0.783+1.542[\log 10(\mathrm{~K})]+0.181\left[\log 10\left(\mathrm{NO}_{3}\right)\right]$ 
On the northwestern blocks, mean radish shoot length $(\mathrm{n}=30)$ was $103.39 \mathrm{~mm}$ $(\mathrm{SD}=30.79)$. Shoot lengths were significantly correlated with $\mathrm{NO}_{3}(\mathrm{r}=0.625, \mathrm{p}<0.01)$ and $\mathrm{K}$ $(r=0.627, p<0.01) . \mathrm{NH}_{4}$ was not significantly correlated with shoot length $(r=0.174)$. When entered into the multiple linear regression analysis, $\mathrm{NO}_{3}, \mathrm{~K}$, and $\mathrm{NH}_{4}$ significantly predicted shoot length, $\mathrm{F}(3,25)=21.20, \mathrm{p}<0.001$, Adjusted $\mathrm{R}^{2}=0.684$. Equation 5 (linear regression model 5) describes the shoot growth response on the northwestern blocks.

$\log 10($ ShootLength $)=-1.982+0.195[\log 1.2(\mathrm{~K})]+0.002\left(\mathrm{NO}_{3}\right)-0.028\left(\mathrm{NH}_{4}\right)$

On the southeastern blocks, mean radish shoot length $(\mathrm{n}=30)$ was $102.88 \mathrm{~mm}(\mathrm{SD}=43.5)$. Shoot lengths were significantly correlated with $\mathrm{NO}_{3}(\mathrm{r}=0.450, \mathrm{p}<0.05)$ and $\mathrm{NH}_{4}(\mathrm{r}=0.367$, $\mathrm{p}<0.05)$ but not $\mathrm{K}(\mathrm{r}=0.184)$. When each predictor variable was entered into the multiple linear regression analysis, only $\mathrm{NO}_{3}$ was able to significantly predict shoot length, $\mathrm{F}(1,28)=7.091$, $\mathrm{p}=0.013$, Adjusted $\mathrm{R}^{2}=0.174 . \mathrm{NO}_{3}$ was considered a significant variable for predicting shoot length, $\mathrm{p}=0.013$ respectively. Equation 6 (linear regression model 6) describes the shoot growth response model for the southeastern blocks.

Log $10($ ShootLength $)=1.762+0.015\left(\mathrm{NO}_{3}\right)$

The residuals for models 4, 5, and 6 were homoscedastic and normal, satisfying assumptions regarding the distribution of residuals.

\subsection{Effect of Treatment}

\subsection{Penetration Resistance}

Analysis of covariance (ANCOVA) was used to analyse the effects of radish treatment on the change in penetration resistance at depth $1\left(\Delta \mathrm{PR}_{1}\right)$ and at depth $2\left(\Delta \mathrm{PR}_{2}\right)$ by controlling for initial penetration resistance (IPR) at each depth. Initial descriptive statistics suggested that the location of the treatment blocks affected the value of $\Delta \mathrm{PR}_{1}$. On the southeastern blocks, $\Delta \mathrm{PR}_{1}$ 
values, while not significant, were more negative for radish blocks $(M=-604.5, S D=465.65)$ than on control blocks $(\mathrm{M}=-503.28, \mathrm{SD}=661.41)$, and in the northwestern blocks, $\Delta \mathrm{PR}_{1}$ values, while also not significant, seemed more positive on radish blocks $(\mathrm{M}=101.49, \mathrm{SD}=289.65)$ than on control blocks $(\mathrm{M}=50.93, \mathrm{SD}=349.14)$. A preliminary ANCOVA confirmed that the location of the blocks, whether they were located on northwestern blocks or southeastern blocks, had a significant effect on the relationship between $\triangle \mathrm{PR}$ and IPR at depth 1 and at depth 2 . The results indicated that there was actually a greater negative change for both treatment and control blocks at a given IPR on the northwestern blocks. As treatment blocks were selected using a stratified random design based on these two distinct locations, $\Delta \mathrm{PR}_{1}$ and $\Delta \mathrm{PR}_{2}$ were analyzed separately within each location. At the first depth the change in penetration resistance was analyzed by grouping values into radish plots vs control plots. However, as root growth may affect the ability of radish to remediate compaction at depth $2, \Delta \mathrm{PR}_{2}$ was analyzed by grouping the blocks based on average growth. As shoot length on block 4 was found to be significantly greater than shoot length on all other blocks, it was classified as high shoot growth, while all other radish treatment blocks were classified as moderate growth. Change in penetration resistance at depth $3\left(\Delta \mathrm{PR}_{3}\right)$ was not analyzed as modest Radish growth would unlikely have been able to affect penetration resistance at that depth.

For soil on the southeastern blocks, IPR at soil depth 1 ranged from 503 to $4275 \mathrm{kPa}$, with a mean of $1688 \mathrm{kPa}(\mathrm{SD}=627) . \Delta \mathrm{PR}_{1}$ values on control blocks ranged from 380 to -2725 $\mathrm{kPa}$, with a mean of $-503.28(\mathrm{SD}=661.41)$, while $\Delta \mathrm{PR}_{1}$ values on radish blocks ranged from 304 to $-2065 \mathrm{kPa}$, with a mean of $-604.5(\mathrm{SD}=465.65)$. A Levene's Test of Equality of Error Variances indicated that the assumption of the homogeneity of variances was violated, $\mathrm{F}(1,123)=13.40, \mathrm{p}<0.001$. However, the violation was minor as the number of samples in each 
group was similar, with 50 samples from radish plots and 75 from control plots (Leech, 2008).

All other assumptions were met, including the most important assumption, homogeneity of regression slopes, $\mathrm{F}(1,123)=0.001, \mathrm{p}=0.982$. Results indicate that there was a large significant effect of initial penetration resistance, $F(1,123)=546.72, p<0.001, \eta^{2}$ partial $=0.818$, and a small effect of treatment, $\mathrm{F}(1,123)=11.21, \mathrm{p}=0.001, \eta^{2}$ partial $=.084$, on the variance of $\Delta \mathrm{PR}_{1}$. The estimated mean of $\Delta \mathrm{PR}_{1}$ at an IPR of $1688 \mathrm{kPa}$ on the southeastern blocks with radish (-637 $\mathrm{kPa}$, $\mathrm{SE}=36)$ was $155 \mathrm{kPa}$ more negative than the estimated mean on control plots $(\mathrm{M}=-482 \mathrm{kPa}$, $\mathrm{SE}=29$ ). The significant effect of treatment on the relationship between initial penetration and $\Delta \mathrm{PR}_{1}$ can be seen in Figure 3.6. The negative regression model slopes indicate that there was a greater reduction in penetration resistance when pre-treatment soil penetration resistance was

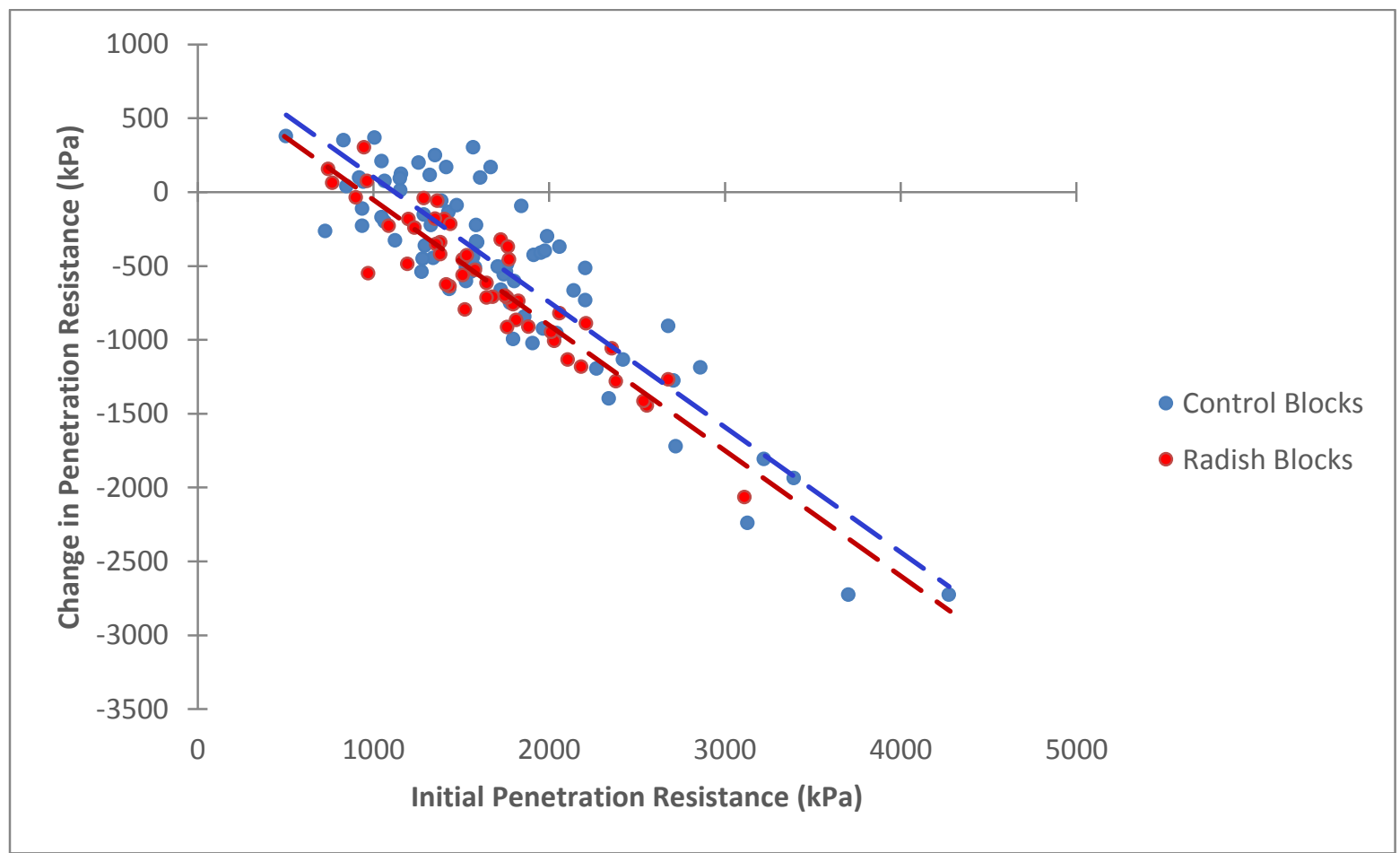

Figure 3.6: Scatter plot and regression lines displaying the change in penetration resistance at depth 1 (2.5 $15 \mathrm{~cm}$ ) versus the initial penetration resistance on the southeastern blocks, categorized by treatment. Data used was collected in May 2012 and May 2013 at Ignatius Jesuit Centre, Guelph, Ontario. 
high. Differences in the regression models indicate that penetration resistance was reduced to a greater degree on radish plots, at all levels of compaction.

IPR at depth 1 on the northwestern portion of the plot was significantly lower than on the southeastern plot, ranging from 239 to $1593 \mathrm{kPa}$, with a mean of $685 \mathrm{kPa}(\mathrm{SD}=280) . \Delta \mathrm{PR}_{1}$ values on control blocks ranged from 1170 to $-1018 \mathrm{kPa}$, with a mean of $501 \mathrm{kPa}(\mathrm{SD}=349)$, while $\Delta \mathrm{PR}_{1}$ values on radish blocks ranged from 527 to -1181 , with a mean of $101 \mathrm{kPa}(\mathrm{SD}=290)$. All of the assumptions required to run ANCOVA were met, including homogeneity of variance $\mathrm{F}(1,147)=2.68, \mathrm{p}=0.104$, and homogeneity of slopes, $\mathrm{F}(1,147)=0.90, \mathrm{p}=0.345$. The results of ANCOVA indicated that there was a large significant effect of initial penetration resistance, $F(1,147)=359.67, p<0.001, \eta^{2}$ partial $=0.710$, and a small adverse effect of treatment, $\mathrm{F}(1,147)=4.13, \mathrm{p}=0.044, \eta^{2}$ partial $=0.021$, on $\Delta \mathrm{PR}_{1}$. The estimated mean of $\Delta \mathrm{PR}_{1}$ at an IPR of $685.82 \mathrm{kPa}$ for the radish blocks on the northwestern portion of the plot was $105 \mathrm{kPa}(\mathrm{SE}=20)$, $58 \mathrm{kPa}$ greater than the estimated mean from the control blocks $(\mathrm{M}=47 \mathrm{kPa}, \mathrm{SE}=20)$. These numbers express 1) that average penetration resistance on the northwestern half of the plot increased between year 1 and year 2 and 2) that the change in penetration resistance increased to a greater degree on radish treatment blocks. The significant adverse effect of treatment on the relationship between initial penetration resistance and $\Delta \mathrm{PR}_{1}$ is displayed in Figure 3.7. Interestingly, areas that increased in penetration resistance were all below a threshold of initial compaction, roughly around $750 \mathrm{kPa}$. IPR at depth 2 , on the southeastern portion of the plot, ranged from 1029 to $5585 \mathrm{kPa}$ and had a mean of $2389 \mathrm{kPa}$ ( $\mathrm{SD}=977) . \Delta \mathrm{PR}_{2}$ values on control blocks ( $\mathrm{n}=75)$ ranged from 860 to $-4059 \mathrm{kPa}$ and had a mean of $-761 \mathrm{kPa}(\mathrm{SD}=1150)$, while $\Delta \mathrm{PR}_{2}$ values on radish blocks $(\mathrm{n}=50)$ ranged from 830 to $-2304 \mathrm{kPa}$ and had a mean of $-486 \mathrm{kPa}$ ( $\mathrm{SD}=771)$. All of the assumptions required to run ANCOVA were met, including homogeneity 


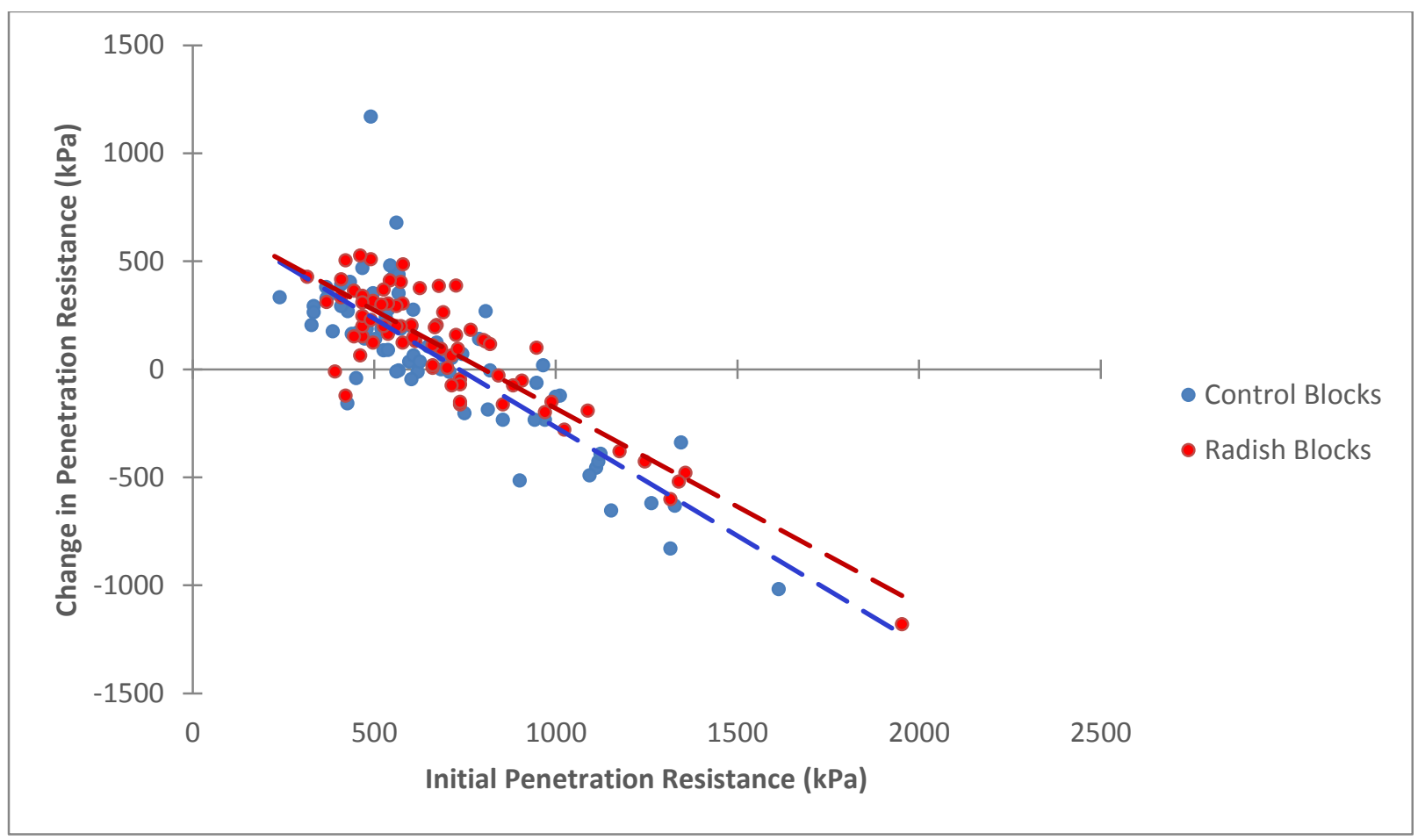

Figure 3.7: Scatter plot and regression lines displaying the change in penetration resistance at depth 1 (2.5 $15 \mathrm{~cm})$ versus the initial penetration resistance on the northwestern blocks, categorized by treatment. Data used was collected in May 2012 and May 2013 at Ignatius Jesuit Centre, Guelph, Ontario.

of variance, $F(1,123)=0.241, p=0.624$, and homogeneity of slopes, $F(1,123)=3.058, p=0.083$. The results of ANCOVA indicated that there was a large significant effect of initial penetration resistance on $\Delta \mathrm{PR}_{2}, \mathrm{~F}(1,123)=1117.18, \mathrm{p}<0.001, \eta^{2}$ partial $=0.902$, and no significant effect of treatment on the relationship between $\triangle \mathrm{PR}_{2}$ and IPR, $F(1,123)=1.62, \mathrm{p}=0.205, \eta^{2}$ artial $=0.013$. The estimated mean of $\Delta \mathrm{PR}_{2}$ at an IPR of $2388.96 \mathrm{kPa}$ was $-696 \mathrm{kPa}(\mathrm{SE}=45.71), 76 \mathrm{kPa}$ lower than the estimated mean of the control blocks $(\mathrm{M}=-620 \mathrm{kPa}, \mathrm{SE}=37)$. The relationship between IPR and $\Delta \mathrm{PR}_{2}$ for control and treatment blocks, on the southeastern portion of the plot, is displayed in Figure 3.8.

IPR at depth 2, on the northwestern portion of the plot, ranged from 725 to $4117 \mathrm{kPa}$ and had a mean of $1722 \mathrm{kPa}(\mathrm{SD}=716)$. The mean of $\Delta \mathrm{PR}_{2}$ was similar for blocks with moderate radish growth $(\mathrm{M}=-551 \mathrm{kPa}, \mathrm{SD}=727)$ and blocks with high average growth $(\mathrm{M}=-517 \mathrm{kPa}$, 


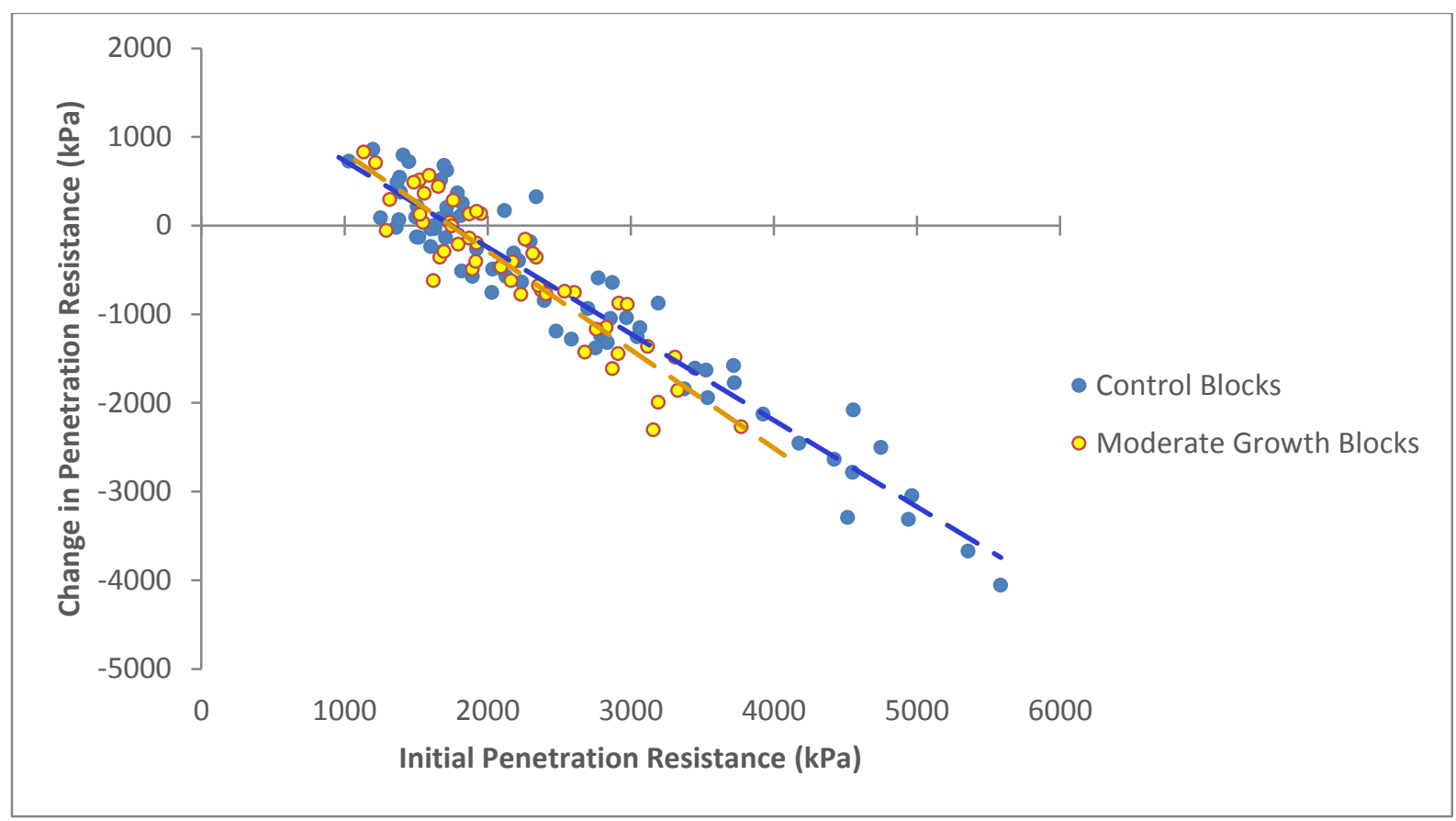

Figure 3.8: Scatter plot and regression lines the change in penetration resistance at depth $2(15-30 \mathrm{~cm})$ versus the initial penetration resistance on the southeastern blocks, categorized by radish growth. Data used was collected in May 2012 and May 2013 at Ignatius Jesuit Centre, Guelph, Ontario.

$\mathrm{SD}=712)$. Control plots were less negative, with a mean of $-201(\mathrm{SD}=667)$. All assumptions of ANCOVA were met, including homogeneity of variance, $\mathrm{F}(2,147)=0.731, \mathrm{p}=0.483$, and homogeneity of slopes, $\mathrm{F}(2,147)=0.393, \mathrm{p}=0.676$. Results indicated that there was a large significant effect of initial penetration resistance on $\Delta \mathrm{PR}_{2}, \mathrm{~F}(1,147)=579.14, \mathrm{p}<0.001$, $\eta^{2}$ partial $=0.799$, and no significant effect of treatment on the relationship between IPR and $\Delta \mathrm{PR}_{2}$, $F(2,147)=6.11, p=0.197, \eta^{2}$ partial $=0.022$. The estimated mean of $\Delta P_{2}$ at an IPR of $1721.63 \mathrm{kPa}$, for the block with high shoot growth, was $-463 \mathrm{kPa}(\mathrm{SE}=62.61), 139 \mathrm{kPa}$ lower than the estimated mean of $\Delta \mathrm{PR}_{2}$ for the blocks with moderate growth $(\mathrm{M}=-324 \mathrm{kPa}, \mathrm{SE}=45.24)$, and 94 $\mathrm{kPa}$ lower than the estimated mean of $\Delta \mathrm{PR}_{2}$ for control blocks $(\mathrm{M}=-369, \mathrm{SE}=36.80)$. The relationship between IPR and $\triangle \mathrm{PR}_{2}$ for blocks with high shoot growth, moderate root growth, and control blocks, on the southeastern portion of the plot, is displayed in Figure 3.9. 


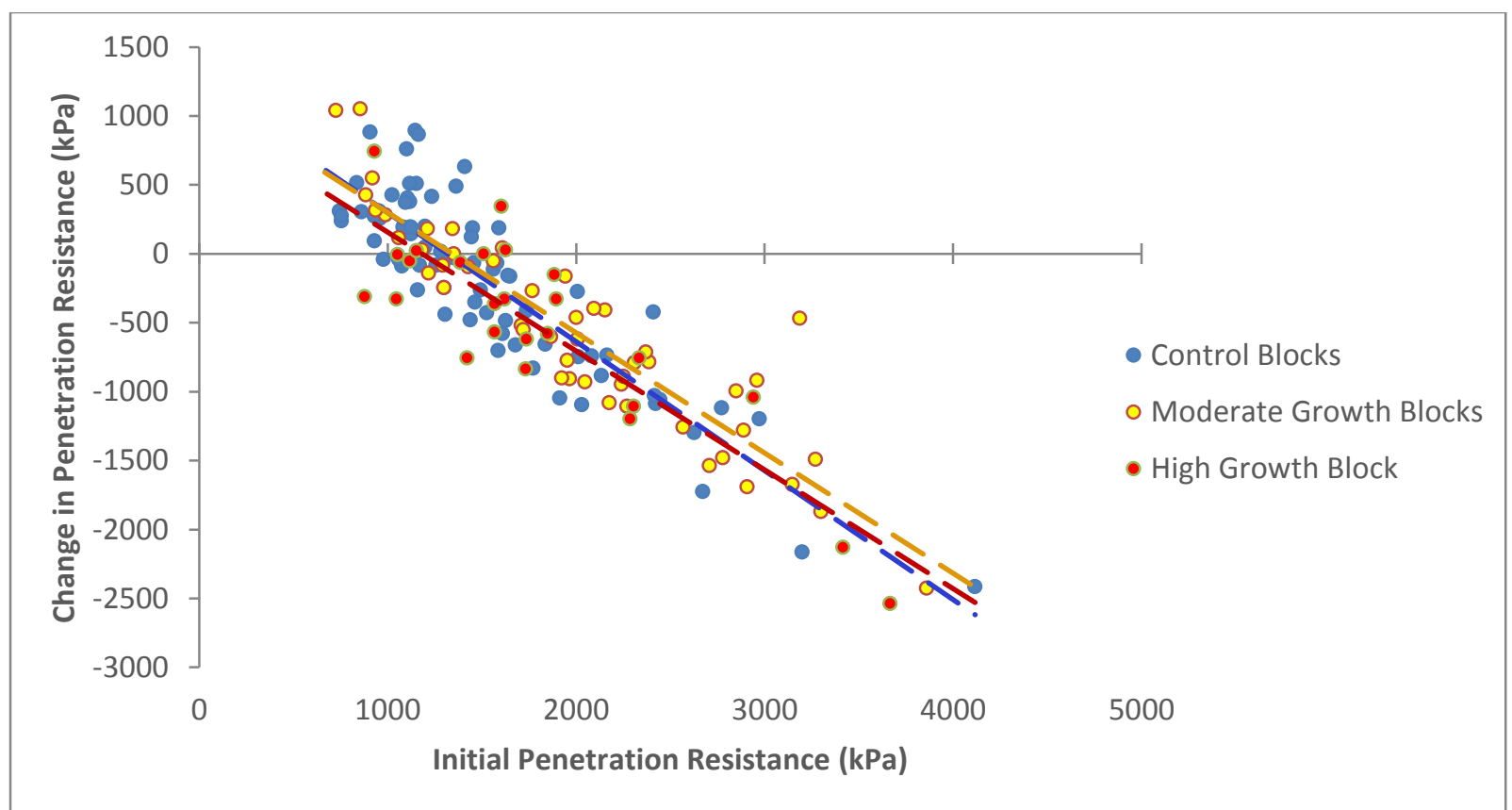

Figure 3.9: Scatter plot and regression lines displaying the change in penetration resistance at depth 2 (15 $30 \mathrm{~cm}$ ) versus the initial penetration resistance on the northwestern blocks, categorized by radish growth. Data used was collected in May 2012 and May 2013 at Ignatius Jesuit Centre, Guelph, Ontario.

\subsection{Bulk Density}

There was no significant difference in the change in bulk density $\left(\Delta \mathrm{D}_{\mathrm{b}}\right)$ between control blocks $(\mathrm{N}=12)$ and radish blocks $(\mathrm{N}=10), \mathrm{F}(1,20)=0.006, \mathrm{p}=0.940$. The difference in means was $-0.007 \mathrm{Mg} / \mathrm{m}^{3}(\mathrm{SD}=0.076)$ and $-0.010 \mathrm{Mg} / \mathrm{m}^{3}(\mathrm{SD}=0.093)$, respectively. While the assumptions of homogeneity of variance and homogeneity of slopes were met, ANCOVA results indicated that there was no significant effect of initial bulk density or treatment on $\Delta \mathrm{D}_{\mathrm{b}}$. The relationship between initial bulk density and $\Delta \mathrm{D}_{\mathrm{b}}$, categorized by treatment, is displayed in Figure 3.10 . The only visible trend is that, on radish plots, as initial bulk density increases, the variance in $\Delta \mathrm{D}_{\mathrm{b}}$ becomes smaller.

\subsection{Infiltration Rate}

Overall, there was a negative change in the infiltration rates $(\Delta \mathrm{IR})$ from year 1 to year 2 , $\mathrm{M}=-312 \mathrm{~mm} / \mathrm{hr}$. However, figure 3.11 indicates that $\Delta \mathrm{IR}$ values were only negatively affected where penetration resistance was also increased. On sites in which penetration resistance was 


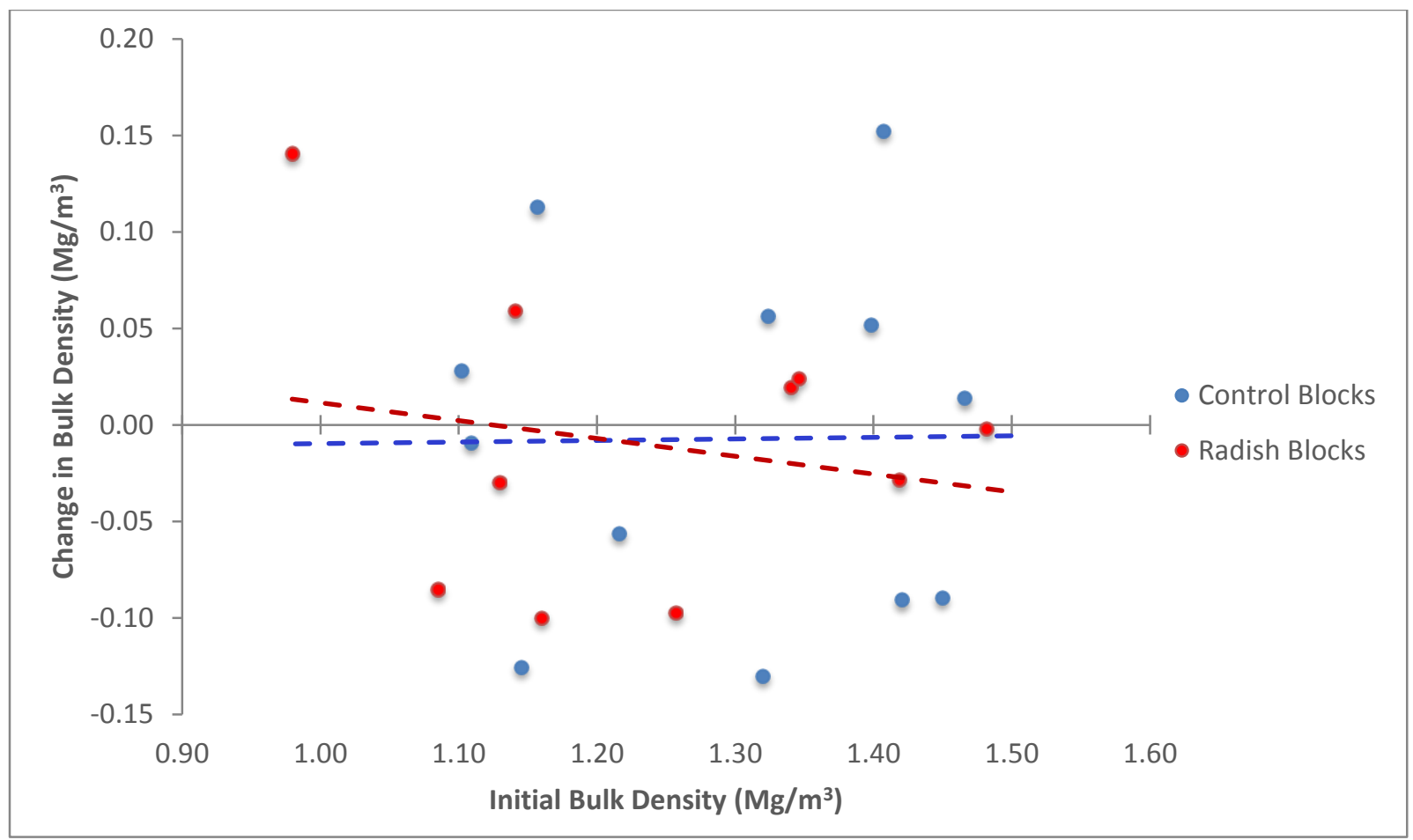

Figure 3.10: Scatter plot and regression lines displaying the change in bulk density $\left(\mathrm{Mg} / \mathrm{m}^{3}\right)$ versus initial bulk density $\left(\mathrm{Mg} / \mathrm{m}^{3}\right)$, categorized by treatment. Data used was collected in May 2012 and May 2013 at Ignatius Jesuit Centre, Guelph, Ontario.

reduced or remained the same, the infiltration capacity remained close to zero. A preliminary ANOVA test indicated that $\triangle \mathrm{IR}$ was not found to be significantly different on radish plots ( $\mathrm{M}=-$ $116 \mathrm{~mm} / \mathrm{hr}, \mathrm{SD}=370, \mathrm{n}=10)$ when compared to control plots $(\mathrm{M}=-112 \mathrm{~mm} / \mathrm{hr}, \mathrm{SD}=195, \mathrm{n}=10)$. ANCOVA analysis was run to control for $\triangle \mathrm{PR}_{1}$. In order to ensure a linear relationship, $\Delta \mathrm{IR}$ was transformed using a $\log 10$ transformation and $\Delta \mathrm{PR}_{1}$ was transformed using a power of 4 . ANCOVA assumptions were met; though, an outlier influenced the results (Figure 3.12). When the outlier was removed, the effect of $\Delta \mathrm{PR}_{1}$ became significant, $\mathrm{F}(1,17)=3872.40, \mathrm{p}<0.001$, $\eta^{2}$ partial $=0.201$, but there was still no significant effect of treatment. However, interestingly, the estimated $\Delta \mathrm{IR}$ mean, which has been back transformed, was higher for radish blocks (-9.69 $\mathrm{mm} / \mathrm{hr}$ ) than for control blocks (-156.93 $\mathrm{mm} / \mathrm{hr}$ ). The relationship between $\Delta \mathrm{PR}_{1}$ and $\Delta \mathrm{IR}$, categorized by treatment, is displayed in Figure 3.12. 


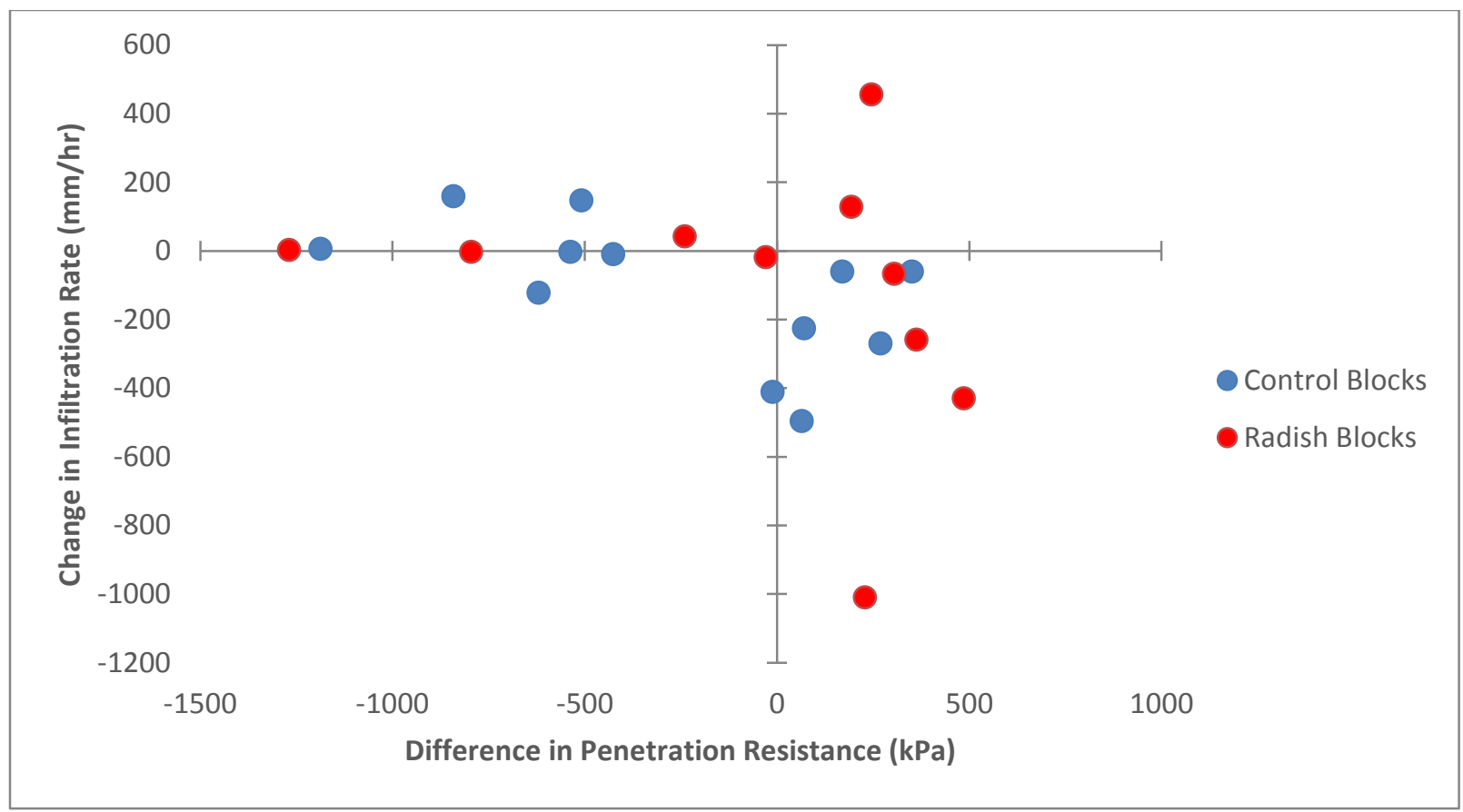

Figure 3.11: Scatter plot of the change in infiltration rate $(\mathrm{mm} / \mathrm{hr})$ versus the change in penetration resistance at depth 1, categorized by treatment. Data used was collected in May 2012 and May 2013 at Ignatius Jesuit Centre, Guelph, Ontario.

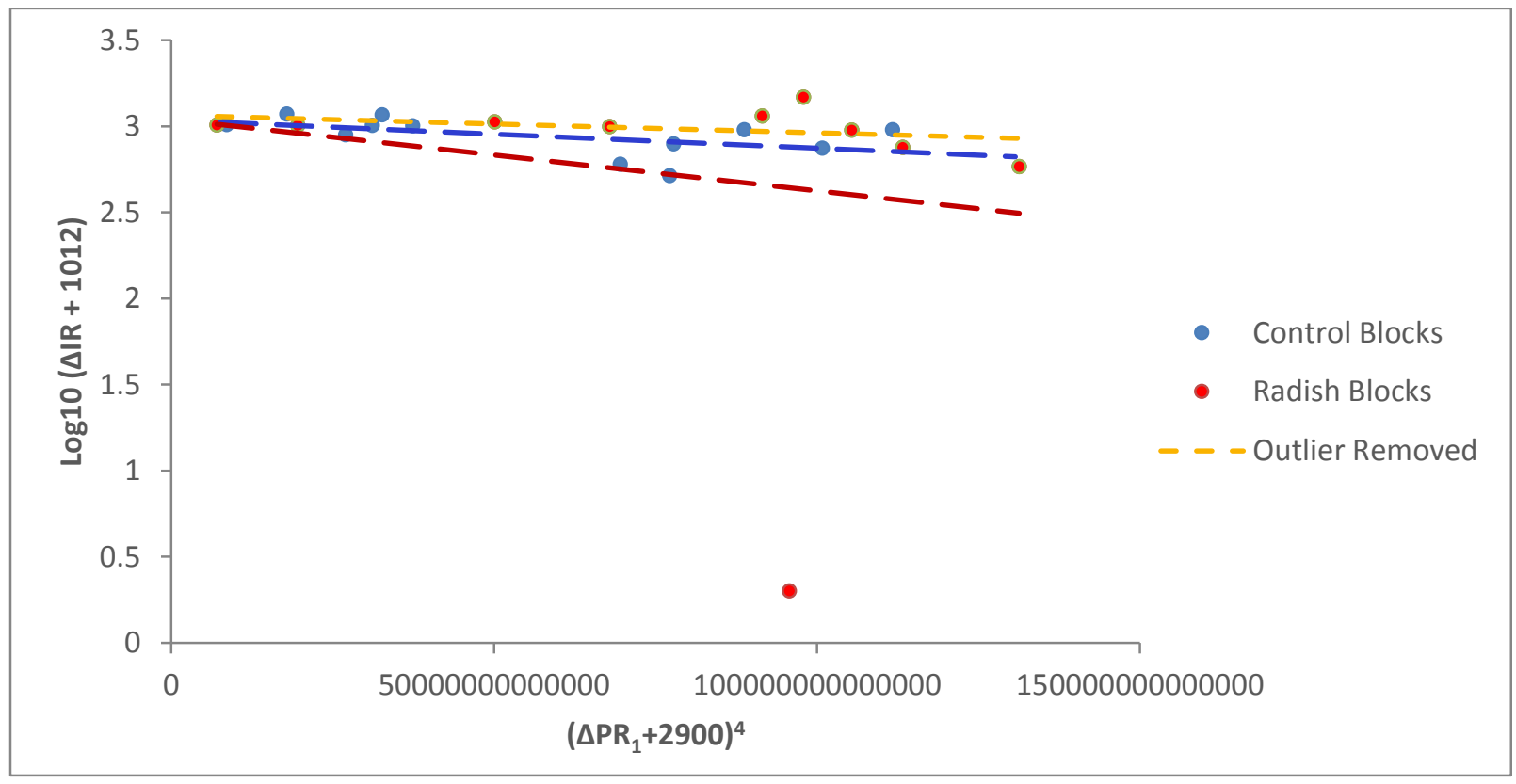

Figure 3.12: Scatter plot and regression lines displaying the change in infiltration capacity versus the change in penetration resistance at depth 1 , categorized by treatment. $\Delta I R$ was transformed using a $\log 10$ transformation [Log10 $(\Delta \mathrm{IR}+1012)]$. $\Delta \mathrm{PR}$ at Depth 1 was transformed using a power transformation of 4 $\left[\left(\Delta \mathrm{PR}_{1}+2900\right)^{4}\right]$. Data used was collected in May 2012 and May 2013 at Ignatius Jesuit Centre, Guelph, Ontario. 


\subsection{Change in Nutrient Availability}

Soil nutrient availability was only recollected on four sites, two control points and two treatment points. All nutrients saw a marked decrease in availability with the exception of phosphorous, which increased on treatment points ( $\mathrm{M}=1.58 \mu \mathrm{g} / \mathrm{cm}^{2} / 42$ days) (Table 3.1). Overall, control blocks experienced a larger decrease in $\mathrm{Mg}, \mathrm{NH}_{4}, \mathrm{Ca}, \mathrm{P}$, and $\mathrm{S}$ than treatment blocks. Treatment blocks experienced a larger decrease in $\mathrm{NO}_{3}$. The change in $\mathrm{K}$ was similar for both control and treatment blocks. Treatment sampling point 1 experienced less change in $\mathrm{NO}_{3}$ than all other points, had the greatest increase in $\mathrm{P}$, and was the only point that increased in $\mathrm{Ca}$ and $\mathrm{Mg}$ availability.

Table 3.1: Change in nutrient availability ( $\mu \mathrm{g} / \mathrm{cm}^{2} / 42$ days) from year 1 to year 2 of two re-measured points on block 4, a treatment block, versus block 5, a control block. Data used was collected in May 2012 and May 2013 at Ignatius Jesuit Centre, Guelph, Ontario.

\begin{tabular}{|c|c|c|c|c|c|c|c|c|}
\hline \multirow[b]{2}{*}{ Nutrients } & \multicolumn{4}{|c|}{ Control } & \multicolumn{4}{|c|}{ Treatment } \\
\hline & Point 1 & Point 2 & M & SD & Point 1 & Point 2 & M & SD \\
\hline $\mathrm{NO}_{3}$ & -13.95 & -89.34 & -51.65 & 37.70 & -8.58 & -132.24 & -70.41 & 61.83 \\
\hline $\mathrm{NH}_{4}$ & 1.70 & -11.72 & -5.01 & 6.71 & -3.62 & -1.44 & -2.53 & 1.09 \\
\hline $\mathrm{Ca}$ & -48.92 & -72.78 & -60.85 & 11.93 & 344.60 & -345.02 & -0.21 & 344.81 \\
\hline $\mathrm{Mg}$ & -64.90 & -50.38 & -57.64 & 7.26 & 33.97 & -75.36 & -20.70 & 54.67 \\
\hline $\mathrm{K}$ & -21.66 & -21.13 & -21.40 & 0.26 & -23.92 & -24.78 & -24.35 & 0.43 \\
\hline $\mathrm{P}$ & -0.83 & -0.38 & -0.61 & 0.23 & 2.74 & 0.41 & 1.58 & 1.17 \\
\hline $\mathrm{S}$ & -107.14 & -53.48 & -80.31 & 26.83 & -70.43 & -48.63 & -59.53 & 10.90 \\
\hline
\end{tabular}

\subsection{Discussion}

Trees offer important benefits to city residence (van Bueren, 2011; van Bohemen 2011; Nowak \& Dwyer, 2007; Akbari, 2002). Expanding tree canopy coverage has been recognized by several cities around the world as a way to enhance these benefits (City of Toronto, 2013). However, compact soils, which are common in city environments, can create a difficult environment for trees to grow in (Hamza \& Anderson, 2005; Rosolem et al., 2002; Gomez et al., 2002; Kozlowski, 1999; Craul, 1992; Patterson, 1977). Frequently, plans to increase tree canopy 
focus on tree planting, rather than enhancing tree growth by managing soil quality (Jim, 2008; Clark, 1997). However, considering the continued competition for space in city environments and the financial costs of tree mortality, it would be more efficient to improve the soil growing medium. Current methods of successful remediation of compacted urban soil are often expensive, ineffective, or both (Rosolem et al., 2002; Day and Bassuk, 1994). An effective and inexpensive strategy to remediate compacted soil and improve of tree growth will help to enhance urban forest cover. The research reported on in this paper demonstrates that bio-drilling plants, which are used in agriculture, can improve the growing medium in soils that are characteristic of the urban environment. More specifically, Tillage Radish ${ }^{\circledR}$ treatment can reduce the penetration resistance in moderately to highly compact soils and that Tillage Radish growth is not hindered by soil compaction.

\subsection{Tillage Radish ${ }^{\circledR}$ Growth}

Bulk density and penetration resistance were not found to be significant prediction variables in the shoot growth response models (equations 4,5 , and 6 ), indicating that compaction levels did not impact Tillage Radish ${ }^{\circledR}$ growth. Moreover, the root growth response model (equation 1) revealed that Tillage Radish ${ }^{\circledR}$ root growth actually increased with increasing compaction. These results both suggest that Tillage Radish ${ }^{\circledR}$ grows equally well in highly compact and uncompact soils, an extremely important characteristic for a compaction remediating plant. Research by Chen and Weil (2010) support this finding. In their study, radish, in addition to other common cover crop species, were planted in soils with varying levels of compaction. They found that radish growth improved with each increase in compaction. Conversely, the root growth of other common cover crops was reduced (Chen \& Weil, 2010). 
The fact the soil compaction does not reduce Tillage Radish ${ }^{\circledR}$ growth suggest that it is suitable for remediating highly compact soils, a common characteristic of urban environments.

In general, there was no indication in the growth models (equations 1, 4, 5 and 6) that there was any directional trend affecting radish growth. Considering that the northwest portion of the plot was shaded by canopy, this finding indicates that canopy coverage did not limit the growth of Tillage Radish ${ }^{\circledR}$, at least to the degree that could not be overcome by fertilizer. This finding suggests that Tillage Radish ${ }^{\circledR}$ growth was satisfactory in the shade of established trees. Tillage Radish ${ }^{\circledR}$ could, therefore, be planted to remediate soil where established trees exist. Nitrogen and potassium were found to be important predictor variables for Tillage Radish ${ }^{\circledR}$ growth, suggesting that growth, at least on part of the plot, was limited by one or both of these nutrients. The fact that these nutrients were selected in shoot growth model 3 (equation 6) and the variable nitrogen was selected in shoot growth model 2 (equation 5) indicates that nitrogen limited growth in the southeast and that nitrogen and potassium co-limited growth in the northwest. Moreover, nitrogen availability was found to be lowest in the southeast. This provides further evidence of the nitrogen dynamics suggested above, considering the law of the minimum, which states that the nutrient that is in the most limited supply is the limiting nutrient and that only an increase in that nutrient will improve plant growth (Verhoeven et al., 1996). In other words, where nitrogen was lowest, only nitrogen limited growth, and where nitrogen was higher, on the northwest half, potassium also became a limiting nutrient. Research by Verhoeven et al. (1996) supports these findings. Their research found that nitrogen and potassium are both common limiters to plant growth and sometimes limit plant growth together. Research by Tessier and Raynal (2003) also indicate that nitrogen is a relatively common limiting nutrient. 
The root lengths measured in the extraction block ranged from 8 to $26 \mathrm{~cm}$ and were likely representative of the growth on the rest of the plot. As Tillage Radish® tubers commonly grow to depths of $76 \mathrm{~cm}$ (CCS, 2012), it is evident that Tillage Radish ${ }^{\circledR}$ growth across the research plot was lower than expected. While it is difficult to determine the exact cause of poor growth, likely explanations include a less than adequate nutrient supply as a result of generally low nutrient availability, and insufficient soil moisture as a result of lower than normal precipitation. Regardless of the cause, modest radish growth has two major implications for the study. First, radishes, which are typically good weed suppressors, were encroached upon and out competed by weeds and grass (Malik et al., 2008; Weil \& Kremen, 2007). To avoid light competition, the grass and weeds had to be continually cut back. As a result, radish blocks experienced more unintended disturbance from foot traffic, possibly countering some of the near-surface soil compaction improvements made to the soil. Second, the benefits of Tillage Radish are often associated with growth (Chen \& Weil, 2010; Williams and Weil, 2004; Rosolem et al, 2002). The larger the tuber grows, the more nutrients its stores and the more it can break up compaction. Therefore, smaller tubers likely resulted in fewer benefits. Ultimately, fertilization would produce better growth in a nutrient poor area (Wright et al., 2011); however, at an increased cost to the management strategy. The cost-benefit of adding fertilizer will need to be assessed in a future study to help determine a best management strategy.

\subsection{Effect of Tillage Radish® Treatment on Soil Compaction and Water Infiltration}

Overall, soil penetration resistance values across all blocks were, on average, lower in 2013 than they were in 2012, suggesting that Tillage Radish® treatment was not the only factor in decreasing penetration resistance. According to Vaz et al. (2001), penetration resistance is a factor of bulk density and soil moisture. Considering bulk density was not found to be 
statistically different, the change in penetration resistance can be attributed to a fluctuation in soil moisture. This is supported by the fact that precipitation, which can have a significant effect on soil moisture (Laporte et al., 2002), was lower in 2012 than in 2013 and by the fact that soils with greater initial penetration resistance experienced a larger change in penetration resistance, a common occurrence in soils that increase in soil moisture (Vaz et al., 2001).

Increases in penetration resistance occurred only in areas of low initial compaction. Considering that soils with minimal compaction are more compressible than soils with higher soil strength (Craul, 1992), it is plausible that these areas were compacted during necessary plot maintenance activities, such as plant bed preparation and seeding. Research by Hamza and Anderson (2005) support this finding, suggesting that surface soils can be easily compacted with human and animal traffic. Bio-drilling plants would not be planted to remediate low penetration resistance as these soils are not compact but could be planted as a preventative measure. However, this research suggests that this is not an effective preventative strategy.

Growing Tillage Radish® produced promising, albeit mixed, results concerning its ability to improve penetration resistance. In the surface soils of the southeastern half of the plot, penetration resistance was reduced in Tillage Radish $®$ treatment blocks by $155 \mathrm{kPa}$ more than control blocks. This suggests that the Tillage Radish ${ }^{\circledR}$ tubers were successfully able to break up soil to a degree that significantly improved penetration resistance. Moreover, it was demonstrated that Tillage Radish ${ }^{\circledR}$ could improve penetration resistance in both moderate and highly compact soils. The results of the present study are supported in the research of Folorunso et al. (1992), who indicate that cover crops are capable of positively influencing soil strength. The fact that soil penetration resistance is highly correlated with plant root growth suggests that tree growth could be improved on Tillage Radish ${ }^{\circledR}$ treatment sites (Bassett et al., 2005; Hamza 
\& Anderson, 2005; Day \& Bassuk, 1994). These results are especially interesting considering the relatively modest growth of Tillage Radish $®$ in this study.

In contrast, in the northwestern half of the plot, penetration resistance increased in the surface soils of radish blocks. This increase can likely be explained by the fact that soils in the northwestern half of the plot had significantly lower initial penetration resistance. As discussed, soils of low penetration resistance are more easily compressed (Craul, 1992). Considering that in order to avoid growth competition, radish blocks had to be continually weeded, it is likely that the soil in the radish blocks on the northwestern half of the plot, could not bear the compressive forces incurred during weeding and thus, were compacted to a greater degree than soil on the control blocks. Therefore, in order to avoid growth competition, it may be beneficial to completely remove grass prior to planting Tillage Radish ${ }^{\circledR}$ as a soil remediation strategy. Leaving a wide enough barrier of weed free soil can be an effective method for reducing grass and weed encroachment. However, fertilization may also be an effective strategy if the improvements to radish growth can help suppress grass and weed growth. These strategies should be sufficient to avoid weed competition for a single treatment season.

The change in bulk density, infiltration rate, and subsoil penetration resistance (15 to 30 $\mathrm{cm}$ depth) was not found to be significantly different between control and treatment blocks, suggesting that treatment was not effective at improving these soil conditions. The results concerning the effect of radish on bulk density are comparable to research by Chen and Weil (2010), Weil and Kremen, (2007), and Williams and Weil (2004), all of whom found that single treatments of radish had no effect on bulk density. Conversely, the results of the present study concerning the effect of radish on infiltration rates are contrary to research by Weil and Kremen, 2007, Justes et al. (1999), Wilson et al. (1982), and Kemper and Derpsch (1981), all of whom 
report that planting cover crops significantly improved infiltration rates. One explanation as to why radish did not improve infiltration in the present study is that the radish tubers, as a result of lower than normal growth, did not penetrate into the more greatly compacted subsoil. This explanation is supported by Weil and Kremen (2007), in which the increase to infiltration rates were attributed to the large visible root channels developed as a result of large radish tuber growth. In the study, cameras deployed within the soil also provided evidence that the root channels penetrated the compaction zone (Weil \& Kremen, 2007). Modest root growth would also explain a lack of improvement to penetration resistance within the subsoil.

Overall, nutrient availability, with the exception of phosphorous, decreased on both treatment and control blocks. Considering that the plot was altered from its natural state (i.e., the grass was cut, litter removed, and branches trimmed), nutrient losses were likely the result of site disturbance (Vitousek et al., 1985; Vitousek et al., 1979). After liter and grass removal, losses can occur as a result of rapid mineralization followed by nutrient leaching (Vitousek et al., 1985; Vitousek et al., 1979). While statistical significance could not be confirmed, nutrient losses seemed to be less severe in treatment blocks. This was especially true in the case of phosphorous, the only nutrient which increased on both re-measured treatment points, while decreasing on both re-measured control blocks. Sulfur and calcium losses were also seemingly reduced in the treatment block. Considering that radishes are good nutrient scavengers, it is possible that their presence may have limited nutrient losses (Dabney et al., 2001; Justes et al., 1999). The descriptive statistics in this study support the findings reported in CCS (2012), which indicate that Tillage Radish ${ }^{\circledR}$ are good scavengers of phosphorous, sulfur, and calcium. However, the loss of nitrogen and potassium, which are also reported to be important nutrients in the growth of Tillage Radish®, were found to be similar on both the control block and treatment block. 
According to research by Constantin et al. (2010), Justes et al. (1999), Wyland et al. (1996), and Wilson et al. (1982), cover crops can actually significantly improve nutrient conditions the following season, but considering in these studies the cover crops were fertilized, only if sufficient nutrients exist within the site's soil. With the knowledge that soil disturbance under established trees could result in nutrient losses, which can ultimately harm tree growth, and with the knowledge that when fertilized, bio-drilling plants can improve soil nutrient conditions the following season, fertilization is likely the preferred management strategy when planting Tillage Radish ${ }^{\circledR}$ under established trees. Fertilization, in this case, will also reduce any chance of nutrient competition between the trees and Tillage Radish $®$. However, in the case where Tillage Radish ${ }^{\circledR}$ is being planted to prepare a soil bed for planting, as the soil is already being disturbed, planting radish may actually reduce nutrient losses and fertilization may not be a necessary management strategy.

A study by Williams and Weil (2004) provided evidence that when grown in soil, radish establish root channels that have important implications for plant growth. Plant roots following root treatment were able to utilize the root channels and experienced an increase in total yield. This finding suggests that there may be additional improvements to soil physical conditions that were not investigated in the present study (Weil \& Kremen, 2007). Therefore, improvements to future plant growth may be greater than expected.

A large body of research exists that indicate cover crops improve the physical, chemical, and biological properties of agricultural soil and that the improvements to the soil subsequently enhance plant growth (Constantin et al., 2010; Justes et al., 1999; Folorunso et al., 1992; Wilson et al. 1982). In addition, research by Sanchez et al. (2007) and Broughton (1977) provide evidence that planting cover crops can improve tree growth in compact soils. And research by 
Chen \& Weil (2010), Weil \& Kremen (2007), and Williams and Weil (2004), indicates that radish species are excellent at breaking up soil compaction. The present study confirms the research by Chen \& Weil (2010), Weil \& Kremen (2007), and Williams and Weil (2004) by demonstrating that radish are capable of significantly reducing penetration resistance when grown in moderately to highly compact soils. It also provides preliminary evidence that radish can remediate non-agricultural soils, suggesting that radish could be adopted for use in an urban environment.

Future research should focus on two vegetation enhancement strategies: (1) the ability of radish to improve and enhance growing conditions in unplanted areas, and as a second objective, the impact of treatment on the growth of newly planted seedlings; and, (2) the ability of radish to improve the growth of established trees rooted in compact soil. Both strategies should consider the cost-benefit of fertilization. Moreover, future studies should also consider alternative biodrilling and cover crop species or a combination of species. For example, leguminous plants are able to fix nitrogen into the soil, improving nutrient conditions without the addition of fertilizer (Broughton, 1977; Rosolem et al., 2002), while rye is known to have a very dense root system within the surface of the soil, possibly being able to reduce surface compaction to a greater degree, and when it bio-degrades, it provides a surface mulch (Williams and Weil, 2004; Rosolem et al., 2002). Using these plants alone or in combination with Tillage Radish® may provide different or additional effects.

If the future research finds bio-drilling plants to be effective in improving soil quality and enhancing tree growth in urban soils, bio-drilling plants could be adopted for use on a wide variety of urban environments that are commonly afflicted with compacted soils, including parks, private residential lots, brownfields, and construction sites (Doick et al., 2009; Gregory et 
al., 2006; Dickinson et al., 2005; Sinnett et al., 2006; Alberty et al., 1984). Management strategies would be similar; however, use on private land would require voluntarily adoption. A management strategy might involve removing grass and weeds from the soil, seeding the soil using a row planter, applying an appropriate amount of fertilizer, watering the site once, directly after planting, and leaving the bio-drilling plants to grow, die over winter, and biodegrade. If the approach was to be used to prepare a soil for planting, the trees would be planted in the spring following treatment.

Planting radish could be an effective alternative to conventional compaction remediating practices used in the urban environment. The low cost and versatility of bio-drilling plants would allow for wide-scale adoption. Currently, the dominant paradigm in urban forestry is to expand canopy coverage by planting large quantities of trees. Wide-scale adoption of bio-drilling plants could shift the focus to enhancing canopy cover through individual canopy growth. Considering the limited planting space within urban environments, and the high cost of tree planting, expanding individual tree canopy cover is a much more efficient use of space and resources.

\subsection{Conclusion}

The aim of this study was to assess the ability of Tillage Radish® to remediate soil compaction and improve soil quality under a zero nutrient input scenario, in non-agricultural soil, and under established trees. Results of the study indicated that planting Tillage Radish® in moderately to highly compact surface soils was able to improve penetration resistance by small degree, roughly $155 \mathrm{kPa}$. In contrast, planting Tillage Radish® in soils with low to moderate penetration resistance was not effective at reducing penetration resistance. As soils with low penetration resistance are often more easily compressed, it is likely that these soils were further compacted during plant bed preparation, seeding, and weeding, which thus countered the 
compaction reducing benefits of planting radish. Bulk density and infiltration rates were also not improved by treatment.

While the effectiveness of a Tillage Radish $®$ treatment to improve the growing medium was mixed, the modest improvements to compaction as well as improvements to other soil physical characteristics may have a positive effect on tree growth. Improvement to plant growth has been reported in other studies and is frequently attributed to the root channels established during the growth of radish, and the ability of radish to limit the leaching of soil nutrients.

Tillage Radish® growth was not found to be limited by soil compaction. Moreover, growth was found to be sufficient under the light restrictions imposed by moderate canopy coverage. These finding suggest that Tillage Radish ${ }^{\circledR}$ should be able to grow well in compacted, shaded conditions, which are common in urban environments. Tillage Radish $®$ growth was, however, found to be limited, at least, partially, by nutrient availability (potassium and nitrogen). Therefore, a zero nutrient input scenario may not be an ideal management strategy.

This study provided preliminary evidence that Tillage Radish $®$ is a suitable treatment method for remediating compact soils in an urban environment. Future studies are encouraged that focus on the ability of Tillage Radish ${ }^{\circledR}$ to prepare soil beds for tree planting and to improve tree growth, where specific consideration of the cost-benefit of radish fertilization is required. 


\subsection{References}

Aelion, C. M., Davis, H. T., McDermott, S., and Lawson, A. B. (2008). Metal concentrations in rural topsoil in South Carolina: Potential for human health impact. Science of the Total Environment, 40: 149-156.

Aerts, R., and Chapin III, F. S. (2000). The mineral nutrition of wild plants revisited: Reevaluation of processes and patterns. In A. H. Fitter, \& D. G. Raffaelli (Eds.), Advance in Ecological Research (Volume 30). London, U.K.: Academic Press.

Akbari, H. (2002). Shade trees reduce building energy use and CO2 emissions from power plants. Environmental Pollution, 116: 119-126.

Alberty, C. A., Pellett, H. M., and Taylor, D. H. (1984). Characterization of soil compaction at construction sites and woody plant response. Journal of Environmental Horticulture, 2: $48-53$.

Askegaard, M., Olesen, J. E., Rasmussen, I. A., and Kristensen, K. (2011). Nitrate leaching from organic arable crop rotations is mostly determined by autumn field management. Agriculture, Ecosystems and Environment, 142: 149-160.

Bassett, I. E., Simcock, R. C., and Mictchell, N. D. (2005). Consequences of soil compaction for seedling establishment: Implications for natural regeneration and restoration. Austral Ecology, 30: 827-833.

Bengough A. G., and Mullins C. E. (1990). Mechanical impedance to root growth: a review of experimental techniques and root growth responses. European Journal of Soil Science, 41:341-358.

Bishop, J. C., and Grimes, D. W. (1978). Precision tillage effects on potato root and tuber production. American Potato Journal, 55: 65-71.

Bolund, P., and Hunhammar, S. (1999). Ecosystem services in urban areas. Ecological Economics, 29: 293-301.

Broughton, W. J. (1977). Effect of various covers on soil fertility under Hevea brasiliensis Muell. Arg. and on the growth of the tree. Agro-Ecosystems, 3: 147-170.

Canada Department of Agriculture. (1963). Soil survey of Wellington County Ontario: Report No 35 of the Ontario soil survey. Ottawa, ON: U.S. Government Printing Office.

Chaplot, V., Darboux, F., Bourennane, H., Leguedois, S., Silvera, N., \& Phachomphon, K. 
(2006). Accuracy of interpolation techniques for the derivation of digital elevation models in relation to landform types and data density. Geomorphology, 77: 126-141.

Chen, G., and Weil, R. R. (2010). Penetration of cover crop roots through compacted soils. Plant and Soil, 331: 31-43.

Cheng, J., Shi, Z., Zhu, Y. (2007). Assessment and mapping of environmental quality in agricultural soils of Zhejiang Province, China. Journal of Environmental Sciences, 19: $50-54$.

City of Toronto (2013). Every Tree Counts. Retrieved from http://www.toronto.ca/trees/ every_tree_counts.htm.

Clark, J. R., Matheny, N. P., Cross, J., and Wake, V. (1997). A model of urban forest sustainability. Journal of Arboriculture, 23: 17-30.

Cochran, W. G. (1946). Relative accuracy of systematic and stratified random samples for a certain class of populations. The Annals of Mathematical Statistics, 17: 164-177.

Constantin, J., Mary, B., Laurent, F., Aubrion, G., Fontaine, A., Kerveillant, P., and Beaudoin, N. (2010). Effects of catch crops, no till and reduced nitrogen fertilization on nitrogen leaching and balance in three long-term experiments. Agriculture, Ecosystems and Environment, 135: 268 -278.

Cover Crop Solutions (CCS). (2012). Tillage radish resource guide: the cover crop that pays. Retrieved from http://www.tillageradish.com/documents/tillage-radish-resourceguide.pdf.

Craul, P. J. (1999). Urban soils: Applications and practices. New York, NY :John Wiley and Sons.

Craul, P. J. (1992). Urban soil in landscape design. New York, NY :John Wiley and Sons.

Craul, P. J. (1985). A description of urban soils and their desired characteristics. Journal of Arboriculture, 11.

Dabney, S., Delgado, J. and D. Reeves. (2001). Using winter cover crops to improve soil and water quality. Communications in Soil Science and Plant Analysis, 32: 1221-1250.

Day, S. D. and Bassuk, N. (1994). A Review of the effects of soil compaction and amelioration treatments on landscape trees. Journal of Arboriculture, 20: 9-17.

Day, S. D., Bassuk, N. L., and van Es, H. (1995). Effects of four compaction remediation 
methods for landscape trees on soil aeration, mechanical impedance, ands tree establishment. Journal of Environmental Horticulture, 13: 641-671.

Day, S. D., Wiseman, P. E., Dickinson, S. B., and Harris, R. J. (2010). Tree root ecology in the urban environment and implications for a sustainable rhizosphere. Arboriculture and Urban Forestry, 35: 193-205.

Dexter, A. R. (1991). Amelioration of soil by natural processes. Soil and Tillage Research, 20: $87-100$.

Dickinson, M. N., Hartley, W., Uffindell, L. A., Plumb, A. N., Rawlinson, H., and Putwain, P. (2005). Robust descriptors of soil health for use in reclamation of brownfield land. Land Contamination and Reclamation, 13: 317-326.

Doick, K. J., Sellers, G., Castan-Broto, V., and Silverthorne, T. (2009). Urban forestry \& Urban Greening, 8: 163-178.

Dwyer, J.F., McPherson, E.G., Schroeder, H.W., and Rowntree, R.A. (1992). Assessing the benefits and costs of the urban forest. Journal of Arboriculture, 18: 227-234.

Dwyer, J.F., Nowak, D.J., and Noble, M.H. (2003). Sustaining urban forests. Journal of Arboriculture, 29: 49-55.

Environment Canada. (2014). Guelph arboretorium, Ontario Canada yearly/monthly/daily/climate information: Guelph arboretum average monthly temperature, precipitation, snowfall \& weather extremes. Retrieved from http://www.eldoradocountyweather.com/canada/climate2/ Guelph\%20Arboretum.html

Environment Canada. (2012). Canada's top ten weather stories from 2012. Retrieved from http://ec.gc.ca/meteo-weather/default.asp?lang=En\&n=B7D225D0-1

ESRI (Environmental Systems Resource Institute). (2013). ArcMap 10.2. Redlands, California: ESRI.

Fitzpatrick, R. W., McKenzie, N., and Maschmedt, D. J. (1999). Soil morphological indicators and their importance to soil fertility. In K. I. Pervill, L. A. Sparrow, \& D. L. Reuter. (Eds.), Soil Analysis: An Interpretation Manual (55-68). Collingwood, VIC: CSIRO Publishing.

Folorunso, O. A., Rolston, D. E., Prichard, P. T., and Louie, D. T. (1992). Cover crops lower soil surface strength, may improve soil permeability. California Agriculture, 46: 26-27.

Foshee, W. G., Goff, W. D., Patterson, M. G., and Ball, D. M. (1995). Orchard floor crops 
reduce growth of young pecan trees. Horticultural Science, 30: 979-980.

Franzen, D. W. 2011. Collecting and analyzing soil spatial information using krigging and inverse distance weighted. In D. E. Clay \& J. F. Shanahan (Eds.), GIS applications in agriculture: Nutrient management for energy efficiency (2nd ed.) (61-79). Boca Raton, FL: CRC Press.

Gardner, B., Suvllivan, P., \& Lembo, A. J. (2003). Predicting stream temperatures: geostatistical model comparison using alternative distance metrics. Canadian Journal of Fish Aquatics Science, 344-351.

Gomez, A., Powers, R. F., Singer, M. J., and Horwath, W. R. (2002). Soil compaction on growth of young Ponderosa Pine following litter removal in California's Sierra Nevada. Soil Science Society of America Journal, 66: 1334-1343.

Gomez, J., Guzman, M., Giraldez, and J., Fereres, E. (2009). The influence of cover crops and tillage on water and sediment yield, and on nutrient, and organic matter losses in an olive orchard on a sandy loam soil. Soil \& Tillage Research, 106: 137-144.

Greer, K. J., and Schoenau, J. J. (1994). Salinity and salt contamination assessment using anion exchange resin membranes. In Soils and Crops Workshop Proc., p.44-48. University of Saskatchewan.

Greer, K. J., Sulewski, C., and Hangs, R. (2003). Applying PRS ${ }^{\mathrm{TM}}$ technology for nutrient management. Western Nutrient Management Conference, Salt Lake City, UT. 5: 170175.

Gregory, J. H., Dukes, M. D., Jone, P. H., and Miller, G. L. (2006). Effect of urban soil compaction on infiltration rate. Journal of Soil and Water Conservation, 61: 117-123.

Gregory, J. H., Dukes, M. D., Miller, G. L., and Jone, P. H., (2005). Analysis of double ring infiltration techniques and development of a simple automatic water delivery system. Applied Turfgrass Science, doi:10.1094/ATS-2005-0531-01-MG.

Gotway, C. A., Ferguson, R. B., Hergert, G. W., and Peterson, T. A. (1996). Comparison of Kriging and Inverse-Distance methods for mapping soil parameters. Soil Science Society of America Journal, 60: 1237-1247.

Hamza, M. and Anderson, W. (2005). Soil compaction in cropping systems: A review of the nature, causes and possible solutions. Soil and Tillage Research, 82: 121-145.

Hangs, R., Greer, K., Sulewski, C., and Hicks, D. (2002). Plant Root Simulator-probes: An 
effective alternative for routine soil testing. Soils and Crops Workshop Proc., p.44-48. University of Saskatchewan.

Hartwig, N. L., and Ammon, H. U. (2002). Cover crops and living mulches. Weed Science, 50: 688-699.

Hill, A.C. (1971). Vegetation: a sink for atmospheric pollutants. Journal of the Air Pollution Control Association, 21: 341-346.

Hooker, P. J., and Nathanail, C. P. (2006). Risk-based characterisation of lead in urban soils. Chemical Geology, 226:340-351.

Hummel, R. L., and Johnson, C. R. (1985). Amended back-fills: Their cost and effect on transplant growth and survival. Journal of Environmental Horticulture, 3: 76-79.

James, E. B., and Barber, G. M. (1996). Elementary statistics for geographers ( $2^{\text {nd }}$ ed). New York: The Guliford Press.

Jim, C. Y. (2008). Opportunities and alternatives for enhancing urban forests in compact cities and developing countries. Carreiro, M. M., Song, Y. C., and Wu, J., Ecology, planning, and management of urban forests: international perspectives (118-467). Springer: New York.

Jim, C. Y. (1998). Urban soil characteristics and limitations for landscape planting in Hong Kong. Landscape and Urban Planting, 40: 235-249.

Johnston, K., Ver Hoet, J. M., Krivouchko, K., \& Lucas, N. (2001). Using ArcGIS Geostatistical Analyst. California: ESRI.

Johnson, J. F., Voorhees, W. B., Randall, G. W. (1987). Effect of recompaction on penetrometer resistance on a soil loosened by subsoil tillage. Agronomy Journal, 79: 24.

Justes, E., Mary, B., and Nicolardot, B. (1999). Comparing the effectiveness of radish cover crop, oilseed rape volunteers, and oilseed rape residues incorporation for reducing nitrate leaching. Nutrient Cycling in Agroecosytems, 55: 207-220.

Kemper, B., and Derpsch, R. (1981). Results of studies made in 1978 and 1979 to control erosion by cover crops and no-tillage techniques in Parana, Brazil. Soil \& Tillage Research, 1: 253-267.

Kettler, T., Doran, J., and Gilbert, T. (2001). Simplified method for soil particle-size determination to accompany soil-quality analyses. Soil Science Society of America Journal, 65: 849-852. 
Khakestar, M. S., Madani, H., Hassani, H., and Moarefvan, P. (2013). Determining the best search neighborhood in reserve estimation, using geostatistical method: A case study anomaly No 12A iron deposit in central Iran. Journal Geological Society of India, 81: $581-585$.

Kozlowski, T. (1999). Soil compaction and growth of woody plants. Scandinavian Journal of Forest Research, 14: 596-619.

Kravchenko, A., and Bullock, D. (1999). A comparative study of interpolation methods for mapping soil properties. Agronomy, 91: 393-400.

Kravchenko, A. N., and Bullock, D. G. (2000). Correlation of corn and soybean grain yield with topography and soil properties. Agronomy, 92: 75-83.

Krivoruchko, L. (2005). Introduction to modeling spatial data process using Geostatistical Analyst. Retlands: Environmental Systems Research Institute.

Laporte, M. F., Duchesne, L. C., and Wetzel, S. (2002). Effect of rainfall petterns on soil surface $\mathrm{CO}_{2}$ efflux, soil moisture, soil temperature and plant growth in a grassland ecosystem of northern Ontario, Canada: Implications for climate change. BMC Ecology, 2: 10-16.

Leech, N. L., Barrett, K. C., and Morgan, G. A. (2008). SPSS for intermediate statistics: Use and interpretation $\left(3^{\text {rd }}\right.$ ed). New York, London: Lawrence Erlbaum Associates.

Liang J., and Schoenau, J. J (1995). Development of resin membranes as a sensitive indicator of heavy metal toxicity in the soil environment. International Journal of Environmental Analytical Chemistry, 59: 265-275.

Mainstone, B. J. (1969). Residual effects of ground cover and nitrogen fertilisation of Hevea prior to tapping. Journal of the Rubber Research Institute of Malaysia, 21: 113-125.

Malik, M. S., Norsworthy, J. K., Culpepper, A. S., Riley, M. B., and Bridges, W Jr. (2008). Use of wild radish (Raphanus raphanistrum) and rye cover crops for weed suppression in sweet corn. Weed Science, 56: 588-595.

Materechera, S. A., Alston, A. M., Kirby, J. M., and Dexter, A. R. (1992). Influence of root diameter on the penetration of seminal roots into a compacted subsoil. Plant and Soil, 144: 297-303.

Millward, A., Paudel, K., and Briggs, S. (2011). Naturalization as a strategy for improving soil physical characteristics in a forested urban park. Urban Ecosystems, 14: 261-278.

Millward, A.A., and Sabir, S. (2010). Structure of a forested urban park: Implications for 
strategic management. Journal of Environmental Management, 91: 2215-2224.

Mitas, L., \& Mitasova, H. (1999). Spatial Interpolation. In L. Mitas, \& H. Mitasova, Geographical Information Systems: Principles (pp. 481-492).

Mokany, K., Raison, R. J, and Prokushkin, A. S. (2006). Critical analysis of root: shoot ratios in terrestrial biomes. Global Change Biology, 12: 84-96.

Motavalli, P. P., Stevens, W. E., and Hartwig, G. (2003). Remediation of subsoil and compaction effects on corn $\mathrm{N}$ availability by deep tillage and application of poultry manure in a sandy-textured soil. Soil and Tillage Research, 71: 121-131.

Mulholland, B. J., and Fullen, M. A. (1991). Cattle trampling and soil compaction on loamy sands. Soil Use and Management, 7: 189-193.

Nambiar, E. K. S., and Sands, R. (1992). Effects of compaction and simulated root channels in the subsoil on root development, water uptake and growth of radiate pine. Tree Physiology, 10: 297-306.

Nevill, A. M., and Holder, R. L. (1995). Scaling, normalizing, and per ratio standards: An allometric modelling approach. Journal of Applied Physiology, 79: 1027-1031.

Nowak, D. J., and Dwyer, J. F. (2007). Understanding the benefits and costs of urban forest ecosystems. In J. E. Kuser (Eds.), Urban and Community Forestry in the Northeast (2 $2^{\text {nd }}$ $E d)(25-13)$. New York, NY: Springer.

Nowak, D. J., Crane, D. E., and Stevens, J. C. (2006). Air pollution removal by trees and shrubs in the United States. Urban Forestry \& Urban Greening, 4: 115-123.

Ouyang, Y., Higman, J., Campbell, D., Davis, J. (2003). Three-dimensional kriging analysis of sediment mercury distribution: a case study. J Am Water Resour Assoc, 39:689-702

Owen, S. V., and Froman, R. D. (1998). Focus on qualitative methods: Uses and abuses of the analysis of covariance. Research in Nursing \& Health, 21: 557-562.

Pan, E., and Bassuk, N. (1985). Effect of soil type and compaction on the growth of Ailanthus altissima seedlings. Journal of Environmental Horticulture, 3: 158-162.

Patterson, J. C. (1977). Soil compaction: Effects on urban vegetation. Journal of Arboriculture, 3: $161-167$.

Piper, J. K. (1989). Distribution of dry mass between shoot and root in nine understory species. American Midland Naturalist, 122: 114-119.

Qian, P., and Schoenau, J. J. (1995). Assessing nitrogen mineralization from soil organic matter 
using anion exchange membranes. Fertilizer Research, 40:143-148.

Qian, P., and Schoenau, J. J. (2002). Practical applications of ion exchange resins in agriculture and environmental soil research. Canadian Journal of Soil Science, 82: 9-21.

Qian, P., and Schoenau, J. J., Greer, K. J., and Liu, Z. (1996). Assesing plant-available potassium in soil using cation exchange membrane burial. Canadian Journal of Soil Science, 76: 191-194.

Radford, B. J., Yule, D. F., McGarry, D., and Playford, C. (2001). Crop responses to applied soil compaction and to compaction repair treatments. Soil and Tillage Research, 61: 157-166.

Ramos, M. E., Benitez, E., Garcia, P. A., Robles, A. B. (2010). Cover crop under different managements vs. frequent tillage in almond orchards in semiarid conditions: Effects on soil quality. Applied Soil Ecology, 44: 6-14.

Ravindranath, N. H., and Ostwald, M. (2007). Carbon inventory methods: Handbook for greenhouse gas inventory, carbon mitigation and roundwood production projects. Springer.

Rivenshield, A., and Bassuk, N. L. (2007). Using organic amendments to decrease bulk density and increase macroporosity in compacted soils. Arboriculture and Urban Foresty, 33: 140-146.

Robinson, T., and Metternicht, G. (2006). Testing the performance of spatial interpolation techniques for mapping soil properties. Computer and Electronics in Agriculture, 50: 97 108.

Rolf, K. (1994). A review of preventative and loosening measures to alleviate soil compaction in tree planting areas. Arboricultural Journal, 18: 431-448.

Rosenzweig, C., Solecki, W.D., and Slosberg, R. (2006). Mitigating New York City's heat island with urban forestry, living roofs, and light surfaces. A report to the New York State Energy Research and Development Authority, Retrieved September 20, 2012 from - http//www.fs.fed.us/ccrc/topics/urban-forests/docs/NYSERDA_heat_island.pdf .

Rosolem, C., Foloni, J., and Tiritan, C. (2002). Root growth and nutrient accumulation in cover crops as affected by soil compaction. Soil and Tillage Research, 65: 109-115.

Sanchez, E. E., Giayetto, A., Cichon, L., Fernandez, D., Aruani, M. C., and Curetti, M. (2007). Cover crops influence soil properties and tree performance in an apple (Malus domestica Borkh) orchard in northern Patagonia. Plant and Soil, 292: 193-203. 
Sands, R., Greacen, E. L and Gerard, C. J. (1979). Compaction of sandy soils in radiata pine forests. I A penetrometer study. Australia Journal of soil Research, 17: 101-113.

Sarrantonio, M., and Gallandt, E. (2014). The role of cover crops in North American cropping systems. Journal of Crop Production, 8: 53-74.

Schefler, W. C. (1979). Statistics for the biological sciences ( $2^{\text {nd }}$ ed). Menlo Park, CA: AddisonWesley Publishing Company.

Schmitt, J., Ehrhardt, D. W., and Cheo, M. (1986). Light-dependant dominance and supression in experimental radish populations. Ecology, 67: 1502-1507.

Seeley, S. (1990). Hormonal transduction of environmental stresses. Horticultural Science, 25 : 1369-1376.

Sheskin, D. J. (2004). Handbook of parametric and nonparametric statistical procedures ( $3^{\text {rd }}$ ed). Boca Raton, Florida: Chapman \& Hall/CRC.

Sinnett, D., Poole, J., and Hutchings, T. R. (2006). The efficacy of three techniques to alleviate soil compaction at a restored sand and gravel quarry. Soil Use and Management, 22: 362371.

Smiley, E.T., Watson, G. W., Fraedrich, B. R., and Booth, D. C. (1990). Evaluation of soil aeration equipment. Journal of Arboriculture, 16: 118-123.

Snapp, S. S., Swinton, S. M., Labarta, R., Mutch, D., Black, J. R., Leep, R., Nyiraneza, J., and O’neil, K. (2005). Evaluating cover crops for benefits, costs, and performance within cropping system niches. Agronomy Journal, 97: 322-332.

SPSS-IBM Corp. (2012). IBM SPSS Statistics 21.0 for windows, Version 21.0. Armonk, NY: IBM Corp.

Soane, B. D. (1990). The role of organic matter in soil compatibility: A review of some practical aspects. Soil and Tillage Research, 16: 179-201.

Soil Science Society of America, (1996). Glossary of Soil Science Terms. Madison, WI: Soil Science Society of America Inc.

Szmigielska, A. M., Schoenau, J. J., and Greer, K. J. (1998). Comparison of chemical extraction and bioassay for measurement of metsulfuron in soil. Weed Science, 46: 487-493.

Taylor, H. M., and Burnett, E. (1964). Influence of soil strength on the root-growth habits of plants. Soil Science, 98: 174-180.

Tejowulan, R. S., Schoenau, J. J., and Bettany, J. R. (1994). Use of ion exchange resins in soil 
and plant testing for micronutrient availability. In Soils and Crops Workshop Proc., p.255267. University of Saskatchewan.

Tessier, J. T., and Raynal, D. J. (2003). Use of nitrogen to phosphorous ratios in plant tissue as an indicator of nutrient limitation and nitrogen saturation. Journal of Applied Ecology, 40: 523-534.

The Weather Network. (2014). Farmzone: Guelph - Wellington South, Ontario. Retrieved from http://www.farmzone.com/statistics/summary/c16142402/so029 .

Toleti, B. (2008). Urban forest soil characteristics: a geostatistical analysis of Allan Gardens Park, Toronto,Canada. Master of Spatial Analysis Thesis. Department of Geography, Ryerson University, Toronto, ON.

United States Department of Agriculture. (2004). Soil survey laboratory methods manual. Rep. No. 42. Ver. 4.0. Lincoln, NE: Natural Resources Conservation Service.

van Brekelen, G. J. P (2006). ANCOVA versus change from baseline has more power in randomized studies and more bias in nonrandomized studies. Journal of Clinical Epidemiology, 59: 920-925.

van Bohemen, H. (2011). Chapter 2: (Eco)system thinking: Ecological principles for building roads, buildings and industrial and urban areas. In E. van Bueren, H. van Bohemen, L. Itard, \& H. Visscher (Eds.), Sustainable urban environments: An ecosystem approach (14-70). Dordrecht, Heidelberg, London, New York: Springer.

van Bueren, E. (2011). Chapter 1: Introduction. In E. van Bueren, H. van Bohemen, L. Itard, and H. Visscher (Eds.), Sustainable urban environments: An ecosystem approach (1-13). Dordrecht, Heidelberg, London, New York: Springer.

Vaz, C. M. P., Bassoi, L. H., and Hopmans, J. W. (2001). Contribution of water content and bulk density to field soil penetration resistance as measured by a combined cone penetrometer -TDR probe. Soil \& Tillage Research, 60: 35-42.

Verhoeven, J. T. A, Koerselman, W., and Meuleman, A. F. M. (1996). Nitrogen- or phosphorous-limited growth in herbaceous, wet vegetation: relations with atmospheric input and management regimes. Trends in Ecology and Evolution, 11: 494-497.

Vitousek, P. M, Gosz, J. R., Grier, C. C., Melillo, J. M., Reiners, W. A., and Todd, R. L. (1979). Nitrate losses from disturbed ecosystems. Science, 204: 469-474.

Vitousek, P. M., Pickett, S. T. A., and White, P. S. (1985). Community turnover and ecosystem 
nutrient dynamics. Retrieved from http://www.citeulike.org/group/10326/article/4422384

Voltz, M., \& Webster, R. (1990). A Comparison of kriging, cubic splines and classification for predicting soil properties from sample information. Journal of Soil Science, 41: 473-490.

Waller, L. A., Gotway, C. A. (2004). Applied spatial statistics for public health data. New York: Wiley- Interscience.

Watson, G. W., and Kelsey, P. (2006). The impact of soil compaction on soil aeration and fine root density of Quercus palustris. Urban Forestry and Greening. 4: 69-74.

Weber, D. D., and Englund, E. J. (1994). Evaluation and comparison of spatial interpolators, II: Math. Geology, 26: 589-603

Weil, R., and Kremen, A. (2007). Thinking across and beyond disciplines to make cover crops pay. Journal of the Science of Food and Agriculture, 87: 551-557.

Western Ag Innovations Inc. (2014). PRS Technology. Retrieved from http://www.westernag.ca/innovations/technology/basics

White, R. E. (2006). Principles and practice of soil science. Malden, MA :Blackwell Publishing.

Williams, S. M. W., and Weil, R. R. (2004). Crop cover root channels may alleviate soil compaction effects on soybean crop. Soil Science Society of America Journal, 68: 1403.

Willmott, C. J., and Matsuura, K. (2005). Advantages of the mean absolute error (MAE) over the root mean square error (RMSE) in assessing average model performance. Climate Research, 20: 79-82.

Wilson, G. F., Lal, R., and Okigbo, B. N. (1982). Effects of cover crops on soil structure and on yield of subsequent arable crops grown under strip tillage on an eroded alfisol. Soil \& Tillage Research, 2: 233-250.

Wright, S. J., Yavitt, J. B., Wurzburger, N., Turner, B. L., Tanner, V. J., Sayer, E. J., Santiago, L. S., Kaspari, M., Hedin, L. O., Harms, K. E., Garcia, M. N., and Corre, M. D. (2011). Potassium, phosphorous, or nitrogen limit root allocation, tree growth, or litter production in a lowland tropical forest. Ecology, 92: 1616-1625.

Wyland, L. J., Jackson, L. E., Chaney, W. E., Klonsky, K., Koike, S. T., and Kimple, B. (1996). Winter cover crops in a vegetable cropping system: Impacts on nitrate leaching, soil water, crop yield, pests and management costs. Agriculture, Ecosystems and Environment, 59: 1-17.

Zimmerman, D., Pavlik, C., Ruggles, A., and Armstrong, M. P. (1999). An experimental 
comparison of Ordinary Kriging and Inverse Distance Weighting. Mathematical Geology, 31: 375-390. 


\section{Chapter 4}

\subsection{Limitations}

There were two main limitations to this study: 1) while radish germination was excellent, the total growth was more modest than expected; and, 2) an equipment failure resulted in the inability to collect ancillary data that included meteorological and continuous soil moisture.

Tillage Radish® tubers can grow up to $76 \mathrm{~cm}$ (CCS, 2012). In this study, tubers ranged from $8 \mathrm{~cm}$ to $26 \mathrm{~cm}$, with a mean of $15 \mathrm{~cm}$. While roots were only extracted from the extraction plot, the allometric models developed enable the inference of root growth based on shoot growth. When considering the allometric models, the radish shoot lengths measured throughout the plot indicate that growth measurements in the extraction plot were representative of the whole plot. Modest radish growth may be a result of nutrient limitations or a drier than average growing season. As the size of Tillage Radish ${ }^{\circledR}$ plants is related to the total benefits imparted to the soil, increased radish growth is expected to provide greater improvements to soil quality (Williams \& Weil, 2004; Rosolem et al., 2002). Thus, modest radish growth may have resulted in smaller improvements to soil quality.

A second limitation that resulted from only modest Tillage Radish ${ }$ growth was the added cost of weeding. Weeding increases the cost of manual labour and can cause additional disturbance to the soil. Radish, as a genus, is usually very good at supressing weed growth (Malik et al., 2008). However, in the present study, as a result of only modest radish growth, weeds and grasses competed with radish for both space and light availability. To avoid these additional costs, it may be necessary to completely remove all grass and weeds prior to planting radish. However, fertilization may be an alternative option. But only if early fertilization can 
quickly establish larger radish plants that can out-compete grass and weeds for light and nutrients.

Another limitation was the lack of ancillary data. While this data was being collected, equipment malfunction caused the data to be lost. The data lost included ambient temperature, accumulated precipitation, relative humidity, soil moisture. These data, especially soil moisture, would have been useful to compare seasonal differences in the soil conditions. However, this data loss was not detrimental to the overall study objectives as the seasonal differences in soil properties could be controlled for by comparing the control group and treatment group with ANCOVA.

\subsection{Future Research}

Based on a growing body of research concerning the ability for cover crops to remediate degraded soil in agricultural conditions, including the findings of the present study, there is evidence to suggest that bio-drilling plants could be used successfully to remediate compaction in urban soils. However, there remains necessary research to be completed before an implementation strategy can be successfully developed. Several gaps in the knowledgebase exist that include evaluating: 1) the cost-benefit of varying levels of nutrient input necessary for radish growth; 2) the ability of bio-drilling plants to enhance urban tree growth through soil remediation; 3) the effect of multiple treatment years; and 4) the effect of other species of biodrilling plants, or the effect of a combination of species. It is also necessary that future studies with bio-drilling plants take place under established tree canopies and on land that is to be prepared for tree planting. 
While the present study determined that Tillage Radish® can remediate compaction, to some extent, in unfertilized soil, a subsequent study could investigate whether tree growth is enhanced over time as a result of soil improvements.

At a second plot, a similar bio-drilling plant study is already underway at Ignatius Jesuit Centre in Guelph, Ontario. The second study is investigating the ability of fertilized Tillage Radish® to remediate soil compaction and improve soil quality on unplanted land. In addition to investigating soil quality, this study will also determine the effect of Radish treatment on tree growth. Further investigations could also consider the effects of different management strategies on soil characteristics, including a) long term treatments, 2) fall versus spring treatments, and 3) the combined application of different bio-drilling species.

\subsection{Management Applications}

The end goal of the present and future research on the use of biodrilling plants in urban areas is to develop a management strategy that can improve tree growth by ameliorating degraded soil conditions. Should future research on bio-drilling plants find them to be useful and cost effective, a strategy could be devised by city planners for use on public lands, or by individuals and organizations, for use on private lands. The presence of compacted urban soil can be identified by incorporating soil testing into urban forestry planning, especially in areas that are to be planted or in areas where tree growth is currently compromised.

An approach to remediate compaction on public lands may be more easily adopted as municipalities can develop policies and management strategies to ensure standardization. For example, where such degraded soil exists on public land, the area could be fenced off and, by utilizing inexpensive row planters, seeded with bio-drilling plants. Radish treatment could be applied over a single season or over multiple years. 
While adopting a bio-drilling remediation approach may be simpler on public lands, it is also applicable on private land. Private land, which contains soils that are often compacted include, but are not limited to, residential areas, tree plantations, (Ramos et al., 2010; Sanchez et al., 2007; Broughton, 1977), construction sites (Gregory et al., 2006; Alberty et al., 1984), and brown fields (Doick et al., 2009; Dickinson et al., 2005; Sinnett et al., 2006).

Residential private land contains a large portion of urban trees and plantable spaces. Residential land owners could choose to plant bio-drilling plants in areas with high soil compaction. However, in order to persuade residential land owners to adopt the use of biodrilling plants, municipalities will have to take on the role of educators and may have to provide additional incentives. A strategy similar to that suggested for public land could be used.

Trees plantations can be easily compacted during the clearing or harvesting of trees (Sanchez et al., 1987). Ultimately, compaction can lead to a loss of production of wood and fruit. If bio-drilling plants are determined to be useful and practical at improving soil conditions for urban tree growth, they could also be considered for application as a management strategy in tree plantations and orchards (Sanchez et al., 2007). Two management strategies are possible. One strategy is to plant bio-drilling plants under established trees to improve the growing medium by ameliorating soil compaction, an approach explored by Broughton et al. (1977). A second strategy would be to plant bio-drilling plants following land clearance, alleviating some of the soil compaction that was incurred from the heavy machinery.

Construction often causes soil compaction due to heavy vehicle traffic. This can lead to poor vegetation establishment in yards, and decreased infiltration, which, during heavy rainfall events, can put greater pressure on storm water systems (Gregory et al., 2006; Alberty et al., 1984). According to Alberty et al. (1984), "Use of a backhoe or subsoiler have proven successful 
in modifying compacted soils prior to establishing woody plants, but there needs to be additional research into more effective and economical methods for reducing soil compaction." Currently, prevention by use of zoning is the preferred strategy. In this strategy, vegetation sites are identified and access restricted. However, inadvertent compaction still occurs as a result of foot traffic (Randrup \& Dralle, 1997). Planting bio-drilling plants could be adopted, rather inexpensively, by the construction industry to reverse inadvertent soil compaction. A strategy could involve laying down top soil, followed by planting bio-drilling plants. Once the biodrilling plants biodegrade, the soil would be ready for laying down sod and planting more permanent vegetation.

Brownfields are often heavily compacted, making it difficult to re-establish vegetation (Doick et al., 2009; Sinnett et al., 2006; Dickinson et al., 2005). Complete cultivation, a soil replacement method, is currently the best management strategy for remediating compaction in these areas. However, this method is expensive, and as a result, other less effective methods are often used (Sinnett et al., 2006). Sinnett et al. (2006) suggests that prevention should be a focus. While prevention is always ideal, bio-drilling plants could be an inexpensive alternative to mechanical soil remediation methods.

Planting bio-drilling plants is an inexpensive and versatile compaction remediation strategy. Results from this study and future studies will be important in the development and adoption of the remediation strategies discussed. 


\subsection{References}

Alberty, C. A., Pellett, H. M., and Taylor, D. H. (1984). Characterization of soil compaction at construction sites and woody plant response. Journal of Environmental Horticulture, 2: $48-53$.

Broughton, W. J. (1977). Effect of various covers on soil fertility under Hevea brasiliensis Muell. Arg.and on the growth of the tree. Agro-Ecosystems, 3: 147-170.

Cover Crop Solutions. (2012). Tillage radish resource guide: the cover crop that pays. Retrieved from http://www.tillageradish.com/documents/tillage-radish-resource-guide.pdf.

Dickinson, M. N., Hartley, W., Uffindell, L. A., Plumb, A. N., Rawlinson, H., and Putwain, P. (2005). Robust descriptors of soil health for use in reclamation of brownfield land. Land Contamination and Reclamation, 13: 317-326.

Doick, K. J., Sellers, G., Castan-Broto, V., and Silverthorne, T. (2009). Urban forestry \& Urban Greening, 8: 163-178.

Gregory, J. H., Dukes, M. D., Jone, P. H., and Miller, G. L. (2006). Effect of urban soil compaction on infiltration rate. Journal of Soil and Water Conservation, 61: 117-123.

Malik, M. S., Norsworthy, J. K., Culpepper, A. S., Riley, M. B., and Bridges, W Jr. (2008). Use of wild radish (Raphanus raphanistrum) and rye cover crops for weed suppression in sweet corn. Weed Science, 56: 588-595.

Ramos, M. E., Benitez, E., Garcia, P. A., Robles, A. B. (2010). Cover crop under different managements vs. frequent tillage in almond orchards in semiarid conditions: Effects on soil quality. Applied Soil Ecology, 44: 6-14.

Randrup, T. B., and Dralle, K. (1997). Influence of planning and design on soil compaction in construction sites. Landscape and Urban Planning, 38: 87-92.

Rosolem, C., Foloni, J., and Tiritan, C. (2002). Root growth and nutrient accumulation in cover crops as affected by soil compaction. Soil and Tillage Research, 65: 109-115.

Sanchez, E. E., Giayetto, A., Cichon, L., Fernandez, D., Aruani, M. C., and Curetti, M. (2007). Cover crops influence soil properties and tree performance in an apple (Malus domestica Borkh) orchard in northern Patagonia. Plant and Soil, 292: 193-203.

Sanchez, P. A. (1987). Chapter 13: Soil productivity and sustainability in agroforestry systems. In E. H. A. Steppler, \& P. K. R. Nair (Eds.), Agroforestry: a decade of development (205-227). Caroline Agola, Nairobi: Printfast Kenya Limited. 
Sinnett, D., Poole, J., and Hutchings, T. R. (2006). The efficacy of three techniques to alleviate soil compaction at a restored sand and gravel quarry. Soil Use and Management, 22: 362371.

Williams, S. M. W., and Weil, R. R. (2004). Crop cover root channels may alleviate soil compaction effects on soybean crop. Soil Science Society of America Journal, 68: 1403. 


\section{Appendices}

\section{Appendix A: Descriptive statistics of block data for year 1 and year 2}

A.1.i: Descriptive statistics of the soil penetration resistance (PR), infiltration rate (IR), bulk density ( $\left.\mathrm{D}_{\mathrm{b}}\right)$, texture, and pH for each block in year 1. Soil data were collected in May 2012 and 2013 at Ignatius Jesuits Centre, Guelph, Ontario.

\begin{tabular}{|c|c|c|c|c|c|c|c|c|c|c|c|c|}
\hline \multirow[b]{2}{*}{ Blocks } & \multicolumn{2}{|c|}{$\mathrm{PR}_{1}(\mathrm{kPa})$} & \multicolumn{2}{|c|}{$\mathrm{PR}_{2}(\mathrm{kPa})$} & \multicolumn{2}{|c|}{$\mathrm{PR}_{3}(\mathrm{kPa})$} & \multicolumn{2}{|c|}{$\mathrm{D}_{\mathrm{b}}\left(\mathrm{Mg} / \mathrm{m}^{3}\right)$} & \multicolumn{2}{|c|}{$\mathrm{IR}(\mathrm{mm} / \mathrm{hr})$} & \multicolumn{2}{|c|}{$\mathrm{pH}$} \\
\hline & M & $\mathrm{SD}$ & $\mathrm{M}$ & SD & $\mathrm{M}$ & SD & M & SD & M & $\mathrm{SD}$ & $\mathrm{M}$ & SD \\
\hline 1 & 816 & 387 & 2316 & 729 & 2595 & 650 & 1.14 & 0.02 & 742 & 931 & 7.37 & 0.06 \\
\hline 2 & 633 & 214 & 1633 & 638 & 2144 & 713 & 1.17 & 0.12 & 30 & 17 & 7.50 & 0.11 \\
\hline 3 & 574 & 205 & 1568 & 751 & 2214 & 964 & 1.23 & 0.12 & 541 & 132 & 7.41 & 0.15 \\
\hline 4 & 619 & 125 & 1781 & 719 & 2307 & 534 & 1.06 & 0.11 & 418 & 106 & 7.23 & 0.09 \\
\hline 5 & 669 & 281 & 1224 & 270 & 1892 & 655 & 1.11 & 0.01 & 435 & 64 & 7.36 & 0.07 \\
\hline 6 & 804 & 323 & 1808 & 647 & 2817 & 666 & 1.19 & 0.04 & 165 & 148 & 7.47 & 0.18 \\
\hline 7 & 1622 & 558 & 2444 & 902 & 2332 & 530 & 1.41 & 0.02 & 185 & 163 & 7.39 & 0.18 \\
\hline 8 & 1713 & 495 & 2193 & 556 & 2275 & 799 & 1.41 & 0.10 & 35 & 15 & 7.42 & 0.14 \\
\hline 9 & 1559 & 513 & 2343 & 982 & 2449 & 876 & 1.44 & 0.04 & 32 & 2 & 7.28 & 0.34 \\
\hline 10 & 1959 & 920 & 2800 & 1430 & 3020 & 1152 & 1.39 & 0.09 & 14 & 2 & 7.10 & 0.02 \\
\hline 11 & 1587 & 521 & 2164 & 724 & 2273 & 903 & 1.38 & 0.06 & 57 & 37 & 6.99 & 0.08 \\
\hline 12 & 1904 & 848 & 2989 & 1246 & 2528 & 800 & 1.43 & 0.01 & 38 & 32 & 7.20 & 0.13 \\
\hline
\end{tabular}

A.1.ii: Descriptive statistics of the soil penetration resistance (PR), infiltration rate (IR), bulk density $\left(\mathrm{D}_{\mathrm{b}}\right)$, texture, and pH for each block in year 2. Soil data were collected in May 2012 and 2013 at Ignatius Jesuits Centre, Guelph, Ontario.

\begin{tabular}{lrrrrrrrrrr}
\hline & \multicolumn{2}{c}{$\mathrm{PR}_{1}(\mathrm{kPa})$} & \multicolumn{2}{c}{$\mathrm{PR}_{2}(\mathrm{kPa})$} & \multicolumn{2}{c}{$\mathrm{PR}_{3}(\mathrm{kPa})$} & \multicolumn{2}{c}{$\mathrm{D}_{\mathrm{b}}(\mathrm{Mg} / \mathrm{m} 3)$} & \multicolumn{2}{r}{$\mathrm{IR}(\mathrm{mm} / \mathrm{hr})$} \\
Blocks & $\mathrm{M}$ & $\mathrm{SD}$ & $\mathrm{M}$ & $\mathrm{SD}$ & $\mathrm{M}$ & $\mathrm{SD}$ & $\mathrm{M}$ & $\mathrm{SD}$ & $\mathrm{M}$ & $\mathrm{SD}$ \\
\hline 1 & 760 & 96 & 1482 & 363 & 1741 & 633 & 1.08 & 0.03 & 465.00 & 106.07 \\
2 & 818 & 121 & 1365 & 247 & 1595 & 222 & 1.08 & 0.11 & 85.50 & 86.97 \\
3 & 777 & 254 & 1383 & 298 & 1646 & 379 & 1.11 & 0.12 & 180.00 & 59.40 \\
4 & 795 & 199 & 1264 & 364 & 1530 & 387 & 1.16 & 0.06 & 73.50 & 14.85 \\
5 & 678 & 141 & 1315 & 330 & 1625 & 377 & 1.12 & 0.02 & 168.50 & 140.71 \\
6 & 744 & 172 & 1301 & 303 & 1647 & 272 & 1.22 & 0.08 & NA & NA \\
7 & 1284 & 322 & 1776 & 310 & 1479 & 292 & 1.39 & 0.08 & 157.50 & 116.67 \\
8 & 1018 & 206 & 1824 & 259 & 1529 & 217 & 1.43 & 0.08 & 54.00 & 16.97 \\
9 & 1097 & 296 & 1697 & 319 & 1594 & 384 & 1.52 & 0.06 & 184.50 & 10.61 \\
10 & 1250 & 292 & 1831 & 348 & 1563 & 345 & 1.37 & 0.01 & 7.50 & 2.12 \\
11 & 1072 & 182 & 1562 & 300 & 1436 & 380 & 1.38 & 0.02 & 24.75 & 11.67 \\
12 & 823 & 321 & 1396 & 307 & 1388 & 378 & NA & NA & NA & NA \\
\hline \hline
\end{tabular}


A.2: Descriptive statistics of available macronutrients $\left(\mathrm{ug} / 10 \mathrm{~cm}^{2} / 42\right.$ days) for each block in year 1 . Soil data were collected in May 2012 and 2013 at Ignatius Jesuits Centre, Guelph, Ontario.

\begin{tabular}{lrrrrrrrrrrrrrrrrrrr}
\hline & \multicolumn{1}{c}{} & \multicolumn{1}{c}{$\mathrm{NO}_{3}$} & \multicolumn{1}{c}{$\mathrm{NH}^{4}$} & \multicolumn{1}{c}{$\mathrm{Ca}$} & \multicolumn{4}{c}{$\mathrm{Mg}$} & \multicolumn{4}{c}{$\mathrm{K}$} & \multicolumn{4}{c}{$\mathrm{P}$} & \multicolumn{4}{c}{ Shoot } \\
Block & $\mathrm{M}$ & $\mathrm{SD}$ & $\mathrm{M}$ & $\mathrm{SD}$ & $\mathrm{M}$ & $\mathrm{SD}$ & $\mathrm{M}$ & $\mathrm{SD}$ & $\mathrm{M}$ & $\mathrm{SD}$ & $\mathrm{M}$ & $\mathrm{SD}$ & $\mathrm{M}$ & $\mathrm{SD}$ & $\mathrm{M}$ & $\mathrm{SD}$ \\
\hline 1 & 62.4 & 39.8 & 1.4 & 0.1 & 2977 & 138 & 553 & 24 & 39.0 & 1.8 & 1.1 & 0.0 & 104 & 29 & 95 & 13 \\
2 & 33.7 & 24.2 & 6.0 & 2.0 & 2827 & 51 & 595 & 7 & 38.7 & 5.2 & 1.0 & 0.3 & 92 & 0 & 82 & 18 \\
3 & 165.1 & 110.8 & 3.6 & 1.5 & 2661 & 103 & 507 & 92 & 27.9 & 1.1 & 1.7 & 0.3 & 165 & 80 & NA & NA \\
4 & 75.5 & 90.0 & 6.5 & 2.2 & 2690 & 193 & 526 & 35 & 41.1 & 6.8 & 1.2 & 0.4 & 81 & 14 & 135 & 32 \\
5 & 69.3 & 65.1 & 8.2 & 8.9 & 2843 & 151 & 592 & 27 & 34.7 & 0.1 & 1.3 & 0.5 & 112 & 31 & NA & NA \\
6 & 66.4 & 83.9 & 8.1 & 4.1 & 2655 & 51 & 538 & 2 & 45.2 & 13.2 & 1.6 & 0.1 & 128 & 44 & NA & NA \\
7 & 13.1 & 6.9 & 1.2 & 1.1 & 2962 & 25 & 319 & 40 & 41.4 & 11.4 & 1.2 & 0.2 & 130 & 12 & NA & NA \\
8 & 9.8 & 2.7 & 3.5 & 2.0 & 2916 & 125 & 498 & 109 & 43.9 & 4.7 & 7.4 & 7.9 & 123 & 27 & 95 & 25 \\
9 & 13.3 & 1.0 & 2.8 & 1.0 & 2926 & 327 & 582 & 23 & 52.2 & 24.0 & 2.0 & 0.3 & 123 & 39 & NA & NA \\
10 & 14.3 & 3.2 & 2.1 & 0.2 & 2517 & 43 & 535 & 43 & 76.8 & 10.0 & 1.2 & 0.0 & 89 & 5 & NA & NA \\
11 & 10.8 & 1.9 & 1.9 & 0.6 & 2632 & 140 & 539 & 53 & 40.1 & 7.5 & 1.0 & 0.5 & 109 & 11 & 88 & 25 \\
12 & 14.7 & 10.0 & 4.7 & 4.1 & 2857 & 203 & 608 & 25 & 49.7 & 11.8 & 1.7 & 0.4 & 107 & 15 & 126 & 62 \\
\hline \hline
\end{tabular}




\section{Appendix B: Cross Validation Results of the Interpolated Surfaces}

B.1: Cross validation results for the interpolated surfaces describing penetration resistance $(\mathrm{kPa})$. Surfaces were calculated using the ordinary kriging technique from data that were collected in May 2012 and 2013 at Ignatius Jesuit Centre, Guelph, Ontario.

\begin{tabular}{llllrrrr}
\hline Year & Depth & Trend Removal & Model & MAE & RMSE & MSE & RMSS \\
\hline 1 & 1 & 2nd Order & Spherical & -0.010 & 1.338 & -0.007 & 1.020 \\
& 2 & None (Anisotropy) & Spherical & -0.003 & 1.507 & 0.000 & 0.985 \\
& 3 & None (Anisotropy) & Gaussian & -0.014 & 1.592 & -0.008 & 0.984 \\
2 & 1 & 1st Order & Spherical & -0.007 & 1.371 & -0.007 & 1.004 \\
& 2 & 2nd Order & Exponential & -0.003 & 1.096 & -0.004 & 1.014 \\
& 3 & 2nd Order & Spherical & 0.003 & 1.245 & 0.001 & 1.044 \\
\hline \hline
\end{tabular}

B.2: Cross validation results for the interpolated surfaces describing macronutrient availability $\left(\mathrm{ug} / 10 \mathrm{~cm}^{2} / 42\right.$ days), infiltration rates $(\mathrm{mm} / \mathrm{hr})$, bulk density $\left(\mathrm{Mg} / \mathrm{m}^{3}\right)$, and $\mathrm{pH}$. Surfaces were calculated using the Inverse Distance Weighted technique from data that were collected in May 2012 and 2013 at Ignatius Jesuit Centre, Guelph, Ontario.

\begin{tabular}{lclrrrrr}
\hline Surface & Power & Shape & $\begin{array}{r}\text { Major } \\
\text { axis }\end{array}$ & $\begin{array}{r}\text { Anisotropic } \\
\text { Factor }\end{array}$ & $\begin{array}{r}\text { Angis } \\
\text { Ang }\end{array}$ & MAE & RMSE \\
\hline IR Year 1 & 1 & 4 Sector (45 Offset) & 5.44 & 1.50 & 236 & -24.07 & 314.48 \\
IR Year 2 & 4 & 4 Sector & 4.57 & 1.20 & 232 & -7.89 & 83.16 \\
Db Year 1 & 1 & 1 Sector & 5.28 & 1.40 & 95 & 0.01 & 0.09 \\
Db Year 2 & 2 & 4 Sector & 5.28 & 2.44 & 95 & 0.00 & 0.08 \\
$\mathrm{pH}$ & 1 & 1 Sector & 5.34 & 4.49 & 108 & -0.02 & 0.17 \\
Total N & 1 & 4 Sector & 4.82 & 1.79 & 88 & -4.74 & 41.21 \\
$\mathrm{NO}_{3}$ & 1 & 4 Sector & 4.82 & 1.88 & 275 & -4.32 & 42.42 \\
$\mathrm{NH}^{4}$ & 1 & 4 Sector (45 Offset) & 4.82 & 1.13 & 105 & -0.01 & 3.56 \\
$\mathrm{Ca}$ & 1 & 1 Sector & 4.82 & 1.21 & 75 & 0.91 & 172.17 \\
$\mathrm{~K}$ & 1 & 1 Sector & 4.82 & 1.00 & 0 & -0.65 & 13.11 \\
$\mathrm{P}$ & 1 & 4 Sector & 4.82 & 1.00 & 0 & 0.09 & 2.59 \\
$\mathrm{~S}$ & 4 & 4 Sector & 4.82 & 3.74 & 75 & -3.78 & 33.33 \\
$\mathrm{Mg}$ & 2 & 1 Sector & 4.82 & 1.81 & 106 & -2.22 & 55.45 \\
\hline \hline
\end{tabular}




\section{Appendix C: Allometric Model Output}

C.1: Multiple regression analysis summary for the allometric growth models expressed by equations 2 and 3. Model 1 predicts radish root biomass $(\mathrm{mg})$ from radish shoot length $(\mathrm{mm})$. Model two predicts averaged radish root biomass $(\mathrm{mg})$ from averaged radish shoot length $(\mathrm{mm})$. Data were collected in October 2012 at Ignatius Jesuits Centre, Guelph, Ontario.

\begin{tabular}{lrrrrr}
\hline Allometric Model & $\mathrm{B}$ & $\mathrm{SE}$ & $\beta$ & $\mathrm{R}^{2}$ & $\Delta \mathrm{R}^{2}$ \\
\hline Model 1 & & & & 0.784 & 0.783 \\
$\quad$ (Constant) & 0.560 & 0.07 & $* *$ & & \\
$\quad$ Shoot Length (mm) & 0.015 & 0.00 & $0.87^{*}$ & & 0.916 \\
$\quad$ Model 2 & & & & 0.919 & \\
$\quad$ (Constant) & 0.407 & 0.12 & $* *$ & & \\
$\quad$ Average Shoot Length $(\mathrm{mm})$ & 0.019 & 0.00 & $0.96^{* *}$ & & \\
\hline \hline
\end{tabular}

Note: Model $1 \mathrm{~F}(1,136)=494.15, \mathrm{p}<0.001$

Model $2 \mathrm{~F}(1,23)=261.34, \mathrm{P}<0.001$

$* \mathrm{p}<0.05 ; * \mathrm{p}<0.01$

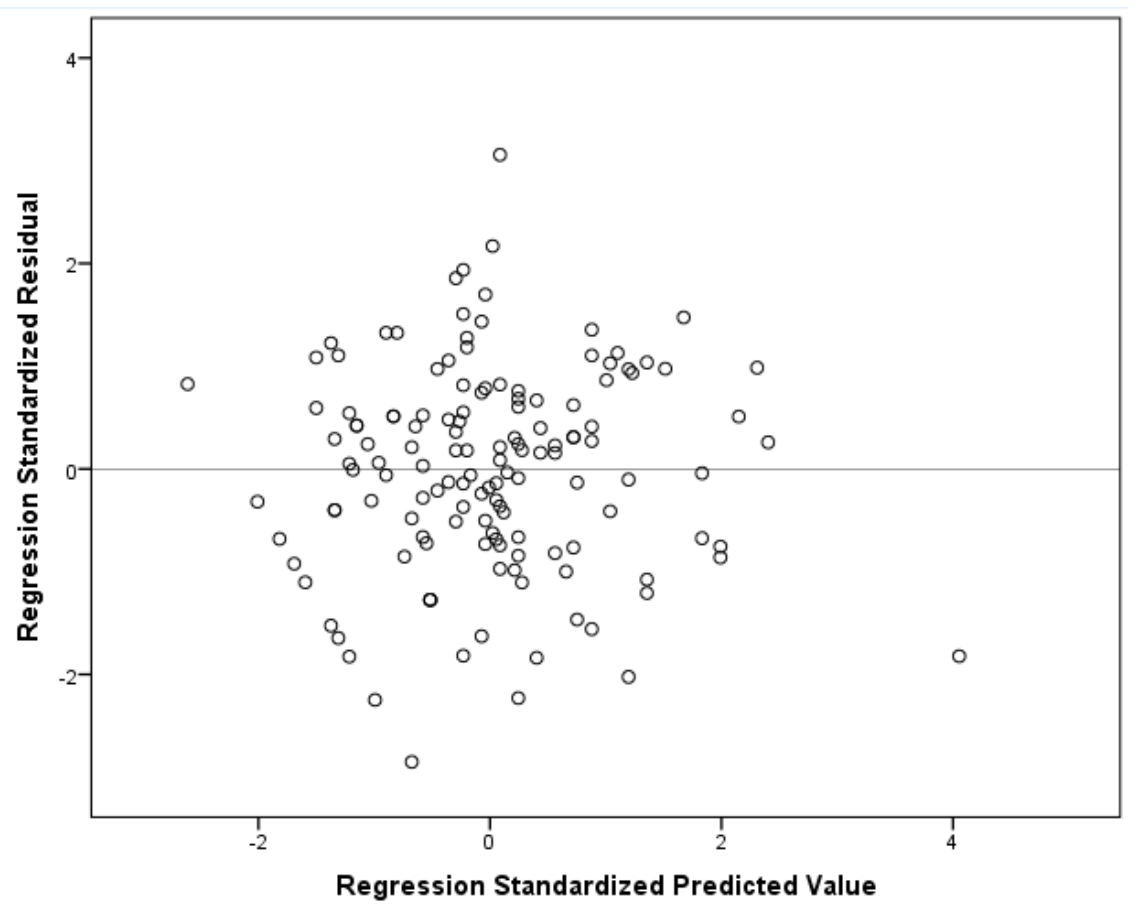

C.2.i: Scatter plot and regression line comparing the $\mathrm{z}$ scores of the residual errors versus the $\mathrm{z}$ scores of the predicted values for equation 2. Soil data was collected in May 2012 and Tillage $\operatorname{Radish} \circledast$ data were collected in October 2012, at Ignatius Jesuits Centre, Guelph, Ontario. 


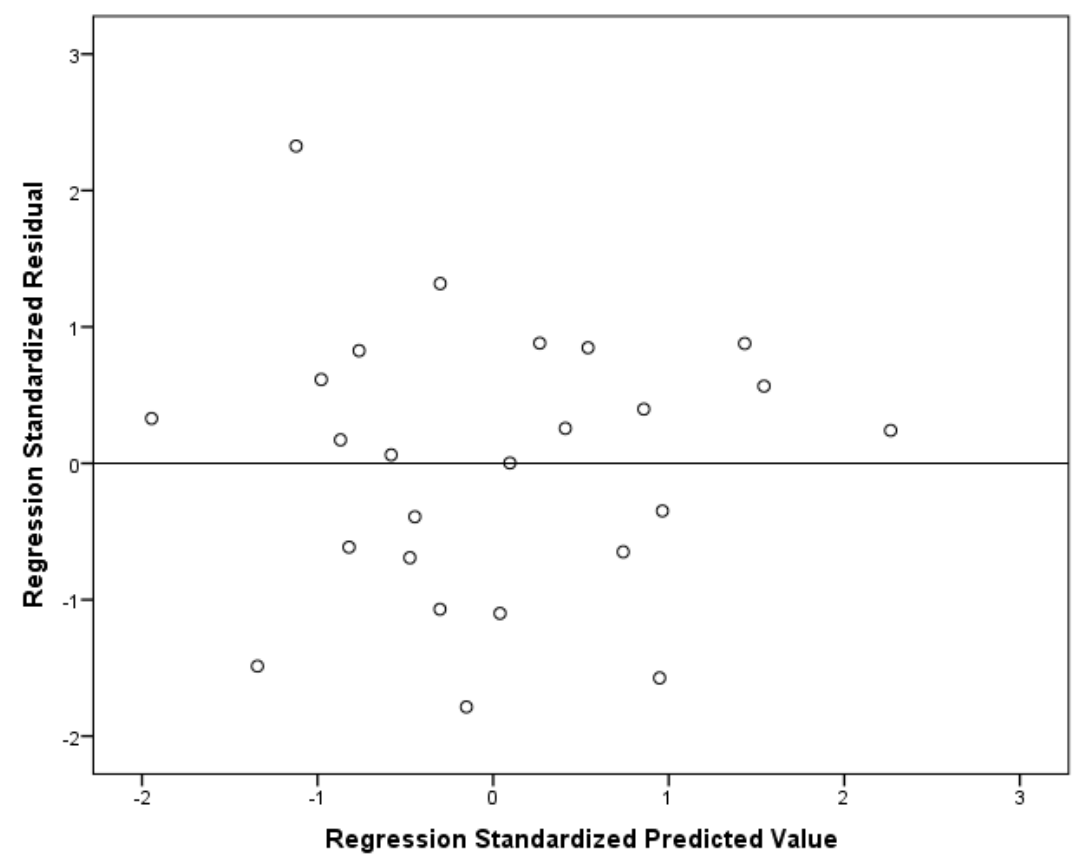

C.1.ii: Scatter plot and regression line comparing the $\mathrm{z}$ scores of the residual errors versus the $\mathrm{z}$ scores of the predicted values for equation3. Soil data was collected in May 2012 and Tillage Radish ${ }^{\circledR}$ data were collected in October 2012, at Ignatius Jesuits Centre, Guelph, Ontario.

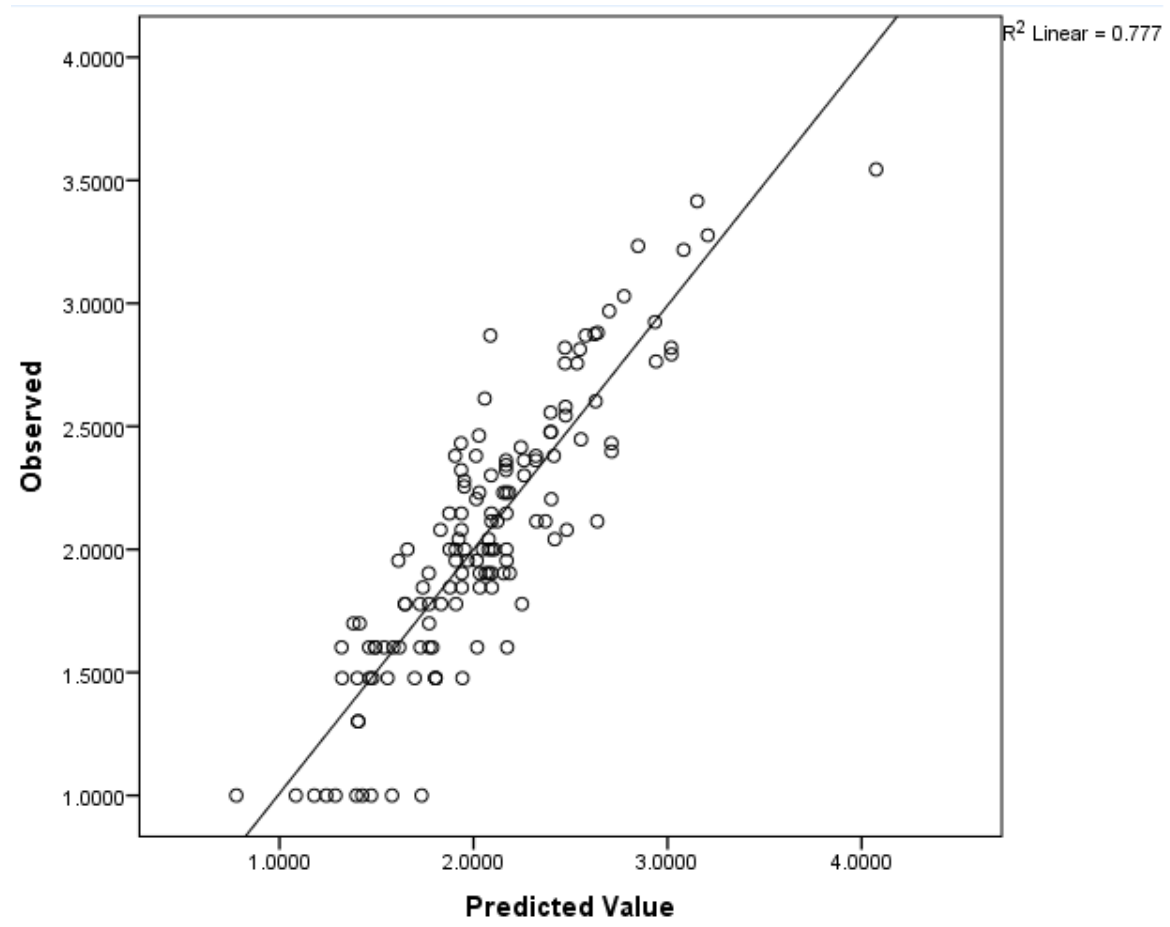

C.3.i: Scatter plot and regression line comparing the observed values versus the predicted values of equation 2. Soil data was collected in May 2012 and Tillage Radish ${ }^{\circledR}$ data were collected in October 2012, at Ignatius Jesuits Centre, Guelph, Ontario. 


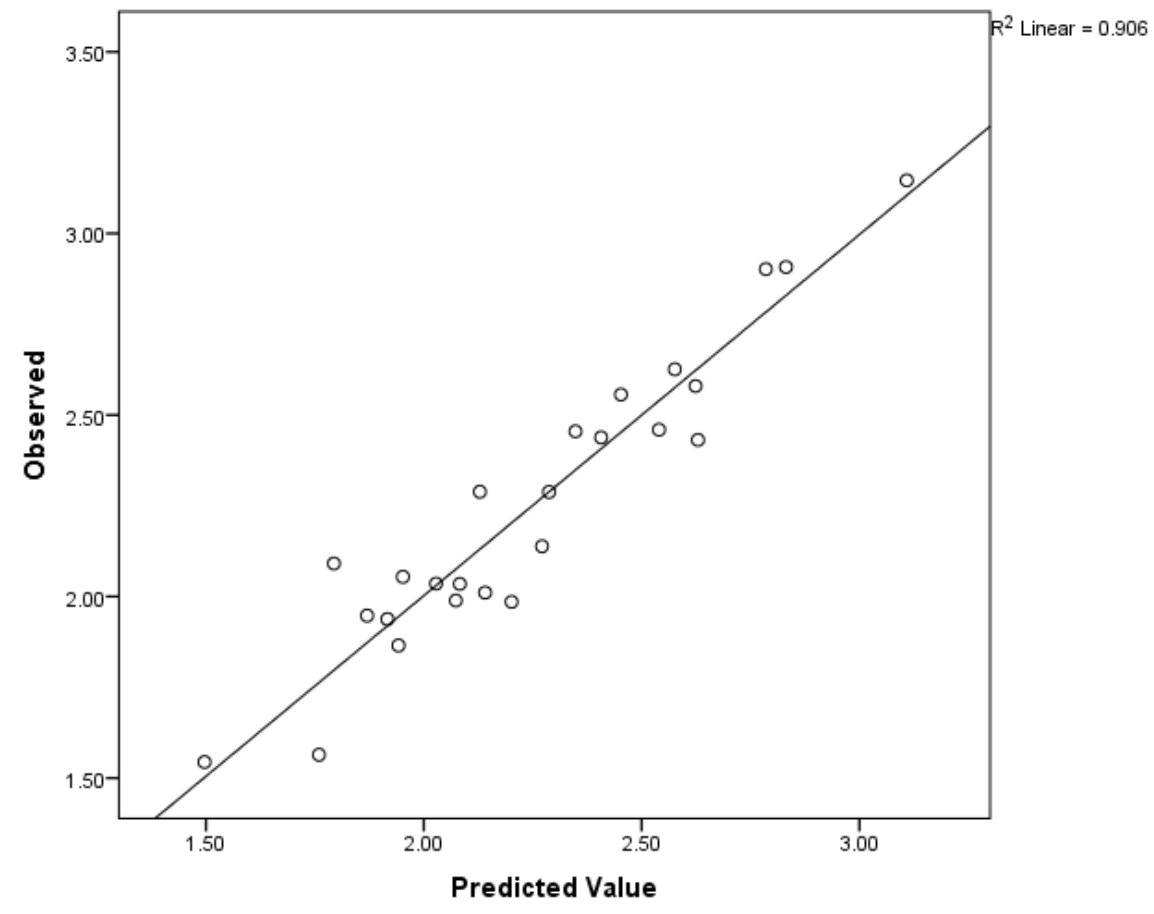

C.3.ii: Scatter plot and regression line comparing the observed values versus the predicted values of equation 3. Soil data was collected in May 2012 and Tillage Radish ${ }^{\circledR}$ data were collected in October 2012, at Ignatius Jesuits Centre, Guelph, Ontario. 


\section{Appendix D: Growth Response Model Output}

D.1.i: Multiple regression analysis summary for the Tillage Radish® root growth response model (equation 1), which predicts radish root biomass $(\mathrm{mg})$ from soil penetration resistance $(\mathrm{kPa})$ at a depth of $22.5 \mathrm{~cm}$. Soil data was collected in May 2012 and Tillage Radish ${ }^{\circledR}$ data were collected in October 2012, at Ignatius Jesuits Centre, Guelph, Ontario.

\begin{tabular}{|c|c|c|c|c|c|}
\hline Growth Response Model & B & SE & $\beta$ & $\mathrm{R}^{2}$ & $\Delta \mathrm{R}^{2}$ \\
\hline Model 1 & & & & 0.216 & 0.182 \\
\hline (Constant) & 1.387 & 0.35 & $* *$ & & \\
\hline$P R 22.5$ & 0.001 & 0.00 & $4.64 *$ & & \\
\hline
\end{tabular}

Note: $\mathrm{F}(1,23)=6.33, \mathrm{p}=0.019$

$* \mathrm{p}<0.05 ; * * \mathrm{p}<0.01$.

D.1.ii: Multiple regression analysis summary for the Tillage Radish® shoot growth response models (Equations 4, 5 and 6). Model 4 predicts radish shoot length $(\mathrm{mm})$ over the whole plot from $\mathrm{K}$ and $\mathrm{NO}_{3}(\mu \mathrm{g} / 10$ $\mathrm{cm}^{2} / 42$ days). Model 5 predicts radish shoot length $(\mathrm{mm})$ on the northwestern portion of the plot from $\mathrm{NO}_{3}, \mathrm{~K}$, and $\mathrm{NH}_{4}\left(\mu \mathrm{g} / 10 \mathrm{~cm}^{2} / 42\right.$ days $)$. Model 6 predicts radish shoot length $(\mathrm{mm})$ on the southeastern portion of the plot from $\mathrm{NO}_{3}\left(\mu \mathrm{g} / 10 \mathrm{~cm}^{2} / 42\right.$ days). Soil data was collected in May 2012 and Tillage Radish ${ }^{\circ}$ data were collected in October 2012, at Ignatius Jesuits Centre, Guelph, Ontario.

\begin{tabular}{|c|c|c|c|c|c|}
\hline Growth Response Model & $\mathrm{B}$ & SE & $\beta$ & $\mathrm{R}^{2}$ & $\Delta \mathrm{R}^{2}$ \\
\hline Model 1 & & & & 0.246 & 0.219 \\
\hline $\log 10(K)$ & 1.542 & 0.43 & $0.36 * *$ & & \\
\hline $\log 10\left(\mathrm{NO}_{3}\right)$ & 0.181 & 0.05 & $0.49 * *$ & & \\
\hline (Constant) & -0.783 & 0.74 & & & \\
\hline Model 2 & & & & 0.718 & 0.684 \\
\hline (Constant) & -1.982 & 0.71 & $*$ & & \\
\hline $\mathrm{NO}_{3}$ & 0.002 & 0.00 & $0.56 * *$ & & \\
\hline $\log 1.2(K)$ & 0.195 & 0.04 & $0.69 * *$ & & \\
\hline $\mathrm{NH}_{4}$ & -0.028 & 0.01 & $-0.39 *$ & & \\
\hline \multicolumn{6}{|l|}{ Model 3} \\
\hline (Constant) & 1.762 & 0.87 & $* *$ & 0.202 & 0.174 \\
\hline$\left(\mathrm{NO}_{3}\right)$ & 0.015 & 0.01 & $0.450 *$ & & \\
\hline
\end{tabular}

Note: Model $1 \mathrm{~F}(2,56)=9.145, \mathrm{p}<0.001$

Model $2 \mathrm{~F}(3,25)=21.20, \mathrm{p}<0.001$

Model $3 \mathrm{~F}(1,28)=7.091, \mathrm{p}<0.013$

$* \mathrm{p}<0.05 ; * *_{\mathrm{p}}<0.01$. 


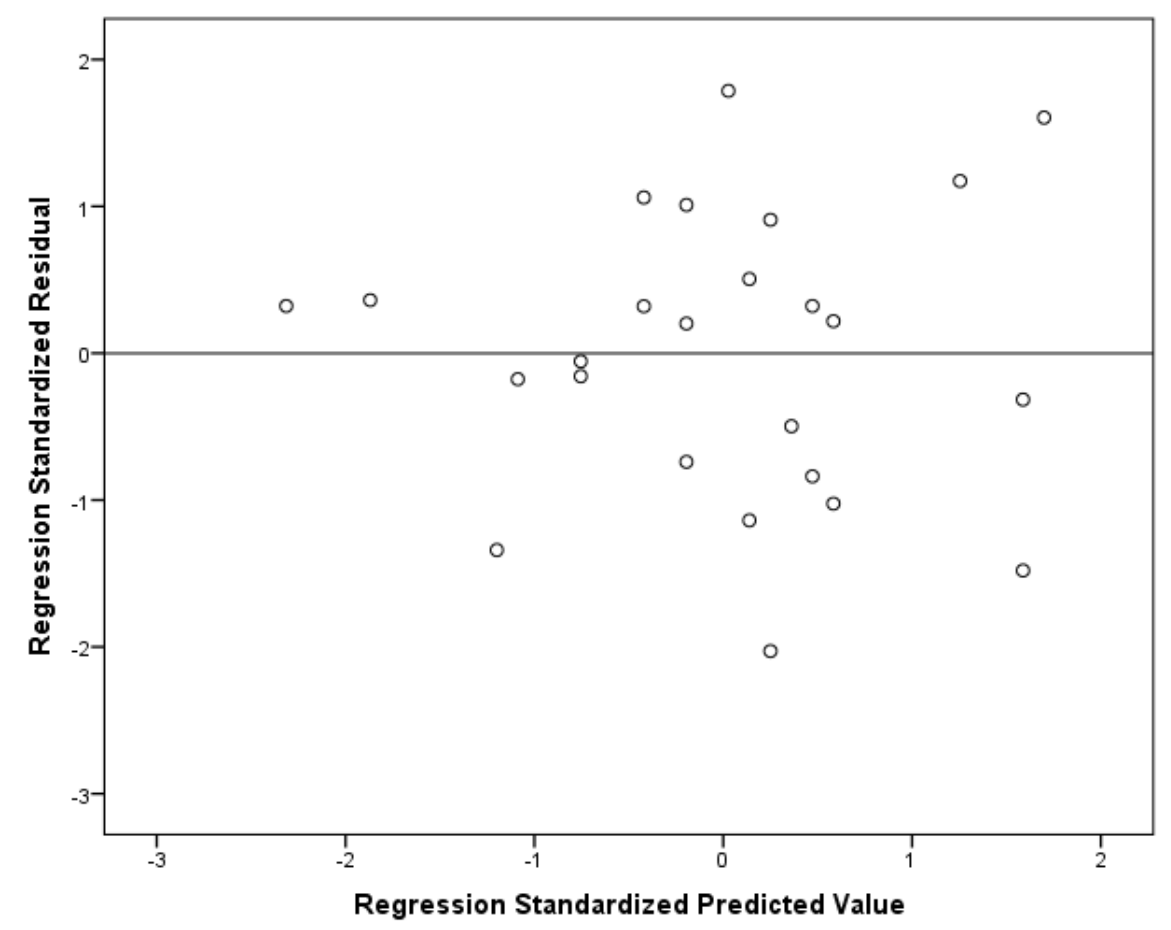

D.2.i: Scatter plot and regression line comparing the $\mathrm{z}$ scores of the residual errors versus the $\mathrm{z}$ scores of the predicted values for equation 1. Soil data was collected in May 2012 and Tillage Radish $®$ data were collected in October 2012, at Ignatius Jesuits Centre, Guelph, Ontario.

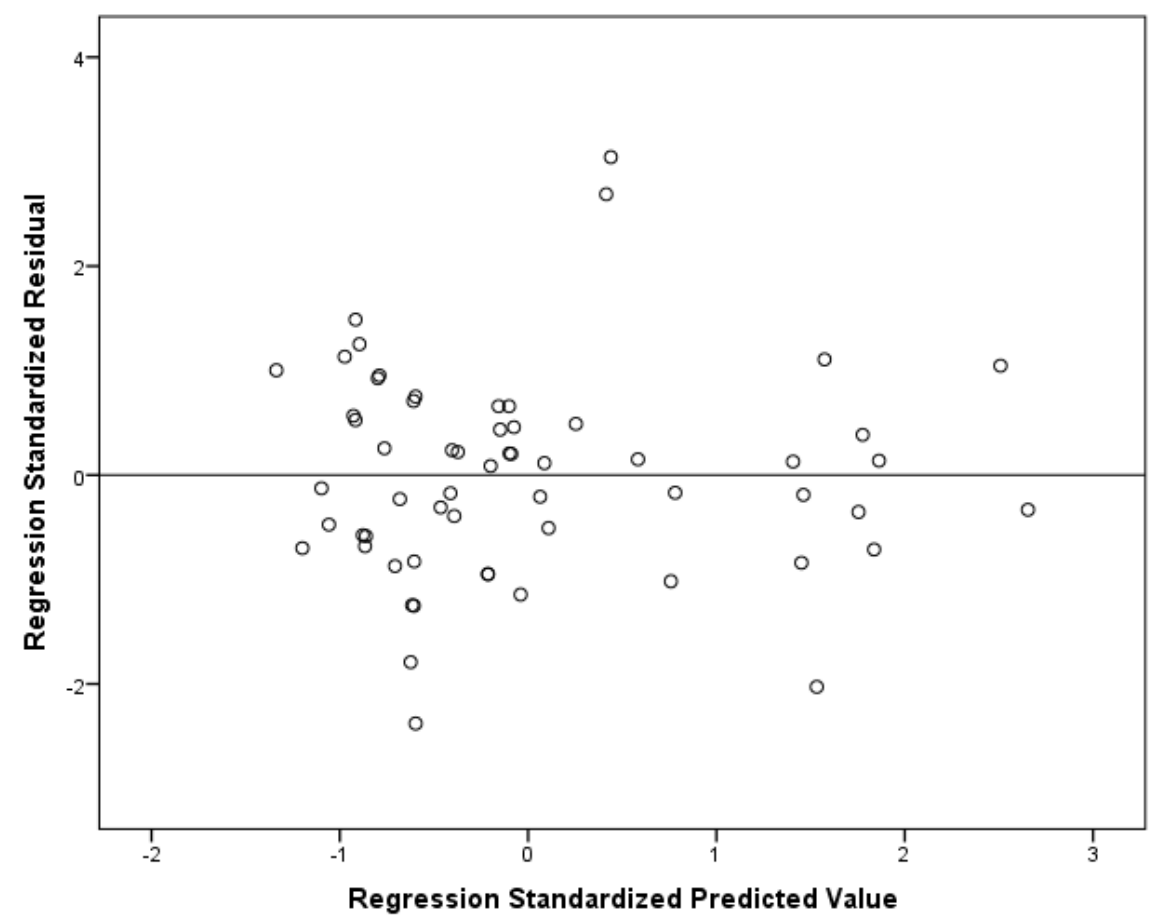

D.2.ii: Scatter plot and regression line comparing the $\mathrm{z}$ scores of the residual errors versus the $\mathrm{z}$ scores of the predicted values for equation 4. Soil data was collected in May 2012 and Tillage Radish ${ }^{\circledR}$ data were collected in October 2012, at Ignatius Jesuits Centre, Guelph, Ontario. 


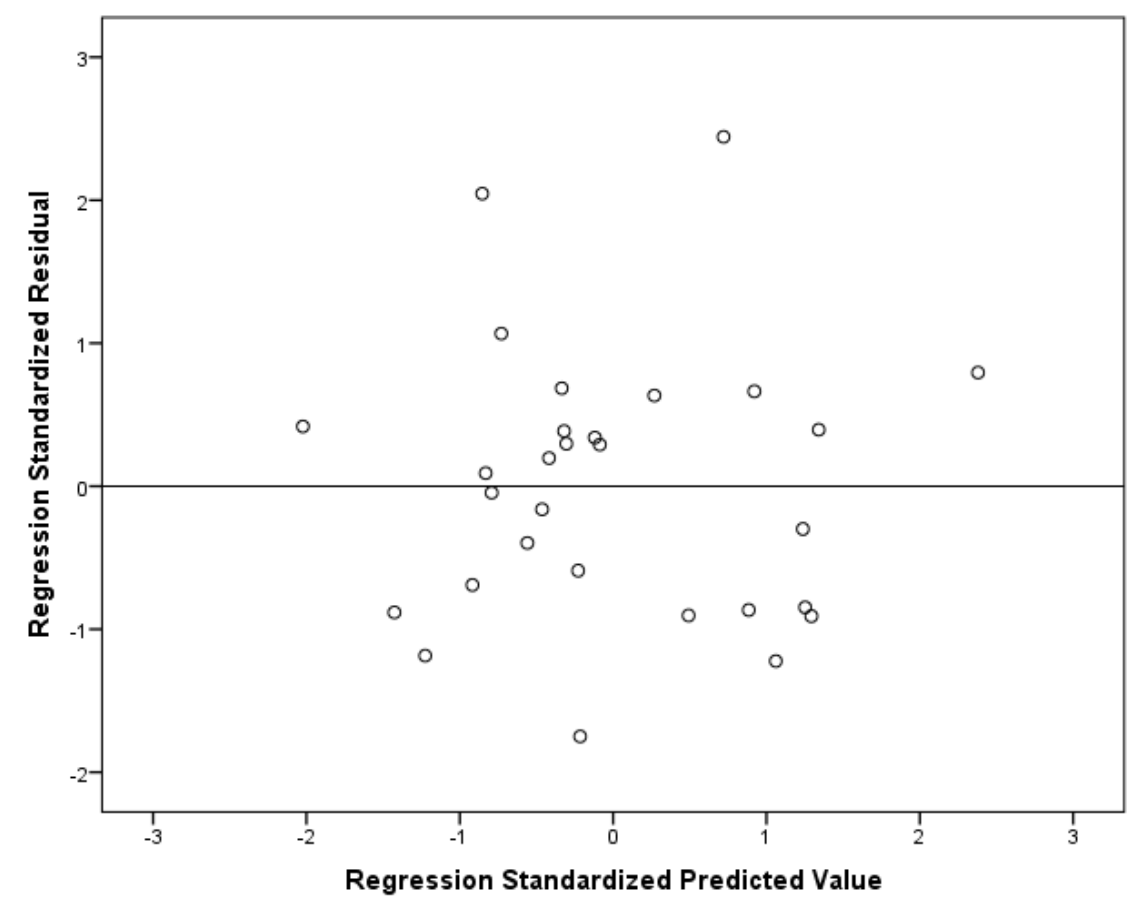

D.2.iii: Scatter plot and regression line comparing the $\mathrm{z}$ scores of the residual errors versus the $\mathrm{z}$ scores of the predicted values for equation 5. Soil data was collected in May 2012 and Tillage Radish® data were collected in October 2012, at Ignatius Jesuits Centre, Guelph, Ontario.

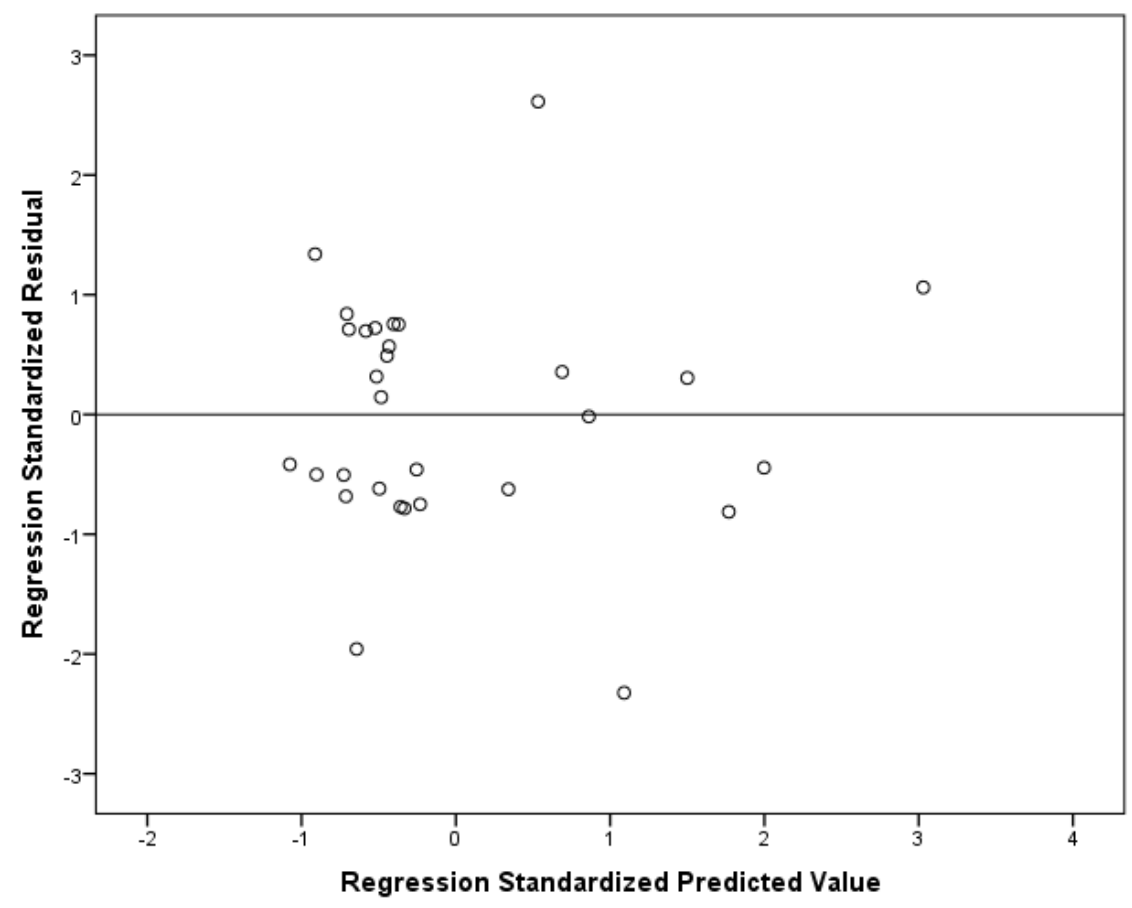

D.2.iv: Scatter plot and regression line comparing the $\mathrm{z}$ scores of the residual errors versus the $\mathrm{z}$ scores of the predicted values for equation 6. Soil data was collected in May 2012 and Tillage Radish® data were collected in October 2012, at Ignatius Jesuits Centre, Guelph, Ontario. 


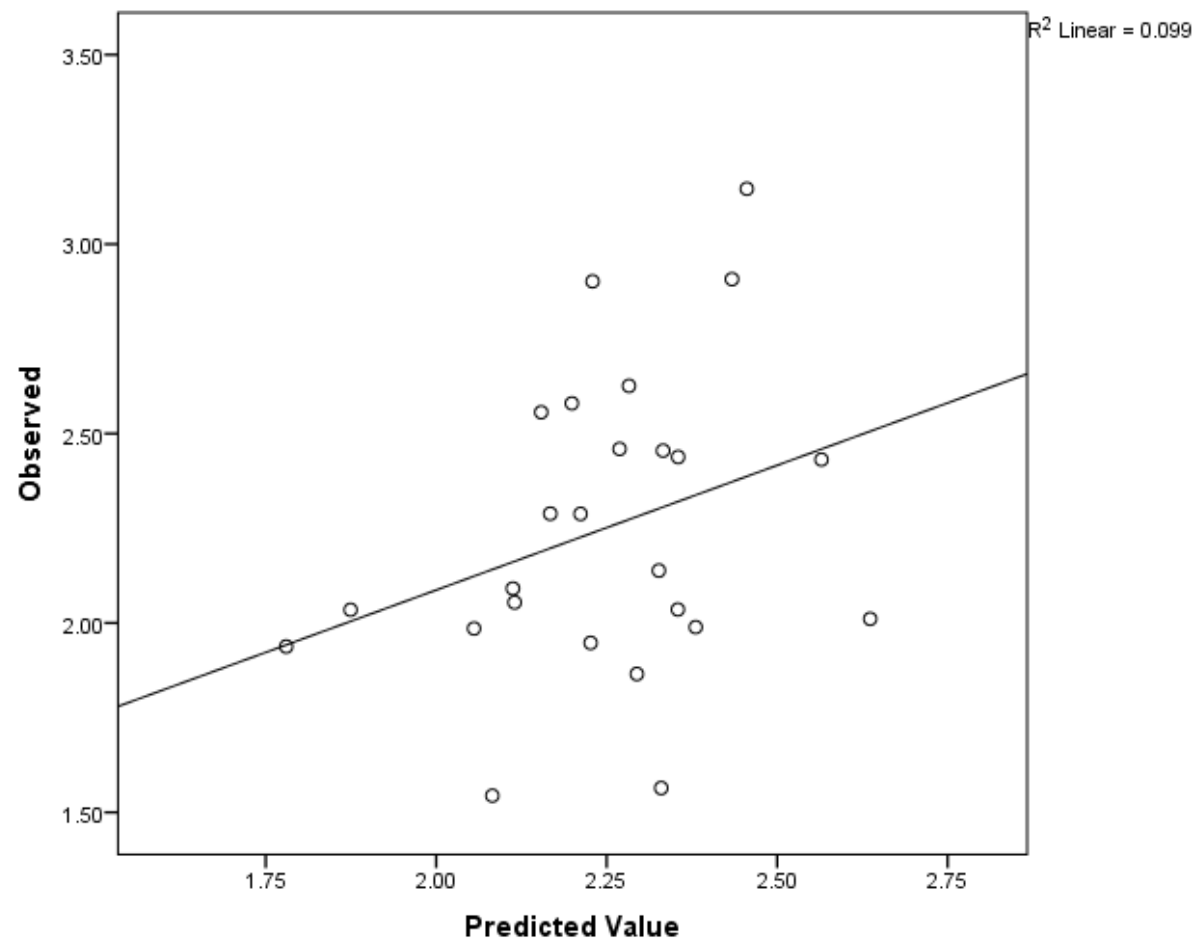

D.3.i: Scatter plot and regression line comparing the observed values versus the predicted values of equation 1. Soil data was collected in May 2012 and Tillage Radish ${ }^{\circledR}$ data were collected in October 2012, at Ignatius Jesuits Centre, Guelph, Ontario.

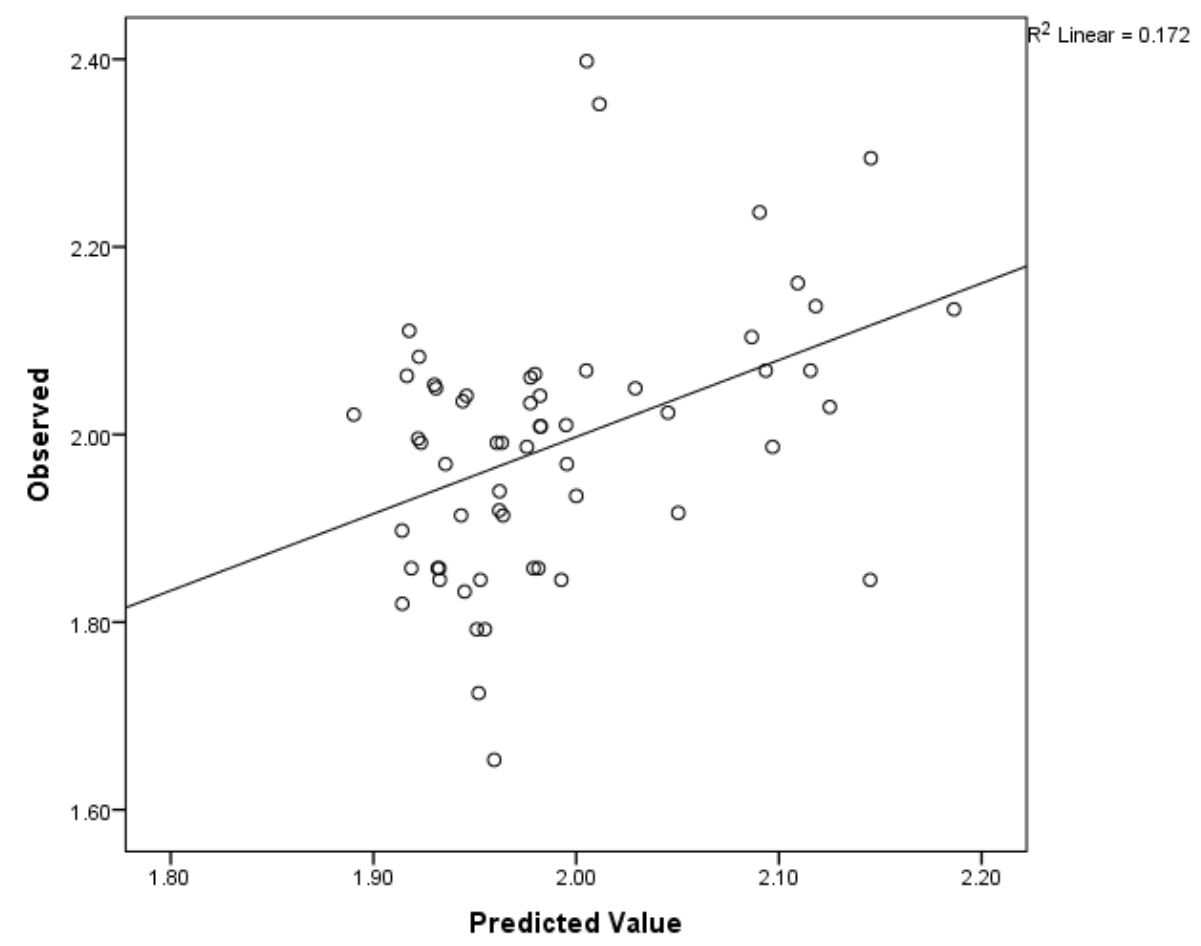

D.3.ii: Scatter plot and regression line comparing the observed values versus the predicted values of equation 4. Soil data was collected in May 2012 and Tillage Radish $®$ data were collected in October 2012, at Ignatius Jesuits Centre, Guelph, Ontario. 


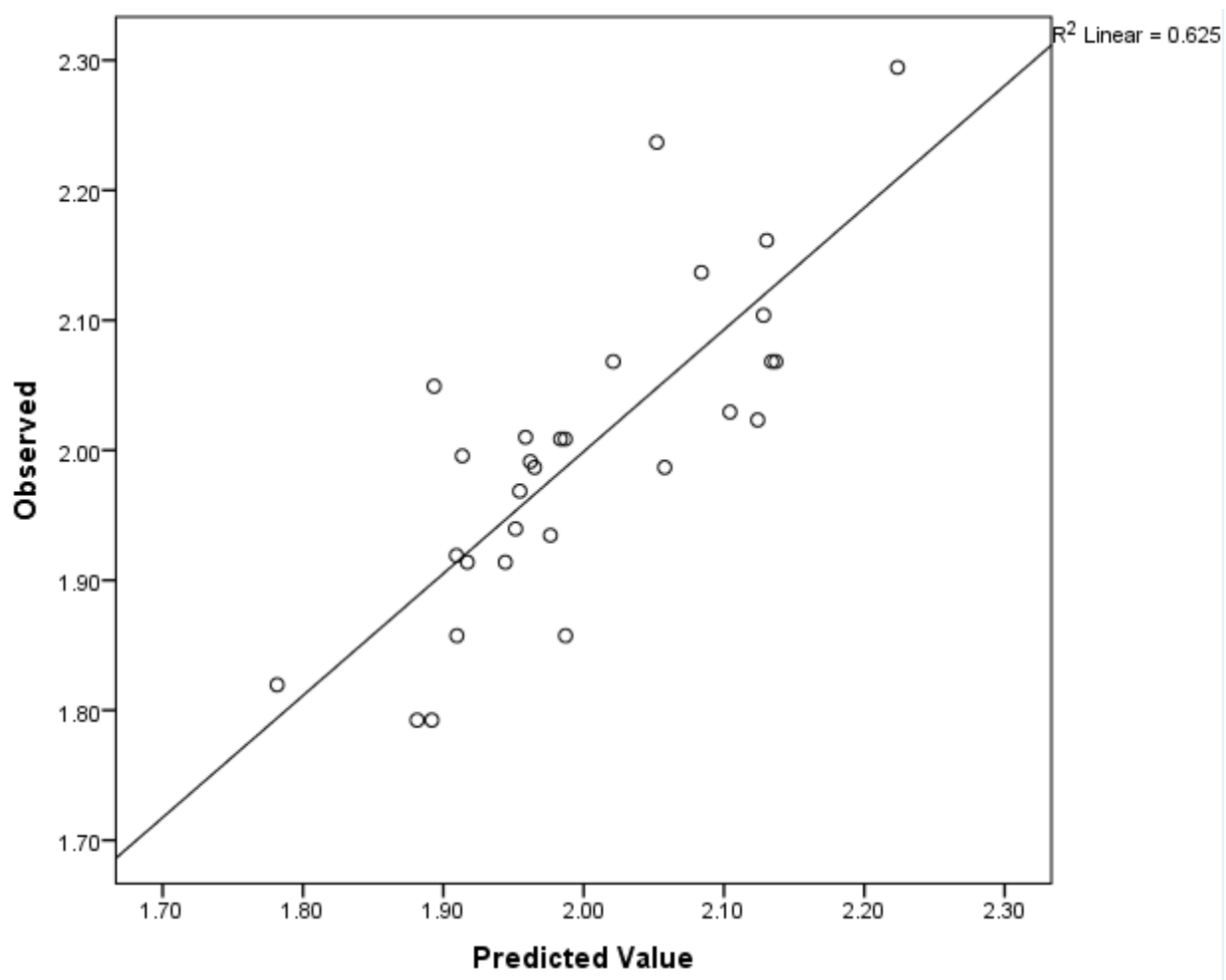

D.3.iii: Scatter plot and regression line comparing the observed values versus the predicted values of equation 5. Soil data was collected in May 2012 and Tillage Radish ${ }^{\circledR}$ data were collected in October 2012, at Ignatius Jesuits Centre, Guelph, Ontario.

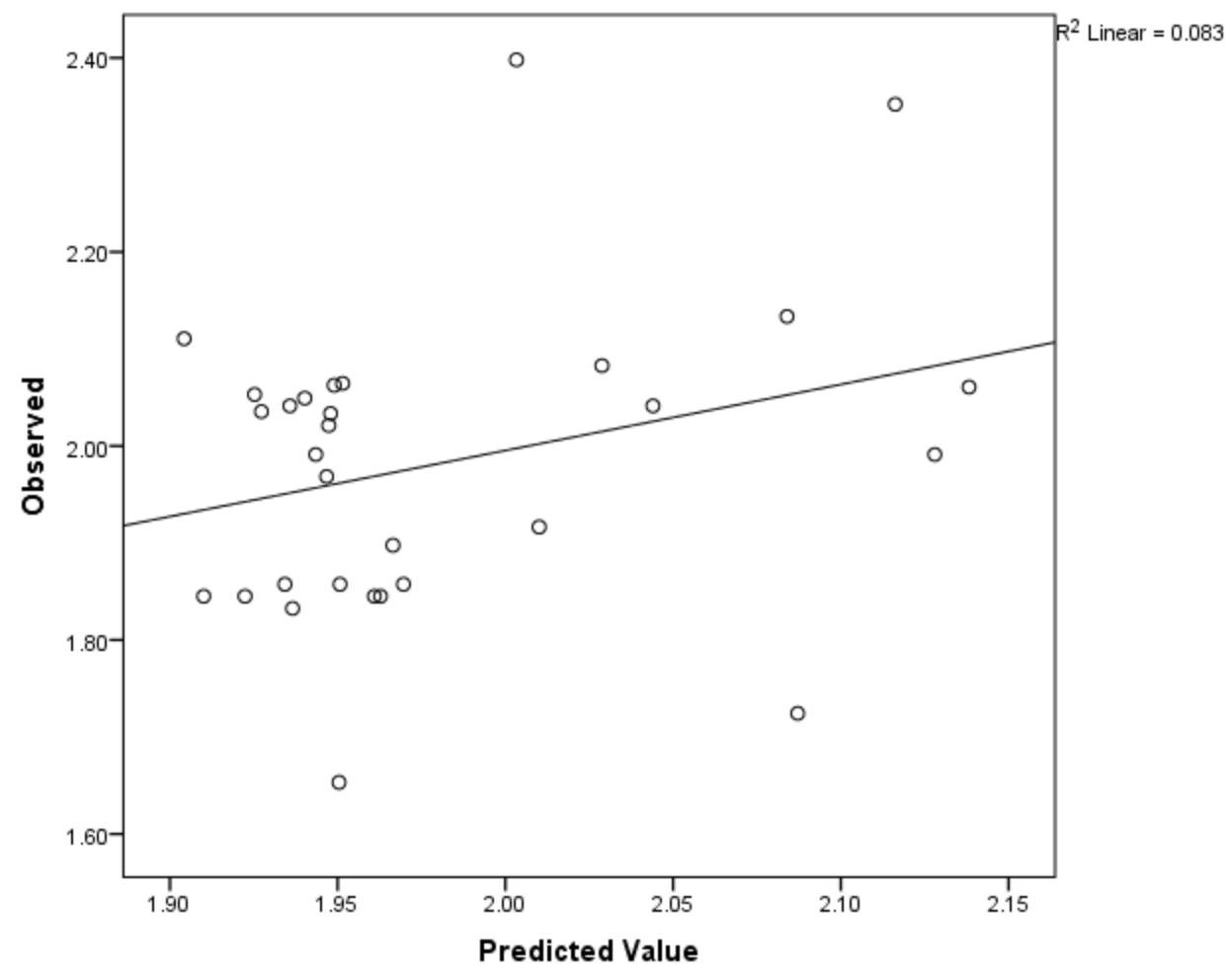

D.3.iv: Scatter plot and regression line comparing the observed values versus the predicted values of equation 6. Soil data was collected in May 2012 and Tillage Radish ${ }^{\circledR}$ data were collected in October 2012, at Ignatius Jesuits Centre, Guelph, Ontario. 


\section{Appendix E: ANCOVA Model Output}

E.1: Analysis of covariance of $\triangle P R_{1}(2.5-15 \mathrm{~cm})$ on the southeastern half of the plot, with initial penetration resistance and treatment as factors. Data used was collected in May 2012 and May 2013 at Ignatius Jesuits Centre, Guelph, Ontario.

\begin{tabular}{lrrrrr}
\hline Source & df & MS & F & p & eta $^{2}$ \\
\hline Initial PR Depth 1 & 1 & 35153067 & 546.72 & 0 & 0.818 \\
Treatment & 1 & 720456 & 11.21 & 0.001 & 0.084 \\
Error & 122 & 64298 & & & \\
\hline \hline
\end{tabular}

$\mathrm{R}^{2}=.819$ (Adjusted $\mathrm{R}^{2}=.814$ )

E.2: Analysis of covariance of $\Delta P R_{1}(2.5-15 \mathrm{~cm})$ on the northwestern half of the plot, with initial penetration resistance and treatment as factors. Data used was collected in May 2012 and May 2013 at Ignatius Jesuits Centre, Guelph, Ontario.

\begin{tabular}{lrrrrr}
\hline Source & df & MS & F & p & eta $^{2}$ \\
\hline Initial PR Depth 1 & 1 & 10810452.87 & 359.67 & 0 & 0.710 \\
Treatment & 1 & 124226.32 & 4.13 & 0.044 & 0.027 \\
Error & 147 & 300057.04 & & & \\
\hline \hline
\end{tabular}

$\overline{\mathrm{R}^{2}=.712 \text { (Adjusted } \mathrm{R}^{2}=.708 \text { ) }}$

E.3: Analysis of covariance of $\triangle P R_{2}(17.5-30 \mathrm{~cm})$ on the southeastern half of the plot, with initial penetration resistance and treatment as factors. Data used was collected in May 2012 and May 2013 at Ignatius Jesuits Centre, Guelph, Ontario.

\begin{tabular}{lrrrrr}
\hline Source & df & MS & F & p & eta $^{2}$ \\
\hline Initial PR Depth 2 & 1 & 114498558.90 & 1117.18 & 0 & 0.902 \\
Treatment & 1 & 16616507 & 1.62 & 0.205 & 0.013 \\
Error & 147 & 102488.81 & & & \\
\hline \hline
\end{tabular}

$\overline{\mathrm{R}^{2}=.903 \text { (Adjusted } \mathrm{R}^{2}=.902 \text { ) }}$

E.4: Analysis of covariance of $\Delta P_{2}(17.5-30 \mathrm{~cm})$ on the northwestern half of the plot, with initial penetration resistance and treatment as factors. Data used was collected in May 2012 and May 2013 at Ignatius Jesuits Centre, Guelph, Ontario.

\begin{tabular}{lrrrrr}
\hline Source & df & MS & F & p & eta $^{2}$ \\
\hline Initial PR Depth 2 & 1 & 56691175.20 & 579.14 & 0 & 0.799 \\
Treatment & 1 & 160597.90 & 1.64 & 0.197 & 0.022 \\
Error & 147 & 97888.25 & & & \\
\hline \hline
\end{tabular}

$\overline{\mathrm{R}^{2}=.810 \text { (Adjusted } \mathrm{R}^{2}=.806 \text { ) }}$ 
E.5: Analysis of covariance of $\Delta \mathrm{IR}$ (removed outlier), with initial penetration resistance and treatment as factors. Data used was collected in May 2012 and May 2013 at Ignatius Jesuits Centre, Guelph, Ontario.

\begin{tabular}{lrrrrr}
\hline Source & df & MS & F & p & eta $^{2}$ \\
\hline Initial PR Depth 1 & 1 & 0.249 & 5.09 & 0.038 & 0.241 \\
Treatment & 1 & 0.131 & 2.79 & 0.115 & 0.148 \\
Error & 16 & 0.011 & & & \\
\hline \hline
\end{tabular}

$\overline{\mathrm{R}^{2}=.266\left(\text { Adjusted } \mathrm{R}^{2}=.175\right)}$

E.6: Analysis of covariance of $\Delta \mathrm{Db}$, with initial penetration resistance and treatment as factors. Data used was collected in May 2012 and May 2013 at Ignatius Jesuits Centre, Guelph, Ontario.

\begin{tabular}{lrrrrr}
\hline Source & df & MS & F & p & eta $^{2}$ \\
\hline Initial Bulk Density & 1 & 0.001 & 0.11 & 0.739 & 0.114 \\
Treatment & 1 & 0.000 & 0.02 & 0.889 & 0.020 \\
Error & 19 & 0.008 & & & \\
\hline \hline
\end{tabular}

$\overline{\mathrm{R}^{2}=.006 \text { (Adjusted } \mathrm{R}^{2}=-.098 \text { ) }}$ 


\section{Reference}

Aelion, C. M., Davis, H. T., McDermott, S., and Lawson, A. B. (2008). Metal concentrations in rural topsoil in South Carolina: Potential for human health impact. Science of the Total Environment, 40: 149-156.

Aerts, R., and Chapin III, F. S. (2000). The mineral nutrition of wild plants revisited: Reevaluation of processes and patterns. In A. H. Fitter, \& D. G. Raffaelli (Eds.), Advance in Ecological Research (Volume 30). London, U.K.: Academic Press.

Akbari, H. (2002). Shade trees reduce building energy use and CO2 emissions from power plants. Environmental Pollution, 116: 119-126.

Alberty, C. A., Pellett, H. M., and Taylor, D. H. (1984). Characterization of soil compaction at construction sites and woody plant response. Journal of Environmental Horticulture, 2: $48-53$.

Altieri, M. A., and Schmidt, L. L. (1986). Cover crops affect insect and spider populations in apple orchards. California Agriculture, 40:15-17.

Askegaard, M., Olesen, J. E., Rasmussen, I. A., and Kristensen, K. (2011). Nitrate leaching from organic arable crop rotations is mostly determined by autumn field management. Agriculture, Ecosystems and Environment, 142: 149-160.

Aubertin, G. M., and Kardos, L. T. (1965). Root growth through porous media under controlled conditions: I. Effect of pore size rigidity. Soil Science Society of America, 29: 290-293

Bakker, D. M., Davis, R. J. (1995). Soil deformation observations in Vertisol under field traffic. Australian Journal of Soil Research, 33: 817-832

Bassett, I. E., Simcock, R. C., and Mictchell, N. D. (2005). Consequences of soil compaction for seedling establishment: Implications for natural regeneration and restoration. Austral Ecology, 30: 827-833.

Bengough A. G., and Mullins C. E. (1990). Mechanical impedance to root growth: a review of experimental techniques and root growth responses. European Journal of Soil Science, 41:341-358.

Bennie, A. T. P., and Botha, F. J. P. (1986). Effects of deep tillage and controlled traffic on root growth, water-use efficiency and yield of irrigated maize and wheat. Soil and Tillage Research, 7: 85-95.

Bharati, L., Lee, K., Isenhart, T. M., and Schultz, R. C. (2002). Soil-water infiltration under 
crops, pasture, and established riparian buffer in midwestern USA. Agroforestry Systems, 56: $249-257$.

Bishop, J. C., and Grimes, D. W. (1978). Precision tillage effects on potato root and tuber production. American Potato Journal, 55: 65-71.

Bolund, P., and Hunhammar, S. (1999). Ecosystem services in urban areas. Ecological Economics, 29: 293-301.

Brady. N. C., and Buckman, H. O. (1990). The nature and properties of soils (10 ${ }^{\text {th }}$ ed.). Macmillan, New York: Prentice Hall.

Breland, A., Hansen, S. (1996). Nitrogen mineralization and microbial biomass as affected by soil compaction. Soil Biology and Biochemistry, 28: 655-663.

Bretz, S., Akbari, H., \& Rosenfeld, A. (1997). Practical issues for using solar-reflective materials to mitigate urban heat islands. Atmospheric Environment, 32: 95-101.

Broughton, W. J. (1977). Effect of various covers on soil fertility under Hevea brasiliensis Muell. Arg. and on the growth of the tree. Agro-Ecosystems, 3: 147-170.

Brown, P. H., Welch, R. M., and Cary, E.E. (1987). Nickel: A micronutrient essential for higher plants. Plant Physiology, 85: 801-803.

Bulmer, G. E., and Simpson, D. G. (2010). Soil compaction reduced the growth of Lodgepole Pine and Douglas-fir seedlings in raised beds after two growing seasons. Soil Science Society of America Journal, 74: 2162-2174.

Canada Department of Agriculture. (1963). Soil survey of Wellington County Ontario: Report No 35 of the Ontario soil survey. Ottawa, ON: U.S. Government Printing Office.

Canadian Urban Forest Network (2012). Canadian urban forest strategy 2013-2018. Retrieved from www.treecanada.ca/publications/pdf/cufs.pdf.

Chaplot, V., Darboux, F., Bourennane, H., Leguedois, S., Silvera, N., \& Phachomphon, K. (2006). Accuracy of interpolation techniques for the derivation of digital elevation models in relation to landform types and data density. Geomorphology, 77: 126-141.

Chen, G., and Weil, R. R. (2010). Penetration of cover crop roots through compacted soils. Plant and Soil, 331: 31-43.

Cheng, J., Shi, Z., Zhu, Y. (2007). Assessment and mapping of environmental quality in agricultural soils of Zhejiang Province, China. Journal of Environmental Sciences, 19: $50-54$. 
City of Toronto (2013). Every Tree Counts.

Retrieved from http://www.toronto.ca/trees/ every_tree_counts.htm

Clark, J. R., Matheny, N. P., Cross, J., and Wake, V. (1997). A model of urban forest sustainability. Journal of Arboriculture, 23: 17-30.

Cochran, W. G. (1946). Relative accuracy of systematic and stratified random samples for a certain class of populations. The Annals of Mathematical Statistics, 17: 164-177.

Comery, W. R. (2007). Tree roots versus sidewalks and sewers. In J. E. Kuser (Ed.), Urban and Community Forestry in the Northeast $(261-266)$. ( $2^{\text {nd }}$ ed.). New York, NY: Springer.

Constantin, J., Mary, B., Laurent, F., Aubrion, G., Fontaine, A., Kerveillant, P., and Beaudoin, N. (2010). Effects of catch crops, no till and reduced nitrogen fertilization on nitrogen leaching and balance in three long-term experiments. Agriculture, Ecosystems and Environment, 135: 268-278.

Cook, D. I. (1978). Trees, solid barriers, and combinations: Alternatives for noise control. Proceedings of the National Urban Forestry. Conference (G. Hopkins, ed.), SUNY College of Environmental Science and Forestry, Syracuse, NY, pp. 330-339.

Costanza, R., and Patten, B. (1995). Defining and predicting sustainability. Ecological Economics, 15:193-196.

Cover Crop Solutions. (2012). Tillage radish resource guide: the cover crop that pays. Retrieved from http://www.tillageradish.com/documents/tillage-radish-resource-guide.pdf.

Craul, P. J. (1999). Urban soils: Applications and practices. New York, NY :John Wiley and Sons.

Craul, P. J. (1992). Urban soil in landscape design. New York, NY :John Wiley and Sons.

Craul, P. J. (1985). A description of urban soils and their desired characteristics. Journal of Arboriculture, 11.

Currie, J. A. (1984). Gas diffusion through soil crumbs: The effects of compaction and wetting. Journal of Soil Science, 35: 1-10.

Dabney, S., Delgado, J. and D. Reeves. (2001). Using winter cover crops to improve soil and water quality. Communications in Soil Science and Plant Analysis, 32: 1221-1250.

Day, S. D. and Bassuk, N. (1994). A Review of the effects of soil compaction and amelioration treatments on landscape trees. Journal of Arboriculture, 20: 9-17.

Day, S. D., Bassuk, N. L., and van Es, H. (1995). Effects of four compaction remediation 
methods for landscape trees on soil aeration, mechanical impedance, ands tree establishment. Journal of Environmental Horticulture, 13: 641-671.

Day, S. D., Seiler, J. R., and Persaud, N. (2000). A comparison of root growth dynamics of silver maple and flowering dogwood in compacted soil at differing soil water contents. Tree Physiology, 20: 257-263.

Day, S. D., Wiseman, P. E., Dickinson, S. B., and Harris, R. J. (2010). Tree root ecology in the urban environment and implications for a sustainable rhizosphere. Arboriculture and Urban Forestry, 35: 193-205.

Deneke, F. (1993). Urban Forestry in North America: Towards a Global Ecosystem Perspective. Proceedings of the First Canadian Urban Forests Conference. Winnipeg, MB: Canada.

Dexter, A. R. (1991). Amelioration of soil by natural processes. Soil and Tillage Research, 20: $87-100$.

Dickinson, M. N., Hartley, W., Uffindell, L. A., Plumb, A. N., Rawlinson, H., and Putwain, P. (2005). Robust descriptors of soil health for use in reclamation of brownfield land. Land Contamination and Reclamation, 13: 317-326.

Doick, K. J., Sellers, G., Castan-Broto, V., and Silverthorne, T. (2009). Urban forestry \& Urban Greening, 8: 163-178.

Dwyer, J.F., McPherson, E.G., Schroeder, H.W., and Rowntree, R.A. (1992). Assessing the benefits and costs of the urban forest. Journal of Arboriculture, 18: 227-234.

Dwyer, J.F., Nowak, D.J., and Noble, M.H. (2003). Sustaining urban forests. Journal of Arboriculture, 29: 49-55.

Eaven, P. H., Evert, R. F., and Eichhorn, S. E. (2005). Biology of Plants (7 ${ }^{\text {th }}$ ed.). New York, NY : W. H. Freeman and Company Publishers.

Epstein, E. (1956). Mineral nutrition of plants: Mechanisms of uptake and transport. Plant Physiology, 7: 1-24.

Environment Canada. (2014). Guelph arboretorium, Ontario Canada yearly/monthly/daily/climate information: Guelph arboretum average monthly temperature, precipitation, snowfall \& weather extremes. Retrieved from http://www.eldoradocountyweather.com/canada/climate2/ Guelph\%20Arboretum.html

Environment Canada. (2012). Canada's top ten weather stories from 2012.

Retrieved from http://ec.gc.ca/meteo-weather/default.asp?lang=En\&n=B7D225D0-1 
ESRI (Environmental Systems Resource Institute). (2013). ArcMap 10.2. Redlands, California: ESRI.

Fitzpatrick, R. W., McKenzie, N., and Maschmedt, D. J. (1999). Soil morphological indicators and their importance to soil fertility. In K. I. Pervill, L. A. Sparrow, \& D. L. Reuter. (Eds.), Soil Analysis: An Interpretation Manual (55-68). Collingwood, VIC: CSIRO Publishing.

Folorunso, O. A., Rolston, D. E., Prichard, P. T., and Louie, D. T. (1992). Cover crops lower soil surface strength, may improve soil permeability. California Agriculture, 46: 26-27.

Foshee, W. G., Goff, W. D., Patterson, M. G., and Ball, D. M. (1995). Orchard floor crops reduce growth of young pecan trees. Horticultural Science, 30: 979-980.

Franzen, D. W. 2011. Collecting and analyzing soil spatial information using krigging and inverse distance weighted. In D. E. Clay \& J. F. Shanahan (Eds.), GIS applications in agriculture: Nutrient management for energy efficiency (2nd ed.) (61-79). Boca Raton, FL: CRC Press.

Frye, W. W., Smith, W. G., and Williams, R. J. (1985). Economics of winter cover crops as a source of nitrogen for no-till corn. Journal of Soil Water Conservation. 40: 246-249.

Gardner, B., Suvllivan, P., \& Lembo, A. J. (2003). Predicting stream temperatures: geostatistical model comparison using alternative distance metrics. Canadian Journal of Fish Aquatics Science, 344-351.

Geigenberger, P. (2003). Response of plant metabolism to too little oxygen. Current Opinion in Plant Biology, 6: 247-256.

Gomez, A., Powers, R. F., Singer, M. J., and Horwath, W. R. (2002). Soil compaction on growth of young Ponderosa Pine following litter removal in California's Sierra Nevada. Soil Science Society of America Journal, 66: 1334-1343.

Gomez, J., Guzman, M., Giraldez, and J., Fereres, E. (2009). The influence of cover crops and tillage on water and sediment yield, and on nutrient, and organic matter losses in an olive orchard on a sandy loam soil. Soil \& Tillage Research, 106: 137-144.

Grant, R. F. (1993). Simulation model of soil compaction and root growth. Plant and Soil, 150: $1-14$.

Greer, K. J., and Schoenau, J. J. (1994). Salinity and salt contamination assessment using anion exchange resin membranes. In Soils and Crops Workshop Proc., p.44-48. University of 
Saskatchewan.

Greer, K. J., Sulewski, C., and Hangs, R. (2003). Applying PRS тм technology for nutrient management. Western Nutrient Management Conference, Salt Lake City, UT. 5: 170175.

Gregory, J. H., Dukes, M. D., Jone, P. H., and Miller, G. L. (2006). Effect of urban soil compaction on infiltration rate. Journal of Soil and Water Conservation, 61: 117-123.

Gregory, J. H., Dukes, M. D., Miller, G. L., and Jone, P. H., (2005). Analysis of double ring infiltration techniques and development of a simple automatic water delivery system. Applied Turfgrass Science, doi:10.1094/ATS-2005-0531-01-MG.

Gotway, C. A., Ferguson, R. B., Hergert, G. W., and Peterson, T. A. (1996). Comparison of Kriging and Inverse-Distance methods for mapping soil parameters. Soil Science Society of America Journal, 60: 1237-1247.

Hamza, M. and Anderson, W. (2005). Soil compaction in cropping systems: A review of the nature, causes and possible solutions. Soil and Tillage Research, 82: 121-145.

Hangs, R., Greer, K., Sulewski, C., and Hicks, D. (2002). Plant Root Simulator-probes: An effective alternative for routine soil testing. Soils and Crops Workshop Proc., p.44-48. University of Saskatchewan.

Hartwig, N. L., and Ammon, H. U. (2002). Cover crops and living mulches. Weed Science, 50: 688-699.

Hawver, G. A., and Bassuk, N. L. (2007). Soils: The key to successful establishment of urban vegetation. In J. E. Kuser (Ed.), Urban and Community Forestry in the Northeast (165182). ( $2^{\text {nd }}$ ed.). New York, NY: Springer.

Hill, A.C. (1971). Vegetation: a sink for atmospheric pollutants. Journal of the Air Pollution Control Association, 21: 341-346.

Hooker, P. J., and Nathanail, C. P. (2006). Risk-based characterisation of lead in urban soils. Chemical Geology, 226:340-351.

Hummel, R. L., and Johnson, C. R. (1985). Amended back-fills: Their cost and effect on transplant growth and survival. Journal of Environmental Horticulture, 3: 76-79.

Hussain, A., Black, C. R., Taylor, I. B., and Roberts, J. A. (1999). Soil compaction. A role for ethylene in regulating leaf expansion and shoot growth in tomato? Plant Physiology, 121: 1227-1237. 
Itai, C., and Vaadia, Y. (1971). Cytokinin activity in water-stressed shoots. Plant Physiology, 47: 87-90.

James, E. B., and Barber, G. M. (1996). Elementary statistics for geographers (2 ${ }^{\text {nd }}$ ed). New York: The Guliford Press.

Jim, C. Y. (2008). Opportunities and alternatives for enhancing urban forests in compact cities and developing countries. Carreiro, M. M., Song, Y. C., and Wu, J., Ecology, planning, and management of urban forests: international perspectives (118-467). Springer: New York.

Jim, C. Y. (1998). Urban soil characteristics and limitations for landscape planting in Hong Kong. Landscape and Urban Planting, 40: 235-249.

Jim, C. Y. (1993). Soil compaction as a constraint to tree growth in tropical \& subtropical urban habitats. Environmental Conservation, 20: 35-49.

Johnson, J. F., Voorhees, W. B., Randall, G. W. (1987). Effect of recompaction on penetrometer resistance on a soil loosened by subsoil tillage. Agronomy Journal, 79: 24.

Johnston, K., Ver Hoet, J. M., Krivouchko, K., \& Lucas, N. (2001). Using ArcGIS Geostatistical Analyst. California: ESRI.

Jorgensen, E. (1974). Towards an urban forestry concept. Proceedings of the 10th Commonwealth Forestry Conference. Ottawa, Ontario: Canada.

Jusoff, K. (1989). Physical soil properties associated with recreational use of a forested reserve area in Malaysia. Environmental Conservation, 16: 339-342.

Justes, E., Mary, B., and Nicolardot, B. (1999). Comparing the effectiveness of radish cover crop, oilseed rape volunteers, and oilseed rape residues incorporation for reducing nitrate leaching. Nutrient Cycling in Agroecosytems, 55: 207-220.

Karlen, D. L., Mausbach, M. J., Doran, J. W., Cline, R. G., Harris, R. F., and Schuman, G. E. (1997). Soil quality: A concept, definition, and framework for evaluation (a guest editorial). Soil Science Society of America Journal, 61: 4-10.

Kemper, B., and Derpsch, R. (1981). Results of studies made in 1978 and 1979 to control erosion by cover crops and no-tillage techniques in Parana, Brazil. Soil \& Tillage Research, 1: $253-267$. 
Kettler, T., Doran, J., and Gilbert, T. (2001). Simplified method for soil particle-size determination to accompany soil-quality analyses. Soil Science Society of America Journal, 65: 849-852.

Khakestar, M. S., Madani, H., Hassani, H., and Moarefvan, P. (2013). Determining the best search neighborhood in reserve estimation, using geostatistical method: A case study anomaly No 12A iron deposit in central Iran. Journal Geological Society of India, 81: $581-585$.

Kozlowski, T. (1999). Soil compaction and growth of woody plants. Scandinavian Journal of Forest Research, 14: 596-619.

Kravchenko, A., and Bullock, D. (1999). A comparative study of interpolation methods for mapping soil properties. Agronomy, 91: 393-400.

Kravchenko, A. N., and Bullock, D. G. (2000). Correlation of corn and soybean grain yield with topography and soil properties. Agronomy, 92: 75-83.

Krivoruchko, L. (2005). Introduction to modeling spatial data process using Geostatistical Analyst. Retlands: Environmental Systems Research Institute.

Laporte, M. F., Duchesne, L. C., and Wetzel, S. (2002). Effect of rainfall petterns on soil surface $\mathrm{CO}_{2}$ efflux, soil moisture, soil temperature and plant growth in a grassland ecosystem of northern Ontario, Canada: Implications for climate change. BMC Ecology, 2: 10-16.

Leech, N. L., Barrett, K. C., and Morgan, G. A. (2008). SPSS for intermediate statistics: Use and interpretation ( $3^{\text {rd }}$ ed). New York, London: Lawrence Erlbaum Associates.

Liang J., and Schoenau, J. J (1995). Development of resin membranes as a sensitive indicator of heavy metal toxicity in the soil environment. International Journal of Environmental Analytical Chemistry, 59: 265-275.

Logsdon, S. D., and Karlen, D. L. (2004). Bulk density as a soil quality indicator during conversion to no-tillage. Soil and Tillage Research, 78: 143-149.

Lyr, H., and Hoffman, G. (1967). Growth rates and growth periodicity of tree roots. International Review of Forestry Research, 2: 181-236.

Mainstone, B. J. (1969). Residual effects of ground cover and nitrogen fertilisation of Hevea prior to tapping. Journal of the Rubber Research Institute of Malaysia, 21: 113-125.

Malik, M. S., Norsworthy, J. K., Culpepper, A. S., Riley, M. B., and Bridges, W Jr. (2008). Use 
of wild radish (Raphanus raphanistrum) and rye cover crops for weed suppression in sweet corn. Weed Science, 56: 588-595.

Materechera, S. A., Alston, A. M., Kirby, J. M., and Dexter, A. R. (1992). Influence of root diameter on the penetration of seminal roots into a compacted subsoil. Plant and Soil, 144: 297-303.

Meek, B. D., Rechel, E. R., Carter, L. M., DeTar, W. R., and Urie, A. L. (1992). Infiltration rate of a sandy loam soil: Effects of traffic, tillage, and plant roots. Soil Science Society of America Journal, 56: 908-913.

Meisinger, J. J., Hargrove, W. L., Mikkelsen, R. L., Williams, J. R., and Benson, B. W. (1991). Effects of cover crops on groundwater quality (57-68). In W .L. Hargrove (ed.) Cover Crops for Clean Water. Ankeny, IA: SWCS.

Millward, A., Paudel, K., and Briggs, S. (2011). Naturalization as a strategy for improving soil physical characteristics in a forested urban park. Urban Ecosystems, 14: 261-278.

Millward, A.A., and Sabir, S. (2010). Structure of a forested urban park: Implications for strategic management. Journal of Environmental Management, 91: 2215-2224.

Mitas, L., \& Mitasova, H. (1999). Spatial Interpolation. In L. Mitas, \& H. Mitasova, Geographical Information Systems: Principles (pp. 481-492).

Mokany, K., Raison, R. J, and Prokushkin, A. S. (2006). Critical analysis of root: shoot ratios in terrestrial biomes. Global Change Biology, 12: 84-96.

Monti, P. W., and Mackintosh, E. E. (1979). Effects of camping on surface soil properties in the boreal forest region of northwestern Ontario, Canada. Soil Science Society of America Journal, 43: 1024-1029.

Morachan, Y.B., Moldenhauer, W.C. and Larson, W.E. (1972). Effects of increasing amounts of organic residues on continuous corn. I. Yields and soil physical properties. Agronomy Journal, 64: 199-203.

Motavalli, P. P., Stevens, W. E., and Hartwig, G. (2003). Remediation of subsoil and compaction effects on corn $\mathrm{N}$ availability by deep tillage and application of poultry manure in a sandy-textured soil. Soil and Tillage Research, 71: 121-131.

Mulholland, B. J., and Fullen, M. A. (1991). Cattle trampling and soil compaction on loamy sands. Soil Use and Management, 7: 189-193.

Nambiar, E. K. S., and Sands, R. (1992). Effects of compaction and simulated root channels in 
the subsoil on root development, water uptake and growth of radiate pine. Tree Physiology, 10: 297-306.

Nevill, A. M., and Holder, R. L. (1995). Scaling, normalizing, and per ratio standards: An allometric modelling approach. Journal of Applied Physiology, 79: 1027-1031.

Nowak, D. J., and Dwyer, J. F. (2007). Understanding the benefits and costs of urban forest ecosystems. In J. E. Kuser (Eds.), Urban and Community Forestry in the Northeast $\left(2^{\text {nd }}\right.$ Ed) (25-13). New York, NY: Springer.

Nowak, D. J., Crane, D. E., and Stevens, J. C. (2006). Air pollution removal by trees and shrubs in the United States. Urban Forestry \& Urban Greening, 4: 115-123.

Ontario Ministry of Finance (OMF). (2013). Ontario population projections update (ISBN 978-1-4606-2022-9). Ontario: CA. Queen's printer for Ontario.

Osunbitan, J. A., Oyedele, D. J., and Adekalu, K. O. (2005). Tillage effects on bulk density, hydraulic conductivity and strength of a loamy sand soil in southwestern Nigeria. Soil and Tillage Research, 82: 57-64.

Ouyang, Y., Higman, J., Campbell, D., Davis, J. (2003). Three-dimensional kriging analysis of sediment mercury distribution: a case study. J Am Water Resour Assoc, 39:689-702

Overvoorde, P., Fukaki, H., and Beeckman, T. (2010). Auxin control of root development. Cold Spring Harbor Perspectives in Biology, 2: 1-16.

Owen, S. V., and Froman, R. D. (1998). Focus on qualitative methods: Uses and abuses of the analysis of covariance. Research in Nursing \& Health, 21: 557-562.

Pan, E., and Bassuk, N. (1985). Effect of soil type and compaction on the growth of Ailanthus altissima seedlings. Journal of Environmental Horticulture, 3: 158-162.

Patterson, J. C. (1977). Soil compaction: Effects on urban vegetation. Journal of Arboriculture, 3: $161-167$.

Piper, J. K. (1989). Distribution of dry mass between shoot and root in nine understory species. American Midland Naturalist, 122: 114-119.

Qian, P., and Schoenau, J. J. (1995). Assessing nitrogen mineralization from soil organic matter using anion exchange membranes. Fertilizer Research, 40:143-148.

Qian, P., and Schoenau, J. J. (2002). Practical applications of ion exchange resins in agriculture and environmental soil research. Canadian Journal of Soil Science, 82: 9-21.

Qian, P., and Schoenau, J. J., Greer, K. J., and Liu, Z. (1996). Assesing plant-available potassium 
in soil using cation exchange membrane burial. Canadian Journal of Soil Science, 76: 191-194.

Radford, B. J., Yule, D. F., McGarry, D., and Playford, C. (2001). Crop responses to applied soil compaction and to compaction repair treatments. Soil and Tillage Research, 61: 157-166.

Ramos, M. E., Benitez, E., Garcia, P. A., Robles, A. B. (2010). Cover crop under different managements vs. frequent tillage in almond orchards in semiarid conditions: Effects on soil quality. Applied Soil Ecology, 44: 6-14.

Randrup, T. B., and Dralle, K. (1997). Influence of planning and design on soil compaction in construction sites. Landscape and Urban Planning, 38: 87-92.

Ravindranath, N. H., and Ostwald, M. (2007). Carbon inventory methods: Handbook for greenhouse gas inventory, carbon mitigation and roundwood production projects. Springer.

Reethof, G., and McDaniel, O. H. (1978). Acoustics and the urban forest. Proceedings of the National Urban Forestry Conference (G. Hopkins, ed.), SUNY College of Environmental Science and Forestry, Syracuse, NY, pp. 321-329.

Rivenshield, A., and Bassuk, N. L. (2007). Using organic amendments to decrease bulk density and increase macroporosity in compacted soils. Arboriculture and Urban Foresty, 33: $140-146$.

Roberts, J., Jackson, N., and Smith, M. (2006). Tree roots in the built environment. Norwich, NOR: The Stationary Office.

Robinson, T., and Metternicht, G. (2006). Testing the performance of spatial interpolation techniques for mapping soil properties. Computer and Electronics in Agriculture, 50: 97 108.

Rolf, K. (1994). A review of preventative and loosening measures to alleviate soil compaction in tree planting areas. Arboricultural Journal, 18: 431-448.

Rosenzweig, C., Solecki, W.D., and Slosberg, R. (2006). Mitigating New York City's heat island with urban forestry, living roofs, and light surfaces. A report to the New York State Energy Research and Development Authority, Retrieved September 20, 2012 from - http//www.fs.fed.us/ccrc/topics/urban-forests/docs/NYSERDA_heat_island.pdf

Rosolem, C., Foloni, J., and Tiritan, C. (2002). Root growth and nutrient accumulation in cover crops as affected by soil compaction. Soil and Tillage Research, 65: 109-115. 
Saebo, A., and Ferrini, F. (2006). The use of compost in urban green areas - A review for practical application. Urban Forestry and Greening, 4: 159-169.

Sanchez, E. E., Giayetto, A., Cichon, L., Fernandez, D., Aruani, M. C., and Curetti, M. (2007). Cover crops influence soil properties and tree performance in an apple (Malus domestica Borkh) orchard in northern Patagonia. Plant and Soil, 292: 193-203.

Sanchez, P. A. (1987). Chapter 13: Soil productivity and sustainability in agroforestry systems. In E. H. A. Steppler, \& P. K. R. Nair (Eds.), Agroforestry: a decade of development (205-227). Caroline Agola, Nairobi: Printfast Kenya Limited.

Sands, R., Greacen, E. L and Gerard, C. J. (1979). Compaction of sandy soils in radiata pine forests. I A penetrometer study. Australia Journal of soil Research, 17: 101-113.

Sarrantonio, M., and Gallandt, E. (2008). The role of cover crops in North American cropping systems. Journal of Crop Production, 8: 53-74.

Schefler, W. C. (1979). Statistics for the biological sciences ( $2^{\text {nd }}$ ed). Menlo Park, CA: AddisonWesley Publishing Company.

Schmitt, J., Ehrhardt, D. W., and Cheo, M. (1986). Light-dependant dominance and supression in experimental radish populations. Ecology, 67: 1502-1507.

Seeley, S. (1990). Hormonal transduction of environmental stresses. Horticultural Science, 25: 1369-1376.

Sheskin, D. J. (2004). Handbook of parametric and nonparametric statistical procedures ( $3^{\text {rd }} \mathrm{ed}$ ). Boca Raton, Florida: Chapman \& Hall/CRC.

Sinnett, D., Poole, J., and Hutchings, T. R. (2006). The efficacy of three techniques to alleviate soil compaction at a restored sand and gravel quarry. Soil Use and Management, 22: $362-$ 371.

Smiley, E.T., Watson, G. W., Fraedrich, B. R., and Booth, D. C. (1990). Evaluation of soil aeration equipment. Journal of Arboriculture, 16: 118-123.

Snapp, S. S., Swinton, S. M., Labarta, R., Mutch, D., Black, J. R., Leep, R., Nyiraneza, J., and O'neil, K. (2005). Evaluating cover crops for benefits, costs, and performance within cropping system niches. Agronomy Journal, 97: 322-332.

SPSS-IBM Corp. (2012). IBM SPSS Statistics 21.0 for windows, Version 21.0. Armonk, NY: IBM Corp.

Soane, B. D. (1990). The role of organic matter in soil compatibility: A review of some practical 
aspects. Soil and Tillage Research, 16: 179-201.

Soil Science Society of America, (1996). Glossary of Soil Science Terms. Madison, WI: Soil Science Society of America Inc.

Sommerfeldt, T.G. and Chang, C. (1985). Changes in soil properties under annual applications of feedlot manure and different tillage practices. Soil Science Society of America Journal, 49: 983-987.

Stadbyggnadskontoret, 1994. Miniskrift om Stockholms parker och naturomra ${ }^{\circ}$ den (Brochure on parks and nature areas in Stockholm). SBK, 94: 6-16 (in Swedish).

Szmigielska, A. M., Schoenau, J. J., and Greer, K. J. (1998). Comparison of chemical extraction and bioassay for measurement of metsulfuron in soil. Weed Science, 46: 487-493.

Tackett, J. L., and Pearson, R. W. (1964). Oxygen requirements of cotton seedling roots for penetration of compacted soil cores. Soil Science Society of America Journal, 28: 600605.

Tarashima, E., Fujii, E., Mishima, K., 1999. Experimental studies on the effect of trampling on the root system of seedlings of Zelkova serrate Makino. Technical Bulletin of Faculty Horticulture Chiba University, 53: 85-92.

Tardieu, F. (1994). Growth and functioning of roots and of root systems subjected to soil compaction: Towards a system with multiple signalling. Soil and Tillage Research, 30: 217-243.

Taylor, H. M., and Burnett, E. (1964). Influence of soil strength on the root-growth habits of plants. Soil Science, 98: 174-180.

Taylor, H. M., Roberson, G. M., and Parker, J. J Jr. (1966). Soil strength-root penetration relations for medium- to course-textured soil materials. Soil Science, 102: 18-22.

Tejowulan, R. S., Schoenau, J. J., and Bettany, J. R. (1994). Use of ion exchange resins in soil and plant testing for micronutrient availability. In Soils and Crops Workshop Proc., p.255267. University of Saskatchewan.

Tessier, J. T., and Raynal, D. J. (2003). Use of nitrogen to phosphorous ratios in plant tissue as an indicator of nutrient limitation and nitrogen saturation. Journal of Applied Ecology, 40: 523-534.

The Weather Network. (2014). Farmzone: Guelph - Wellington South, Ontario. Retrieved from http://www.farmzone.com/statistics/summary/c16142402/so029. 
Toleti, B. (2008). Urban forest soil characteristics: a geostatistical analysis of Allan Gardens Park, Toronto,Canada. Master of Spatial Analysis Thesis. Department of Geography, Ryerson University, Toronto, ON.

Tyrvainen, L., Silvennoinen, H., and Kolehmainene, O. (2003). Ecological and aesthetic values in urban forest management. Urban Forestry and Urban Greening, 1: 135-149.

UNFPA (United Nations Population Fund). (2011). State of world population 2011 - People and possibilities in a World of 7 Billion. New York - UNFPA.

Unger, P. W., and Jones, O. R. (1998). Long-term tillage and cropping systems affect bulk density and penetration resistance of soil cropped to dryland wheat and grain sorghum. Soil and Tillage Research, 45: 39-57.

United States Department of Agriculture. (2004). Soil survey laboratory methods manual. Rep. No. 42. Ver. 4.0. Lincoln, NE: Natural Resources Conservation Service.

United States Department of Agriculture (USDA). (2014). Cover crop plants. Retrieved from http://plants.usda.gov/java/coverCrops.

van Brekelen, G. J. P (2006). ANCOVA versus change from baseline has more power in randomized studies and more bias in nonrandomized studies. Journal of Clinical Epidemiology, 59: 920-925.

van Bohemen, H. (2011). Chapter 2: (Eco)system thinking: Ecological principles for building roads, buildings and industrial and urban areas. In E. van Bueren, H. van Bohemen, L. Itard, \& H. Visscher (Eds.), Sustainable urban environments: An ecosystem approach (14-70). Dordrecht, Heidelberg, London, New York: Springer.

van Bueren, E. (2011). Chapter 1: Introduction. In E. van Bueren, H. van Bohemen, L. Itard, and H. Visscher (Eds.), Sustainable urban environments: An ecosystem approach (1-13). Dordrecht, Heidelberg, London, New York: Springer.

Varsa, E. C., Chong, S. K., Abolaji, J. O., Farquhar, D. A., and Olsen, F. J. (1997). Effect of deep tillage on soil physical characteristics and corn (Zea mays L.) root growth and production. Soil and Tillage Research, 43: 219-228.

Vaz, C. M. P., Bassoi, L. H., and Hopmans, J. W. (2001). Contribution of water content and bulk density to field soil penetration resistance as measured by a combined cone penetrometer -TDR probe. Soil \& Tillage Research, 60: 35-42.

Verhoeven, J. T. A, Koerselman, W., and Meuleman, A. F. M. (1996). Nitrogen- or 
phosphorous-limited growth in herbaceous, wet vegetation: relations with atmospheric input and management regimes. Trends in Ecology and Evolution, 11: 494-497.

Vitousek, P. M, Gosz, J. R., Grier, C. C., Melillo, J. M., Reiners, W. A., and Todd, R. L. (1979). Nitrate losses from disturbed ecosystems. Science, 204: 469-474.

Vitousek, P. M., Pickett, S. T. A., and White, P. S. (1985). Community turnover and ecosystem nutrient dynamics. Retrieved from http://www.citeulike.org/group/10326/article/4422384

Voltz, M., \& Webster, R. (1990). A Comparison of kriging, cubic splines and classification for predicting soil properties from sample information. Journal of Soil Science, 41: 473-490.

Vzzotto, V. R., Marchezan, E., Segabinazzi, T. (2000). Effect of cattle trampling on lowland soil physical properties. Ciencia Rural, 30: 965-969.

Waller, L. A., Gotway, C. A. (2004). Applied spatial statistics for public health data. New York: Wiley- Interscience.

Watson, G. W., and Kelsey, P. (2006). The impact of soil compaction on soil aeration and fine root density of Quercus palustris. Urban Forestry and Greening. 4: 69-74.

Weber, D. D., and Englund, E. J. (1994). Evaluation and comparison of spatial interpolators, II: Math. Geology, 26: 589-603

Weil, R., and Kremen, A. (2007). Thinking across and beyond disciplines to make cover crops pay. Journal of the Science of Food and Agriculture, 87: 551-557.

Western Ag Innovations Inc. (2014). PRS Technology. Retrieved from http://www.westernag.ca/innovations/technology/basics

White, R. E. (2006). Principles and practice of soil science. Malden, MA :Blackwell Publishing.

Williams, S. M. W., and Weil, R. R. (2004). Crop cover root channels may alleviate soil compaction effects on soybean crop. Soil Science Society of America Journal, 68: 1403.

Williamson, J. R., and Neilsen, W. A. (2003). The effect of soil compaction, profile disturbance and fertilizer application on the growth of eucalypt seedlings in two glasshouse studies. Soil and Tillage Research, 71: 95-107.

Willmott, C. J., and Matsuura, K. (2005). Advantages of the mean absolute error (MAE) over the root mean square error (RMSE) in assessing average model performance. Climate Research, 20: 79-82.

Wilson, G. F., Lal, R., and Okigbo, B. N. (1982). Effects of cover crops on soil structure and on 
yield of subsequent arable crops grown under strip tillage on an eroded alfisol. Soil \& Tillage Research, 2: 233-250.

Wright, S. J., Yavitt, J. B., Wurzburger, N., Turner, B. L., Tanner, V. J., Sayer, E. J., Santiago, L. S., Kaspari, M., Hedin, L. O., Harms, K. E., Garcia, M. N., and Corre, M. D. (2011). Potassium, phosphorous, or nitrogen limit root allocation, tree growth, or litter production in a lowland tropical forest. Ecology, 92: 1616-1625.

Wyland, L. J., Jackson, L. E., Chaney, W. E., Klonsky, K., Koike, S. T., and Kimple, B. (1996). Winter cover crops in a vegetable cropping system: Impacts on nitrate leaching, soil water, crop yield, pests and management costs. Agriculture, Ecosystems and Environment, 59: 1-17.

Zimmerman, D., Pavlik, C., Ruggles, A., and Armstrong, M. P. (1999). An experimental comparison of Ordinary Kriging and Inverse Distance Weighting. Mathematical Geology, 31: 375-390. 